\title{
DR. 898
}

$3|14|$

DOE/CS/05314-1

Unlimited Release

UC-63a Distribution

Photovoltaic Concentrator

Application Experiment to be

Located at Sea World Park,

Orlando, Florida

Phase I - System Design Final Report

(June 1, 1978 to February 28, 1979)

A. S. Kirpich

General Electric Space Division

Printed December 1979
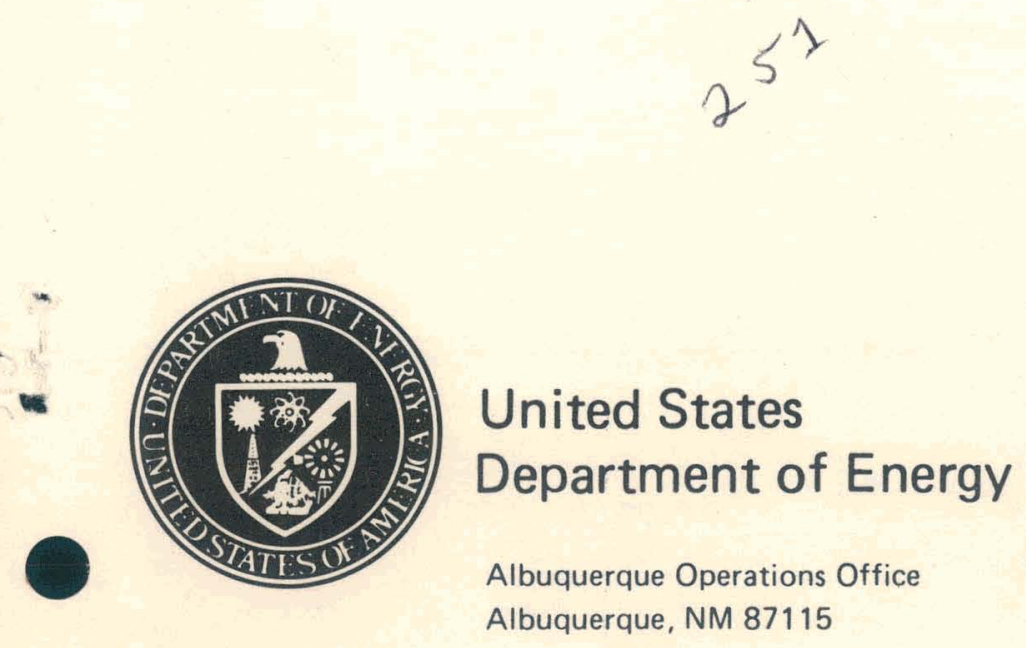


\section{DISCLAIMER}

This report was prepared as an account of work sponsored by an agency of the United States Government. Neither the United States Government nor any agency Thereof, nor any of their employees, makes any warranty, express or implied, or assumes any legal liability or responsibility for the accuracy, completeness, or usefulness of any information, apparatus, product, or process disclosed, or represents that its use would not infringe privately owned rights. Reference herein to any specific commercial product, process, or service by trade name, trademark, manufacturer, or otherwise does not necessarily constitute or imply its endorsement, recommendation, or favoring by the United States Government or any agency thereof. The views and opinions of authors expressed herein do not necessarily state or reflect those of the United States Government or any agency thereof. 


\section{DISCLAIMER}

Portions of this document may be illegible in electronic image products. Images are produced from the best available original document. 


\section{NOTICE}

This report was prepared as an account of work sponsored by the United States Government. Neither the United States nor the Department of Energy, nor any of their employees, nor any of their contractors, subcontractors, or their employees, makes any warranty, express or implied, or assumes any legal liability or responsibility for the accuracy, completeness or usefulness of any information, apparatus, product or process disclosed, or represents that its use would not infringe privately owned rights.

Printed in the United States of America

Available from

National Technical Information Service

U. S. Department of Commerce

5285 Port Royal Road

Springfield, VA 22161, $/, 20$

Price: Printed Copy $\$ 9.25 ;$ Microfiche $\$ 3.00$ 
Report No. DOE/CS/05314-1

Unlimited Release

UC-63a Distribution

PHOTOVOLTAIC CONCENTRATOR

APPLICATION EXPERIMENT

TO BE LOCATED AT

SEA WORLD PARK

ORLANDO;: FLORIDA

FINAL REPORT - PHASE I SYSTEM DESIGN

JUNE 1, 1978 - FEBRUARY 28, 1979

A. S. KIRPICH, ET AL

31 MARCH, 1979

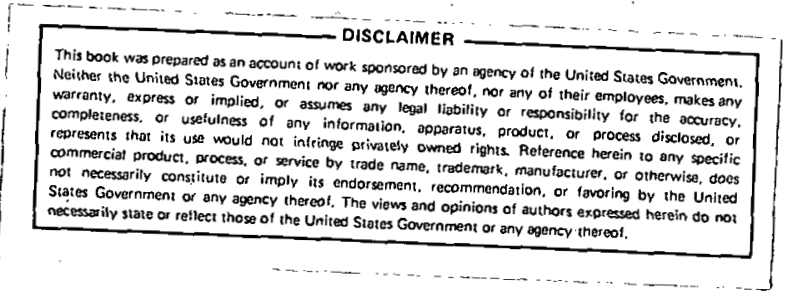

WORK PERFORMED UNDER

CONTRACT ET-78-C-04-5314

\section{GENERAL ELECTRIC SPACE DIVISION \\ Valley. Forge Space Center \\ P. O. Box 8555 - Philadelphia, Penna. 19101}


THIS PAGE

\section{WAS INTENTIONALLY LEFT BLANK}




\begin{abstract}
The General Electric/Sea. World Photovoltaic Concentrator Application Experiment will be located at Sea World's Marine Park near Orlando, Florida. The experiment will consist of nine azimuth-tracking turntable arrays, each containing twenty-four elevation-tracking parabolic trough PV concentrators of a type developed on this contract. The system will produce a peak power output of $330 \mathrm{~kW}$ and an annual net electrical energy of $355 \mathrm{MWh}$ corresponding to an annual direct normal insolation of $1375.5 \mathrm{kWh} / \mathrm{m}^{2}$. A line-commutated DC/ AC inverter controlled to operate at the solar array maximum power point will deliver three-phase power through a bidirectional transformer to a 13-kilovolt line serving the Sea World Park. In addition to generating electrical power, the system will produce $3.56 \times 10^{5}$ ton-hours of cooling for air conditioning a nearby shark exhibit by supplying collected thermal energy to a lithium-bromide absorption chiller. With credit included for the amount of electricity that would be required to produce this cooling by a vapor compression cycle, the overall system efficiency is estimated to be 11.7 percent.
\end{abstract}


$\underline{\text { Section }}$

INTRODUCTION • • • • • • • • • • • • • •

2.1 Concept . . . . . . . . . . . . . . . . . . . . . 2-1

2.2 Application and Site Description . . . . . . . . . . . . . $2-2$

2.3 Physical Characteristic Summary . • . . . . . . . . . $2-7$

2.4 Performance Summary . . . . . . . . . . . . . 2-8

SYSTEM DESCRIPTION. $\cdot$ •

3.1 System Overview . . . . . . . . . . . . . . . . . 3-1

3.1.1 Requirements . . . . . . . . . . . . . . . 3-1

3.1.2 System Definition. . . . . . . . . . . . . . . 3-3

3.1.3 Subsystem Definition. . . . . . . . . . . $3-6$

3.2 Solar Array. • . . . . . . . . . . . . . . . : 3-16

3.2.1 Solar Collector . . . . . . . . . . . . 3-16

3.2.2 Solar Cell Receiver . . . . . . . . . . . . . . 3-21

3.2.3 Turntable Framework . . . . . . . . . . . . . 3-25

3.2.4 Mechanical Drive Hardware . . . . . . . . . 3-26

3.2.5 Turntable Foundation . . . . . . . . . . . . 3-28

3.2.6 Solar Array Material Breakdown. . . . . . . . . . 3-29

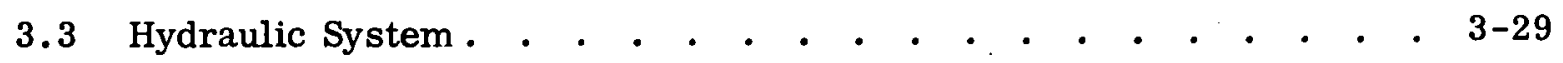

3.3.1 Turntable Coolant Circuit . . . . . . . . . . . 3-29

3.3.2 Field Coolant Loop . . . . . . . . . . . . . . 3-32

3.3.3 Heat Delivery Loop - Absorption Chiller Option. . . . . 3-33

3.3.4 Heat Delivery Loop - Domestic Hot Water Option . . . . 3-34

3.4 Electrical Systems (Power Conditioning, Control, and Major

Switchgear) . . . . . . . . . . . . . . . 3-34

3.4.1 Inverter System . . . . . . . . . . . . . . 3-35

3.4.2 Utility Interface . . . . . . . . . . . . . . . 3-43

3.4.3 Emergency Power System (EPS) . . . . . . . . . . 3-43

3.4.4 Control System . . . . . . . . . . . . . . . 3-45

3.4.5 Instrumentation . . . . . . . . . . . . . . 3-47

3.4.6 Lightning Protection . . . . . . . . . . . . . . 3-48 
TABLE OF CONTENTS ( CONTINUED)

$\underline{\text { Section }}$

$\underline{\text { Page }}$

3.5 Field System

3.5 .1 Plant Layout . . . . . . . . . . . . . . $3-52$

3.5.2 Control Building . . . . . . . . . . . . . . 3-54

SYSTEM AND DESIGN ANALYSIS . • • • • • • • •

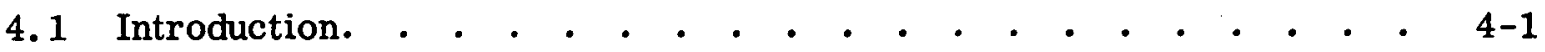

4.2 System Performance. . . . . . . . . . . . . . . . . 4-1

4.2.1 Simulation Models . . . . . . . . . . . . . . 4-1

4.2.2 System Performance Results . . . . . . . . . . 4-16

4.3 Economic Analysis . . . . . . . . . . . . . . . . . 4-19

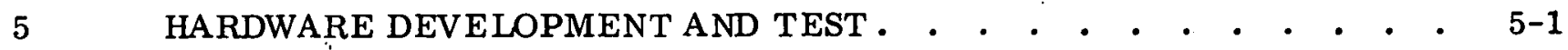

5.1 Introduction. • . . . . . . . . . . . . . . . . . 5-1

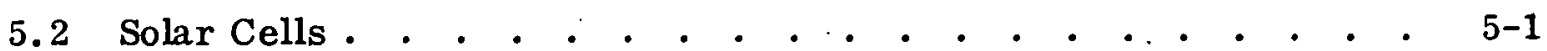

5.3. Solar Cell Receiver Fabrication . . . . . . . . . . . . . 5-4

5.4 Receiver Thermal Impedance Tests. . . . . . . . . . . . 5-9

5.5 Reflective Material Evaluation . . . . . . . . . . . . . 5-10

5.630 -Foot Prototype Collector . . . . . . . . . . . . . . 5-11

5.7 Collector Segment Tests . . . . . . . . . . . . . . 5-14

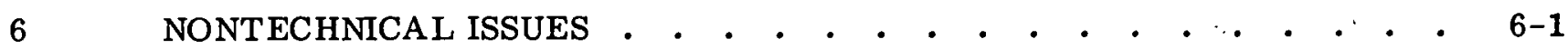

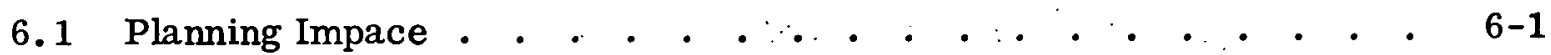

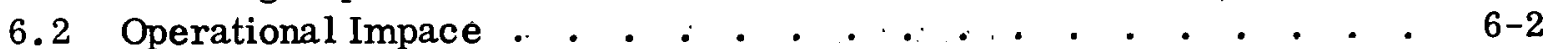

6.3 Economic Impact . . . . . . . . . . . . . . . . . . . . . 6-2

6.4 Insurance Coverage . . . . . . . . . . . . . . . . . . . 6-2

6.5 Visitor Demographics . . . . . . . . . . . . . . . 6-2

6.5 .1 Visitor Scope . . . . . . . . . . . . . . . . 6-2

6.5 .2 Visitor Character. . . . . . . . . . . . . . 6-2

Appendix A

Appendix B

Appendix C
DC/AC INVERTER THEORY OF OPERATION

A-1 to $\mathrm{A}-34$

LIFE-CYC LE COST METHODOLOGY .

LIGHTNING PROTECTION ANALYSIS
B-1 to B-6

$\mathrm{C}-1$ to $\mathrm{C}-39$ 


\section{SECTION 1}

\section{INT RODUCTION}

As part of its PRDA-35 Phase I contract with the Department of Energy, the General Electric Company, in cooperation with Sea World, has designed a Photovoltaic Concentrator Application Experiment to be located adjacent to Sea World's Marine Park in Orlando, Florida. As illustrated on the artist's rendering of Figure 1-1, the concept uses nine turntable solar arrays deployed on a 5. 8-acre site. The turntables track the sun's azimuth while trunnion-mounted parabolic collectors track the sun's elevation. Solar cells mounted along the focal lines of the parabolic collectors supply DC power to a line-commutated inverter which, in turn, feeds its AC output through transformation to a Sea World 13 kilovolt distribution network, operated and maintained by the Florida Power Corporation. Additionally, circulating hot water for cooling the solar cells, is fed to a lithium-bromide absorption chiller which produces chilled water for air conditioning a nearby newly constructed shark exhibit.

Because of its proximity to Sea World's Theme Park, the PV plant location is excellent fór project visibility. Over 3 million visitors are expected annually, including management decision makers in industry and government. A Visitor Information Center will be designed and constructed by Sea World along the perimeter of the project site and will serve to create public understanding of photovoltaics. The role played by Florida Power Corporation will assure proper treatment of technical and institutional interfaces with electric utilities.

This study was led by Advanced Energy Programs of General Electric's Space Division. The participation and contributions by the following organizations and individuals to the results of this study are gratefully acknowledged: 


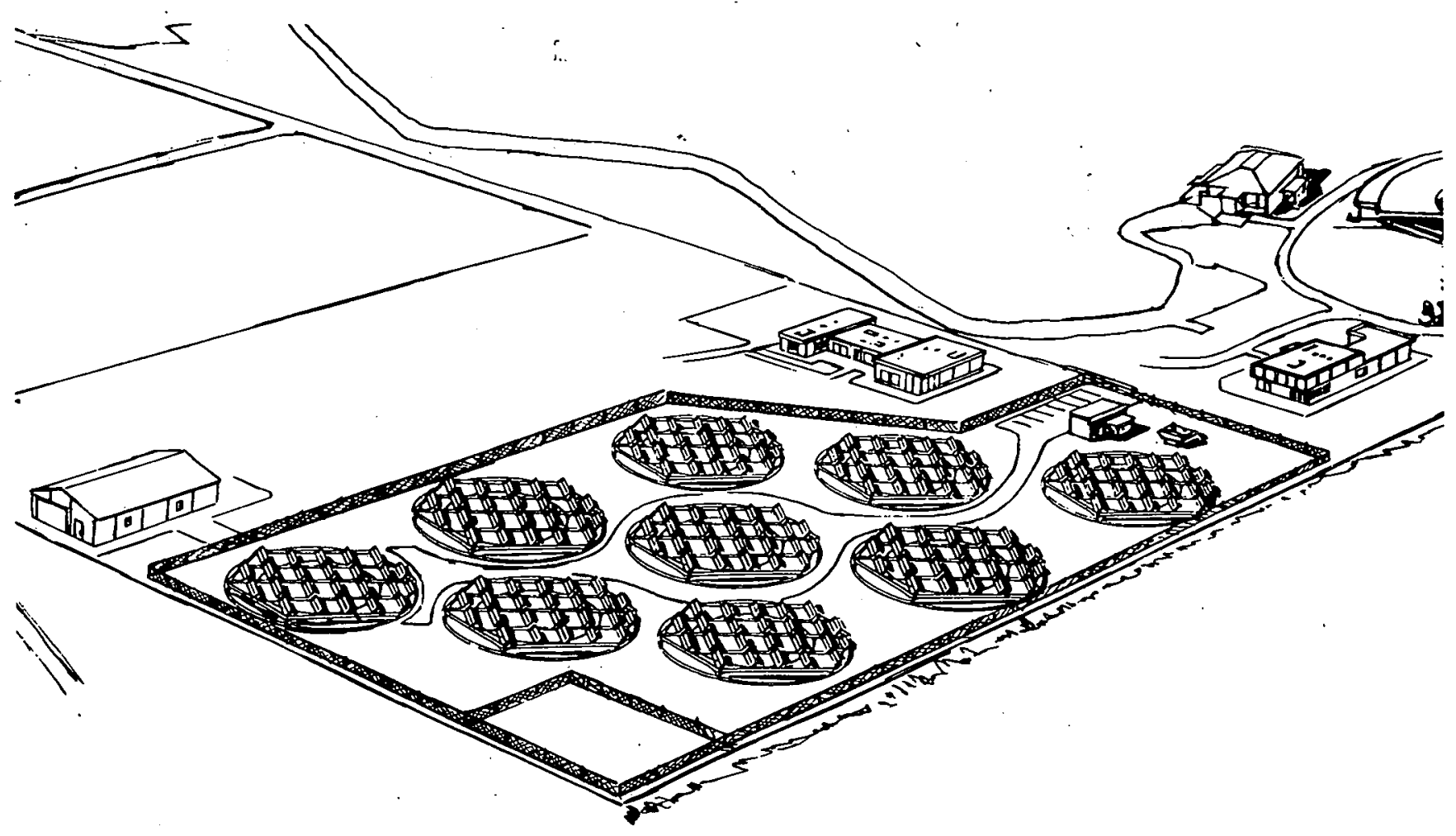

Figure 1-1. Photovoltaic Concentrator System Installed at Sea World, Florida 


\title{
General Electric - Advanced Energy Programs
}
L. Amore
J. Bagdon
B. Bellinger
W. Billbrough
O. Bitzer
J. Busciacca
J. Callender
S. Caltabiano
J. Chan
M. Concannon

C. Delavelle

T. Duff

A. Engel

E. Ernst

N. Grant

J. Hogan

R. Huber

A. Hughes

A. Kirpich

J. Kita
A. Koenig
A. Laganelli
E. Leinroth
J. Nichols
B. Nyce
S. Peck
D. Podgurski
J. Ramsay
J. Troyano
B. Washington

\section{Sea World of Florida}

\author{
A. Finn \\ B. Peters
}

Rogers + Lopatka (Architect-Engineers)

W. Chase

Florida Power Corporation

L. Rodriquez

J. Holland

General Electric - Electric Utility System Engrg. Dept.
H. Trojan
R. Pohl

Lightning Technology, Inc.

j. A. Plumer

K. E. Crouch

Special thanks to Eve Webb for her secretarial assistance in preparing numerous writeups, presentations, proposals, and this final report. 


\section{SECTION 2}

\section{PROJECT SUMMARY}

\subsection{CONCEPT}

Evaluation of performance, cost, and availability have resulted in the selection of a concept for the Sea World application which utilizes two-axis tracking, and, as illustrated earlier on Figure 1-1, consists of nine turntable solar arrays. The turntables track the sun's azimuth while trunnion-mounted parabolic collectors track the sun's elevation. Solar cells are vee-mounted on a liquid-cooled tube located along the focal line of each collector. The geometric concentration ratio is 33.4. The photovoltaic output is produced at a nominal 360 Volts dc. The power is routed through spiral wraps at each turntable hub and underground cabling to a control building where it is inverted to $277 / 480$ volts ac. It is parallel-connected through transformers to a 13 $\mathrm{kV}$ utility loop owned and maintained by the Florida Power Corporation, which serves various Sea World loads. The plant is rated at a peak output of $330 \mathrm{~kW}$. Using hourly Miami weather data corrected for the latitude at Sea World, computer analysis indicates a net annual electrical energy production of 355 MWH.

Through a spiral hose at each turntable hub, the thermal by-product associated with solar cell cooling is routed to an absorption chiller. The resulting chilled water (annual output: $356 \mathrm{x}$ $10^{3}$ ton-hours) is furnished to a nearby shark exhibit building.

Features of the proposed concept include:

- Demonstrated PV concentrator with: (1) tested PV annual efficiency of 7.1 percent with projected efficiency of 8.7 percent (coolant temperature at $83^{\circ} \mathrm{C}$, suitable for absorption chiller operation); (2) tested thermal efficiency of 33 percent with coolant at $83^{\circ} \mathrm{C}$.

- Structurally-proven solar collector with following features: (1) aluminized polyester (U-V stabilized) reflective surface bonded to $25-\mathrm{mil}$ aluminized steel substrate; (2) demonstrated 74 percent optical efficiency; (3) $7 \times 30$-foot low-weight design $(<2.8$ $\mathrm{lbs} / \mathrm{ft}^{2}$ aperture not including solar cell receivers) with exceptional beam and torsional stiffness; (4) low-cost construction consisting of stretch-formed ribs, standard section longerons, and flat sheet metal laminate; (5) design adaptable to on-site assembly.

- Tested solar cell receiver of unique design: (1) cells mounted on split-vee extrusion five-foot segments easily clamped or removed from electrically insulated coolant tube without interrupting fluid lines; (2) uninterrupted glass encapsulation; (3) compliant bond materials and flexible interconnects to fully accommodate differential expansion; (4) aluminum heat sink which serves as current bypass for failed or shaded cells.

- Levelized Annual economic benefit of $\$ 31,400$ for PV-generated electricity and thermal by-product chilled water production. 
- Two-axis tracking turntable solar array with low physical profile $(<8$-feet high) and low wind loading effects.

- Simple I-beam/box-beam turntable framework with turnbuckle diagonal rod bracing.

- Concentric track turntable mounting with 16 uniformly distributed wheel supports plus center pintle. Azimuth drive provided by two motorized wheels on outer track.

- Stiff, though light-weight linkages and structural transitions (e.g., use of collector torsional stiffness) throughout the turntable, permitting use of single elevation drive.

- Alignment features including: (1) collector end-to-end angular twist; (2) in-line collectorto-collector angular adjustment; (3) two degrees-of-freedom in row-to-row linkage adjustment. Optical alignment of entire field achieved by carpenter's level - no complicated boresighting required.

- Coarse azimuth and elevation tracking from central computer; fine elevation tracking with receiver mounted fiber optics sun sensors.

- Inverter System based on proven commercially available components.

- Hydraulic system designed in accordance with standard codes and practices - readily - adaptable to the production of hot or chilled water.

\subsection{APPLICATION AND SITE DESCRIPTION}

The GE/SEA World photovoltaic experiment will be located at Sea World, southwest of Orlando, Florida: As shown on Figure 2-1, the selected plant site is located at the southeast corner of the Sea World property adjacent to the shark exhibit. The aerial view of Figure 2-2 shows the proposed PV site along with other planned additions to Sea World Park.

The solar array will be installed on level land with a total slope of approximately two feet in 420 feet. The site is well drained by existing canals on the north and east boundaries. The site and adjacent areas, east, south and west of the site, are undeveloped with low-lying vegetation and a scattering of trees. An access road skirts the northern edge of the site. The nine turntables, each having a swept diameter of 150 feet, are arranged symmetrically, with sufficient spacing for roadways and access.

A control building and heat removal equipment associated with the solar array active cooling system will be located in the northern area of the site. This location is close to the access road and avoids any possibility of array shadowing by building structures and equipment.

The distances for transporting the electricity and chilled water output to the utility tie-in and shark exhibit points a re also minimized. Underground piping and cabling interconnect each of the solar array turntables with the centrally located control building and heat removal equipment. 


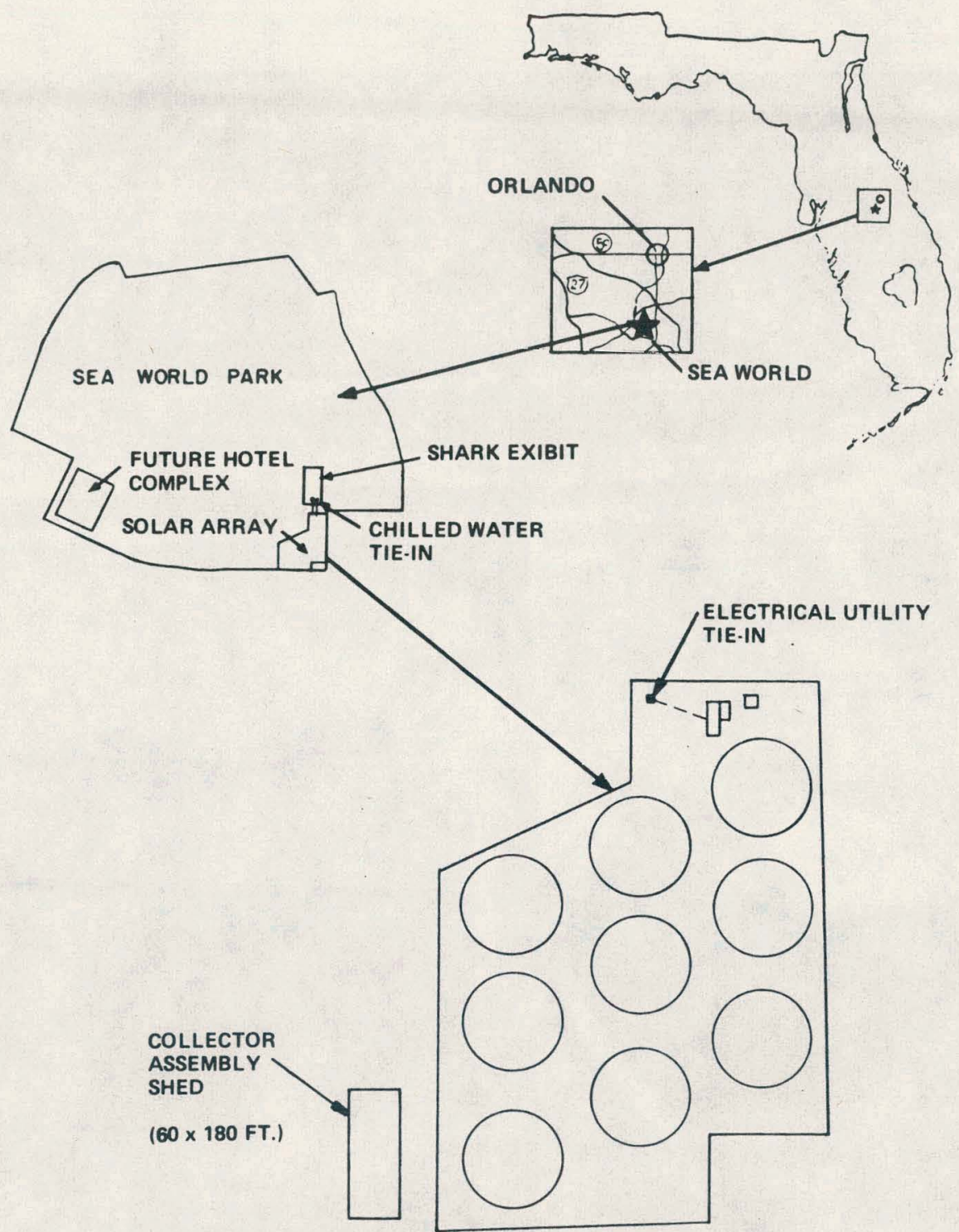

Figure 2-1. PV Plant Site Description

Site preparation will consist of clearing all vegetation, sterilizing the soil against seeding, and back filling areas with appropriate surface materials. Concentric concrete tracks and a central pier will be poured for each turntable. The areas within each turntable will be back filled with crushed rock while other surrounding areas will be covered with mulch.

It is proposed that the electrical energy derived from the experimental PV station be utilized to subsidize the power requirements of the mammal life-support system for this marine park complex. The existing life-support system consists of an array of sophisticated performing, holding, breeding, isolation and research tanks and attendant mechanical infra-structure, which serve to contain, circulate, filter, cool, chemically balance and purify 2.5 million gallons of man-made saltwater for the healthful subsistence of the park's marine mammal family. 


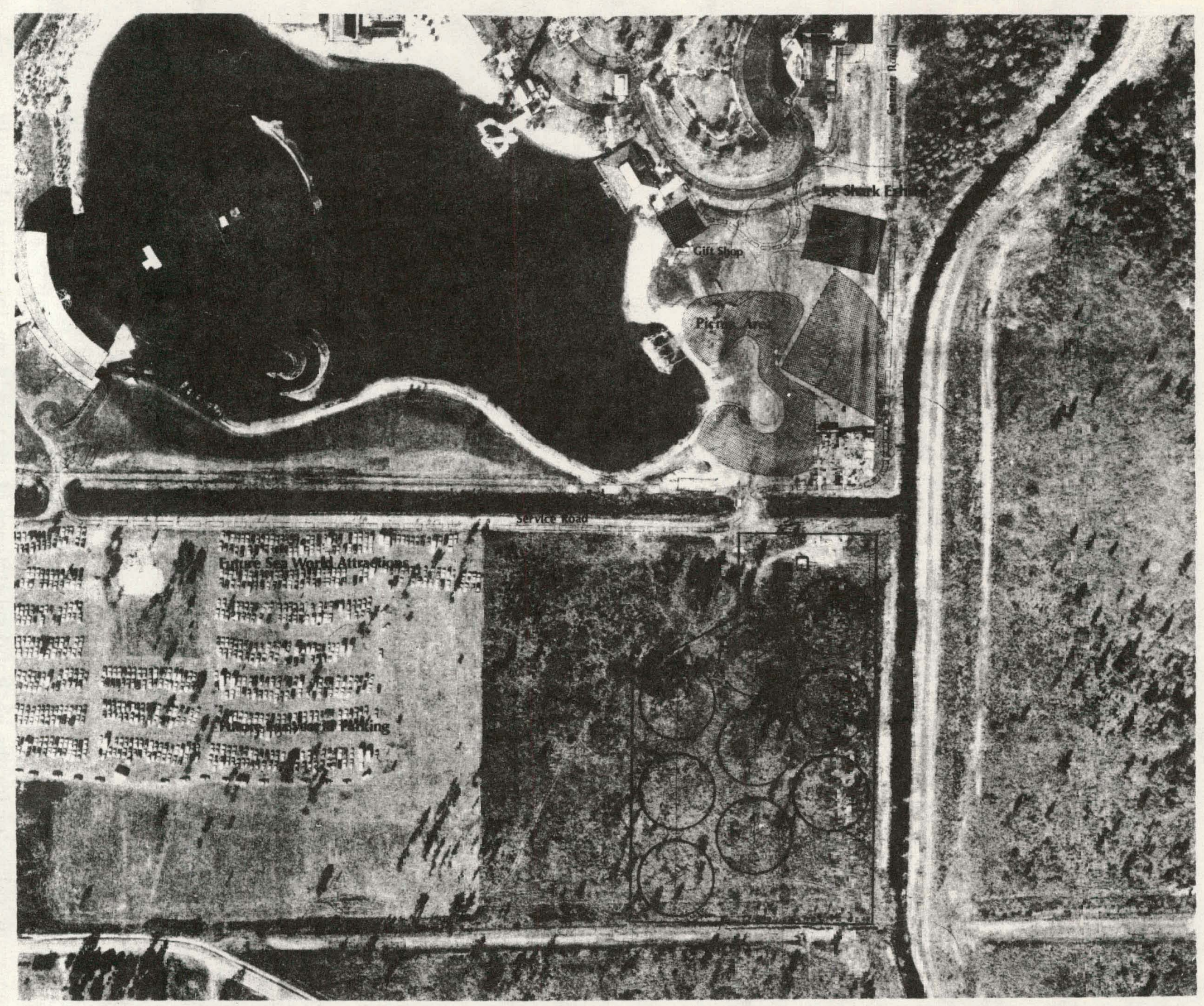

Figure $2-2$. Aerial View of Sea World Park with Proposed PV Site 
The mechanical infra-structure includes a series of twenty 8-foot diameter, high-pressure sand filters, each serviced by a $750 \mathrm{gpm}$ pump and a $40 \mathrm{hp}$ electric motor; an 88,000 gallon filter backwash complex; a high-capacity ozonator/mixer system; two chiller units of 1200 and 600 tons, respectively; a heat exchanger unit utilizing a $50 \mathrm{hp}$ electric pump motor; three $75 \mathrm{hp}$ saltwater circulation pumps; and a 1000 to $1200 \mathrm{gpm}$ non-potable well drawn by a $100 \mathrm{hp}$ electric pump motor. Table 2-1 summarizes these demands.

Table 2-1. Sea World Water Conditioning Loads

\begin{tabular}{|l|r|c|}
\hline \multicolumn{1}{|c|}{ Equipment } & Rating & Quantity \\
\hline 1200 Ton Chiller & $1000 \mathrm{HP}$ & 1 \\
600 Ton Chiller & $500 \mathrm{HP}$ & 1 \\
Chilled Water Pump & $250 \mathrm{HP}$ & 1 \\
Condenser Pump & $100 \mathrm{HP}$ & 1 \\
NPW Well Pump & $100 \mathrm{HP}$ & 1 \\
Saltwater Sump Pump & $75 \mathrm{HP}$ & 3 \\
High Pressure Sand Filters & $40 \mathrm{HP}$ & 21 \\
Cooling Tower Pumps & $7.5 \mathrm{HP}$ & 14 \\
\hline
\end{tabular}

The demand of the mammal life-support system is essentially constant, 24 hours per day, 365 days per year. Peak-load power factors occur in August and range from 74 to $94 \%$.

\subsection{PHYSICAL CHARACTERISTICS SUMMARY}

Table 2-2 presents a summary of the gross physical characteristics of the system.

Table 2-2. Physical Characteristics of 9-Turntable System

\begin{tabular}{|l|c|}
\hline \multicolumn{1}{|c|}{ Item } & \multicolumn{1}{|c|}{ Value } \\
\hline Number of Collectors $(2.1 \times 9.2 \mathrm{~m}$ each) & $\begin{array}{l}216(24 \text { per } \\
\text { turntable })\end{array}$ \\
Number of solar cells $(3.5 \times 4 \mathrm{~m}$ each) & 93,312 \\
Total solar cell area $\left(\mathrm{m}^{2}\right)$ & 112 \\
Total Aperture area $\left(\mathrm{m}^{2}\right)$ & 3,866 \\
Site Area $\left(\mathrm{m}^{2}\right)$ & 23,480 \\
Turntable Swept diameter $(\mathrm{m})$ & 46 \\
Max height above ground-level $(\mathrm{m})$ & 2.5 \\
\hline
\end{tabular}

Each turntable solar array has a swept diameter of approximately 46 meters and has a low profile not exceeding 2.5 meters above ground level. The turntables are spaced sufficiently to permit access for servicing and repair. A roadway snakes through the array field to permit truck access to any turntable. 
Hardware characteristic summaries of the turntable, collector structure and optics, and solar cell receiver are presented on Figures 2-3, 2-4 and 2-5.

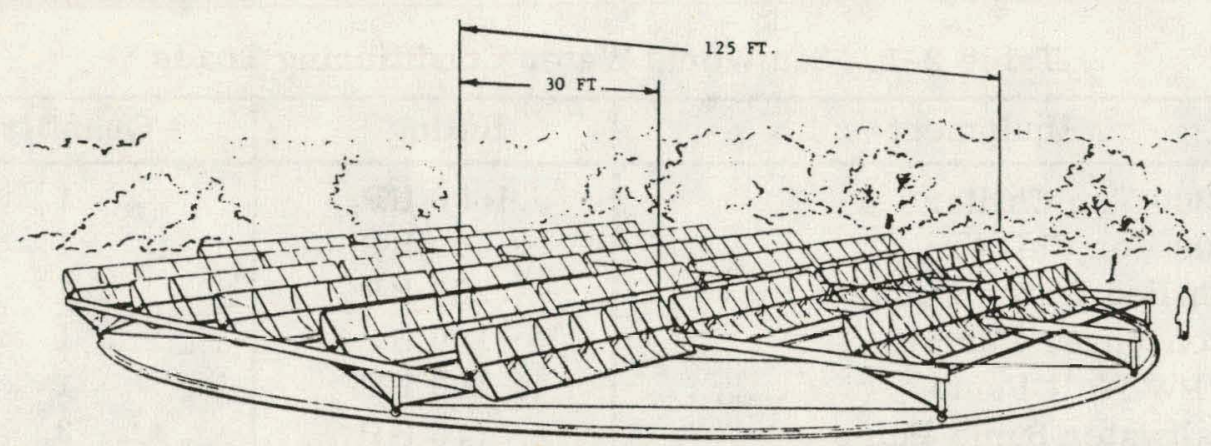

- PEAK electrical RATing: $36.7 \mathrm{~kW} @ 180^{\circ} \mathrm{F}$

- output VOltage: $360 \mathrm{VDC} \pm 12 \%$

- PEAK THERMAL RATING: $0.49 \mathrm{MBTU} / \mathrm{Hr} @ 180^{\circ} \mathrm{F}$

- TOTAL ENERGY CONVERSION EFFICIENCY: $42 \%$

- COLLECTORS: 24 paraholic troughs; $7 \mathrm{ft} \times 30 \mathrm{ft} ; 5$-ft segmented solar cell receivers, each with $36,35 \mathrm{~cm} \times 4 \mathrm{~cm}$ cells; 216 series $\times 2$ parallel circuits. Measured weight per collector $=750 \mathrm{lbs}$.

- AZIMUTH TRACKING: $\pm^{\circ}$. Requires only 2 motorized wheels

- ELEVATION TRACKING: $\pm 0.1^{\circ}$. Extremely rigid troughs permit ganging all 24 collectors to a single drive.

- STRUCTURE: I-Beam and Box Beam framework. Total weight $=16,000 \mathrm{lbs}$.

- TRACKS: Concrete; 137.2 and $83.5 \mathrm{Ft}$. diameters

- ELECTRICAL CONNECTION: Spiral cabling at central hub. Ne slip rings.

- WATER CONNECTION: 3-In. main with spiral hoses at central hub - no rotary joints.

Figure 2-3. Turntable Characteristics 


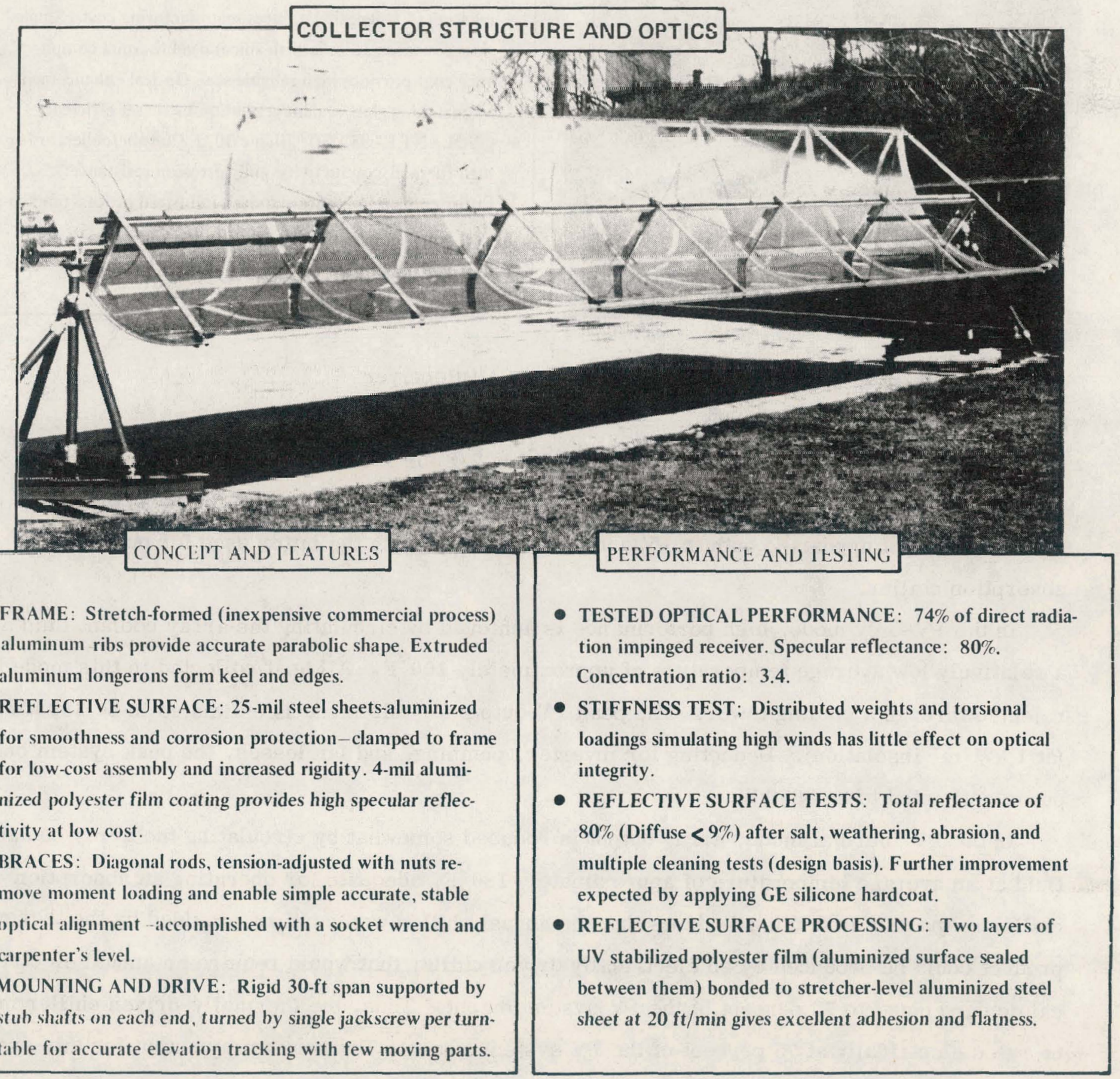

Figure 2-4. Collector Structure and Optics 


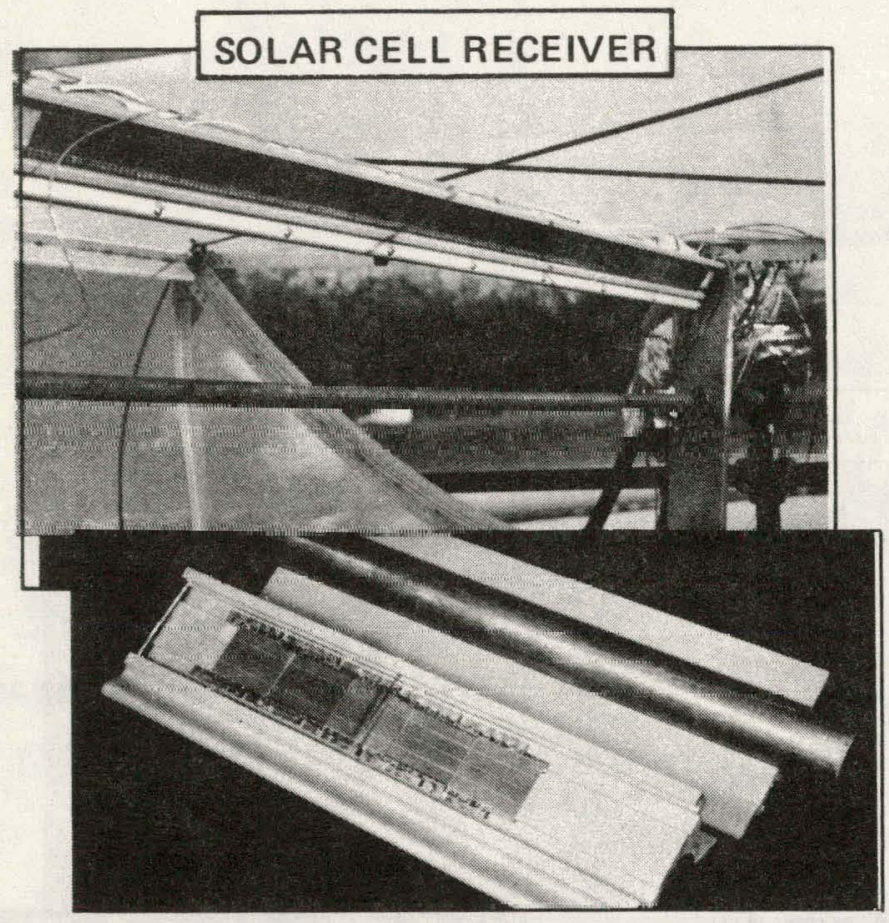

\section{CONCEPT \& FEATURES}

- RECEIVER SUBASSEMBLIES: $36 \mathrm{~N} / \mathrm{P}, 3.5 \times 4 \mathrm{~cm}, 16 \%$ efficient solar cells bonded to $5 \mathrm{ft}$. Aluminum extrusion. 12 units (6/side) clamped to $\mathrm{Cu}$ coolant tube to form receiver. Voltage drop across cell/substrate bond $<25 \mathrm{~V}$, permitting high thermal conductance for effective cell cooling. Segmenting ( $5 \mathrm{ft}$ lengths) reduces manufacturing costs. Single glass cover for 36 cells with silicone gel thermal compli ance coat provides high reliable seal. Optical enhancement by matching glass/sealant refraction increases efficiency.

- COOLANT PASSAGE: Single $30 \mathrm{ft}$. Cu tube/collector for high thermal conductivity and corrosion resistance. Entire coolant loop uses standard industrial process practice.

Figure 2-5. Solar Cell Receiver

\subsection{PERFORMANCE SUMMARY}

A performance summary is presented on Table 2-3 for two modes of system operation: (1) a PV-only mode with output only in the form of inverted PV generation; (2) a PV/thermal mode with output appearing both in PV and thermal forms with the latter used for operating an absorption chiller.

In the PV-only mode, high performance is achieved by circulating the array coolant fluid at a relatively low average temperature of approximately $100^{\circ} \mathrm{F}$. All heat collected in this mode is rejected through a cooling tower. The peak PV output for this mode is estimated to be $388 \mathrm{~kW}$ (at $1 \mathrm{~kW} / \mathrm{m}^{2}$ insolation). Deducting for inverter, pumping, and fan losses, the peak system output is estimated to be $365 \mathrm{~kW}$.

In the PV/thermal mode, array output is reduced somewhat by circulating the array coolant fluid at an average temperature of approximately $180^{\circ} \mathrm{F}$, adequate for operating an absorption chiller. Analysis in Section 4 shows that the annual chilled water output provided by the thermal byproduct could be produced by an electrically driven chiller that would require an annual electrical demand equal to 75 percent of the PV system output. Thus, the thermally-driven chiller may be rated electrically at 75 percent of the PV system output. The peak array output for this system mode is estimated to be $330 \mathrm{~kW}$ (at $1 \mathrm{~kW} / \mathrm{m}^{2}$ insolation). Deducting for inverter, pumps, and fan losses, the peak system output is estimated to be $277 \mathrm{~kW}$. Adding 75 percent of this output for credit to the chiller system yields a total output of $485 \mathrm{~kW}$. 
Table 2-3. Summary of System Performance

\begin{tabular}{|l|c|c|}
\hline \multicolumn{1}{|c|}{ Parameter } & $\begin{array}{c}\text { PV-Only } \\
\text { Mode }\end{array}$ & $\begin{array}{c}\text { PV/Thermal } \\
\text { Mode }\end{array}$ \\
\hline Peak Array Output (kW) & 388 & 330 \\
Peak System Output (kW) & 365 & 277 (PV sys) \\
& & $\frac{208}{485}$ (Chiller) \\
Gross Annual Electrical Output (MWH) & 512 & 460 \\
Annual Parasitic Losses (MHW) & 36 & 105 \\
Annual Thermal Output (MBtu) & - & $5.67 \times 10^{3}$ \\
Annual Cooling Output (ton-hours) & - & $3.56 \times 10^{5}$ \\
Annual Equivalent Electricity to & - & 267 \\
produce Cooling (MHW) & 1376 & 1376 \\
Annual Direct Normal Insolation (kWH/m ${ }^{2}$ ) & 5317 & 5317 \\
For 3866 m ${ }^{2}$ aperture (MHW) & $\frac{512-36}{5317}=9.0 \%$ & $\frac{460-105+267}{5317}=11.7 \%$ \\
System Efficiency & & \\
\hline
\end{tabular}




\section{SECTION 3}

\section{SYSTEM DESCRIPTION}

\subsection{SYSTEM OVERVIEW}

\subsubsection{REQURREMENTS}

A review of the environmental conditions applicable to terrestrial PV plant operation, the demonstration goals defined for the PV experiment, and the specific constraints associated with the Sea World application have led to the broad system design requirements enumerated on Table $3-1$.

Table 3-1. System Design Requirements

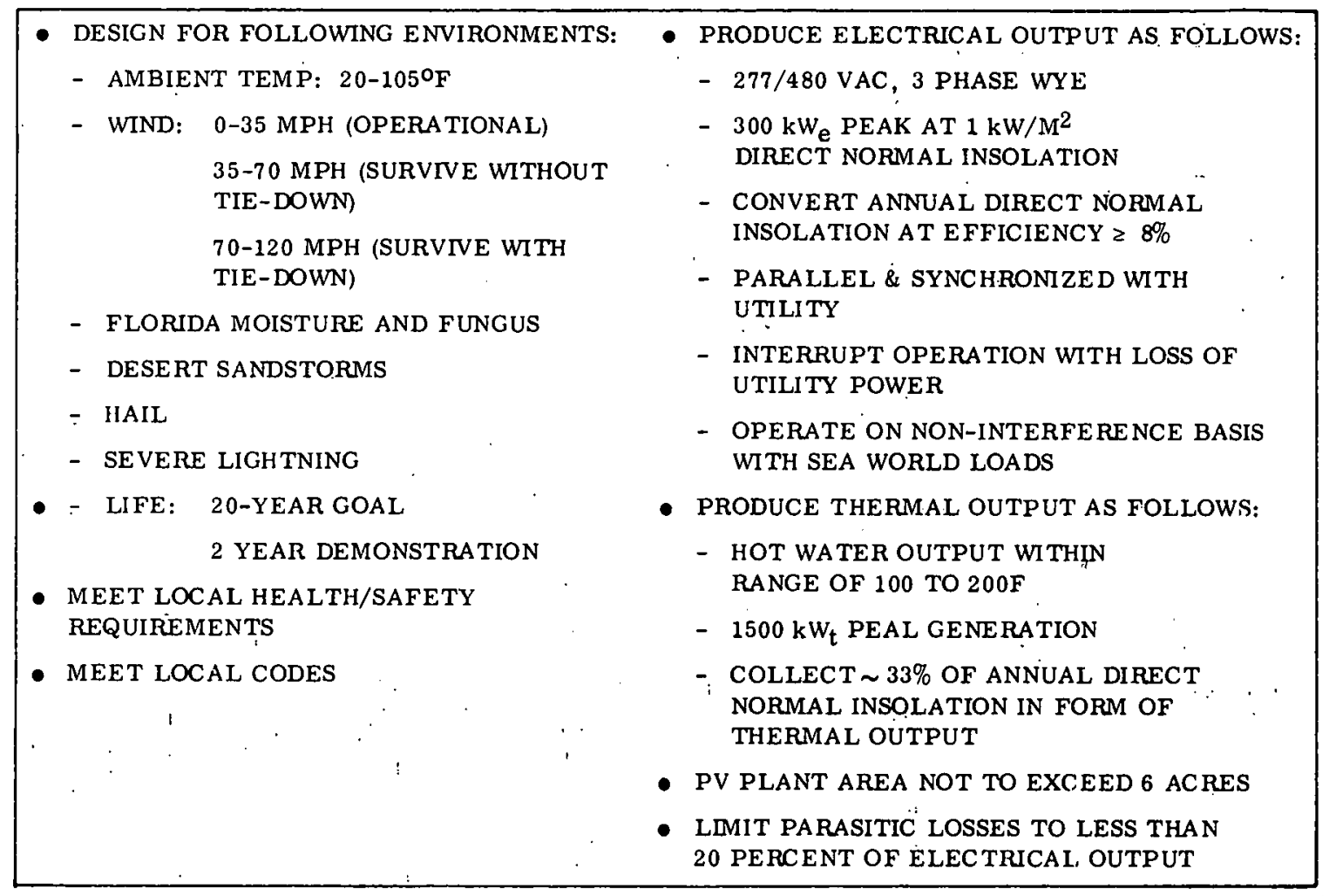

The environmental conditions listed on Table 3-1 are typical for the central Florida region. The design requirements for wind are based on an analysis using several SOLMET weather tapes. The results, shown on Figure 3-1, rank the prevalence of sunshine with wind speed for two widely different regions. The plots indicate that 99 percent of the sunshine occurs at wind speeds of $30 \mathrm{MPH}$ or less. Therefore, the $35 \mathrm{MPH}$ operational design requirement on Table 3-1 conservatively establishes the wind speed for which the design must be optically accurate. The system must, of course, 
be capable of surviving wind speeds up to hurricane force. A wind speed of 70 MPH has been selected as the condition at which the collectors are secured to prevent damage to the solar array.

Lightning is particularly prevalent in the central Florida region and, therefore, careful attention has been given to this environment. A detailed analysis indicates that a direct strike can be anticipated once every 6 years. Strikes causing indirect effects will occur at a frequency of approx1mately 26 times per year. As described in Section 3, several design measures have been included to minimize damaging effects.

The electrical requirements specified on Table 3-1 are largely dictated by the Sea World application. The common form of power distributed for various loads is at 277/480 VAC and, therefore, the PV plant output is specified accordingly. It is not feasible to transport power at these voltages over long distances, even to other locations within the Sea World Park. For this reason, the WIND SPEED, MPH power at $277 / 480 \mathrm{VAC}$ will only be used to serve the PV plant parasitic loads, to operate pumps and fans associated with the absorption chiller, and to serve the needs of a future visitor center to be located adjacent to the PV site. The remaining power will be transformed to $13 \mathrm{KV}$ for distribution to the shark exhibit which has an annual electrical energy demand of $1080 \mathrm{MWh}$ exclusive of that required for air conditioning. Several important requirements relate to the

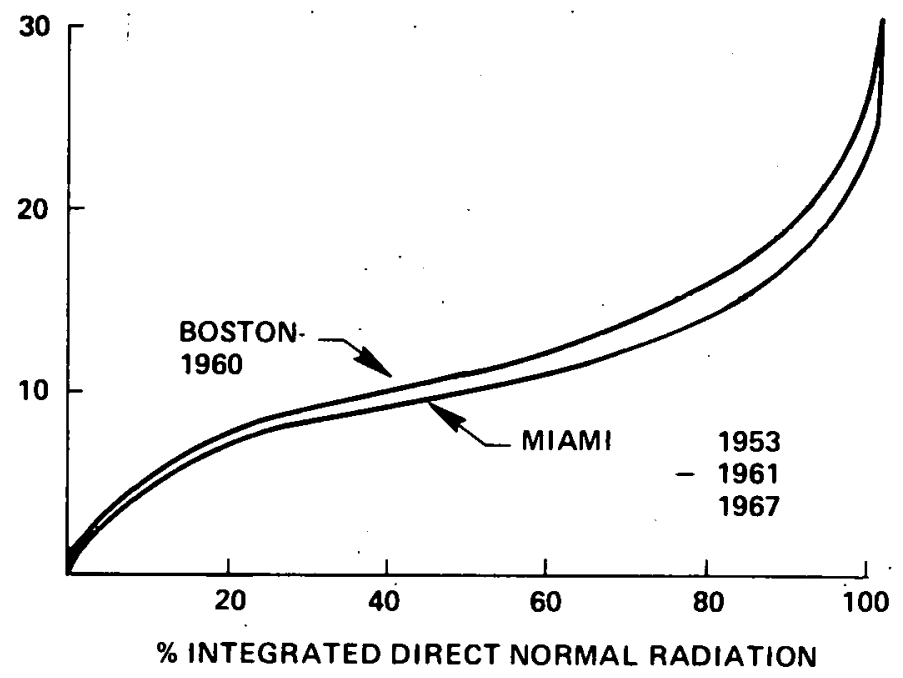
dependence on utility power for operation of the PV plant. Line commutation techniques are employed which assure that the PV plant Figure 3-1. Integrated Insolation vs Wind Speed will in no way interfere with the normal operation of Sea World. As shown later, the inclusion of a circuit breaker at the interface with the PV plant and under the control of the Florida Power Corporation satisfies these requirements。

The thermal requirements specified on Table $3-i$ pertain to the utilization of the thermal energy derived from active solar array cooling which enhances the economic benefits. An investigation of 
Sea World loads with regard to utilizing the thermal energy has identified air conditioning for the nearby shark exhibit as the most attractive. The annual cooling demand for this exhibit is approximately $2 \times 10^{6}$ ton-hours. As an alternative, domestic hot water can be provided for a hotel complex planned for the southwest corner of the Sea World property (See Figure 2-1). All of the solar array thermal byproduct can be used for producing chilled water for air conditioning the shark exhibit, while only about one-third of the thermal byproduct can be used for domestic hot water for the hotel complex. Although the benefit of the chilled water case is somewhat reduced by the cost of an absorption chiller, it is still preferred over the domestic hot water case because of the high cost of transporting the hot water approximately one mile to the hotel complex.

The plant size requirement in Table 2-1 was arrived at after analysis and tradeoff of several considerations including the following:

- It is desirable for the plant to contribute a significant portion of the total required load.

- Plant design is essentially modular by virtue of increasing or decreasing the number of turntables. Hence, the design effort is not significantly affected by the particular number of turntables selected.

- The plant should include enough turntables to permit a good cost assessment, based on volume, including fabrication, site preparation, and installation.

3.1.2 SYSTEM DEFINITION. An overall definition of the system is first presented below with the aid of the block diagram shown on Figure 3-2. Key component and subsystem selections are discussed later in this section.

Each turntable contains twenty-four 7 x 30-foot collectors arranged electrically in six paralleled circuits of 4 collectors each. With each collector containing a double row of vee-mounted solar cells, these circuits result in an equivalent matrix of 12 cells in parallel by 864 in series. The six circuits are paralleled through isolation diodes and the power is then fed through underground conduits to the inverter system located in the control building.

The inverter receives the solar array DC power at $360 \mathrm{VDC} \pm 12$ percent and converts it by line commutation methods to three phase, 4-wire 277/480 VAC in synchronism with local utility power. The inverter duty cycle is adjusted to present an impedance to the photovoltaic source which yields maximum power generation. This is accomplished by a power sense circuit at the inverter output which develops the necessary feedback information for the inverter through software in the computer system.

After providing power for PV plant parasitic loads and an Emergency Power System (EPS), the inverter output feeds a two-way transformer which inserts the power into a $13 \mathrm{kV}$ power loop 


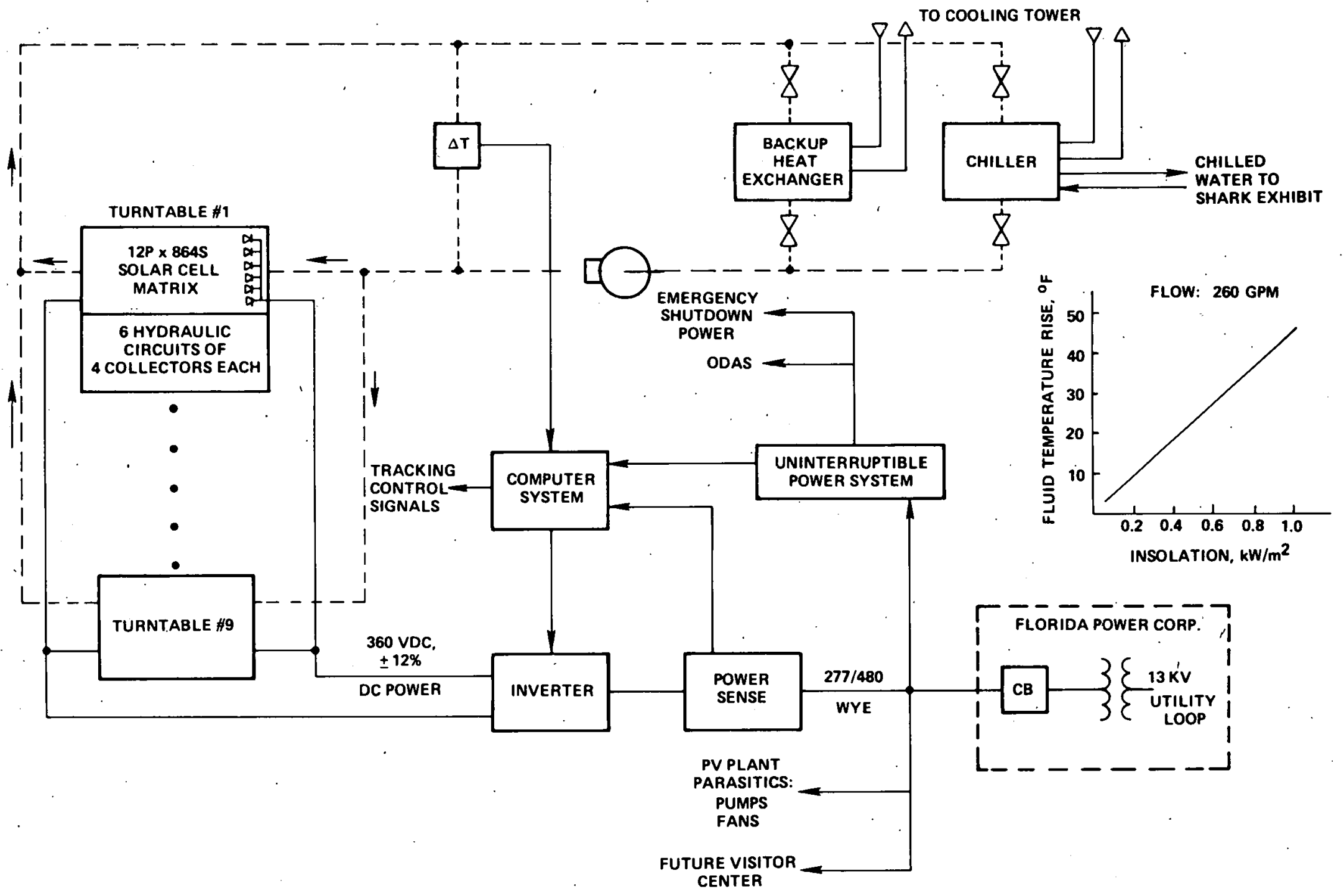

Figure 3-2. GE/Sea World System Block Diagram 
serving the Sea World Park. A circuit breaker on the low voltage side of the transformer, and the transformer itself, are owned and operated by the Florida Power Corporation. Aside from the power connections, no other electrical interface exists with the breaker or transformer. Interruption of utility power for any reason will result in shutdown of the Inverter System. This is a utility requirement.

Each turntable contains azimuth and elevation drives, position sensors, and elevation sun sensors. The centrally located computer system provides the necessary signals for these various turntable components. Though not shown on Figure 3-2, the computer system also has important links with the On-site Data Acquisition System and various components of the Hydraulic System.

The EPS provides continuous power for those functions that require uninterrupted power. These principally include power for the computer system, and the needs of emergency shutdowns. In the latter case, this pertains to defocussing the solar collectors to a safe oposition in the event of a utility outage, interruption of coolant flow, or solar cell overtemperature as detected by thermostats located on selectêd solar cell receivers.

The turntable cooling system consists of separate hydraulic circuits for each electrical set of collectors. By paralleling these circuits, each electrical set is subjected to the identical temperature conditions, resulting in matched output characteristics. Circulating fluid is supplied through underground piping by a pump located near the control building. The fluid is circulated through an absorption chiller which produces chilled water with a COP in the range of 0.65 to 0.8 depending on the supply temperature. A cooling tower is required to reject low-grade heat from the chiller. A back-up heat exchanger is provided to remove heat from the solar array field during times of chiller shutdown.

System operation is briefly described below:

- After the previous day's sunset, the turntables are positioned to the sunrise position by instructions from the computer system.

- At sunrise, azimuth and elevation sun-tracking is initiated by the computer, based on stored aphemeris data; the coolant loop circulating pump is turned on.

- Under constant flow, the solar array fluid temperature rise is proportional to insolation as shown on the plot included on Figure 3-2. At a $\Delta \mathrm{T}$ of $3^{\circ} \mathrm{F}$, the inverter is turned on producing about 10 percent of rated power.

- The solar array temperature rise increases in proportion to insolation. The absolute temperature will also increase until the temperature drop throught the absorption chiller is equal to the solar array temperature rise, not considering heat leaks. This equilibrium condition occurs at temperatures in excess of $160^{\circ} \mathrm{F}$. Pumps and fans associated with the chiller and cooling tower will be activated automatically in response to temperature and pressure control signals. 
- The inverter will be turned off when the output power is less than about 5 percent of rated output and will be turned on only when the solar array temperature rise increases to $3^{\circ} \mathrm{F}$.

- At sunset, sun tracking is turned off by the computer system and turntables returned to the sunrise azimnth position. Collectors are stowed in the night-time inverted position.

3. 1. 3 SUBSYSTEM DEFINTION. The major subsystems and components comprising the overall system are depicted on Figure 3-3. The broad aspects of subsystem definition are covered below according to the categories noted on Figure 3-3, while detailed component descriptions are presented in later sections. A drawing tree for the overall system is shown on Figure 3-4.

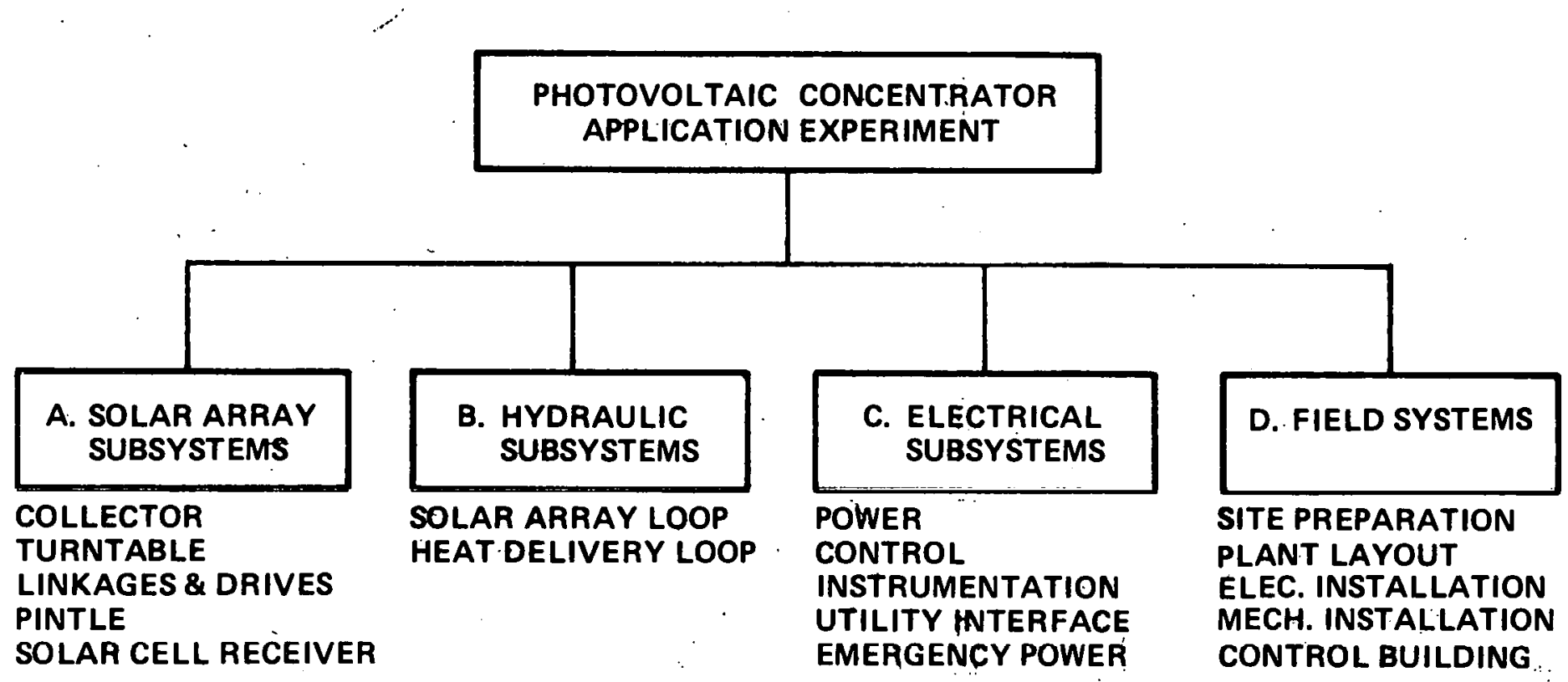

Figure 3-3. Major System Elements

3.1.3.1 Solar Array. Requirements for the solar array are summarized on Table 3-2.

The selected turntable approach for the solar array shown on Figure 3-5 was based on the following characteristics: (1) low physical profile with low wind loading effects; (2) distributed weight with small unit area loading; (3) potential for using fewer tracking drives to serve a large number of collectors; (4) no shadowing by adjacent turntables; (5) shadowing within the turntable collectos at low elevation angles permits power generation within the unshaded portions. .

The turntable design characteristics are summarized on Table 3-3. The basic mechanical design was developed through tradeoffs involving the spacing of major I-beam supports and the 10cation of wheel supports.

The design was strongly influenced by the solar collector design whose basic width and length dimensions ( $7 \times 30$ feet) were selected to permit easy transport on a flat-bed truck. Although the 


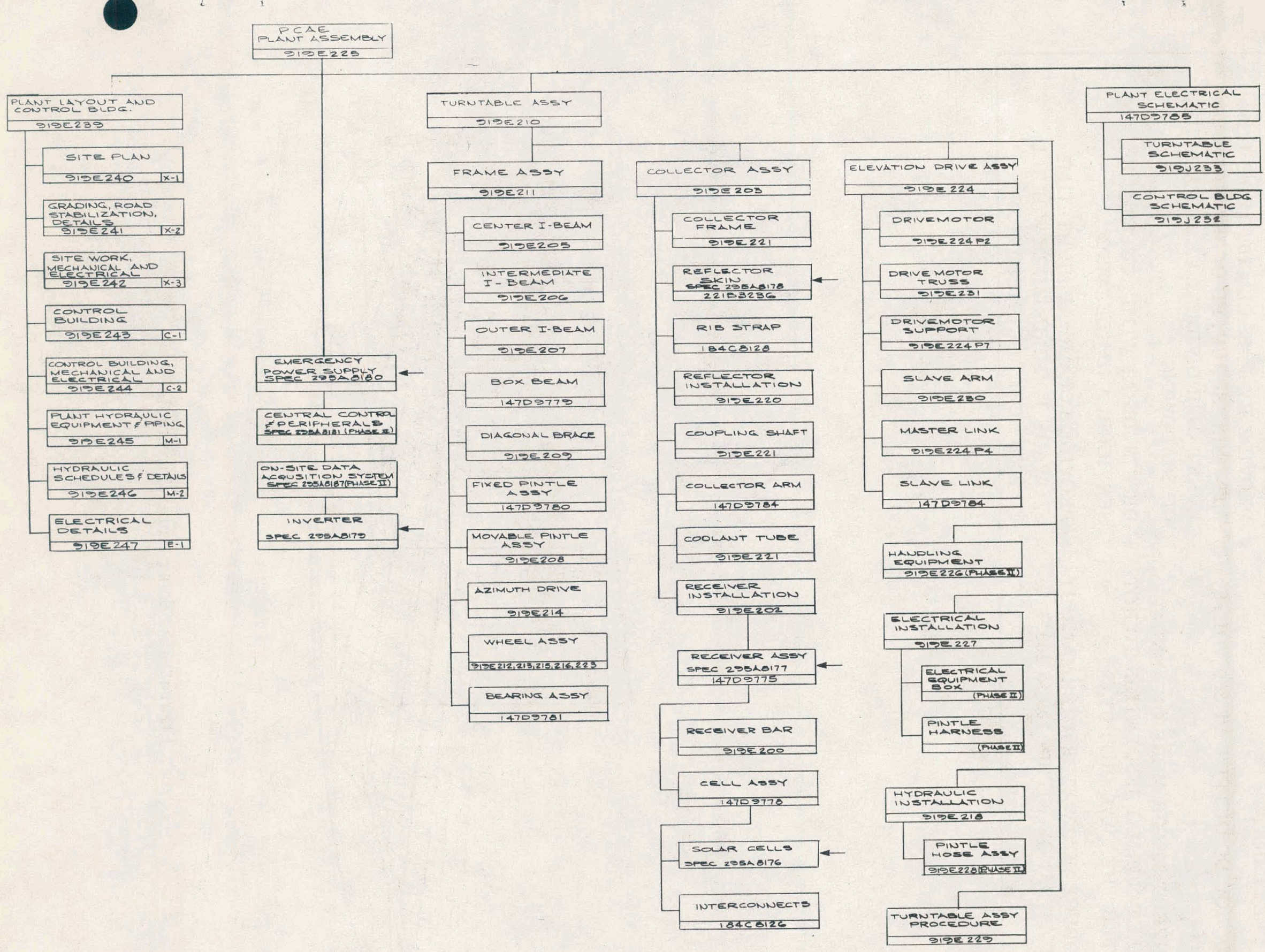


- convert 8\% or more of anNuAl DIRECT NORMAL INSOLATION TO DC ELECTRICITY

- PRODUCE DC OUTPUT AT 360 VOLTS $\pm 12 \%$

- CONVERT 33\% OR MORE of ANNUAl DIRECT NORMAL INSOLATION TO HOT WATER THERMAL OUTPUT

- PRODUCE HOT WATER THERMAL OUTPUT AT RANGE WTTHIN 100 to $200^{\circ} \mathrm{F}$
- PROVIDE 1500-VOLT SOLAR CELL CIRCUIT TO GROUND INSULATION

- PROVIDE BY-PASS CIRCUITRY TO PERMIT UNINTERRUPTED OPERATION IN EVENT OF INDIVIDUAL CELL FAILURE OR SHADOWING

- DESIGN ARRAY WITH ACCESS FOR SERVICING AND CLEANING

PROVIDE FOR ARRAY NIGHT-TIME STOWAGE TO MINIMIZE DEW BUILDUP AND DUST ACCUMULATION
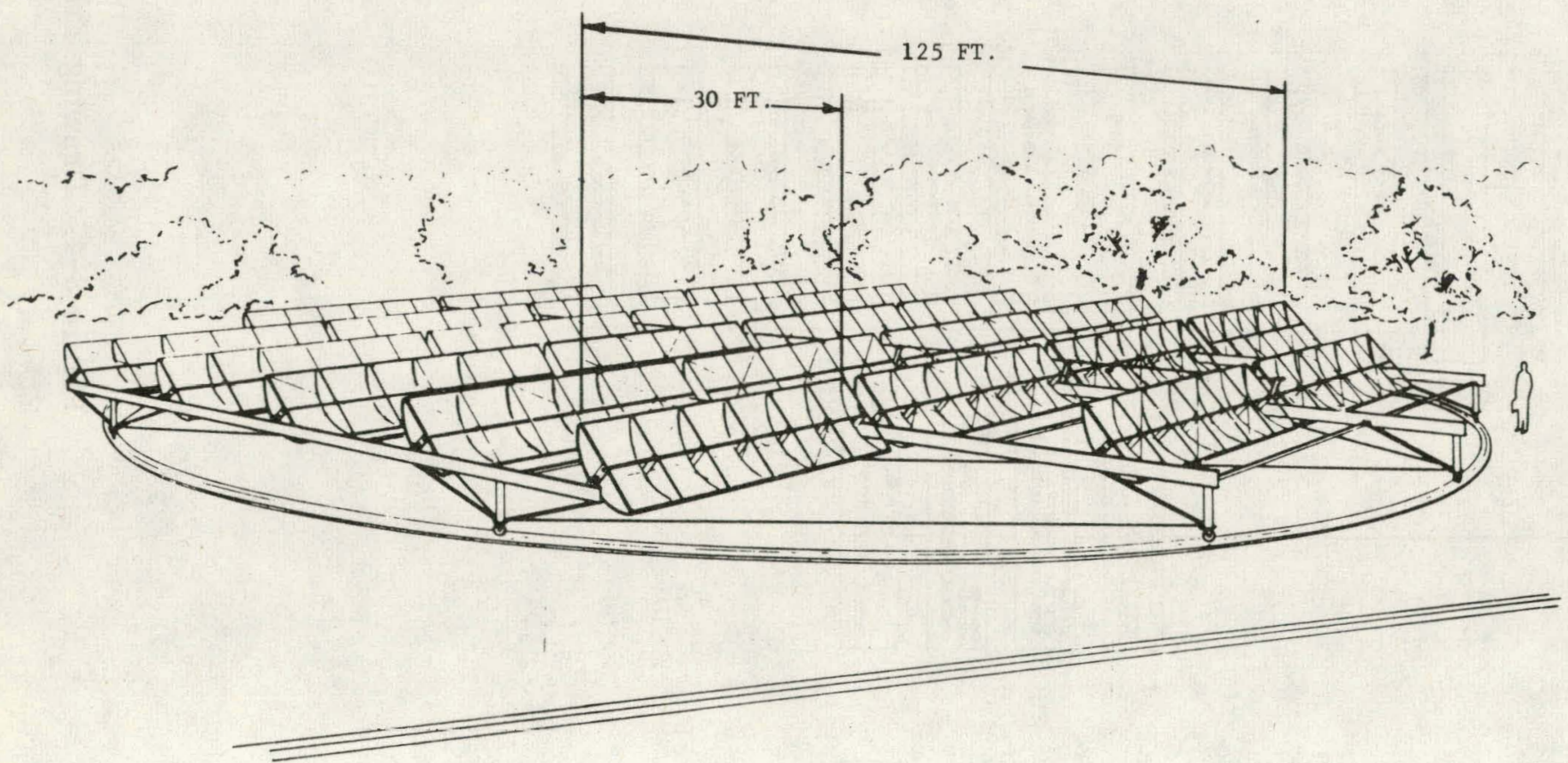

Figure 3-5 Solar Array Turntable 
Table 3-3. Turntable Description

- PEAK PV RATING: $37.8 \mathrm{~kW}$

- $24-7 \times 30-F T$. PARABOLIC COLLECTORS

- WATER-COOLED SEGMENTED SOLAR CELL RECEIVER; 3.5 × 4 CM SOLAR CELLS IN 216 SERIES $\times 2$ PARALLEL MATRIX IN EACH COLLECTOR

- I-BEAM \& BOX-BEAM TURNTABLE FRAMEWORK WITH DIAGONAL ROD BRACING

- $+1^{\circ}$ AZIMUTH TRACKING WITH 2 MOTORIZED WHEELS ON TURNTABLE PERIPHERY

- $\pm 0.1^{\circ}$ ELEVATION TRACKING With A ÁLL COLLECTORS GANGED TO SINGLE DRIVE
- COLLECTOR WEIGHT: 18,000 LBS OTHER WEIGHT: $\quad 16,000$ LBS

- MECHANICAL INTERFACES: PINTLE BEARING 137.2-FT \& 83.5-FT DIAMETER CONCRETE TRACKS 3-INCH WATER SUPPLY \& RETURN THROUGH SPIRAL HOSES AT PINTLE

- ELECTRICAL INTER FACES THROUGH SPIRAL CABLING AT PINTLE: 360 VDC PV OUTPUT 120 VAC SERVICE POWER 5-WIRE SIGNAL LINK

30-foot collector length is somewhat unwieldy in terms of handling, the size is judged to be a positive feature because fewer turntable support members and mechanisms are required. The collector uses stock $4 \times 10$-foot sheet metal sizes which are wrapped to conform to accurately formed ribs and longerons. Simple channel and band clamps snub the sheet metal against the rib/ longeron framework. A significant attribute of the collector design is the exceptional beam and torsional stiffness provided by the sheet metal skin, in addition to the skin's principal function as a reflector.

An important consideration in the development of the turntable concept concerned the means for articulating the collectors for azimuth and elevation tracking. The basic collector geometry permits angular errors of up to several degrees in the axial direction while an accuracy of 0.2 degree is required in the transverse direction. Since the collector axes are oriented in a horizontal direction on the turntable, azimuth tracking within \pm 1 degree is sufficient to achieve the required collector axial pointing accuracy. Elevation tracking to achieve transverse collector pointing within 0.2 degree is somewhat more difficult and is accomplished by careful attention to sources of angular error and the use of regid sections to minimize angular distortions.

Figure 3-6 illustrates the basic approach of the elevation tracking system. A motorized jackscrew drives a series of push-rods connected to crank-arms attached to one column of collectors. These collectors, in turn, drive the remaining collectors in each row through rigid shaft 
couplings . Several key features of this design provide the pointing accuracy required:

1. The crank-arms are positioned relative to the collectors to provide the highest average distance between the point of rotation and the push-rod line of thrust. Maximizing this distance yields the highest accuracy.

2. Ball-joint bearings with small clearances are used to articulate the push-rods with the collector crank-arms.

3. Advantage is taken of the high-torsional stiffness of the collectors in transmitting the required angular motion.

4. Low-friction bearings support the collectors throughout the turntable (Rather than using expensive circumferential bearings, two small trunnion rollers are used).

5. Alignment adjustability is provided at several key locations indicated on Figure 2-7:

a. The length of each push-rod is adjustable.

b. The relative angular position of the collector couplings can be adjusted.

c. The angular twist of each collector can be adjusted by the diagonal rod bracing。

d. An eccentric located at the push-rod end of the collector crank-arm permits crank arm positioning adjustment.

6. Collector alignment is accomplished with a simple carpenter's level placed across the collector edges.

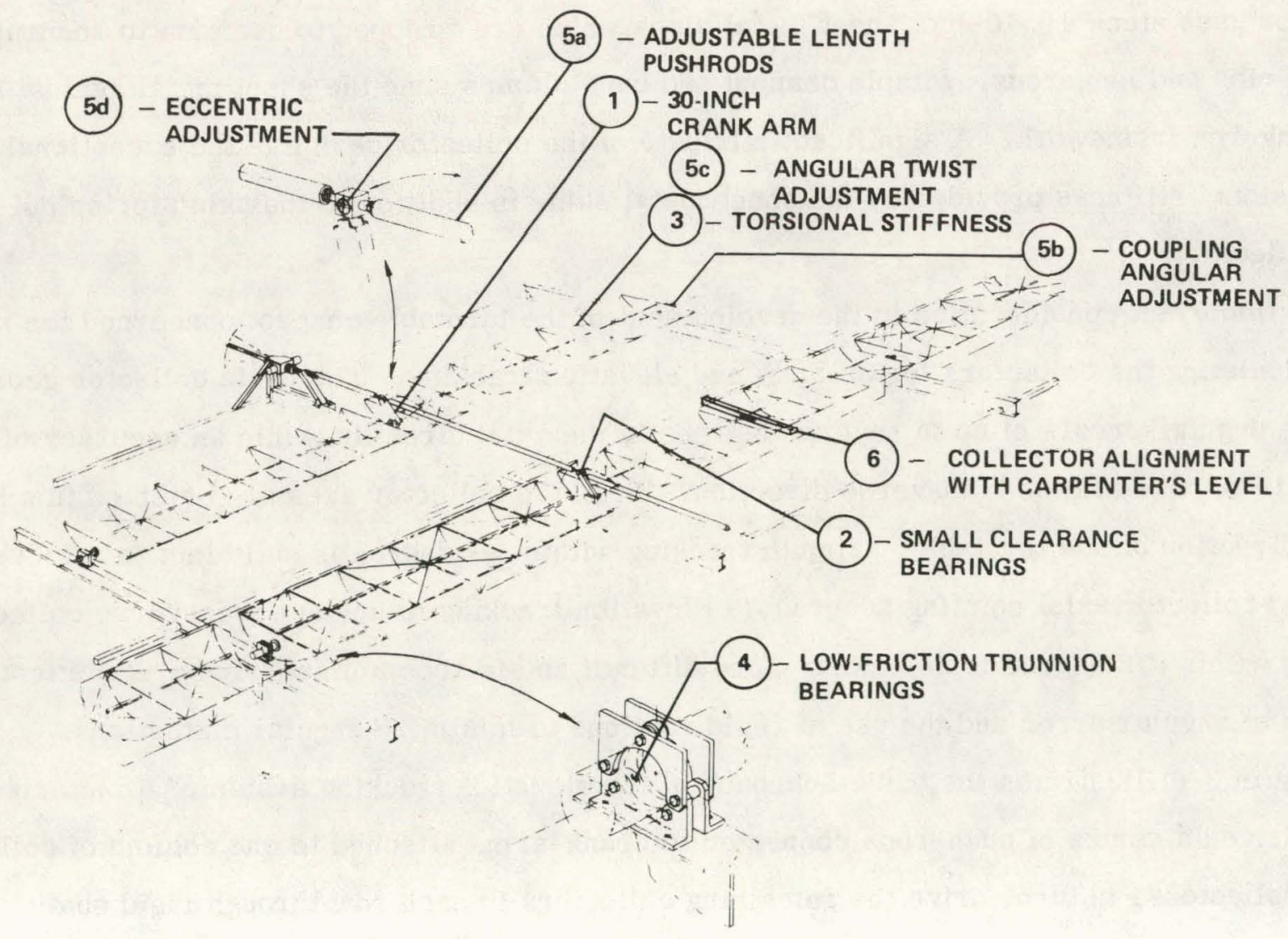

Figure 3-6. Elevation Tracking Systems 


\subsubsection{Hydraulic Coolant System. A requirement for the hydraulic coolant system is to keep}

the solar cells as cool as possible for improved PV performance while at the same time producing a thermal byproduct that will yield attractive economic benefits. These objectives are somewhat in opposition since the highest thermal economic benefits are usually associated with higher temperatures which are counter to PV performance. Thus, the main objective in the design of the coolant system was to obtain the best balance of these opposing requirements.

An additional requirement of importance is to minimize pumping losses. This can be done by using variable-speed or staged pumping in conjunction with the variable solar input received by the solar array。

A number of design alternatives were evaluated for the coolant system. Use of the thermal output for domestic hot water production was compared with producing chilled water using absorption chiller equipment. Comparisons of single versus staged and variable-speed pumps indicate that adequately-sized single-speed pumps were most effective overall. Their slightly higher pumping energy is more than compensated for by the reduced capital requirements and control simplification. The chiller approach was selected because all of the thermal output could be utilized (versus $30 \%$ utilization for the domestic hot water case), and because of the cost of transporting the hot water to its point of use in a planned hotel complex, approximately a mile from the PV site.

The primary approach adopted for the hydraulic coolant system is illustrated on the schematics in Figure 3-7. The turntable hydraulic system consists of seven circuits formed by the interconnected collector tubes together with miscellaneous distribution piping and values. Five circuits contain four collectors each while the forward and rear circuits consist of two collectors each. The tube and pipe sizing is selected to achieve balanced flows among the five circuits, roughly within 10 percent of each other. The forward and rear circuits use throttling valves to reduce the flow to about one-half that of the other circuits. Thus, the temperature rise is identical in all circuits. Since the solar cell circuits of the extreme rows are wired in series, this matching in temperature rise results in all solar cell circuits having the same average temperature.

The flow in each turntable is routed through a spiral hose at the pintle from whence it flows through underground pipes to the heat removal equipment near the control building. The balance of flow among the various turntables is achieved by inlet balance valves as shown on the turntable schematic.

Figure 3-7 (b) shows the other portions of the hydraulic schematic with the flow directed through an absorption ctriller. As noted in earlier discussion, the solar array temperature rise represents one of the important control parameters used for inverter turn-on, since it is proportional to in'solation. It is not necessary to control the absolute level of temperature as long as it is within 
VALVING SYMBOLS

$\rightarrow$ isolation

$\rightarrow$ balance

- maintenance

FL FEXIBLE JOINT

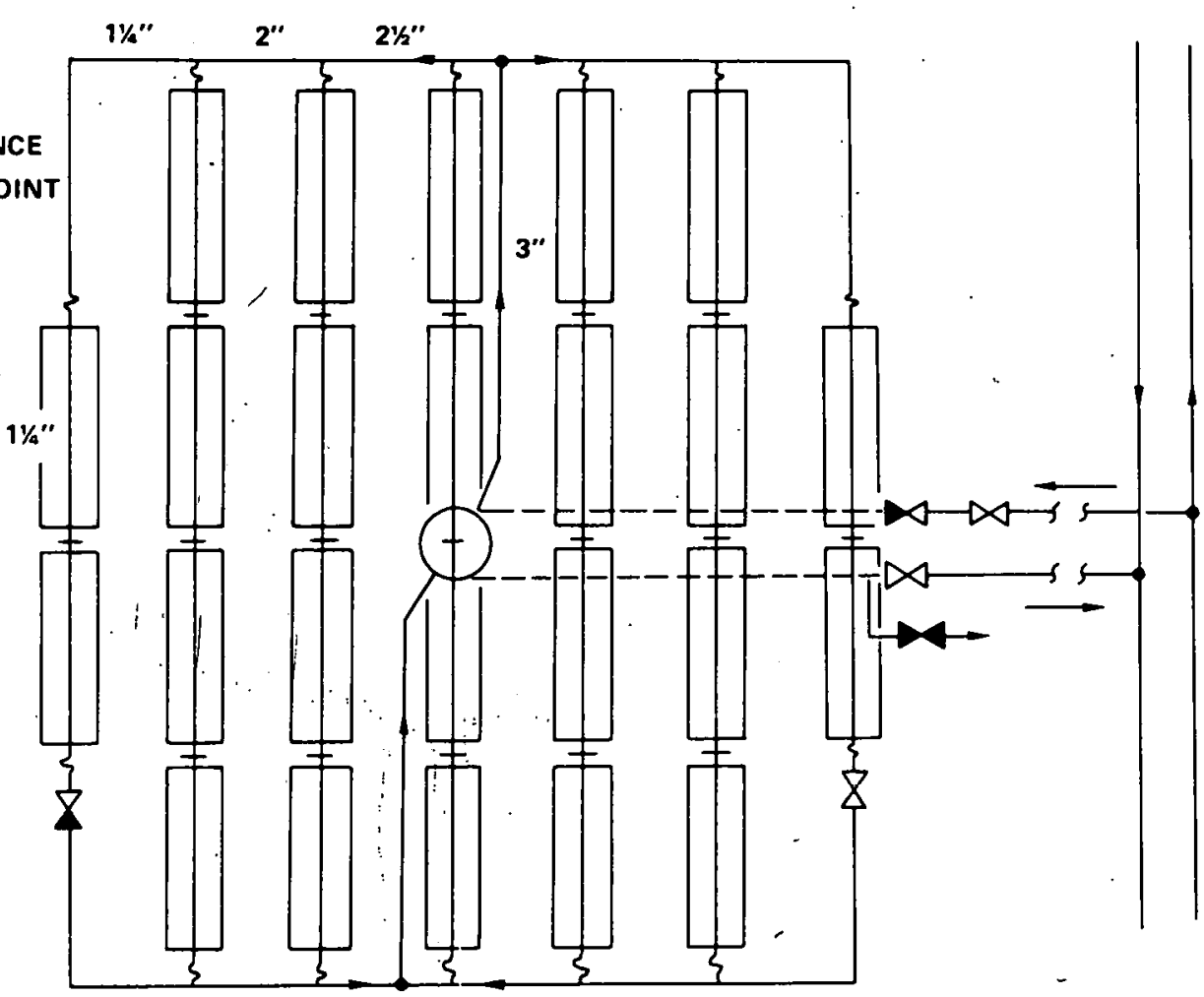

(a) TURNTABLE PIPING SCHEMATIC

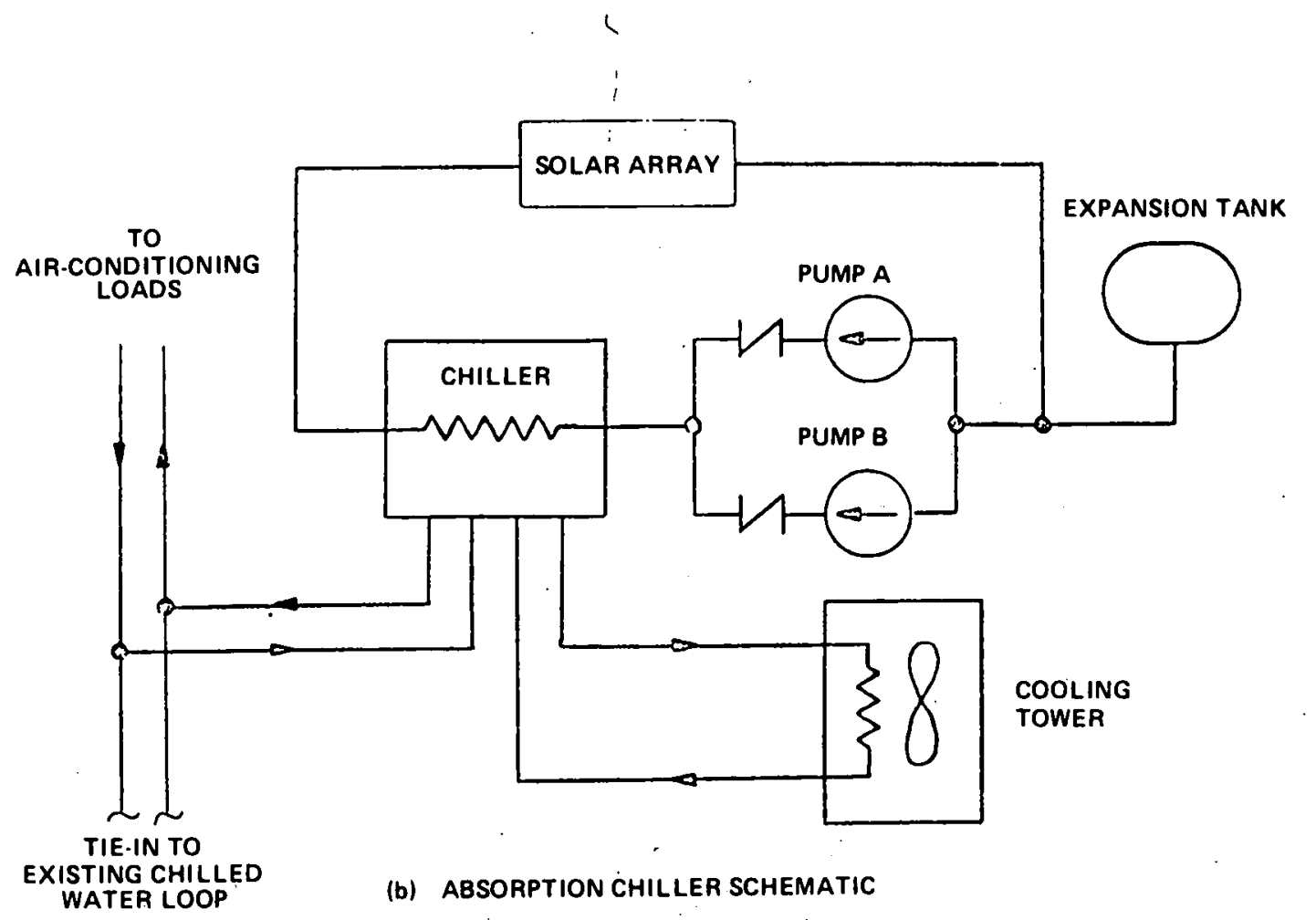

Figure 3-7. Hydraulic System Schematic 
safe limits. Thus, with solar input to the solar array, the temperature level will increase until the heat removed by the chiller and losses is equal to the heat gain in the solar array. The response of the chiller for analyzing system performance is discussed in Paragraph 2.4.

\subsubsection{Electrical Subsystems. Electrical subsystems identified for the PCAE are: (1) power;}

(2) control; (3) instrumentation; (4) utility interface; and (5). emergency power. The principal system requirements are highlighted in Table 3-4 and the major system components required to perform these functions are shown in Figure 3-8.

The solar arrays on each of nine turntables are connected in parallel and provide a peak power capability of $340 \mathrm{~kW}$ at a voltage of approximately $360 \mathrm{VDC}$ to the input of the inverter system. The DC voltage is inverted to three-phase $(277 / 480 \mathrm{VAC})$ power synchronized with utility power by line commutation techniques. The inverter is operated as a current source with the power inserted through the PCAE/utility interface.

The central computer provides the data and logie required for system control. The most significant control functions include: sun-tracking controls for each turntable; solar array peak power tracking; emergency shutdown control; and normal operation start-up and shut-down controls. The computer provides a flexible means for implementing alternate power and tracking control strategies

Table 3-4. Electrical System Requirements

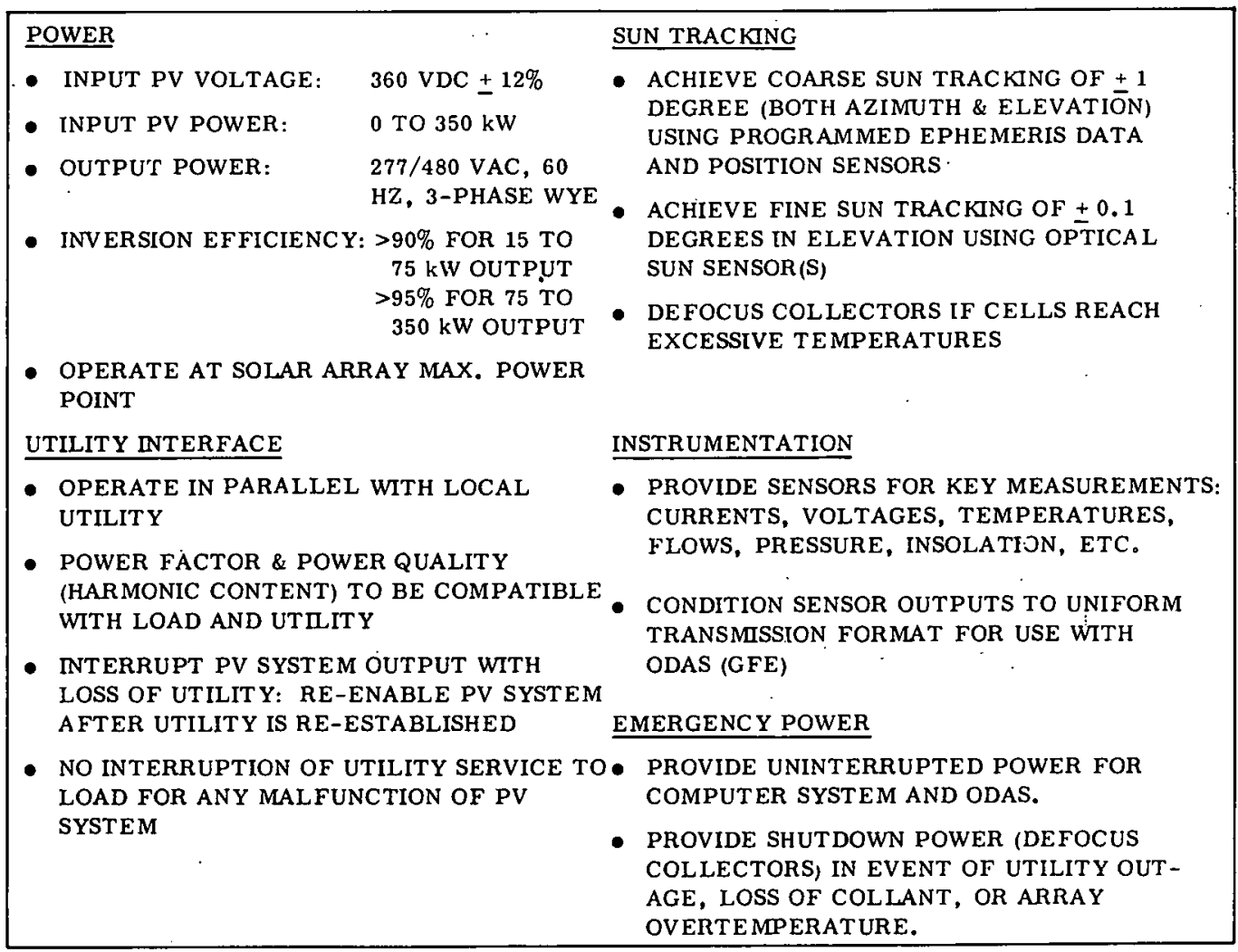




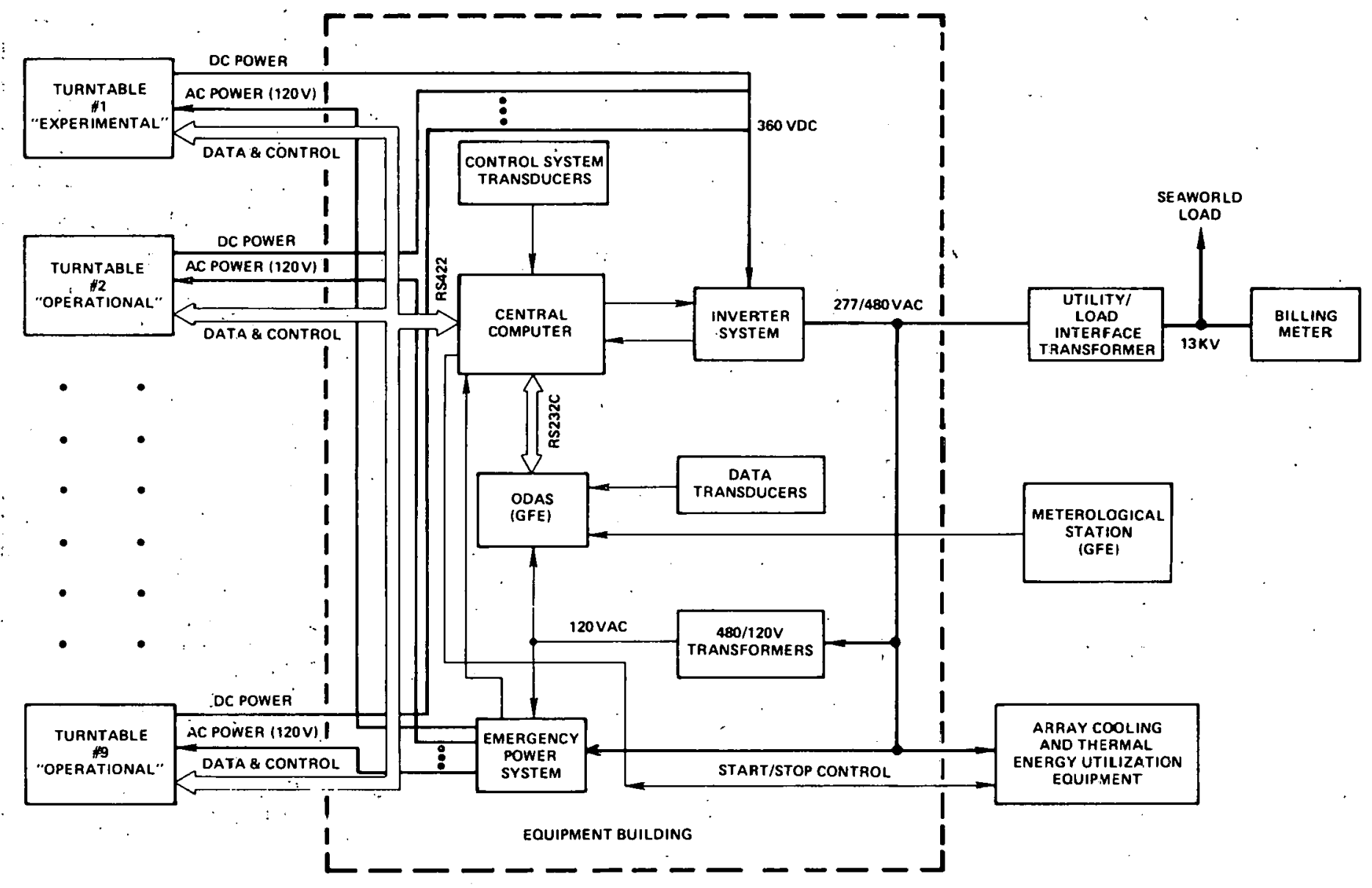

Figure 3-8. Electrical Subsystem Block Diagram 
System performance data is collected and dispatched by the government-furnished On-Site Data Acquisition System. The ODAS has been integrated on a non-interference basis with the PV system controls although both systems will share the inputs from certain sensors. Instrumentation inputs are provided from, many points in the system, although a larger number of measurements will be associated with one "experimental" turntable. This single turntable will be equipped with more versatile data handling equipment to provide greater latitude in the nature of the performance variables to be evaluated.

An emergency power system contains sufficient storage to sustain the computer system for several hours and to also bring the system to a safe shutdown condition in the event of utility or pumping outages.

The system architecture associated with the various power control, tracking control, and instrumentation functions has been selected based on the following objectives: (1) minimizing the power and signal cabling required between the solar array and control bui lding; (2) use of standard circuits and electronic components; (3) low cost by minimizing the amount of equipment required; (4) flexibility for evaluating alternative controls and instrumentation. The selected electrical subsystems described in more detail in Section 3 meet these objectives and facilitate their Phase II hardware implementation.

3.1.3.4 Field Systems. Field systems include the site preparation, construction of turntable foundations, erection of the control building and all electrical and mechanical installations。 The basic site and plant layout characteristics have been described earlier in Section 2.2. Specific features of the control building, and electrical and mechanical installations are noted below.

The turntable foundation consists of two concentric concrete tracks and a concrete pier at the turntable hub. The concrete tracking. is made up of a continuous $12 \times 12$-inch footing with two \#5. steel reinforcing bars placed 3 inches from the bottom. Three-quarter inch expansion joints will be located at the quarter joints of the outer ring and at the half points of the inner ring. The center pier is $10 \times 10 \times 2$ feet thick with a $21 / 2 \times 21 / 2 \times 3$ foot high pedestal for the pintle base.

The control building is a $16 \times 50$-foot concrete masonry structure. It will be supported on a continuous concrete footing and has a 5-inch concrete floor slab. The roof consists of precast concrete slabs with a built-up roof covering. The electrical and mechanical installations both within and outside the control building are designed in accordance with standard engineering practices. 


\section{2 ' SOLAR ARRAY}

\subsubsection{Solar Collector The solar collector consists of the $7 \times 30$-foot skin-frame assembly}

shown schematically on Figure 3-9. The framework is composed of seven accurately formed ribs tied together with three longerons along the keel and edges. Stock size 25-mil $4 \times 10$-foot aluminized steel sheets with a laminated reflective surface are snubbed against the framework by band and edge clamps. Diagonal rod braces across the aperture both stiffen the collector torsionally and provide a means for trimming out angular twist errors. Circulating fluid through a 1.25-inch ID copper tube along the focal line provides the means for cooling solar cell receivers mounted along the tube between each rib section. Stub shafts are provided at each end for bearing support and coupling with adjacent collectors.

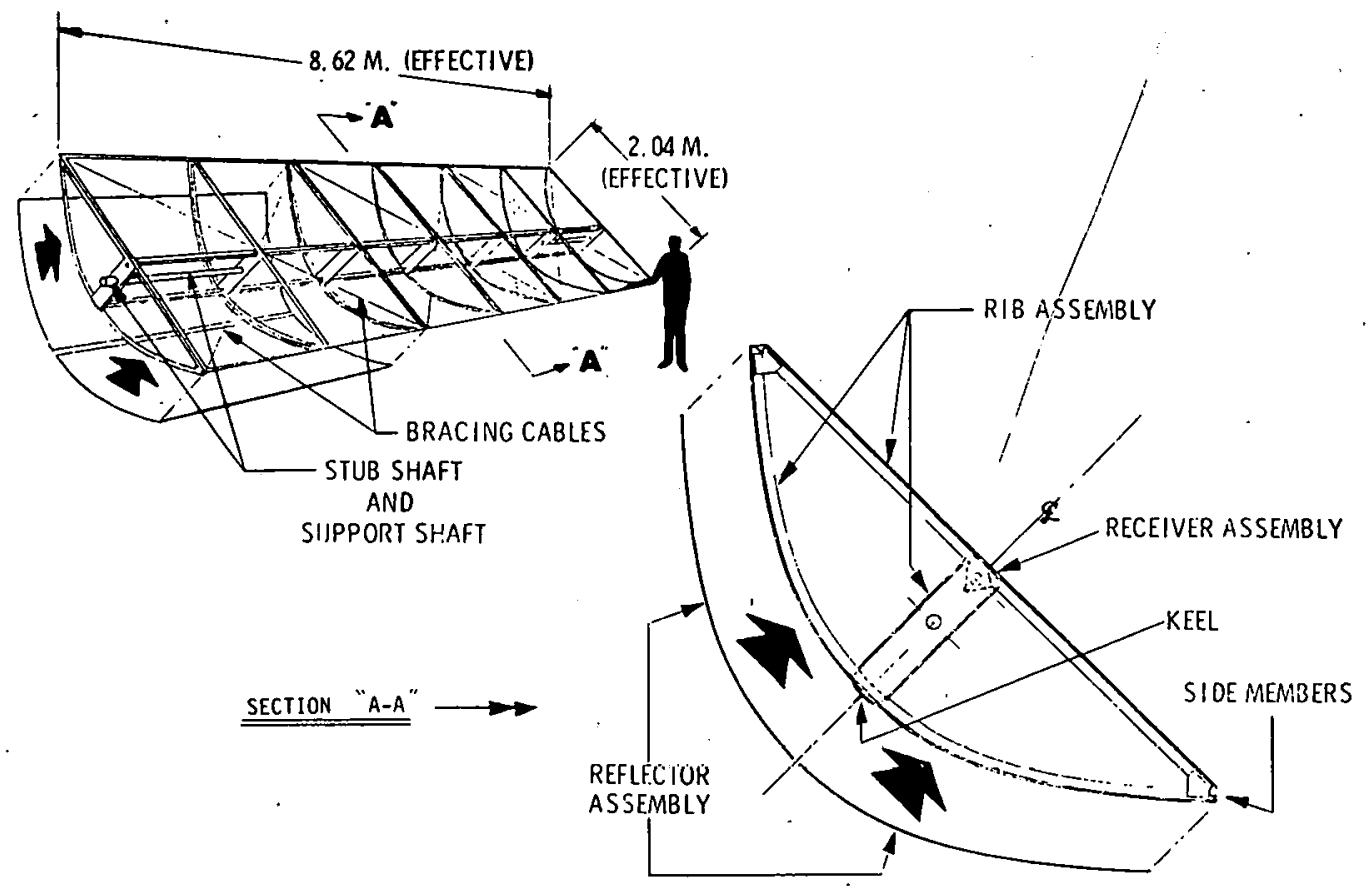

Figure 3-9. Parabolic Collector

The reflector geometry is illustrated on Figure 3-10. The focal point of each half of the parabolic trough is located at the mid-point of the Vee-mounted solar cells. A rim angle of90 degrees is used resulting in a theoretical aperture width to focal length ratio of two. The 20.38-inch focal length was dictated by the arc-length obtained by wrapping the 48 -inch wide reflector sheets around the parabolically shaped ribs with sufficient allowance for longitudinally clamping the sheets along the tee-section keel and ell-section longerons. These clamping surfaces are tangent with the theoretical parabolic cylinders. In conjunction with the parabolic ribs they form the boundary conditions for establishing the parabolic contour. 
With allowance for shadowing by the solar cell receiver the effective half-aperture width is 39.5 inches. The effective length of each of the six sections making up the collector is 58.5 inches. This results in an effective area of $192.2 \mathrm{ft}^{2}\left(17.86 \mathrm{~m}^{2}\right)$ for each collector.

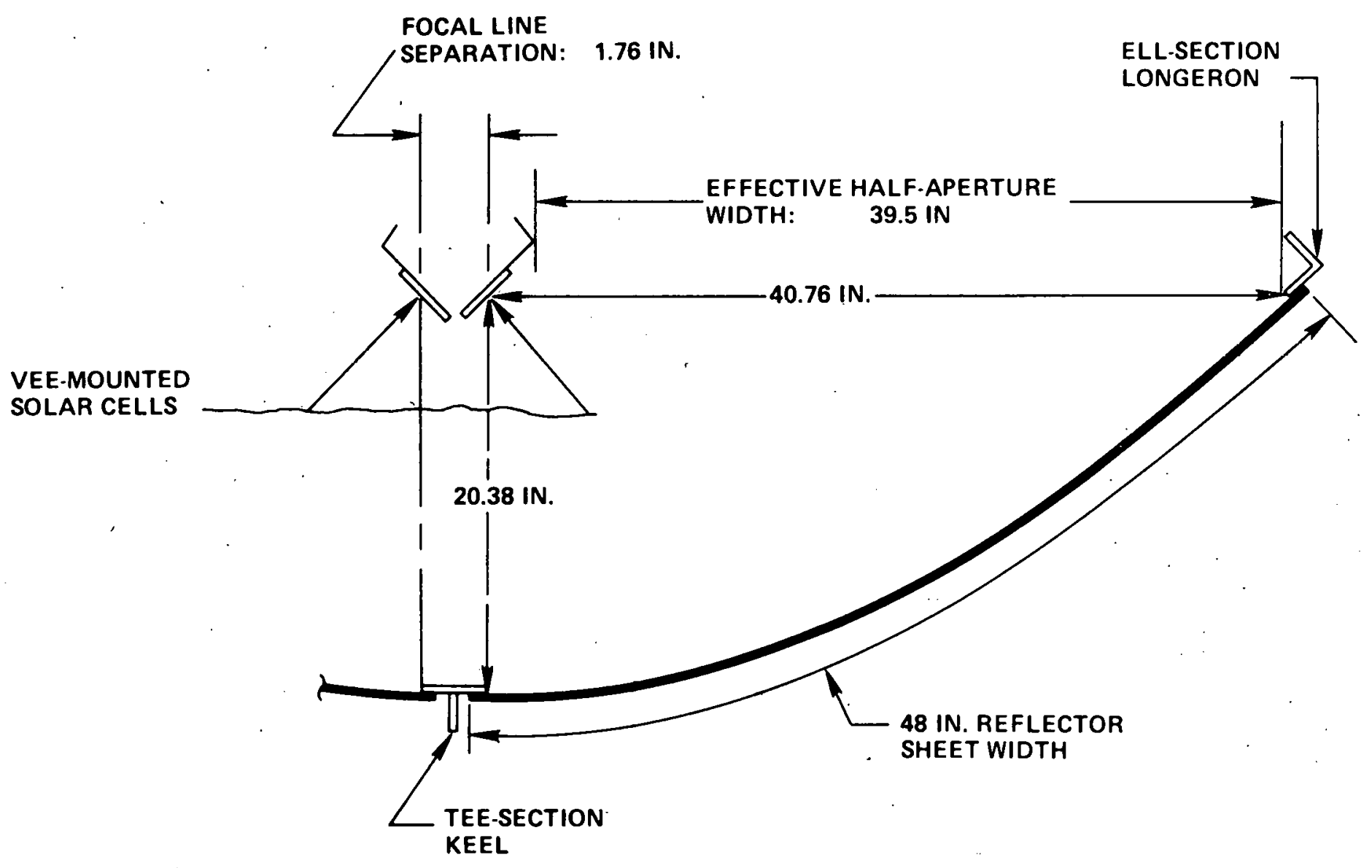

Figure 3-10. Collector Geometry

The parabolic ribs use commercially available aluminum tee sections with a T4 heat treat. Aluminum was chosen to maximize the accuracy of the stretch forming process. The bottom keel and side rails are also aluminum extrusions $(35,000$ psi yield) chosen because of cost and corrosion resistance considerations. The reflective film approach used in this design decouples the reflector surface and reflector substrate material selection and allows the substrate material to be chosen on structural cost effectiveness alone. Sheet steel shows a significant advantage over sheet aluminum in this regard. 
Full structural advantage is taken of the reflector substrate in providing shear and torsional resistance for the collector's 30-foot length. Although bending is primarily resisted by the bottom keel and side rails, the substrate provides the shear resistance required along the section's neutral axis. In conjunction with the diagonal bracing rods and rib members, the substrate also provides a high degree of torsional stiffness.

Moments are taken out of the collector through the shear developed by each support shaft in combination with each end pair of rib assemblies. This removes the requirement to transmit moments through the vertical members of the rib assemblies, thereby reducing their material thickness and cost.

The structure is fastened by rivets and clamp assemblies. Rivets are also used to attach the rib assemblies to the bottom keel and side rails. The $4 \times 10$-foot reflector substrates are attached to the parabolic ribs, bottom keel, and side rails by clamp assemblies. 'These clamp designs reduce assembly time and allow field replacement of a reflector panel if required.

Several features of the collector trough have inherent producibility and cost advantages as discussed below.

The parabolic ribs make use of the mature, high-volume stretch forming technology. The reflector substrate is not preformed but wrapped around the parabolic ribs at assembly. Thus, the rib is the only component formed to an optical requirement. The cost of generating the parabolic trough shape through the use of stretch-forming is approximately $10 \hat{c}$ per square foot of collector aperture.

The reflective film approach adopted in this design makes use of cost-effective materials as well as high-volume production techniques. The 4-foot wide polyester composite film is UV stabilized and metalized in continuous coil processes. Coil lengths are on the order of 600 feet. The lamination of the film to the substrate is provided by the high-volume plastic to steel lamination industry. The polyester is. laminated to coil steel at process speeds of approximately 20 feet per minute.

The upper layer of the composite film is a high clarity 3-mil UV stable film, commercially available under the trade name LLUMAR from Martin Processing, Inc. UV absorbers are added to the film in a dying process. This film is currently in use as a glazing on commercial flat-plate solar collectors and on greenhouses. The lower film is a 1-mil clear polyester film. The upper 
film is vacuum metalized (aluminum) to a thickness having a resistance of less than one ohm per square. The two films are laminated with the metalizing sealed in-between. Cost of the composite film is $23 \xi / \mathrm{ft}^{2}$.

The Martin film has been extensively characterized and compared with other materials in tests conducted at GE. As shown on Table 3-5, five film-type reflective materials were evaluated by subjecting them to a series of environmental exposures with measurements of total and diffuse reflectance made after each exposure. As indicated in the remarks column, the LLUMAR material performed best. However, it did exhibit some rise in diffuse reflectance (and therefore a decrease in specular reflectance) after the abrasion and cleaning tests. The other materials had more severe shortcomings and therefore the LLUMAR has the greatest promise as a low-cost reflective material.

The abrasion resistance required to achieve a field life of 20 years has not yet been determined quantitatively. GE is evaluating the performance and cost of a protective overcoat such as the silicone hard coat developed by GE's Lexan division for outdoor Lexan applications. The coating is commercially used on Lexan head lamps for the automotive industry.

The feature of the collector design which permits easy reflector replacement can be considered as an alternative to 20-year reflector durability. Replacement of the skin, for example after 10 years, may be more cost effective.

Lamination of the reflective film to the substrate has implications on performance because of the resulting surface quality and on costs which are strongly dependent on the manufacturing process. Laminating techniques were evaluated during Phase I with strong emphasis on the appropriateness of the already established decorative film laminating and hot stamping industries. These high volume industries apply films and coatings to steel and aluminum substrates in both coil and sheet processes.

Two 150-foot coils of the Martin composite polyester film and other candidate materials were obtained and used in the trial laminations, noted in Table 3-6, using high-volume process rates. Finished products were evaluated on the basis of adhesion and surface flatness. The term "orange peel" is used to indicate the most common type of non-flatness encountered in laminating films to substrates. The orange peel effect can be caused by non-uniform thickness of the adhesive layer between film and substrate, failure to remove all air between film and substrate, and/or surface imperfections in the substrate. 
Table 3-5. Reflective Surface Evaluations

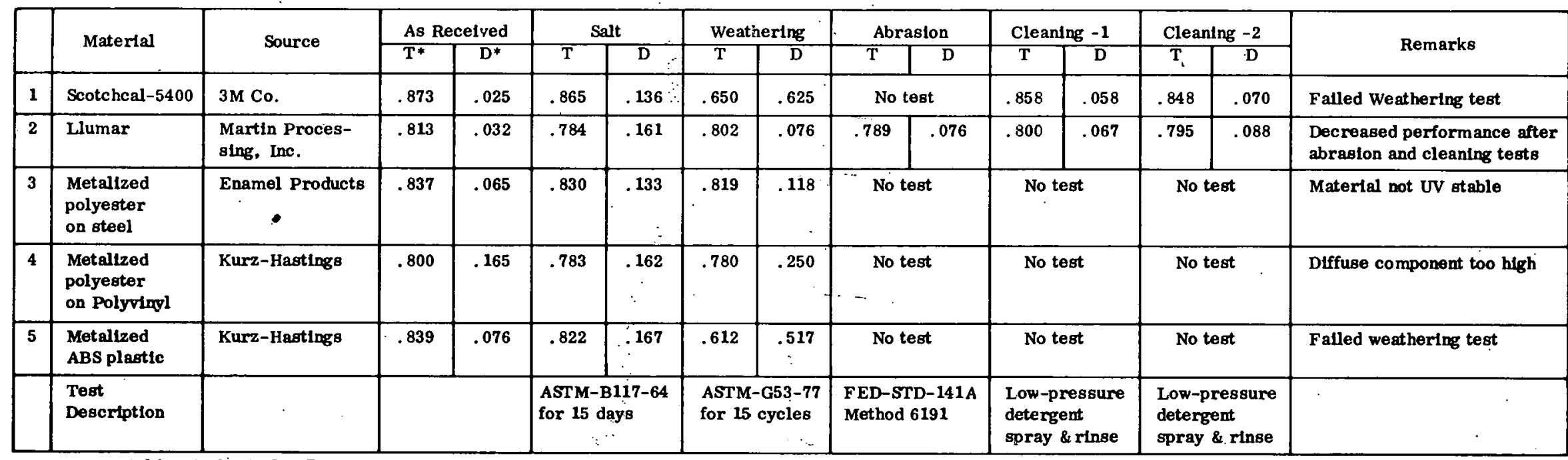

*T: Total hemispherical reflectance

*D: Diffuse rellectance $\left(3^{\circ}\right.$ aperture)

-.......

Table 3-6. Lamination Test Results

\begin{tabular}{|c|c|c|c|c|c|c|}
\hline & Laminator & $\begin{array}{l}\text { Process } \\
\text { Type }\end{array}$ & Fulm & $\begin{array}{l}\text { Process } \\
\text { Speed }\end{array}$ & Substrate & Results \\
\hline 1 & $\begin{array}{l}\text { Enamel Products, } \\
\text { McKeesport, Pa. }\end{array}$ & Coil & $\begin{array}{l}\text { Martin Composite } \\
\text { Single Piece } \\
\text { Polyester }\end{array}$ & $\begin{array}{c}80 \mathrm{ft} / \mathrm{min} \\
\ddots\end{array}$ & $\begin{array}{l}\text { Steel } \\
\text { Commercial } \\
\text { Brite Steel }\end{array}$ & $\begin{array}{l}\text { Steel showed moderate orange } \\
\text { peel. Commercial Brite showed } \\
\text { light orange peel. Good adhesion. }\end{array}$ \\
\hline 2 & $\begin{array}{l}\text { Poloron } \\
\text { Industrles, } \\
\text { Scranton, } \mathrm{Pa} \text {. }\end{array}$ & Sheet & Martin Composite & $20 \mathrm{ft} / \mathrm{min}$ & $\begin{array}{l}\text { Galvanized Steel } \\
\text { Steel } \\
\text { Aluminum }\end{array}$ & $\begin{array}{l}\text { Galvanized spangle showed through } \\
\text { fllm. Poor adhesion with all } \\
\text { substrates. }\end{array}$ \\
\hline 3 & $\begin{array}{l}\text { Raymond } \\
\text { Engineering, } \\
\text { Quebec, Canada }\end{array}$ & Sheet & $\begin{array}{l}\text { Martin Composite } \\
\text { Single Piece } \\
\text { Polyester. }\end{array}$ & $\begin{array}{c}20 \mathrm{ft} / \mathrm{min} \\
\therefore\end{array}$ & $\begin{array}{l}\text { Aluminum } \\
\text { Aluminized Steel }\end{array}$ & $\begin{array}{l}\text { Essentially no orange peel with } \\
\text { single plece polyester on aluminum. } \\
\text { Good adhesion. Martin Composite } \\
\text { fllm and aluminized steel presently } \\
\text { under evaluation. }\end{array}$ \\
\hline 4 & Laminex & Sheet & $\begin{array}{l}\text { Scotchcal } \\
\text { (Pressure } \\
\text { sensitive adhesive) }\end{array}$ & $10 \mathrm{ft} / \mathrm{min}$ & Aluminum & $\begin{array}{l}\text { Essentially no orange peel. (Film } \\
\text { will not withstand outdoor } \\
\text { environment.) }\end{array}$ \\
\hline 5 & $\begin{array}{l}\text { Kurz-Hastings, } \\
\text { Phll adelphia }\end{array}$ & Coil & Hot Stamping Foil & $50 \mathrm{ft} / \mathrm{min}$ & Plastic & Moderate orange peel \\
\hline
\end{tabular}


The results of this lamination development program are briefly outlined in the final column of Table 3-6. Note that the smoothness of the substrate surface is also important in minimizing the orange peel of the reflector surface. Galvanizing spangles showed through to the film's surface and thus galvanized steel was discounted as an acceptable substrate. On the other hand, aluminum generated the best film reflective surface with virtually no orange peel visible. Since aluminum is more expensive than steel and requires more energy in its production, GE is continuing to work with these lamination vendors to increase the cost effectiveness of the reflector assembly. Aluminized steel, an inexpensive, smooth, corrosion resistant, commercially available product, is an attractive candidate for achieving a low-cost high-performance lamination.

An additional factor of importance concerns the flatness of the substrate needed to obtain the geometrical accuracy when the substrate is wrapped to form the parabolic reflector. Sheet metal in coiled mill runs may deviate significantly from the flatness required. Stretcher-leveling provides the means for correcting any non-flatness in which the sheet metal is yielded slightly on a flat surface removing any wrinkles and waviness. This step is generally applied to such commercial products as truck panelling and steel partitions in which waviness would detract from esthetic appeal. Requirements for the reflector substrate include the stretcher-leveling specification.

Summary Specifications

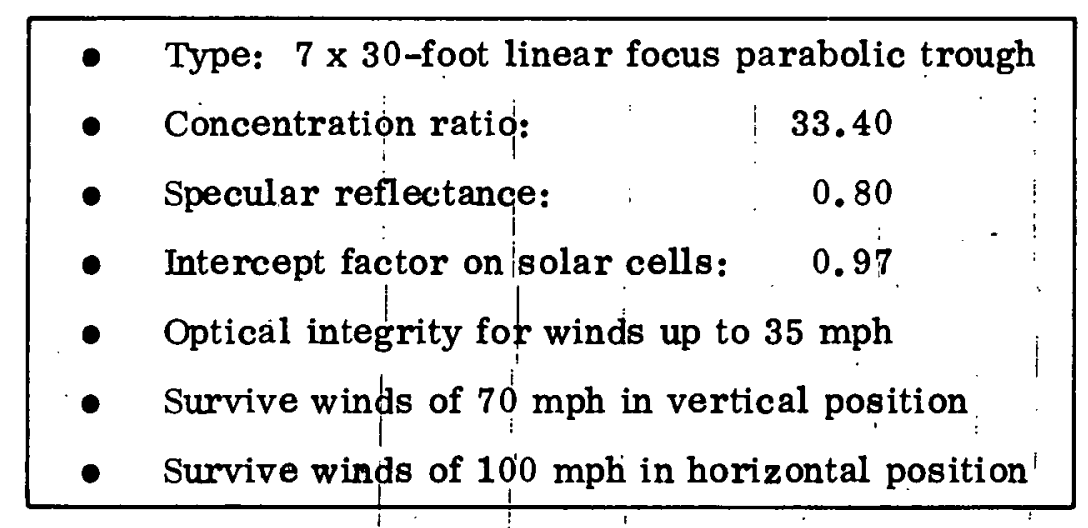

3.2.2 Solar Cell Receiver The solar cell receiver converts the concentrated sunlight to electrical energy by means of N/P-type silicon cells which are vee-mounted along the collector focal line. In addition, the receiver absorbs the non-converted thermal energy and transfers it to the copper tube for removal by the circulating fluid.

A $\dot{s}$ shown on Figure 3-11 a split design is used in which two aluminum extrusion receiver halves, each with a string of solar cells, are clamped to the copper tube through an electrical insulating layer. Principal advantages of this split design are: (1) easy removal and replacement of receivers without interrupting fliud lines; (2) use of the copper tube as a fully qualified 


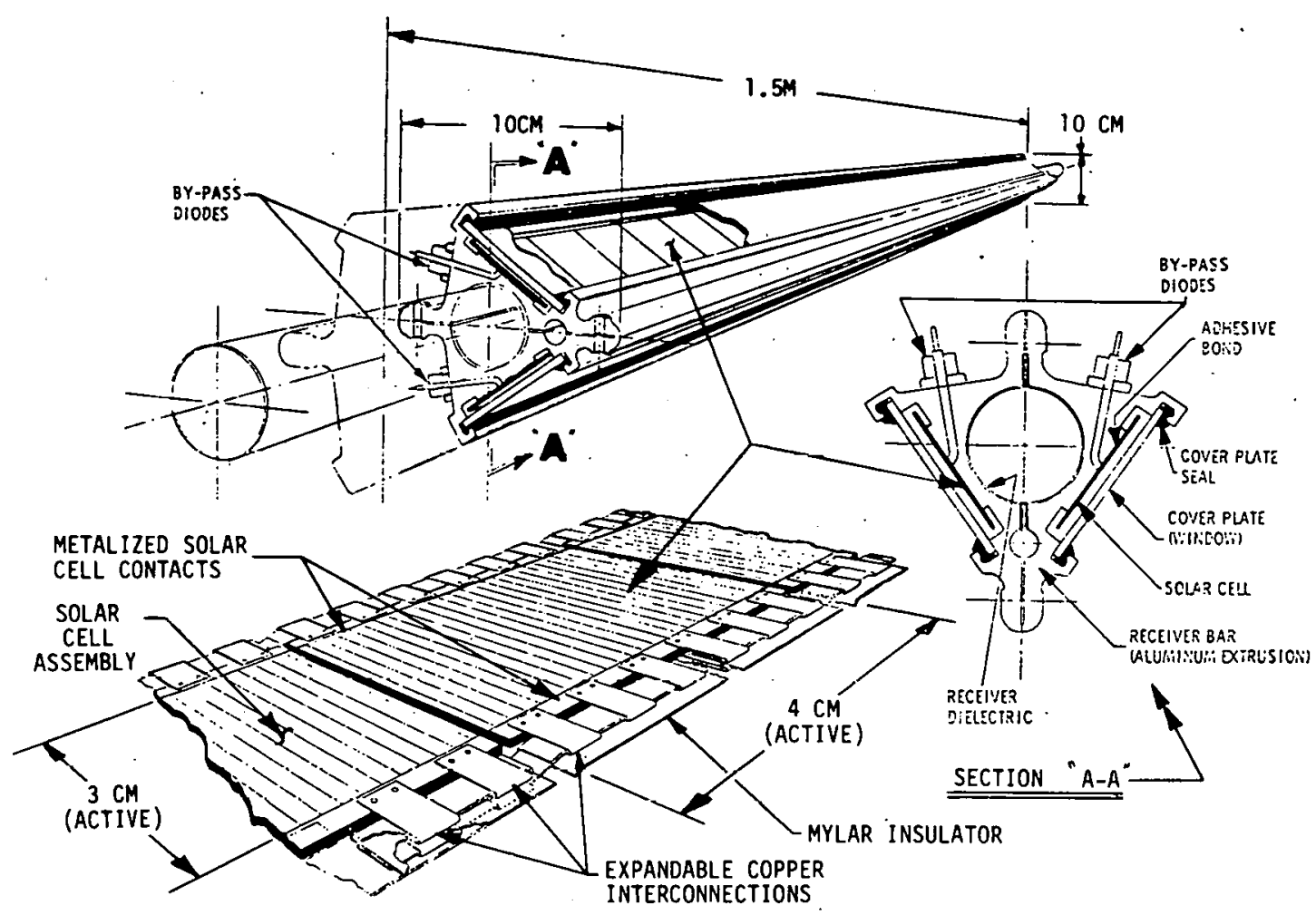

Figure 3-11. Solar Cell Receiver

corrosion-resistant material for plumbing systems; (3) the use of the electrically insulated aluminum bar, in conjunction with a diode, as a current bypass for shaded or damaged solar cells; (4) small voltage drop between the solar cells and aluminum substrate resulting from the previous advantage, permitting the use of more thermally conductive materials (see discussion below); and (5) ease of manufacture resulting from the segmented approach.

Each receiver half is about 5 feet in length and accommodates $363.5 \times 4 \mathrm{~cm}$ solar cells in series. Multiple tab copper interconnector strips are connected along the cells edges and are-used to accommodate thermal expansion displacements. A 3 to 5-mil thickness of adhesive is used to bond the cells to the anodized aluminum substrate. It is important to keep the adhesive as thin as possible and use high-thermal conductivity materials. Analysis of this characteristic is summarized on Figures 3-12(a) and 3-12(b) which show the effect of film thickness and conductivity respectively. The line of higher slope on Figure 3-12(a) pertains to the effect of uneven distribution of light reaching the receiver which at its peak may be on the order of twice the average value. Figure 3-12(b) shows the effect of introducing high conductivity fillers into silicone adhesives. For the nominal 5-mil design thickness and the nominal aluminum fill factor of 30 percent yielding $\mathrm{K}_{\mathrm{Effective}} / \mathrm{K}_{\mathrm{RTV}}$ equal to 2.5 , the maximum peak temperature drop is computed to be approximately $8.6^{\circ} \mathrm{F} \cdot(-21.5 \div 2.5)$. 


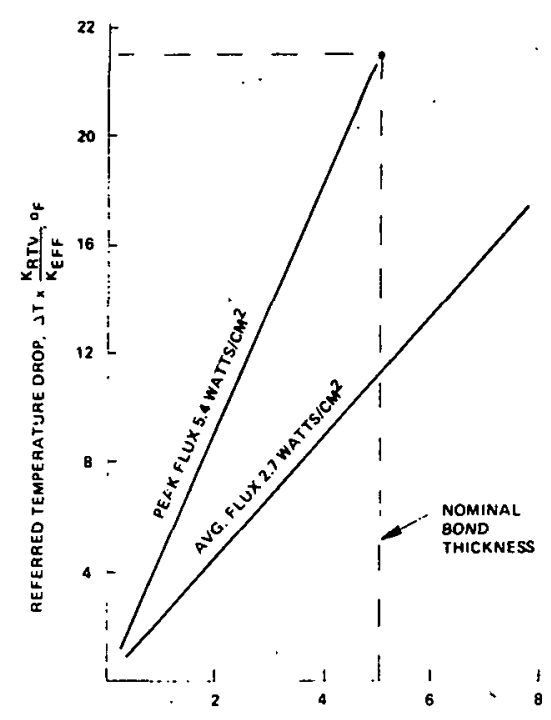

(a) Bond Thickness, mils

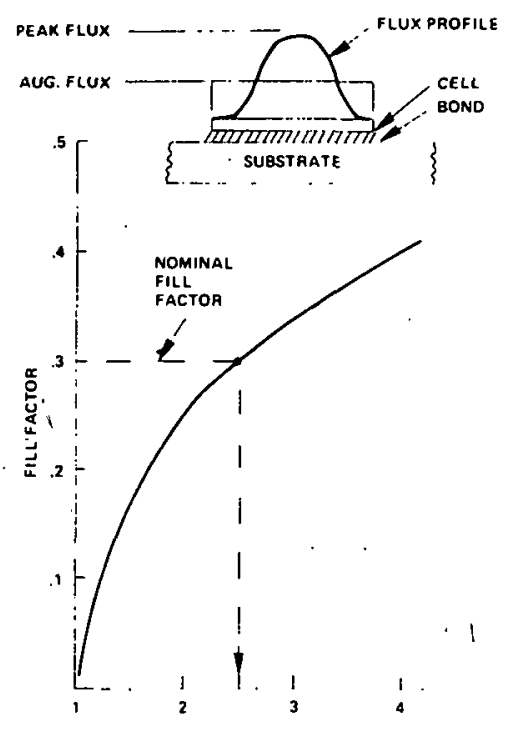

(b) $\mathrm{K}_{\mathrm{EFF}} / \mathrm{K}_{\mathrm{RTV}}$

Figure 3-12. Bond Thermal Characteristics

Methods for achieving the desired thermal characteristics for the cell to substrate bond include the use of film adhesives such as the mica-filled type made by Dow-Corning, or notched trowels or notched rollers for metering on the RTV adhesive, also with good thermal conductivity fillers (e.g., alumina or magnesia) introduced. Final selection of the production process will be based on tests conducted early in Phase II. An attractive alternative arises when the relatively low cellto-substrate voltage breakdown requirements of the split receiver design are considered, since the bulk of the voltage drop occurs across the aluminum substrate and the coolant copper tube. The solar cell voltage breakdown requirement of only 25 volts can easily be satisfied by a $1 / 2-$ mil anodize coating on the aluminum substrate. This opens the possibility of introducing high-thermal conductivity metallic fillers into the cell-to-substrate bond. This is prepared in the form of a semi-cured film adhesive and applied on the back of each cell in postage stamp style to effect the necessary cell-to-cell electrical insulation.

A single piece of glass covers the cells over the entire receiver length. This approach provides the maximum protection against the entry of corrosive moisture. An anti-reflection (AR) coating is being evaluated for the outer glass surface. One of the receiver prototypes described later used a glass with a silic on dioxide AR coating. If performance enhancement/ cost tradeoffs show a positive indication, the AR coated glass would be used for the production receivers.

Silicone rubber glazing strips hold the glass in place and permit relative expansion between the aluminum substrate and glass. The gap between the cells and glass is filled with a transparent silicone gel, RTV 615. The gel has a high degree of compliance for accommodating material differences in thermal expansion. Six receiver pairs are clamped over the tube in a single collector 
and connected in series. Figure 3-13. shows the schematic indicating the cell strings, the bypass diodes and current paths, and the insulation between the receiver bars and copper tube. The bypass diode limits the maximum voltage that can be imposed across any current-deficient cell in the 36-cell string of each receiver. As a worst case, a single $3 \times 4 \mathrm{~cm}$ cell could be subjected to a reverse voltage of about 16 volts at a current of 8 amperes before the bypass diode starts to conduct. The resulting added heat dissipation of $10.7 \mathrm{Watts} / \mathrm{cm}^{2}$ is about twice as high as the normal peak dissipation occurring at the center of the cell (see Figure 3-12 (a)). Thus, the temperature drop across the cell bond would be about three times higher than normal. With a normal design $\triangle \mathrm{T}$ of $9^{\circ} \mathrm{F}$, the abnormal $\triangle \mathrm{T}$ would be approximately $27^{\circ} \mathrm{F}$. As reported later in Paragraph 5.7, the cell bond of the initial receiver prototype indicates $\triangle T^{\prime} g$ of approximately $50^{\circ} \mathrm{F}$. This abnormal $\Delta \mathrm{T}$ will be corrected in the production receivers by one of the methods described above. The tests described in Paragraph 5.7 show that the solar cells can operate safely up to $280^{\circ} \mathrm{F}$ without damage. It is concluded that the worst case dissipation due to current deficiency in one cell can be safely tolerated.

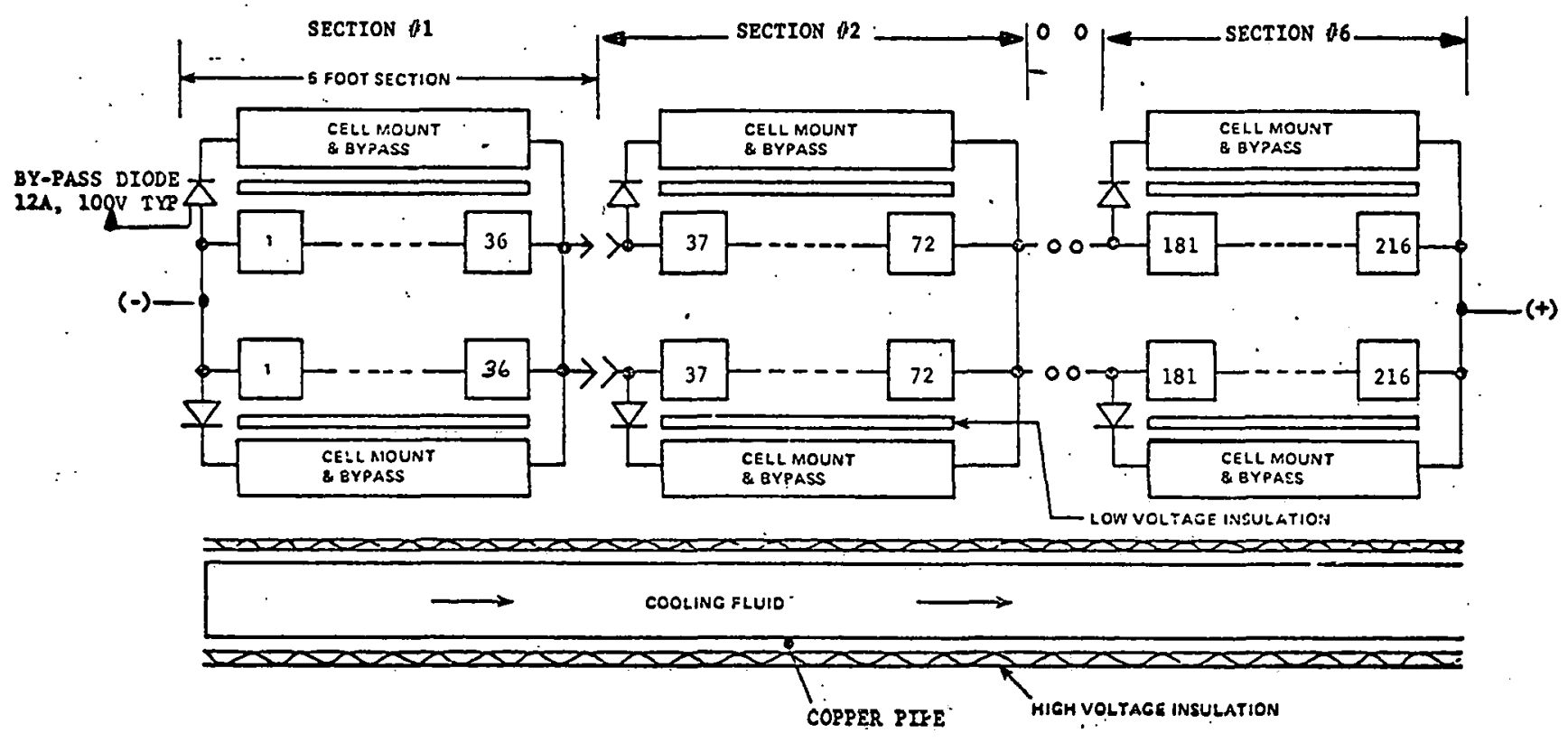

Figure 3-13. Solar Cell Receiver Circuit 


\section{Summary Spectfications}

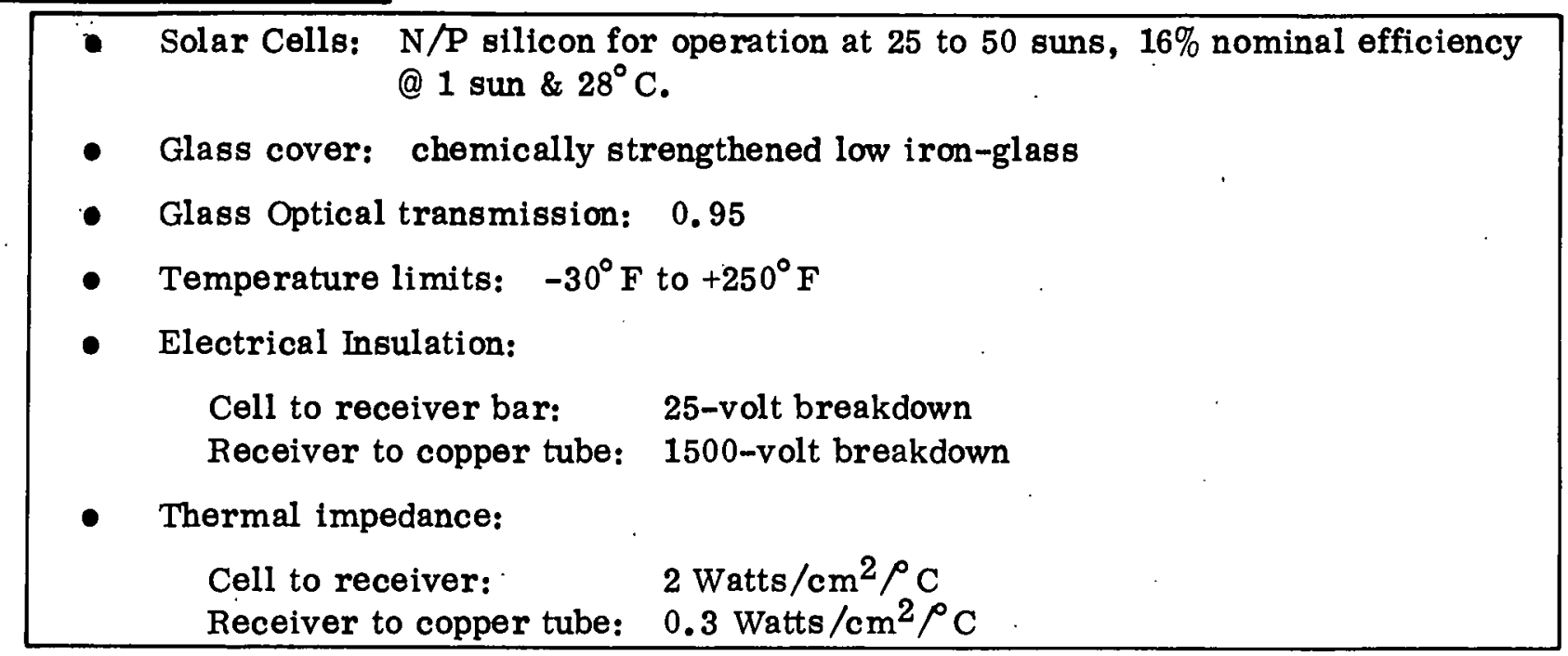

\subsubsection{TURNTABLE FRAMEWORK}

As illustrated on Figure 3-14, the turntable framework consists of 5 main I-beams upon which the collectors are supported. Periodic box beams fix the I-beam spacing. Sixteen distributed wheel assemblies are located along the main I-beams and rest on two concentric tracks, the inner one 83.5 feet in diameter, and the outer one 137.2 feet in diameter. Racking of the entire framework is prevented by diagonal rod braces which span from the base of the wheel assemblies and the central pintle bearing. Since the collectors swing below the plane of the I-beams, the plane of the diagonal rod braces is placed low enough to avoid interference. The wheel assemblies, to which the rods are attached, are braced in several directions in order that the stiffness provided by the rods is properly imparted to the rectilinear framework.

Standard structural forms are used throughout the framework. All field joints are bolted, with the need for field welding eliminated. The five main I-sections are $\mathrm{W} 12 \times 16.5 \mathrm{lbs} / \mathrm{ft}$. beams whose total weight is about 8700 pounds. Periodical gussetting is used to improve lateral stability. The maximum I-section center deflection is estimated to be about 2.0 inches with a corresponding bending stress of about $15 \mathrm{ksi}$. Margin is available for stresses due to small amounts of twisting, local actuator reactions, stress concentrations, fit-up preloads, etc. The cross box-beams are $31 / 2 \times 31 / 2 \times 3 / 16$-inch sections whose weight totals about 6250 pounds. Box sections were chosen because of their stability against buckling. The diagonal rod braces are made of $9 / 16$-inch diameter stock and have a total weight of $690 \mathrm{lbs}$. The diagonal rod braces are intended only as tension members and are preloaded to about 1350 lbs. to impart overall stiffness to the structure. The rods have left- and right-hand screw connections with adjustment accomplished by turn-buckles. The framework weight per turntable is 15,640 lbs. All are made of ASTM A36 steel, primed and painted for corrosion resistance. 


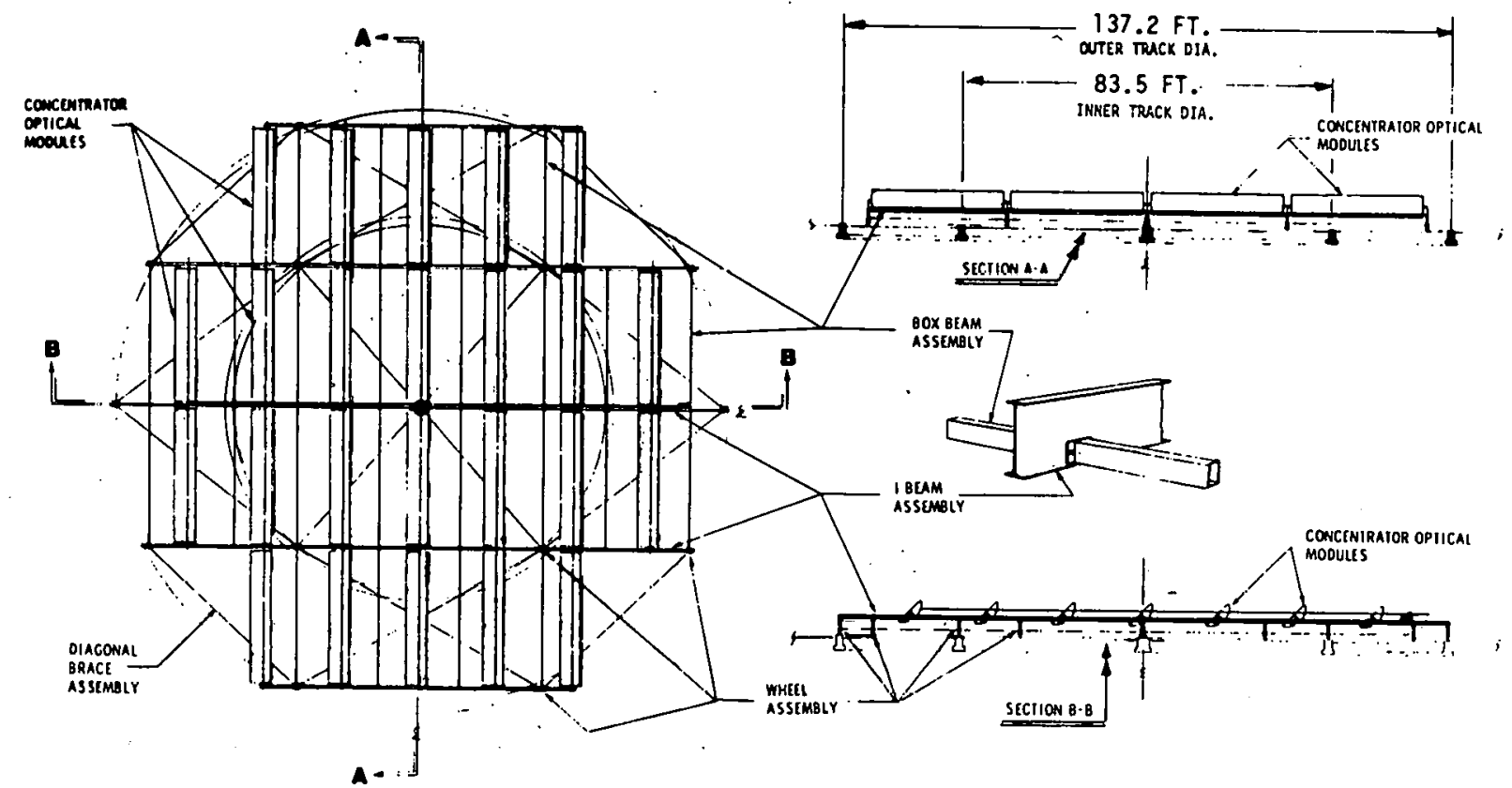

Figure 3-14. Turntable Framework

Summary Specifications

- Provide rotating framework for collectors with planarity held to \pm 2 inches.

- Use standard low-carbon steel structural shapes.

- All field joints to be bolt assembled.

- Use durable weatherproof coatings not requiring maintenance more often than every five years.

3. 2.4. Mechanical Drive Hardware. Mechanical drive hardware consists of the elevation drive motor and connecting linkages to the turntable collectors, the azimuth drive motors, and the central pintle bearing assembly. Figure 3-15 illustrates these components.

A motorized jackscrew is used for elevation tracking which drives a series of pushrods and crank-arms articulated with the turntable collectors. Duty-cycle operation of the jackscrew motor permits sun tracking at variable rates. The jackscrew is outfitted with an additional motor, magnetic clutch, and gear train to permit rapid forward and reverse motions needed for emergency shutdown and ease of servicing. The design of the system was dictated by an overall mechanical error of 0.1 degrees apportioned as follows:

- Jackscrew backlash: $\quad 0.005^{\circ}$

- Bearing play: $0.010^{\circ}$

$\because$ Torsional displacements: $\quad 0.040^{\circ}$

- Push rod compression: . $0.044^{\circ}$

- Collector angular distortion: $0.001^{\circ}$ 


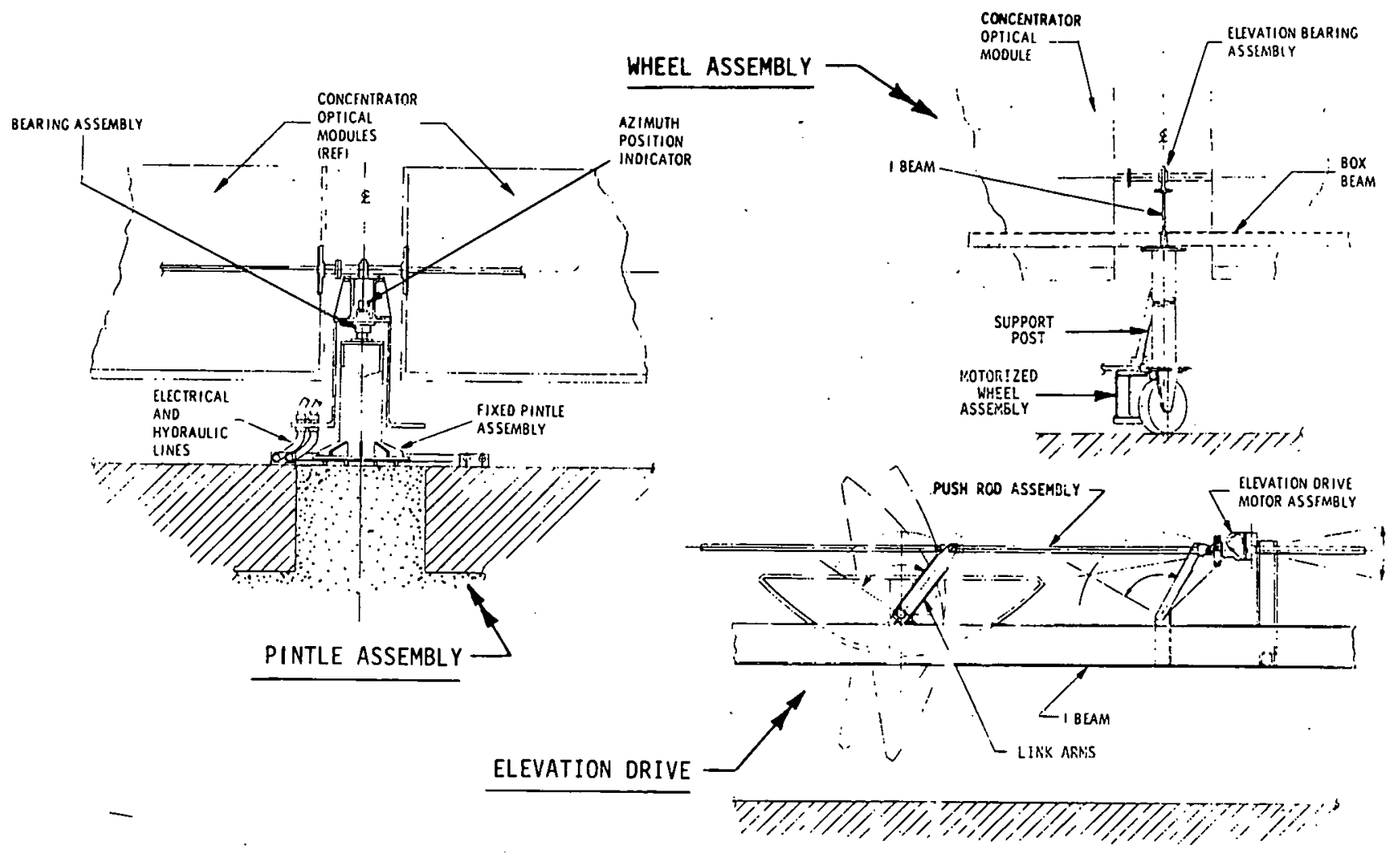

Figure 3-15. Tracking Drive Components

Design features for meeting these allocations include the following: (1) use of a standard jackscrew unit with a 2-mil backlash over the intended life; (2) permanently lubricated bearings with 1/2-mil clearances; (3) 30-inch radius crank-arms on collectors to reduce the bearing clearance angulair errors; (4) large diameter shafting (4.25 inches) between collectors to reduce transmitted angular errors; (5) low-friction collector support bearings consisting of small diameter anti-friction rollers; and (6) exceptionally stiff collectors by virtue of the diagonal bracing torque tube design. As noted previously in Paragraph 2.3.3.1, key adjustment features are designed into the elevation tracking system for achieving collector alignment.

The turntable azimuth drive system shown on Figure3-15consists of two motorized assemblies located at opposite points along the outer track, which also operate on a duty-cycle basis depending on the sun azimuth rate. A double reduction wormgear catalog unit with an $1800 \mathrm{rpm}$ motor was selected for the application. The overhang capability of the unit permits the traction wheel to be mounted directly resulting in an extremely simple installation.

The central pintle consists of mechanical assemblies and bearings which position the entire turntable about its point of rotation. An azimuth position sensor provides a position feedback signal for the tracking control system. The unit is housed at a convenient location inside the movable pintle weldment. The pintle base is bolted to a concrete pier designed for maximum wind loading on the turntable. 


\section{Elevation Drive System}

- Total mechanical tolerance: 0.1 degree

- Operational drive rate ( $100 \%$ duty cycle): 0.0052 to $0.0085 \mathrm{degrees} / \mathrm{sec}$

- Drive torque:

- Screwjack capacity:

23,400 inch-pounds

- Rapid-motion drive rate: $\quad 0.15 \mathrm{degre \theta} / \mathrm{sec}$

- Operational motor rating: $0.025 \mathrm{hp}$

- Rapid-motion motor rating: - $0.167 \mathrm{hp}$

- Number of on-off cycles: $2 \times 10^{6}$

Azimuth Drive System

- Total mechanical tolerance: \pm 1.0 degree

- Operational drive rate (100\% duty cycle): $0.025^{\circ} / \mathrm{sec}$

- Wheel traction load:

$1500 \mathrm{lbs}$

- Motor rating:

- Number of on-off cycles:

$0.25 \mathrm{hp}$

$2 \times 10^{6}$

Linkages, Pintle Assembly

- Small-clearance bearings

- Permanent lubrication

- 5-ton pintle side load

\subsubsection{TURNTABLE FOUNDA TION}

The turntable foundation consists of the two concentric concrete tracks and central pier illustrated schematically on Figure 3-14.

The foundation soil within the turntable area of the Sea World site does not contain any appreciable amount of organic material and will, therefore, be capable of supporting the turntable weight. The foundation footings are sized for an allowable soil pressure of $3,000 \mathrm{psf}$.

Foundations for the concentric tracks will be excavated 24 inches below existing grade to a width of 18 inches. The bottom of the excavation will be compacted to a density of $95 \%$ of modified proctor density of the material. The excavation will be backfilled with 15 inches of select material and compacted to $95 \%$ of modified proctor density. The foundation for the ring will be poured on the prepared base and will consist of a continuous footing $12^{\prime \prime} \times 12^{\prime \prime}$ of $3000 \#$ concrete. Two \#5 steel reinforcing bars will be placed 3 " from the bottom of the footing. Six $3 / 4$ " expansion joints will be installed at quarter points of the exterior rings and three $3 / 4$ " expansion joints at half points on interior rings.

The pintle foundation area will be excavated to appraximately $5^{\prime}$ below existing grade. The size of the excavation will be about $16^{\prime} \times 16^{\prime}$ and the bottom of the excavation will be compacted 
to $95 \%$ of modified proctor density. The foundation will be $10^{\prime} \times 10^{\prime} \times 2^{\prime}$ of $3000 \#$ reinforced concrete. The pedestal for the pintle base will be $21 / 2^{\prime} \times 21 / 2^{\prime} \times 3^{\prime}$ of $3000 \#$ reinforced concrete.

\subsubsection{SOLAR ARRAY MATERIAL BREAKDOWN}

Table 3-7 tabulates the weight for one turntable array by different material categories. Material costs are also indicated using unit costs suggested by Sandia in instructions for the preparation of Phase II \& III proposals.

\subsection{HYDRAULIC SYSTEM}

The hydraulic system for the field of turntables includes all piping, valving, pumps, and subsystem controls pertinent to the operation of the fluid loop. Clean water will be used for the heat transfer fluid which will keep the array heat transfer piping free of scale fouling and eliminate the need for extensive water treatment. As operating temperatures up to 220 degrees $\mathrm{F}$ are planned, minimum system pressure will be maintained at $30 \mathrm{psig}$. Under normal dynamic conditions, maximum system pressure will be 60 psig.

Two hydráulic schemes are presented in this section which are based on serving: (1) the absorption air conditioning load for the Sea World Complex which requires $82^{\circ} \mathrm{C}\left(180^{\circ} \mathrm{F}\right)$ hot water, and (2) a domestic hot water load for a planned hotel complex. The turntable coolant circuits and the overall array coolant loop serving either of these loads are first described below.

\subsubsection{TURNTABLE COOLANT CIRCUIT}

The hydraulic network for each turntable is composed of seven parallel fluid loops, five of which use four 30-foot series connected receiver lengths, and two of which use two $30^{\prime}$ lengths in series (see Figure 3-16). The circuit setting valves in the two extreme branches limit the flow to half that in the interior runs. With a nominal flow rate of $260 \mathrm{gpm}$ from the overall field, each turntable receives approximately $28.9 \mathrm{gpm}$, with each interior branch receiving 4. $82 \mathrm{gpm}$. Flow is equalized to the turntables by the inlet trim valves to each turntable. Pipe sizes are selected to maintain the same flow velocity throughout the hydraulic system.

Each turntable is fed through a 15-foot, 2-inch flexible hose joining the fixed and movable parts of the pintle assembly. The coiling motion caused by the turntable rotation is constrained to a metal pan attached to the fixed portion of the pintle assembly. Hard plastic bushings attached to the flexible hose prevent direct wear to the hose itself. From the pintle, a 2-1/2" black iron pipe runs the radius of the table and feeds the supply headers to the collector assemblies. Hydraulic takeoffs from the headers consist of $18^{\prime \prime}$ lengths of 1-1/4" silicone flex hose. 
Table 3-7. Solar Array Material Cost for One Turntable

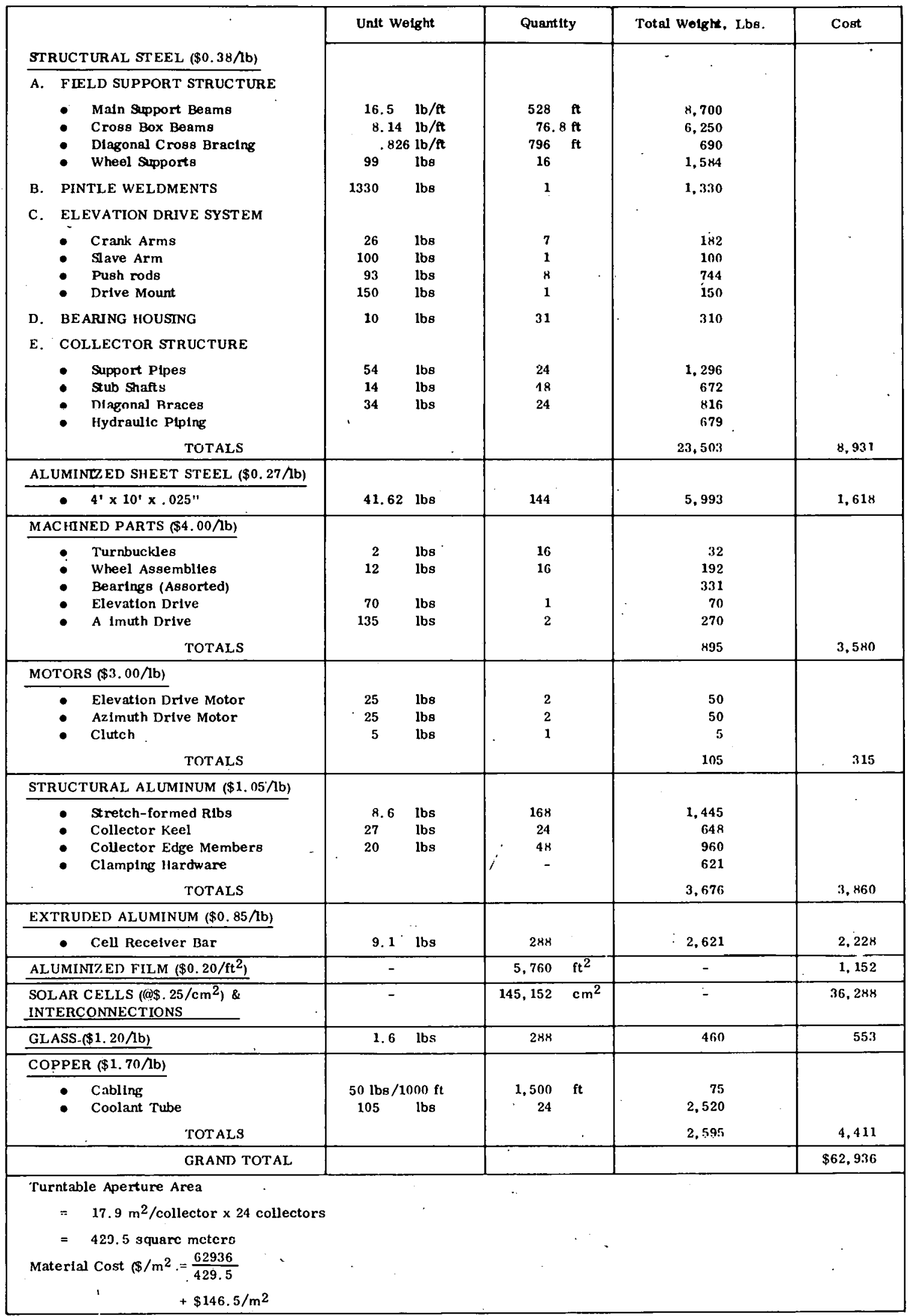




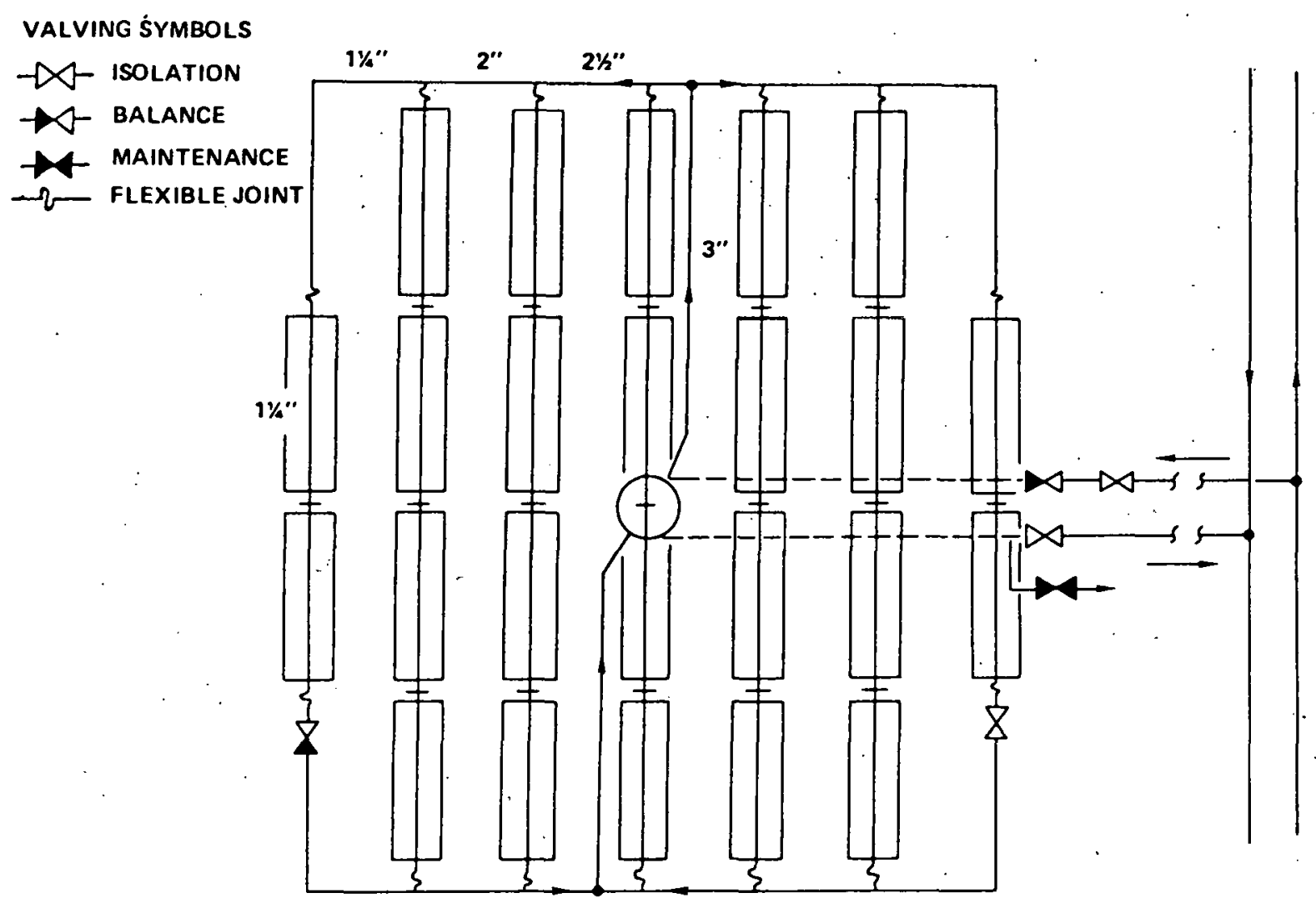

Figure 3-16. Turntable Piping Schem atic

These hoses provide the flexure required at the entrance (exit) of each collector row as the troughs rotate to follow the sun in elevation during the day.

The coolant tubes in each collector are 1-1/4" diameter copper (68 mil wall). The tubing is electrically isolated from the cell and aluminum substrate, and futher electrically buffered from the black iron header by the flex hoses which eliminate galvanic coupling between the copper and iron piping.

All piping is insulated with two-inch thick fiberglass insulation to minimize heat losses. Thermal insulation is also applied to the back surface of the solar cell receivers.

The adjustment of flow to the various branches of the hydraulic circuit will be accomplished with the use of a strap-on flowmeter which can be moved from position to position without the necessity for breaking into fluid lines. The flowmeter intended for this purpose is commercially available and uses a sound wave principle for measuring flow. Once the flows are properly equalized, they should remain fixed with only periodic checks needed to assure that the flow parameters are within acceptable limits. 


\subsubsection{FIELD COOLANT LOOP}

The coolant loop for the nine turntable collector field is shown schematically in Figure 3-17. Turntable supply and return lines are buried underground. Coolant is circulated by dual 5 Hí pumps located near the control building with only one, as selected, operating. Heat is removed from the circulating fluid by heat transfer surfaces associated with the absorption chiller (for the cooling case) or a separate heat exchanger (for the domestic hot water case).

A constant circulating flow of $260 \mathrm{GPM}$ is used for the entire range of insolation with the fluid temperature rise proportional to the insolation level. This proportionality serves as the basis for inverter turn-on. When the lemperature rise is about 3 degrees, the corresponding insolation is about 10 percent of maximum, an acceptable level for inverter turn-on. The inverter is turned off when the current drops to a value corresponding to a nominal insolation at about 8 percent of maximum.

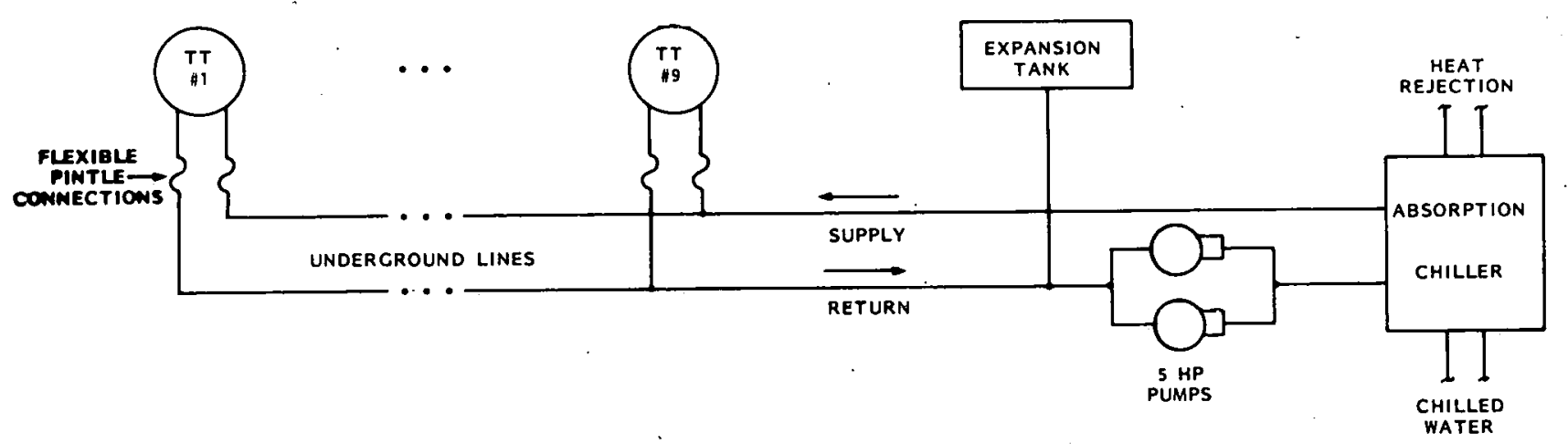

Figure 3-17. Field Coolant Loop 


\subsubsection{HEAT DELIVERY LOOP - ABSORPTION CHILLER OPTION}

The schematic of the coolant loop for operating the absorption chiller is shown on Figure 3-18. The system satisfies the thermal load directly with no storage required. An internal bypass built into the chiller will assure that a minimum temperature limit has been satisfied. Except for the thermal loss in the external field piping, the $\Delta T$ appearing across the input to the chiller will be equal to that occurring across the collector field. The absolute temperature of the system will depend partly on the increasing heat losses as the temperature increases and on the equilibrium temperature conditions of the chiller. Section 4.2 presents the performance analysis of this system.

The absorption chiller is of the lithium-bromide type. Its chilled water output is furnished to the nearby Sea World shark exhibit. The chiller will generate up to 318 tons of cooling at peak insolation.

The thermal loads from the array and the chiller are rejected to atmosphere through an induced draft cooling tower. Dual pumps, connected in parallel, are provided to circulate cooling tower water through the chiller. One or two pumps will operate depending on the thermal transfer required. A 2-speed tower fan will automatically speed adjust with the thermal transfer demand.

A heat exchanger is included in the array cooling circuit for use in heat transfer to the cooling tower circuit whenever the chiller is not in use. The normal mode of operation will be

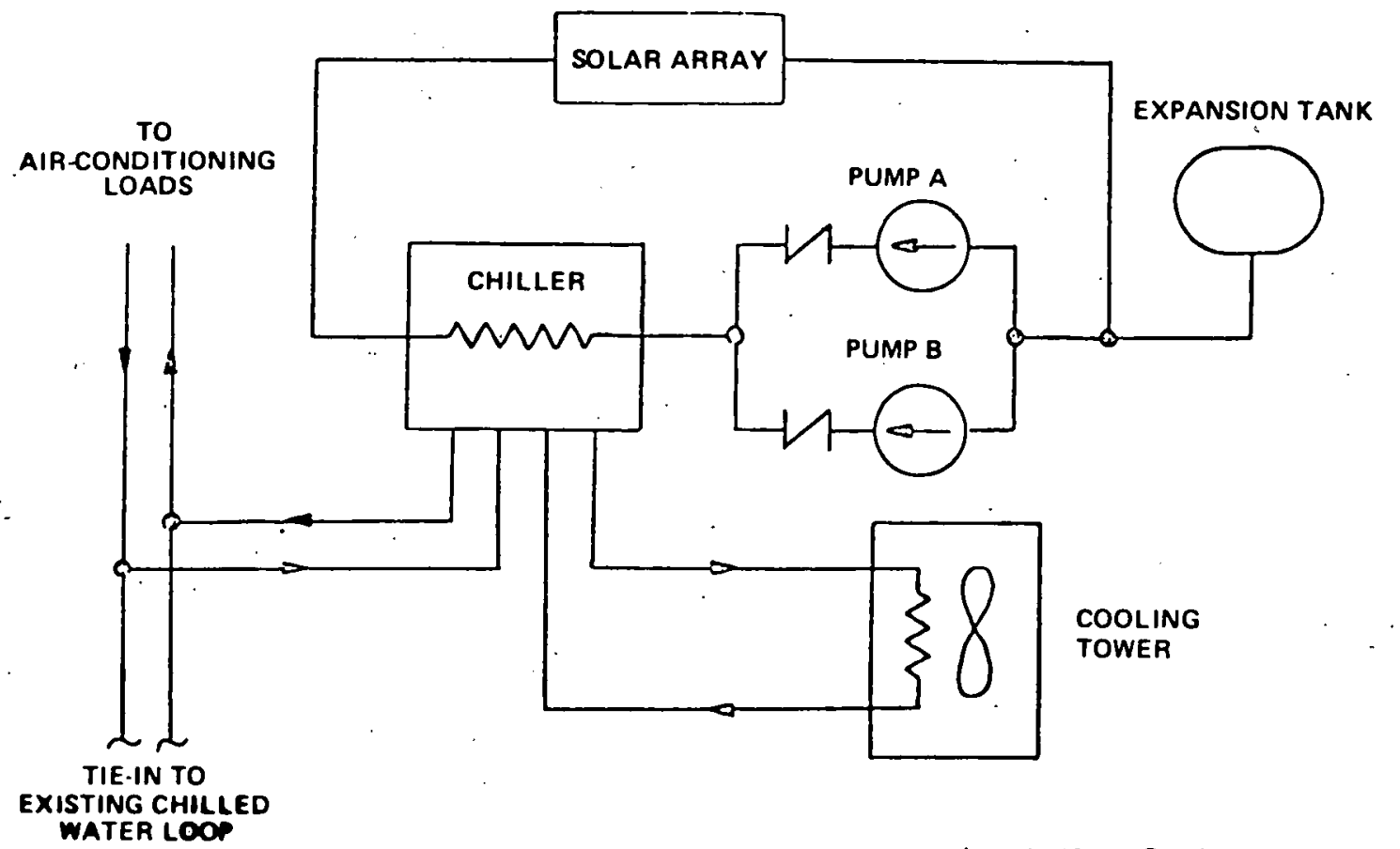

Figure 3-18. Hydraulic System Absorption Chiller Option 
to reject all heat through the chiller and realize cooling effect therefrom, even at periods of low insolation.

Pipe insulation is applied to array cooling piping, and chilled water piping, both above and below ground. Equipment characteristics are summarized on Table 3-8.

Table 3-8. Hydraulic Cooling System Equipment

\begin{tabular}{|c|c|c|c|}
\hline Item & Rating & Source & Lead Ttme \\
\hline Absorption Chiller & 600 Tons & $\begin{array}{l}\text { York* } \\
\text { Carrier } \\
\text { Trane }\end{array}$ & 6 Months \\
\hline Cooling Tower & $\begin{array}{l}300 \text { Tons of refrigeration } \\
\text { based on absorption } \\
\text { service }\end{array}$ & $\begin{array}{l}\text { Marley* } \\
\text { Flour } \\
\text { Goodfellow }\end{array}$ & 5 Months \\
\hline Heat Exchanger & $120 \mathrm{ft}^{2}$ surface & Alfa-Laval* & 5 Months \\
\hline Array Circulation Pump & $5 \mathrm{HP}, 260 \mathrm{GPM}$ & Aurora* & 4 Months \\
\hline Condenser Pump & $15 \mathrm{HP}, 1100 \mathrm{GPM}$ & Aurora* & 4 Months \\
\hline
\end{tabular}

*Basis for design

\section{3.4 HEAT DELIVERY LOOP - DOMESTIC HOT WATER OPTION}

The schematic for the domestic hot water option is shown on Figure 3-19. Solar array heat is removed in the domestic hot water heat exchanger and transferred to a thermal storage tank nominally set at $140^{\circ} \mathrm{F}$. A temperature controlled bypass valve in the heal exchanger domestic water circuit assures that only water at the proper temperature level is delivered to the storage tank for ultimate use by the hotel loads. A thermal excess heat exchanger is required to remove heat if the thermal storage tank is filled to capacity. The schematic shows heat removal by intoducing well. water through the excess heat exchanger. An laternate method would be to circulate water on the secondary side through a cooling tower as described in the previous system option.

3.4 ELECTRICAL SYSTEMS (POWER CONDITIONING, CONTROL, AND MAJOR SWITCHGEAR

Key component characteristics are covered below for the following electrical subsystems: inverter system, utility interface, emergency power, control, instrumentation, and lightning protection. 


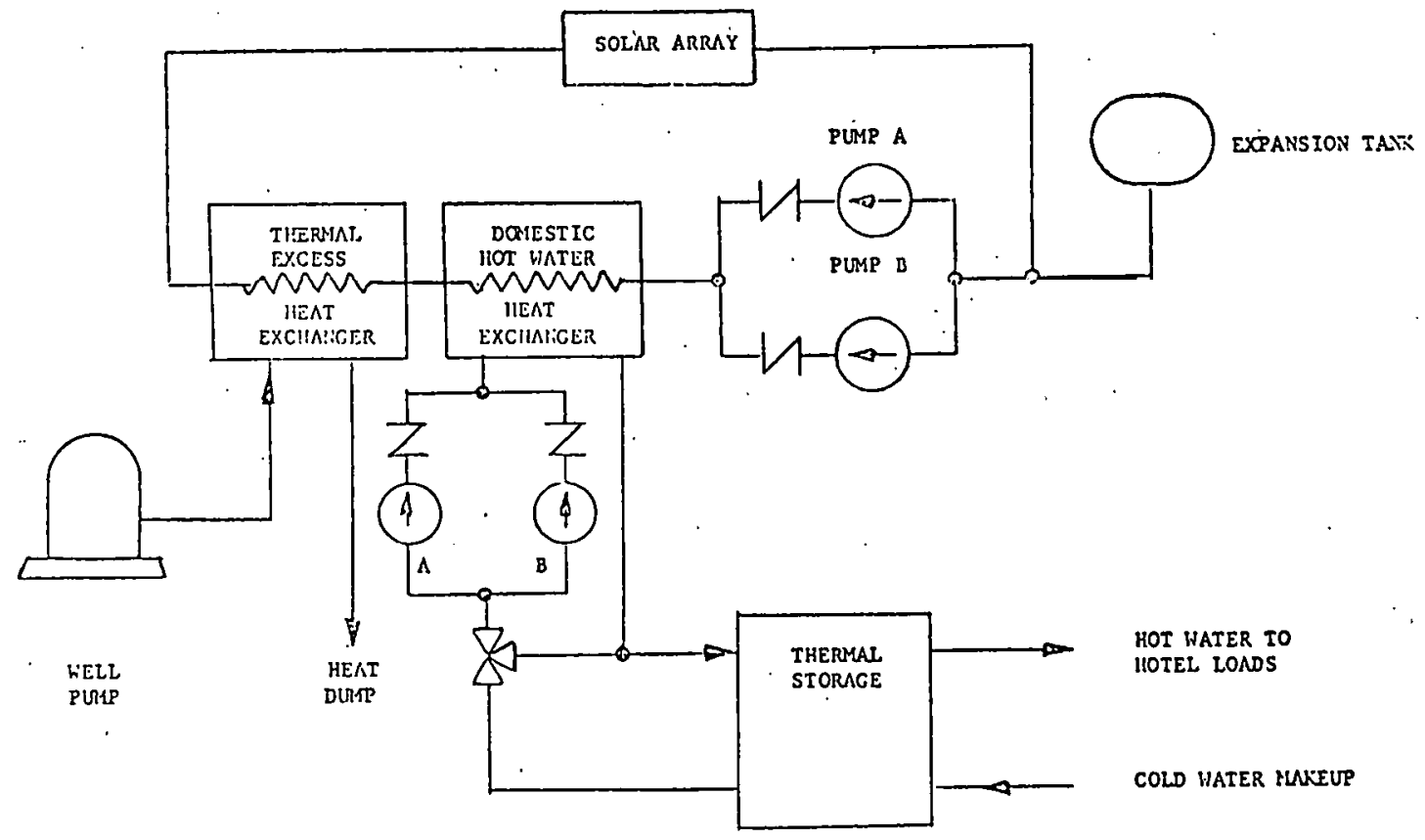

Figure 3-19. Hydraulic System Domestic Hot Water Option

\subsection{INVERTER SYSTEM}

Besides the solar array, the DC/AC inverter system represents the other major element of the power system. The elements which comprise the inverter system are shown in Figure 3-20. Physical characteristics are enumerated in Table 3-9. The inverter and the voltage regulator are standard products manufactured by GE and have been used in similar arrangements with utility power grids. Power inversion is achieved by a line commutated 6-pulse converter which is controlled to regulate its DC input voltage in response to a max-power tracker control voltage. The inverter is line-commutated and only operates if the utility line voltage is present. This type of inverter was selected for several reasons: (1) it is an existing proven design presently in production; (2) it has been successfully used in similar applications and is suitable for solar array-type DC energy sources; and (3) its control flexibilities are adaptable to peak power tracking.

The inverter comes equipped with all of the necessary protection circuits. An electronicallycontrolled circuit breaker is supplied to open the DC circuit in the event of a commutation "failure" which is not self-clearing. Use of the AC induction-type voltage regulator allows the inverter system to operate near unity power factor for large variations in DC input voltage and power. Thus, the kVA rating for a given power rating can be minimized and the efficiency can be maximized. 


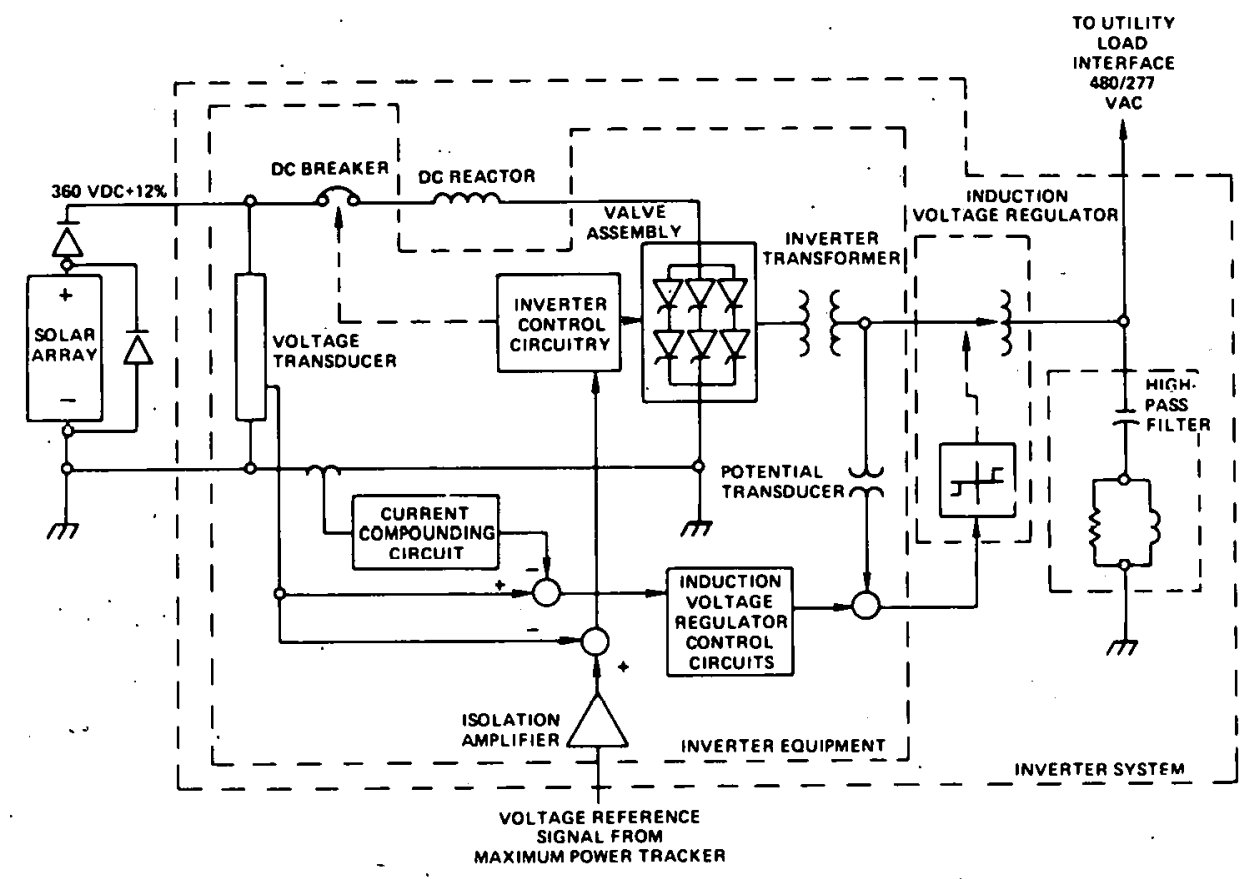

Figure 3-20. Inverter System Block Diagram

Table 3-9. Inverter System Physical Characteristics

\begin{tabular}{|c|c|c|c|}
\hline Item & Size & $\begin{array}{c}\text { Max Thermal } \\
\text { Dissipation, } \mathrm{kW}\end{array}$ & Source \\
\hline $\begin{array}{l}\text { Inverter Equipment } \\
\text { DC Reactor } \\
\text { Induction Voltage Regulator } \\
\text { High-Pass Filter } \\
\text { Capacitor (each of } 3 \text { ) } \\
\text { Reactor (each of } 3 \text { ) } \\
\text { Resistor (each of } 3 \text { ) }\end{array}$ & $\begin{array}{l}11^{\prime} \times 3^{\prime} \times 7.5^{\prime} \\
48^{\prime \prime} \times 48^{\prime \prime} \times 14^{\prime \prime} \\
28^{\prime \prime} \times 25^{\prime \prime} \times 48^{\prime \prime} \\
\\
17^{\prime \prime} \times 5^{\prime \prime} \times 25^{\prime \prime} \\
12^{\prime \prime} \times 12^{\prime \prime} \times 12^{\prime \prime} \\
3^{\prime \prime} \times 3^{\prime \prime} \times 7^{\prime \prime}\end{array}$ & 7.5 & $\begin{array}{l}\text { GE Drive Systems, } \\
\text { Salem, } \mathrm{Va} \text {. }\end{array}$ \\
\hline
\end{tabular}


The predicted efficiency and power factor of the inverter system as a function of load are shown in Figure 3-21. The filter is sized to ensure a maximum harmonic distortion of less than 5 percent.
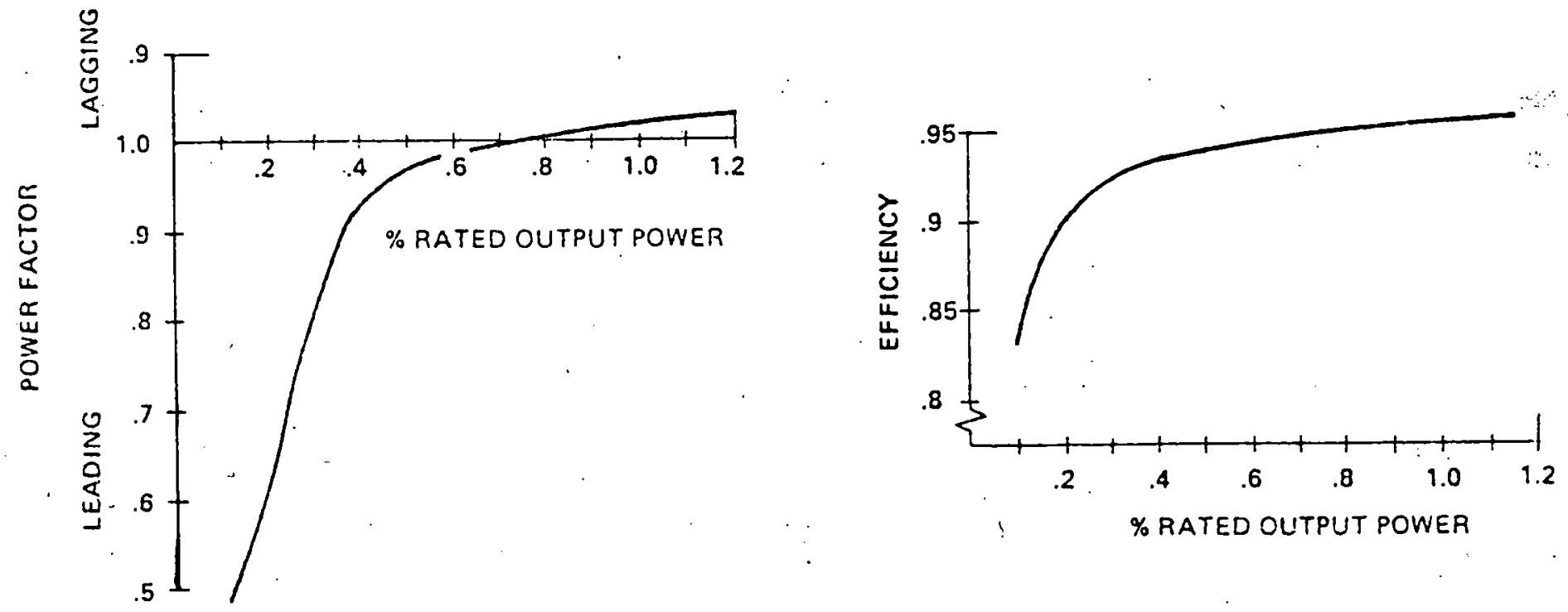

Figure 3-21. Inverter System Efficiency and Power

Factor vs. \% Rated Output Power

The maximum power tracking scheme, as illustrated in Figure 3-20, senses the inverter system output power and, through dithering logic provided by the central computer, establishes the solar array impedance that will yield maximum power. The inverter is turned on whenever the coolant temperature rise across the solar array exceeds approximately $3^{\circ} \mathrm{F}$ indicating that the insolation level is high enough to produce output power in excess of 5-10 percent of the inverter rating. An initial operating point is selected and the dithering logic rapidly converges on the maximum power operating point.

\section{Summary Specifications}

- Inverter System Rating: $350 \mathrm{kVA}$

- Input Voltage: $\quad 360 \pm 12 \%$

- Output Voltage: $\quad 277 / 480$ VAC, 4-wire

- AC output synchronized with utility power by line commutation techniques

- $95 \%$ efficiency at $300 \mathrm{~kW}$

$90 \%$ efficiency at $30 \mathrm{~kW}$ 
Detailed discussion of the inverter system component functions, component ratings, and system modes of operation are presented in the following paragraphs. The theory of inverter operation is presented in Appendix A.

\subsubsection{Preliminary Selections}

The inverter being proposed for the Sea World Concentrator Application Equipment is a 6-pulse unit based on the well-established technology for rectifier-inverter motor drives used in many industrial applications. The inverter is a line-commutated unit in the voltage and power range suitable for the Sea World PCAE.

Rectifier-motor drives have been built for many years and offer the cost advantages associated with assembly line production.

In selecting the most appropriate unit(s) for the application, a basic question considered whether single or multiple units should be used. Estimated costs were obtained for basic inverter equipment (no filters or voltage regulators) in three sizes as lis ted below:

$\begin{array}{cc}\text { Inverters } & \text { Estimated Price } \\ 1-300 \mathrm{~kW} \text { Unit } & \$ 36,920 \\ 3-100 \mathrm{~kW} \text { Units } & 55,177 \\ 9-33 \mathrm{~kW} \text { Units } & 91,996\end{array}$

Based on these cost estimates, the $300 \mathrm{~kW}$ unit was selected for the detailed system design described below.

\subsubsection{Function of Inverter System Components}

The functions of the various inverter system components shown in Figure 3-20 are described below.

\section{INVERTER (VALVE ASSEMBLY AND INVERTER CONTROL CIRC.UITRY)}

The inverter converts the DC power generated by the photovoltaic array to the AC power which is required by the Sea World distribution system. Each thyristor valve will conduct unidirectional current with the start of conduction by thyristor gating circuits.

\section{INVERTER TRANSFORMER}

The inverter transformer serves as the power link between the AC and DC circuits. It provides transformer action to match the AC supply voltage to the working voltage of the inverter valves. It also provides electrical isolation of the DC system from the AC system to permit development and control of the DC voltage.

\section{DC CIRCUIT BREAKER}

The DC circuit breaker protects the inverter system from DC faults, commutation failures and loss of $\mathrm{AC}$ voltage. 


\section{DC REACTOR}

The DC reactor attentuates the harmonics generated by the inverter in the DC portion of the system thus smoothing the DC current. In addition, the reactor limits the overcurrent due to faults in the DC circuit.

5. INDUCTION VOLTAGE REGULATOR

The induction voltage regulator adjusts the AC system voltage to the appropriate value required by the DC voltage at which the photovoltaic array is operating. This regulation enables the inverter to operate at a margin angle of approximately $20^{\circ}$ for all voltage levels. Without the regulator, the inverter would have to operate at larger margin angles which would decrease the inverter power factor.

\section{HIGH PASS FILTER}

The HP filter consisting of a capacitor, reactor and resistor in each phase, furnishes a low impedance path for the harmonic currents generated by the inverter in the AC portion of the circuit. The filter thus reduces the voltage distortion on the AC bus and reduces the harmonic current flow to the AC network to acceptable levels. The filter also contributes capacitive VAR's required by the inverter and thus improves the power factor of the inverter system.

\subsubsection{Rating of Inverter System Components}

The ratings of the inverter system components were determined as follows:

\section{INVERTER}

The maximum output of the photovoltaic array is estimated to be $300 \mathrm{~kW}$ at 360 Volts $\mathrm{DC}$. Thus, the DC current is:

$$
\mathrm{I}_{\mathrm{DC}}=\frac{300,000 \mathrm{~W}}{360 \mathrm{~V}}=833 \text { Amperes }
$$

The DC voltage of 360 volts may increase or decrease $12 \%$. Thus, the maximum DC voltage will be 403 volts and the minimum DC voltage will be 317 volts. Assuming the current of 833 amps is associated with the maximum insolation, then the maximum DC power will occur at the maximum DC voltage and is:

$$
\mathrm{kW}=\frac{403 \times 833}{1000}=336 \text { kilowatts }
$$

Therefore, the inverter must have a maximum power rating of $336 \mathrm{~kW}$.

\section{INVERTER TRANSFORMER}

The inverter transformer must be sized to handle the maximum inverter power rating of $336 \mathrm{~kW}$. For this condition, $\mathrm{U}_{\mathrm{d}}^{*}$ is 403 Volts and $\mathrm{I}_{\mathrm{d}}$ is 833 Amperes.

*See Appendix A for definition of terms. 
The theoretical no load direct voltage $U_{\text {do }}$ was calculated to be 446 volts. The kVA of the transformer was calculated to be $390 \mathrm{kVA}$.

The secondary voltage of the inverter transformer was calculated to be 330 volts RMS lineto-line.

At the nominal inverter rating of $300 \mathrm{~kW}$ and 360 Volts $\mathrm{DC}$, the secondary voltage of the inverter transformer is 295 Volts. Since the nominal AC voltage of the Sea World distribution system is 480 Volts, the primary voltage of the inverter transformer should be 480 Volts giving a transformer turns ratio of $480 / 295$.

If the inverter transformer was rated $480 \mathrm{~V}$ primary and 295 Volts secondary, the transformer at the maximum power point would be operating at 330 secondary volts on the 295 volt winding which could be over the knee of the transformer saturation curve and lead to excessive transformer heating.

Therefore, the transformer primary winding was rated 537 volts and the secondary winding was rated 330 volts which maintains the 480/295 turns ratio but assures that the transformer will always be operated below the knee of the saturation curve.

\section{DC CIRCUIT BREAKER}

The DC current output of the photovoltaic array is 833 Amperes. The array cannot generate much more current than this even for a shorted condition. Therefore, a nominal current rating of 900 Amperes DC was deemed sufficient for the DC breaker.

\section{DC REACTOR}

The DC reactor was sized at 3.8 millihenries which will limit the ripple of the DC current to approximately $1 \%$ of the nominal value of 833 amperes.

\section{VOLTAGE REGULATOR}

The voltage regulator must compensate for $\mathrm{a} \pm 12 \%$ variation of the $\mathrm{DC}$ voltage from the photovoltaic array and $\mathrm{a} \pm 3 \%$ variation of the $\overline{4} 80 \mathrm{~V} \mathrm{AC}$ system for a total of $\pm 15 \%$ variation. The kVA capability of the regulator was calculated to be $51 \mathrm{kVA}$. Induction voltage regulators are available with standard voltage variations of $\pm 10 \%$ and $\pm 20 \%$. Thus, the $\pm 20 \%$ variation was chosen. For this voltage variation, the standard available $\mathrm{kVA}$ ratings step up from $37.5 \mathrm{kVA}$ to $75 \mathrm{kVA}$ regulator was chosen. It was determined that a standard regulator rated $75 \mathrm{kVA}$ and $\pm 20 \%$ voltage variation was more economical than a special regulator rated $51 \mathrm{kVA}$ with $\pm 15 \%$ voltage variation.

\section{HIGH PASS FILTER}

The high pass filter was designed to furnish a low impedance path for the harmonic currents generated by the inverter. The predominant harmonics are the 5 th, 7 th, 11 th and 13 th. The high pass filter reaches a minimum impedance at the 9 th harmonic, midway between the 7 th and 11th harmonics. Designing for minimum impedance at a lower frequency would increase the size and cost of the filter components and also increase the filter losses. The filter as designed is also more effective in minimizing telephone interference. 


\subsection{4 Operation of the Inverter System}

\section{CHANGE IN DC VOLTAGE}

When the photovoltaic array is operating at the nominal voltage of 360 Volts $\mathrm{DC}$, the voltage regulator will be at its neutral position. The AC voltage at the inverter transformer primary will be 480 volts RMS line-to-line and the secondary voltage will be $295 \mathrm{Volts}$. If the photovoltaic array voltage now increases to 360 Volts plus $12 \%$ or 403 Volts $D C$, the voltage regulator will raise the 480 -volt AC distribution voltage $12 \%$ to 538 Volts at the inverter. transformer primary. The inverter transformer secondary voltage will now be 330 volts, which is the required secondary voltage for operation at 403 volts DC.

If the photovoltaic array voltage decreases $12 \%$ to 317 Volts $\mathrm{DC}$, the voltage regulator will decrease the distribution voltage of 480 volts $A C$ minus $12 \%$ to 422 volts at the inverter transformer primary. The inverter transformer secondary voltage will now be 259 Volts, which is the required secondary voltage for operation at 317 Volts DC.

\section{POWER FACTOR}

When the inverter system is operating at $300 \mathrm{~kW}(100 \%$ load), the capacitive KVARS of the high pass filter are not quite enough to meet the inverter requirements so the overall power factor of the inverter system calculates to be $98 \%$ lagging.

At $150 \mathrm{~kW}(50 \%$ load), the capacitive KVARS of the HP filter are more than the requirement of the inverter so the power factor calculates to be $97 \%$ leading.

At $20 \%$ load, the inverter becomes even more over-compensated by the HP filter and the power factor calculates to be $62 \%$ leading.

\section{PROPOSED CONTROL MODE}

Explanation of the proposed control mode is expedited with the use of Figure 3-22 which indicates assumed array overall characteristic curves. $\mathrm{E}$, the open circuit voltage, is assumed to be a function of cell temperature. It is relatively constant with respect to insolation as long as cell temperature is maintained.

The converter is a 6 pulse unit of the type used for rectifier-inverter motor drives in this voltage and power range. It is a line-commutated unit utilizing standard control system as far as possible.

The maximum safe back emf of the inverter is indicated by the curve labeled $E_{d}$ and located above the $\mathrm{E}_{\mathrm{o}}$ characteristics of the array. This margin will allow for sudden changes in AC system voltage. While any desirable margin could be provided it is now visualized as $15 \%$. In other words, the system can withstand sudden AC system voltage dips of $15 \%$. Somewhat greater dips than this will result in commutation failure and temporary interruption of power flow. The larger the margin provided, the greater the cost of the inverter and the greater the consumption of reactive power by the converter.

The converter is coupled to the array through a DC breaker and a smoothing reactor. The DC breaker will be used to open the circuit in the event of a commutation failure which does not clear by itself. The reactor smooths the direct current by absorbing the harmonic voltages generated by the converter. It also controls the current during AC system voltage disturbances. 
The 6 pulse converter operates in a voltage controlling automatic control loop as shown in Figure 3-20. The reference voltage will consist of a signal in analog voltage form provided by the Maximum Power Tracker. The converter will hold the DC voltage as current varies and maximum power will be realized as long as the reference voltage is correct.

The voltage out of the transducer is also presented as a reference to the AC induction voltage regulator located at the input to the converter transformer. This will maintain the voltage $E_{d}$ (Figure 3-22 at the safe margin above $\mathrm{E}_{0}$ ) $;$, The voltage from the transducer is compounded with current to provide a characteristic which changes with insolation to approximate the requirements of the array.

The voltage regulator is a conventional unit with a dead-band control and relatively slow motor drive voltage adjustment. It will look after slow changes in AC system voltage or slow changes in cell characteristics $\mathrm{E}_{\mathrm{o}}$ as temperature chmges.

All rapid changes in operating point due to temperature, insolation or AC system voltage are absorbed by the margin between $\mathrm{E}_{\mathrm{d}}$ and $\mathrm{E} \mathrm{o}^{\cdot}$. If this margin becomes zero, a temporary inverter commutation failure and power interruption occurs. This is not serious since protection circuitry will operate to open the circuit and reclose.

The converter acts as a current source, injecting $\mathrm{AC}$ current into the $\mathrm{AC}$ system. The power factor will always be less than unity, probably in the vicinity of 0.8 with the converter always absorbing reactive power.

The High Pass filter (see Figure 3-20) has a dual purpose: to absorb AC harmonic currents generated by the converter, and to compensate for the reactive power absorbed by the converter.

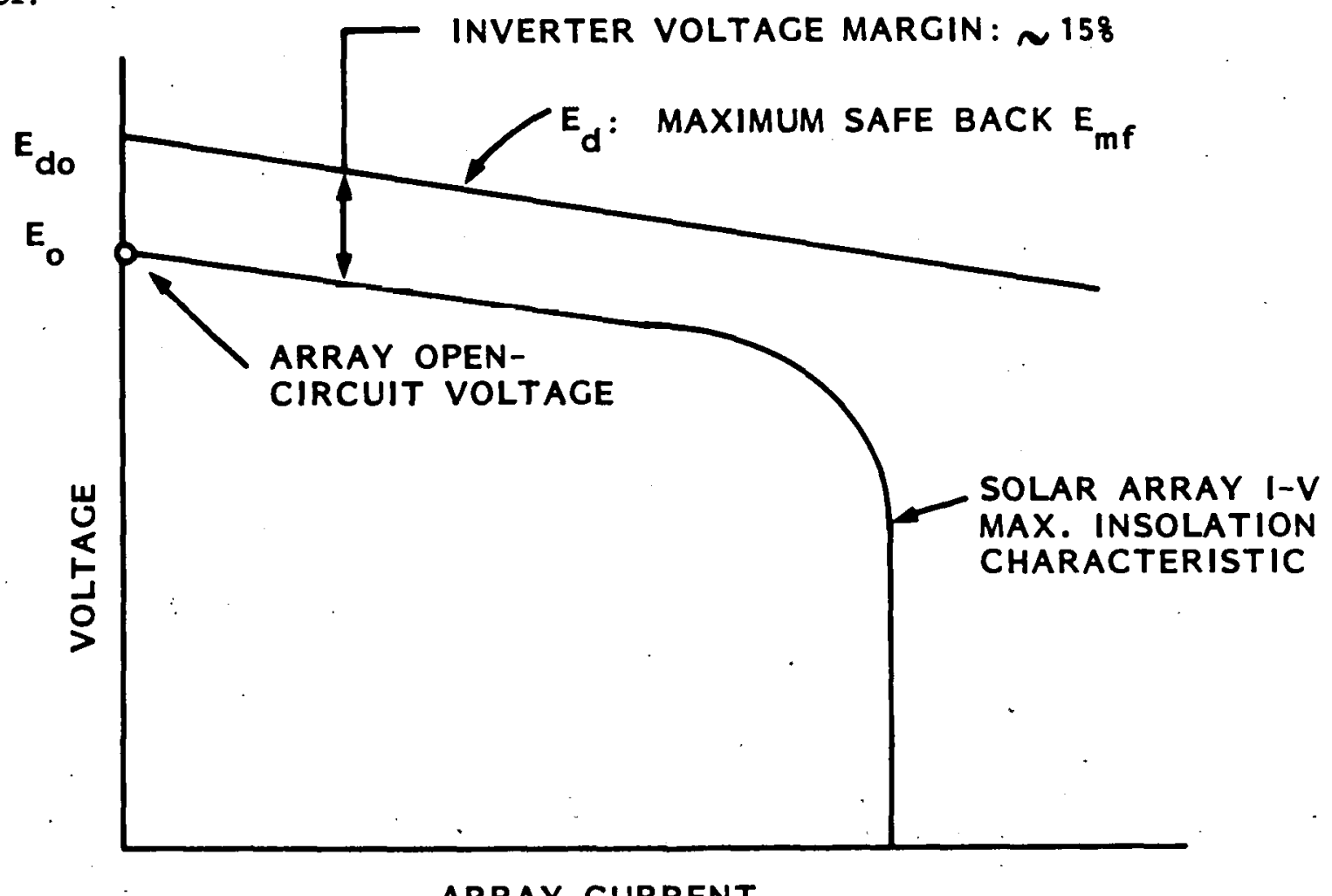

ARRAY CURRENT

Figure 3-22. Inverter Voltage Margin 
3.4.2 UTILITY INTERFACE. A simple tie-in with the utility line has been adopted and is shown schematically on Figure 3-23. Full agreement on this' approach has been reached with Sea World and the Florida Power Corporation. The flow of power is bidirectional with appropriate metering installed to record the relative flow of power.

The utility interface transformer is tied-in with a $13 \mathrm{kV}$ loop serving the general Sea World loads and is owned and maintained by the Florida Power Corporation. A circuit breaker is installed on the low voltage (PCAE) side of the transformer and protects the Sea World system against any PCAE faults. This breaker is controlled by utility safety considerations and is entirely independent of inputs from the PCAE. The breaker and transformer are housed in locked cabinets and are inaccessible to all but authorized utility personnel. This equipment will be provided at no direct expense to the PCAE project.

A safety switch is located in the PCAE control building to permit electrical isolation for maintenance and repair.

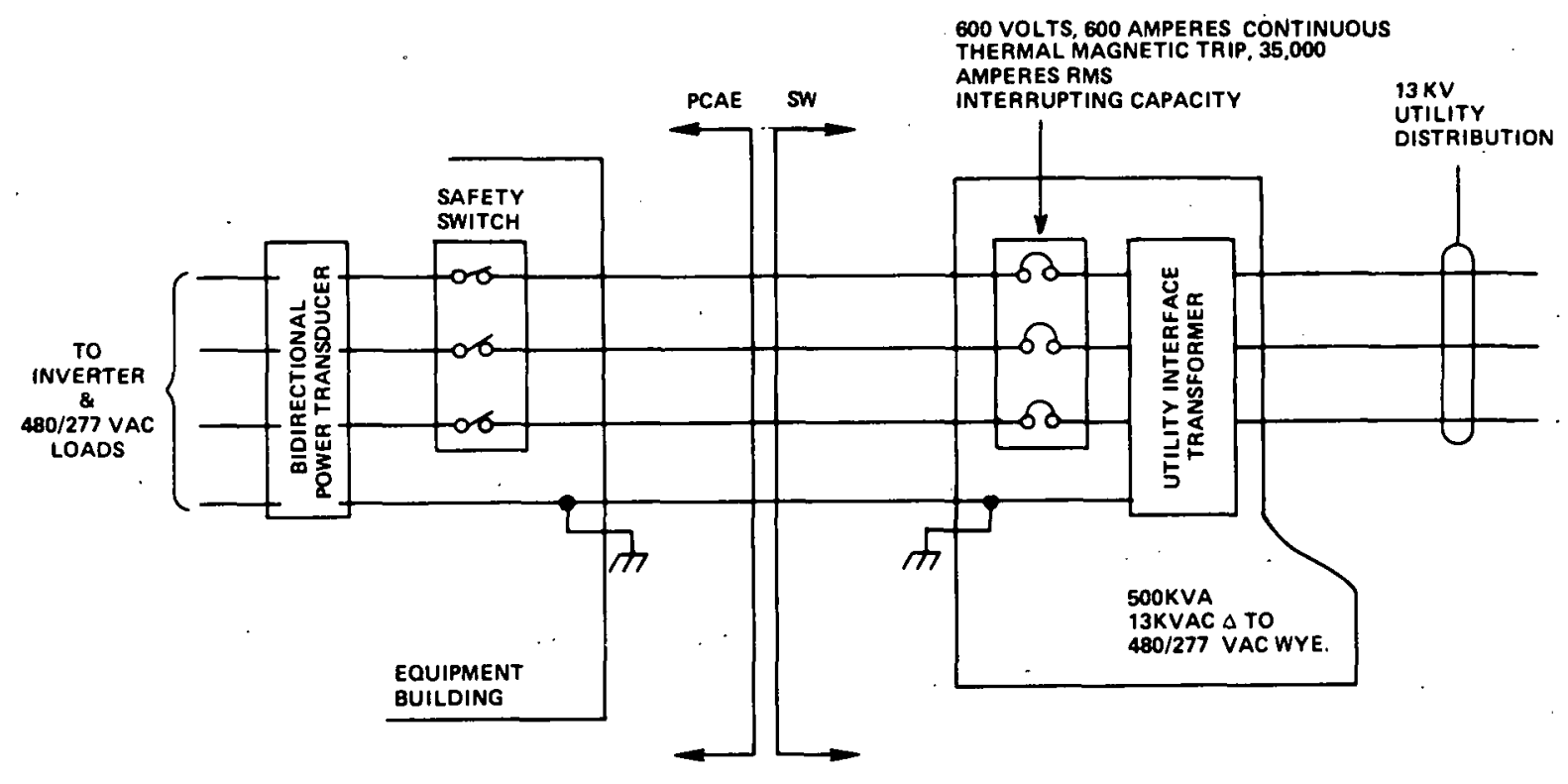

Figure 3-23. Utility Interface Diagram

\subsubsection{EMERGE NCY POWER SYSTEM (EPS). The EPS provides power to two critical loads. It} supplies continuous $\mathrm{AC}$ power $(0.4 \mathrm{~kW}$ max), to the central computer and control system. Also, in the event of a utility power outage, it will supply about $4 \mathrm{~kW}$ of AC power required for programmed system shutdown.

A block diagram of the required functions is illustrated in Figure 3-24. A battery charger operates from utility power and maintains the battery at full charge. Inverter $\mathrm{A}$, rated at $0.5 \mathrm{kVA}$ 


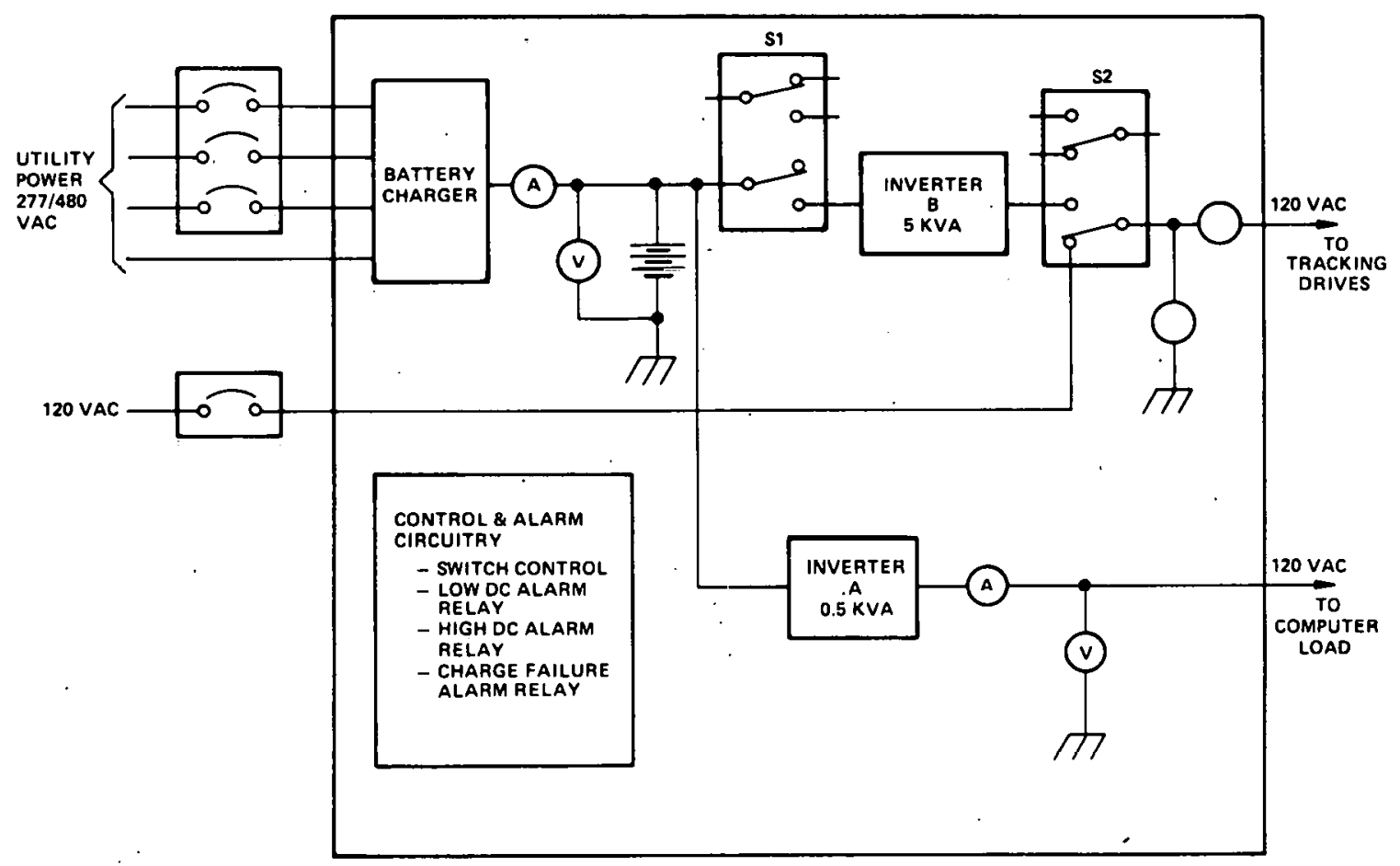

Figure 3-24. Emergency Power System Block Diagram

operates on battery power and continuously supplies AC power to the computer load. Inverter B, rated at $5 \mathrm{kVA}$, supplies power for system shutdown after the closure of switches S1 and S2 in response to a utility outage in excess of 1 to 2 minutes. The battery is sized to provide approximately $5 \mathrm{~kW}$ for 30 minutes to the load. Recovery of the utility power automatically resets switches S1 and S2. Several alarm and metering features are also provided as shown. Physical characteristics are summarized on Table $3-10$.

Table 3-10. Emergency Power System Physical Characteristics

\begin{tabular}{|c|c|c|c|}
\hline Item & Size & $\begin{array}{c}\text { Thermal } \\
\text { Dissipation }\end{array}$ & Source \\
\hline Battery & $\begin{array}{l}2.5 \mathrm{kWh} \\
9^{\prime} \times 13^{\prime \prime} \times 3^{\prime} \\
400 \mathrm{lb}\end{array}$ & - & Solid State Controls, Inc. \\
\hline $\begin{array}{l}\text { Inverter } \\
\text { Equipment }\end{array}$ & $\begin{array}{l}30^{\prime \prime} \times 30^{\prime \prime} \times 6{ }^{\prime}, \\
250 \mathrm{ib}\end{array}$ & $100 \mathrm{w}$ & \\
\hline
\end{tabular}


Continuous supply of $120 \mathrm{VAC}$ to $0.5 \mathrm{~kW}$ load

Supply $120 \mathrm{VAC}$ to $5 \mathrm{~kW}$ load for up to 30 minutes in response to utility outage of 1 to 2 minutes or greater.

3.4.4 CONTROL SYSTEM. As shown on the block diagram of Figure 3-25, a central computer located in the control building issues azimuth and elevation tracking instructions through a digital link to each turntable solar array. This information is processed by turntable conditioning equipment and communicated to and from positioning sensors, fine sum-tracking devices, and tracking motor drives.

Both the azimuth and elevation tracking system on the turntable are controlled by on-off duty cycle operation of the tracking drives. Error signals derived by comparing position sensor information with the central computer reference position data initiate any corrective motions required.

Because azimuth tracking is only required within an accuracy of \pm 1 degree, the azimuth controls only respond to the central computer reference data. An optically encoded position sensor mounted at the turntable pintle provides the position data against which the reference data is compared.

A similar approach is used for coarse elevation tracking. Additionally, fine sun sensors are used to bring elevation pointing within \pm 0.1 degree of the true sun position. Optical fiber elements mounted in several solar cell receivers (see cross-section in Figure 3-26) serve as the fine sun sensors. Slight off-pointing of the solar collector causes an imbalance of the light stimuli to the optical sensors. The resulting error signal is then processed electronically and used to activate the elevation drive. The optical fiber sensors were successfully tested in conjunction with the $5 \times$ 7-foot collector sejgment described in Paragraph 5.3.

Besides normal tracking, the control system has the capability for additional operational modes including repositioning of the turntable overnight to the sunrise position and rapid defocus of the solar collectors in the event of a utility power outage or loss of coolant pumping. Overtemperature thermostatic devices are located at key locations of the turntable collectors that initiate emergency defocussing should the solar cells temperatures exceed the preset limit.

Means are also provided at the control building for overriding automatic controls. Thus, for example, the collectors may be rotated to a stowage position by manual control to minimize the effects of an impending storm or hurricane.

The control system hardware is based on available components. The central computer uses off-the-shelf micro-processors and printed circuit boards. In general, the computer is configured to provide a high degree of experimental flexibility. In addition to its functions for the control 


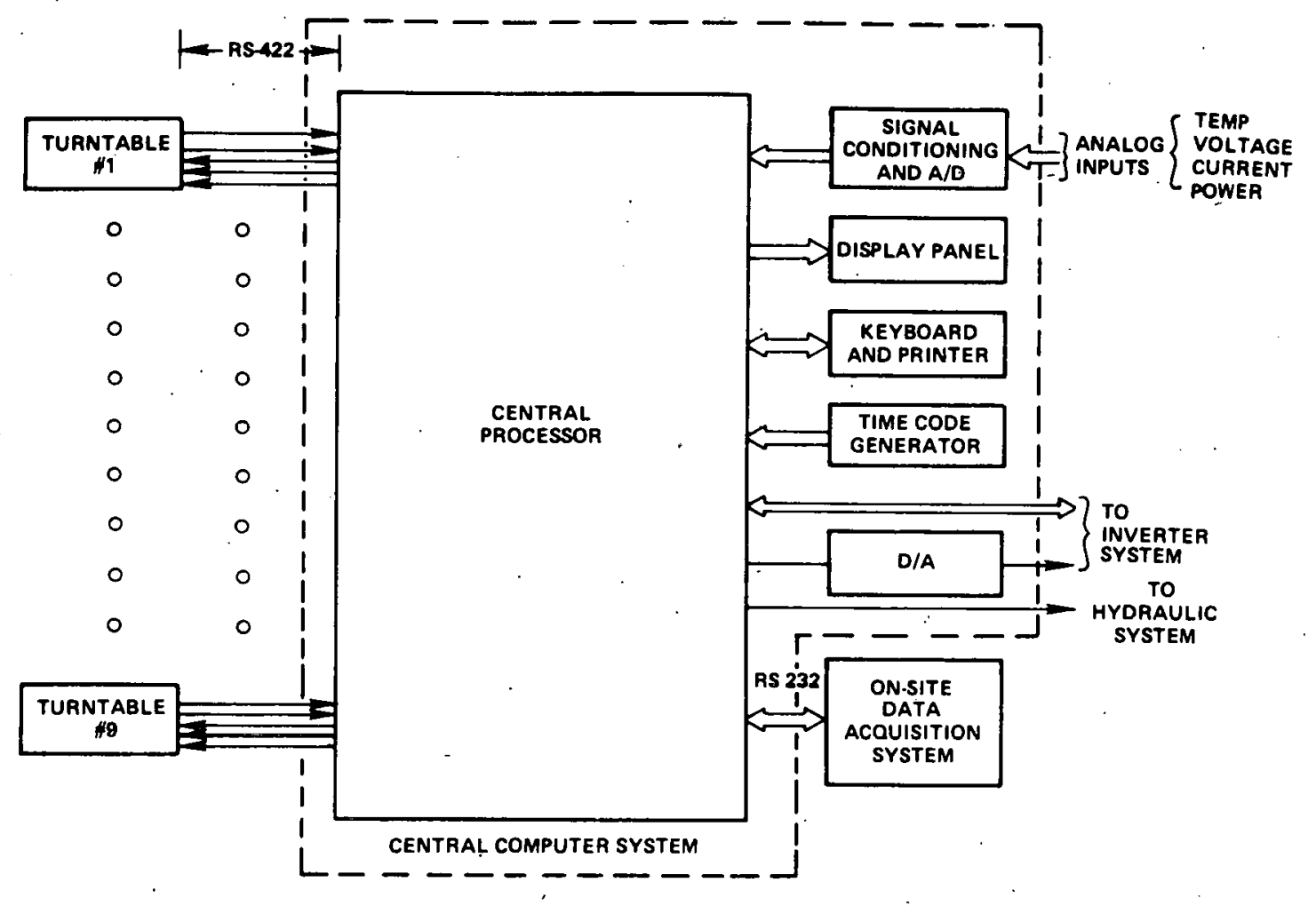

General View

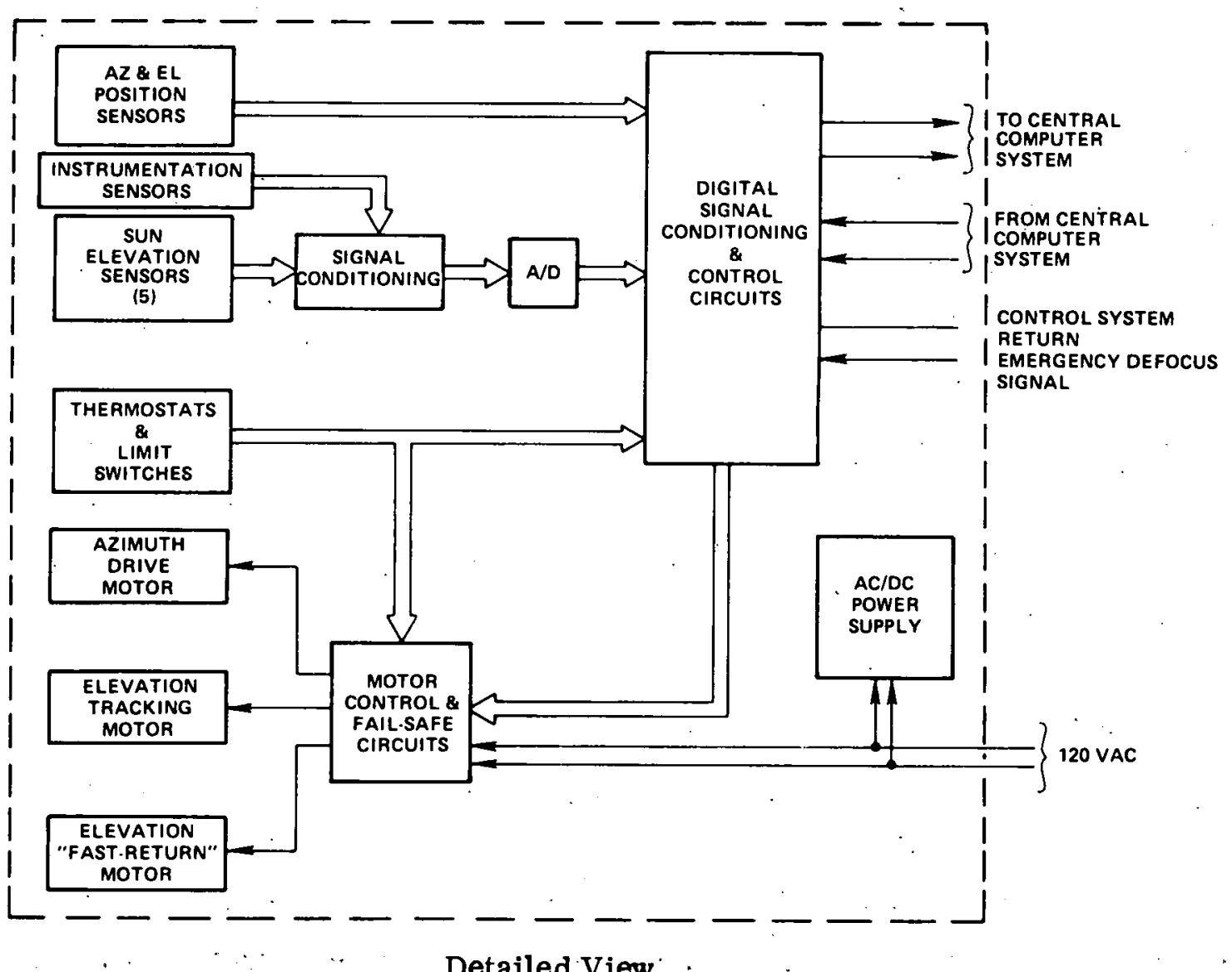

Figure 3-25. Turntable Electronics 
system, the computer also serves the power inverter and instrumentation systems. For the inverter, the computer processes the data for maximum power tracker operation, and for the instrumentation system, it processes sensor outputs for delivery to the on-site data acquisition system (ODAS). Physical characteristics of the control

hardware are summarized on Table 3-11.

Summary Specification

- Provide azimuth and elevation tracking to required accuracies

- Provide means for other non-tracking operational modes (e.g., return to sunrise position, rapid elevation motion for stowage)

- Sense solar cell overtemperatures and initiate collector defocus

- Provide computer capability for inverter max power tracking operation and ODAS data processing.

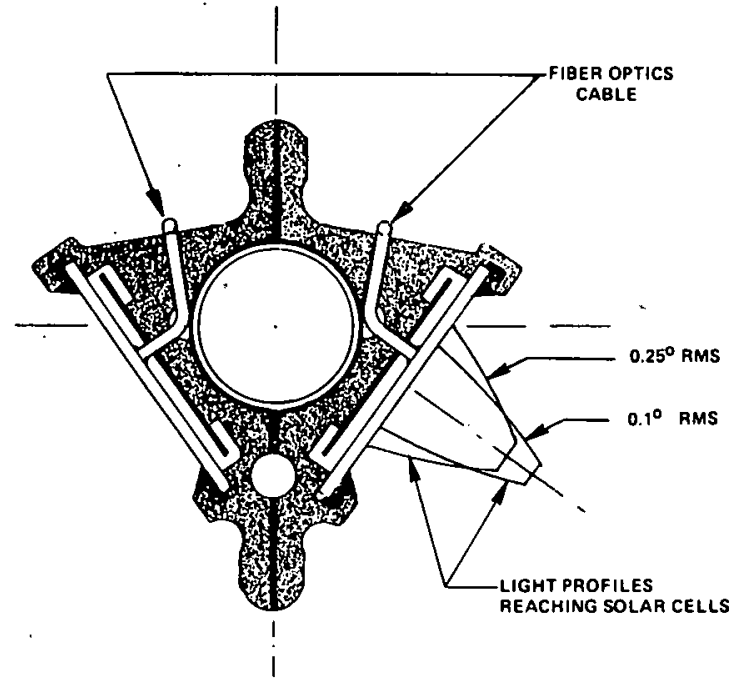

Figure 3-26. Receiver Sun Sensor

Table 3-11. Controls Hardware Physical Characteristics

\begin{tabular}{|l|c|c|c|}
\hline \multicolumn{1}{|c|}{ Major Items } & $\begin{array}{c}\text { Size } \\
\text { (Inches) }\end{array}$ & $\begin{array}{c}\text { Max } \\
\text { Thermal } \\
\text { Dissipation }\end{array}$ & Sources \\
\hline & $12 \times 24 \times 24$ & $100 \mathrm{~W}$ & GE Space Division \\
Turntable Equipment Box & $500 \mathrm{~W}$ & GE Space Division \\
Central Computer \& Peripherals & $60 \times 30 \times 72$ & 5 \\
\hline
\end{tabular}

3.4.5 INSTRUMENTATION. Temperature and electrical instrumentation will be distributed on the turntable and at key points in the power conditioning and fluid cooling systems. One of the nine turntables will have an increased instrumentation capability to permit greater flexibility for evaluating the system during Phase III.

The instrumentation system consists of two basic elements: 1) installed sensors and 2) Onsite Data Acquisition System. This data-gathering system will collect and report both the solar system performance and climatic data. Meteorological sensors will collect outside temperature, humitidy, wind velocity and direction and available sunlight data. Sensors for monitoring the system performance will include voltage and current transducers, and temperature and flow rate sensors. 
Specific sensor data requirements are defined in Table 3-12 including sampling and recordir* frequencies.

Figure 3-27 is a block diagram of the ODAS that is to be supplied as GFE by DOE/Sandia. It will have the capability of accepting $\mathbf{4 0}$ or more channels of transducer data as well as the capability of accepting expansion modules to provide up to 1000 channels for very large test systems. Approximately 76 channels of data are required for this project. The ODAS will also have a capability to record an additional amount of unique data that General Electric might require for additional system evaluation. All output data from the ODAS is accessed via either the RS-232 port or the telephone data access port.

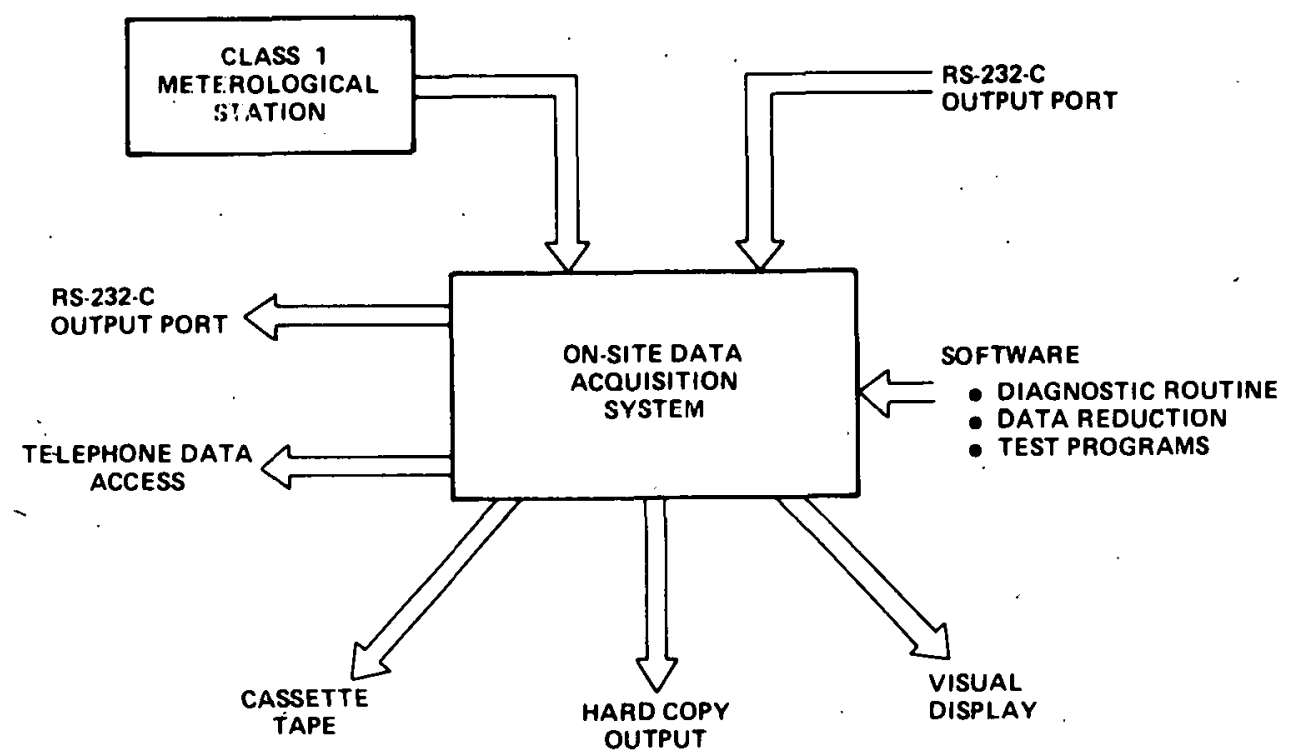

Figure 3-27. Block Diagram of ODAS

Figure 3-28 shows a diagram of turntable transducer locations; most of the sensors are installed only on the experimental turntable transducer locations; most of the sensors are installed only on the experimental turntable assembly.

\subsubsection{LIGH TNING PROTECTION}

The Sea World PCAE will be located in an area of prevalent thunderstorms and lightning strokes. In fact, there are an average of 90 days each year on which thunderstorms are within earshot of Orlando. This degree of exposure implies that positive measures must be provided to protect the experiment from upset or damage due to lightning. Lightning Technologies, Inc. , was engaged to assess the magnitude of the potential lightning problems and to develop protective 
Table 3-12. Transducer Data Acquisition Requirements (Imputs to ADAS)

\begin{tabular}{|c|c|c|c|c|c|}
\hline Parameter & $\begin{array}{l}\text { Unit of } \\
\text { Measure }\end{array}$ & $\begin{array}{l}\text { Sampling } \\
\text { Rate }\end{array}$ & $\begin{array}{l}\text { Recording } \\
\text { Interval }\end{array}$ & $\begin{array}{l}\text { Accuracy of } \\
\text { Measurement }\end{array}$ & $\begin{array}{c}\text { Quantity Used } \\
\text { with PCA System }\end{array}$ \\
\hline Date & $\begin{array}{l}\text { Dayis from } \\
\text { Jan. } 1\end{array}$ & 1 Mln. . & $10 \mathrm{Min}$. & \pm 1 Min. & 1 \\
\hline Time & Local Standard & 1 Min. & 10 Min. & \pm 15 Sec. & 1 \\
\hline $\begin{array}{l}\text { Total incident } \\
\text { Radiation }\end{array}$ & $\mathrm{kW} / \mathrm{m}^{2}$ & 1 Mln. & 10 Min. & $\pm 1.5 \%$ & 1 \\
\hline $\begin{array}{l}\text { Direct Normal } \\
\text { Radiation }\end{array}$ & $\mathrm{kW} / \mathrm{m}^{2}$ & 1 Min. & 10 Min. & $\pm 1.5 \%$ & 1 \\
\hline Wind Speed & $\mathrm{m} / \mathrm{s}$ & 5 Min. & $30 \mathrm{Min}$. & $\pm 1.0 \%$ & 1 \\
\hline Wind Direction & $\begin{array}{l}\text { Decrease from } \\
\text { North }\end{array}$ & 5 Min. & $30 \mathrm{Min}$. & $\pm 3.0 \%$ & 1 \\
\hline Barometric Presgure & $\mathrm{mm} \mathrm{Hg.}$ & 5 Min. & 30 Min. & & 1 \\
\hline $\begin{array}{l}\text { Ambient Air } \\
\text { Temperature }\end{array}$ & ${ }^{\circ} \mathrm{C}$ & 5 Min. & 30 Min. & $\pm 2^{\circ} \mathrm{F}$ & 1 \\
\hline Relative Humidity &.$\%$ & $10 \mathrm{Min}$. & $1 \mathrm{Hr}$. & $\pm 5 \%$ & 1 \\
\hline $\begin{array}{l}\text { Reference Solar Cell } \\
\text { Short Cịrcult Current }\end{array}$ & Amperes & 1 Min. & $10 \mathrm{Min}$. & $\pm 1 \%$ & 1 \\
\hline String Voltage & VDC & 1 Min. & 10 Min. & $\pm 0.5 \%$ & 4 \\
\hline String Current & Amperes & 1 Min. & $10 \mathrm{Min}$. & $\pm 1 \%$ & 1 \\
\hline Turntable Current & Amperes & 1 Min. & $10 \mathrm{Min}$. & $\pm 1 \%$ & 9 \\
\hline Array Voltage & vDC & .1 Min. & $10 \mathrm{Min}$. & $\pm 0.5 \%$ & 1 \\
\hline Utility Phase Voltage & VDC & 1 Min. & $10 \mathrm{Min}$. & $\pm 1 \%$ & 3 \\
\hline $\begin{array}{l}\text { Inverter Output Phase. } \\
\text { Phase Current }\end{array}$ & VDC & 1 Min. & $10 \mathrm{Min}$. & $\pm 1 \%$ & 3 \\
\hline System Output Power. & $k W$ & 1 Min. & $10 \mathrm{Min}$. & $q_{1} q_{0}$ & 1 \\
\hline $\begin{array}{l}\text { Inverter Output } \\
\text { Power/Phase }\end{array}$ & $k w$ & 1 Min. & $10 \mathrm{Min}$. & $\pm 1 \%$ & 3 \\
\hline Condenser Pump Power & $w$ & 1 Min. & $10 \mathrm{Min}$. & $\pm 1 \%$ & 1 \\
\hline Array Pump Power & $w$ & $1 \mathrm{Min}$ & $10 \mathrm{Min}$. & $\pm 1 \%$ & 1 \\
\hline Chlller Pump Power & $w$ & 1 Min. & $10 \mathrm{Min}$. & $\pm 1 \%$ & 1 \\
\hline $\begin{array}{l}\text { Control \& Instrumenta - } \\
\text { Hon }\end{array}$ & $w$ & 1 Min. & $10 \mathrm{Min}$. & $\pm 1 \%$ & 1 \\
\hline $\begin{array}{l}\text { Cooling Tower Fan } \\
\text { Power }\end{array}$ & $w$ & 1 Min. & $10 \mathrm{Min}$. & $\pm 1 \%$ & 1 \\
\hline Solar Cell Temperature & ${ }^{\circ} \mathrm{F}$ & 5 Min. & 30 Min. & $\pm 2^{\circ} \mathrm{F}$ & 4. \\
\hline $\begin{array}{l}\text { String Fluid } \\
\text { Temperature }\end{array}$ & ${ }^{\circ} \mathrm{F}$ & 5 Min. & $30 \mathrm{M} / \mathrm{n}$. & $\pm 2^{\circ} \mathrm{F}$ & 4 \\
\hline $\begin{array}{l}\text { Turntable Inlet } \\
\text { Temperature }\end{array}$ & ${ }^{\circ} \mathbf{F}$ & 5 Min. & $30 \mathrm{Min}$. & $\pm 2^{\circ} \mathrm{F}$ & 9 \\
\hline Turntable Temperature & ${ }^{2} \mathbf{F}$ & 5 Min. & $30 \mathrm{Min}$. & $\pm F$ & 9 \\
\hline $\begin{array}{l}\text { Cooling Tower inlet } \\
\text { Temperature }\end{array}$ & ${ }^{2} \mathrm{~F}$ & 5 Min. & $30 \mathrm{Min}$. & $\pm 2^{\circ} \mathrm{F}$ & 1 \\
\hline $\begin{array}{l}\text { Cooling Tower } \\
\text { Temperature }\end{array}$ & ${ }^{*} \mathrm{~F}$ & 5 Min. & 30 Min. & $\pm 2^{\circ} \mathrm{F}$ & 1 \\
\hline $\begin{array}{l}\text { Chiller Inlet } \\
\text { Temperature }\end{array}$ & ${ }^{-a} F^{-}$ & $5 \mathrm{Min}$. & $30 \mathrm{Min}$. & $\pm 2^{e} F$ & 1 \\
\hline Chiller Temperature & $\because F$ & 5 Min. & $30 \mathrm{~N}$ in. & $\pm 2 \% \mathrm{~F}$ & 1 \\
\hline $\begin{array}{l}\text { Heat Exchanger Inlet } \\
\text { Temperature }\end{array}$ & ${ }^{\circ} \mathrm{F}$ & 5 Min. & $30 \mathrm{M} \ln$. & $\pm 2^{2} F$ & 1 \\
\hline $\begin{array}{l}\text { Heat Exchanger } \\
\text { Temperature }\end{array}$ & ${ }^{\circ} \mathrm{F}$ & 5 Min. & $30 \mathrm{Min}$. & $\pm 2^{2} \mathrm{~F}$ & 1 \\
\hline $\begin{array}{l}\text { Turntable Fluid } \\
\text { Flow Rate }\end{array}$ & GPM & 5 Min. & $30 \mathrm{MIn}$. & $\pm 1.0 \%$ & 1 \\
\hline Cooling Tower Flow & GPM & 5 Min. & $30 \mathrm{Mlin}$. & \pm 19 & 1 \\
\hline Total Fleld Flow-Rate & GPM & 5 Min. & $30 \mathrm{Min}$. & $\pm 1.0 \mathrm{~s}$ & 1 \\
\hline Chiller Outlet Flow & GPM & 5 Min. & $30 \mathrm{Min}$. & $\pm 1 \%$ & 1 \\
\hline
\end{tabular}




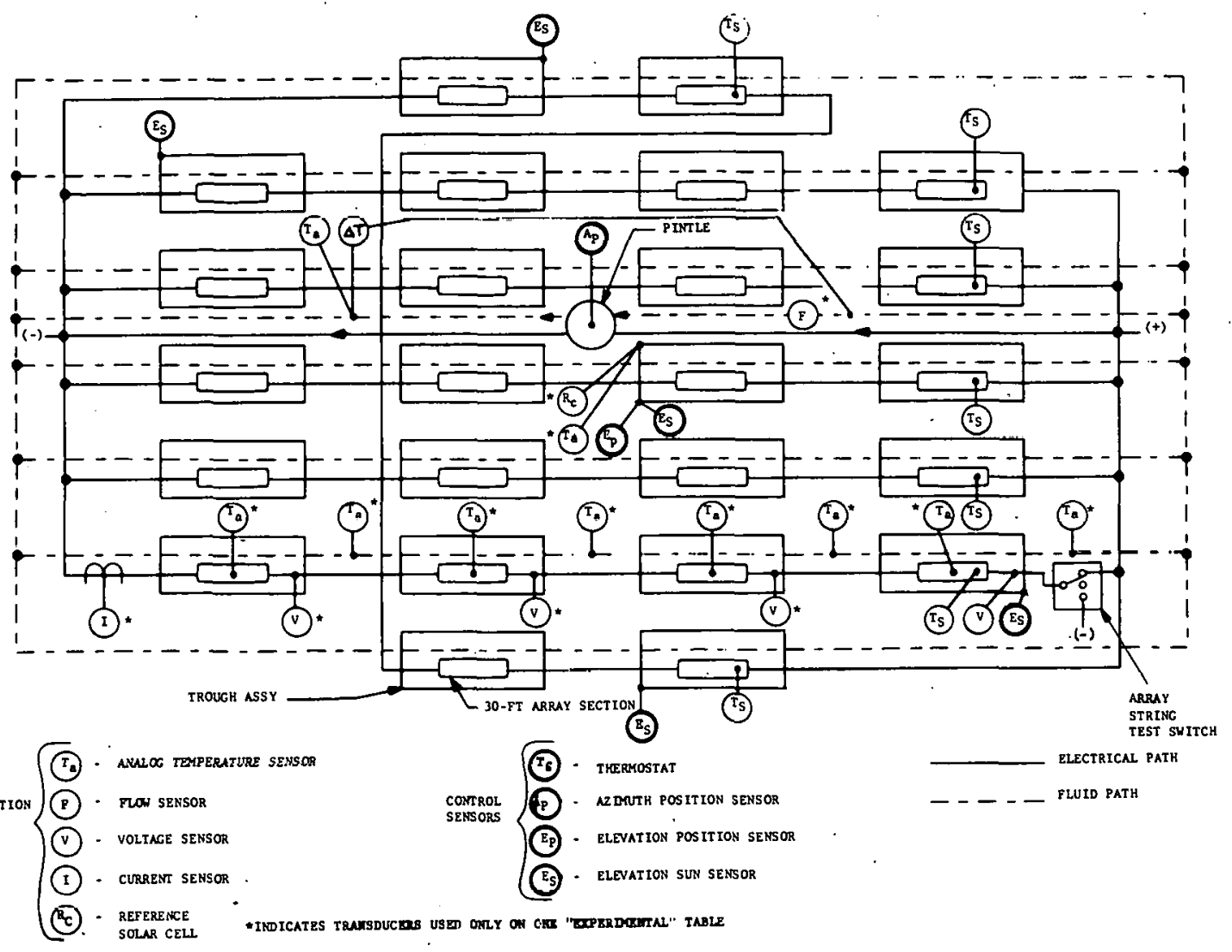

Figure 3-28. Turntable Transducer Locations

measures. Recognizing that lightning protection is most effective and least expensive if designed into a system from the start, potential lightning problems related to the PV system were identi-fied and protective measures developed during the design phase.

Analyses showed that about 26 lightning strikes will fall within a radius of 1 kilometer of the PV site each year generating the magnetic fields and earth voltage rises that may be expected to induce voltage and current surges in the PV electrical systems. These surges are of sufficient magnitude to damage the sensor and control electronics and, possibly, the PV receivers themselves.

A direct strike to one of the PV receiver turntables could cause extensive damage to these items, and it may also produce welding or pitting within mechanical linkages and bearings, that would mechanically disrupt the system operation. The analysis shows, however, that a direct strike can be expected to fall within the plant site only once every six years. The greatest need is to protect the PV system against the much more frequent effects of nearby strikes.

Protective measures developed during this phase for the PV system are intended, first, to reduce, through added shielding, the magnitudes of surge, voltages and currents induced in 
system cabling by the magnetic fields and earth voltages; and second, to suppress remaining surges to levels that can be tolerated by the PV electronic equipment.

Reduction of lightning-induced voltages in the power and electronic circuits will be accomplished by use of shields, grounded at each end, between the equipment building and the turntables. These shields will make a major reduction in the amount of induced voltages that appear in enclosed circuits. The currents driven through these shields can still produce significant voltages which appear on the circuits.

Such shielding can be accomplished by an assignment of the DC and AC power return conductors to double duty as lightning and ground return (LGR).cables and arrangement of them so that they carry proportionately more lightning current than the other cables in the same underground cable runs. This can be done by putting the LGR cables on the periphery of conduit runs so as to minimize their relative inductance, as illustrated in Figure 3-29.

Surge suppression networks and devices have been incorporated into the design of each of the electronic circuit interfaces to protect these systems against the remaining surges.

Analysis indicated that the PV cells should tolerate the voltages and currents induced by nearby strikes fairly well, although their ability to sustain higher amplitude currents produced by very near or direct strikes is not known because the actual tolerance level of photovoltaic cells has never been evaluated by laboratory test.

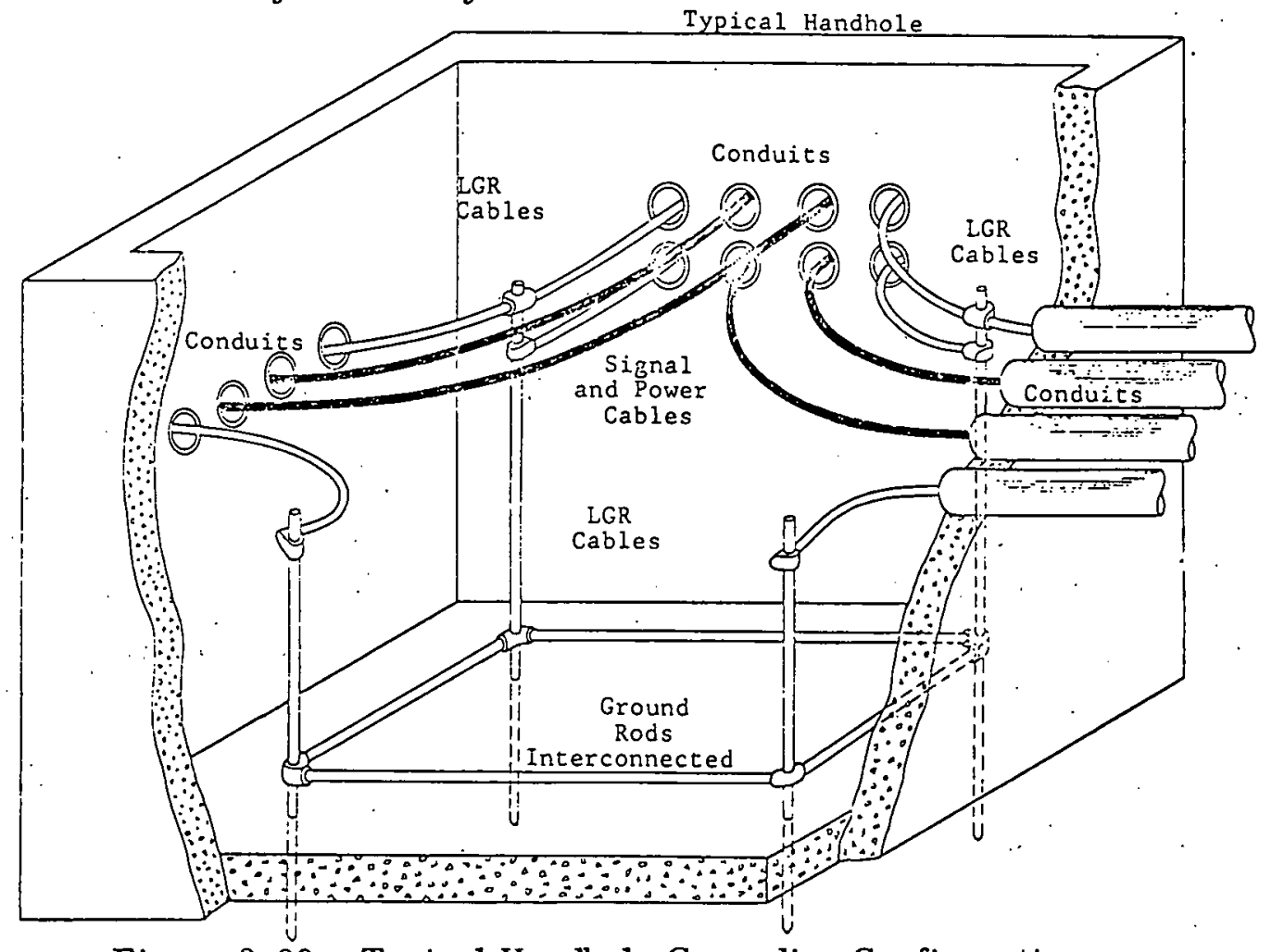

Figure 3-29. Typical Handhole Grounding Configuration 
The Sea World experiment offers an excellent opportunity to evaluate the lightning tolerance of solar cells and acquire the data necessary to assure the design of adequate lightning protection for future PV power generation systems. This can be accomplished by performance of simulated lightning current tests on PV cell units at known current levels, and also by monitoring the performance of the cells under actual thunderstorm conditions after the plant is constructed.

A series of simulated lightning tests is proposed for the Sea World system and will consist of relative geometric scale model tests to validate the induced voltage analysis, followed by current injection tests on a full-scale PV receiver (one of the test units already constructed) to determine its tolerance level.

Because of their necessarily exposed locations, solar PV power plants will nearly always be subjected to lightning effects, and protective measures will be required to prevent damage. The Sea World PV experiment thus offers an excellent opportunity to optimize and validate protective measures for use in future systems; some of which will be larger, more widespread and thus even more susceptible to lightning that the Sea World PV plant itself.

A comprehensive report on the lightning protection philosophy for the Sea World PV application is presented in Appendix C.

\subsection{FIELD SYSTEM}

Field systems encompass the areas of site preparation, plant layout, electrical interconnections between the major plant installation (turntables, control building, field-mounted hydraulic equipment), hydraulic interconnections between major plant installations, and the control building for housing electrical equipment and serving as an operations center.

\subsection{PLANT LAYOUT}

The site plan for the GE/Sea World PCAE is shown in Figure 3-30. The nine turntables are laid out symmetrically resulting in minimum distances for cabling and piping runs.

Access to the site is provided along the northern boundary from an existing road. The control building and equipment pads are conveniently located near the point of entry. Being in the northern area of the site, they cannot cause shadowing of the turntable solar arrays.

A gravel road is constructed through the site to permit access to every turntable for installing equipment and making repairs.

Underground cabling and piping connect the turntables to the control building and equipment pads. Valvepits and manholes are distributed through the field for convenience in servicing and isolating specific turntables. 


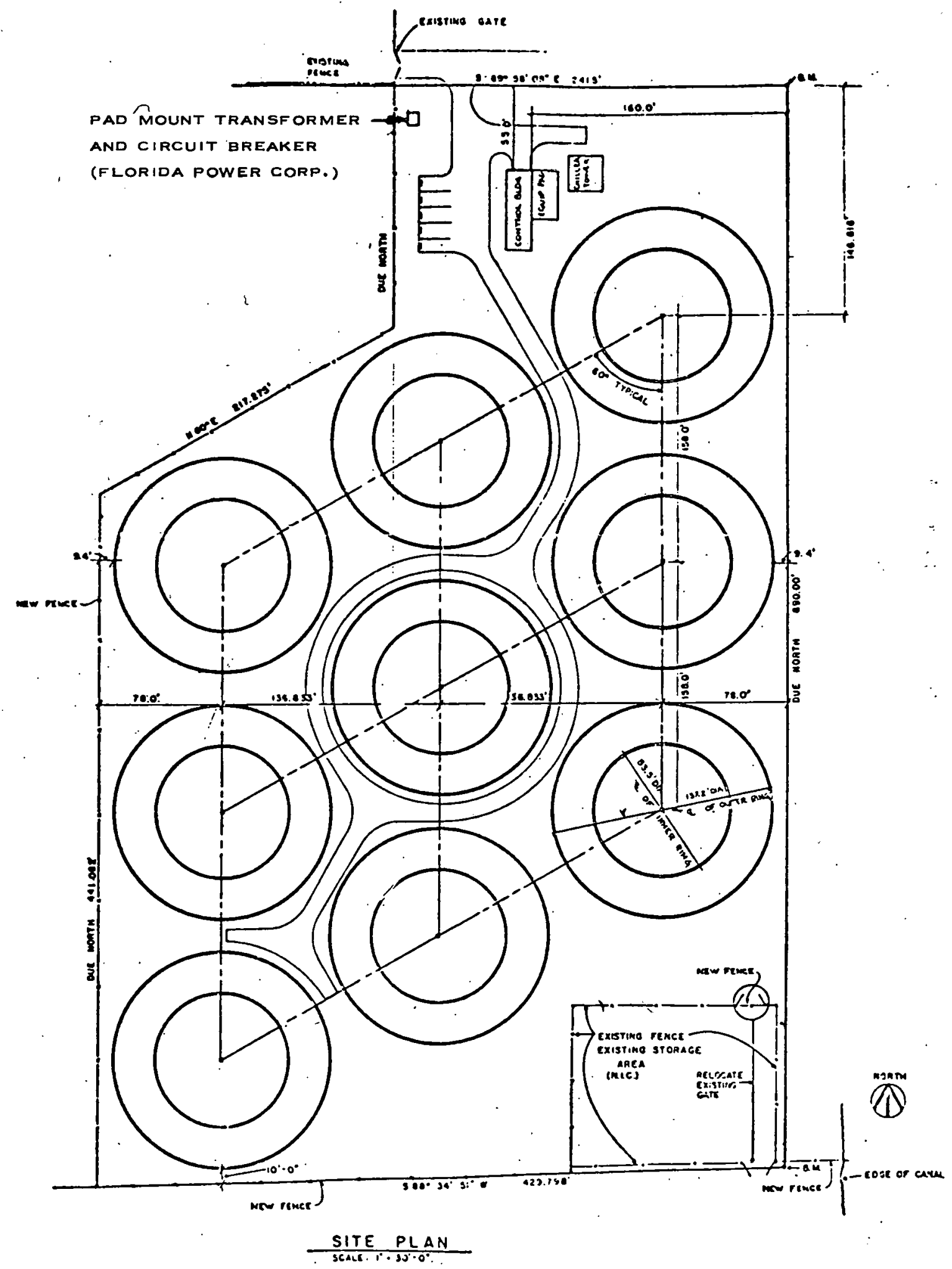

Figure 3-30. PCAE Plant Layout 
A padmount transformer and circuit breaker owned and operated by the Florida Power Cororation are located in the northwest corner of the site and connect the PV plant to the $13 \mathrm{kV}$ grid ocated within the Sea World Park.

Plumbing interconnections between the PCAE and the Sea World Park are made across the northern boundary. The chilled water lines from the absorption chiller mounted on the equipment pad are connected to a nearby shark exhibit just north of the PV plant site. Other service lines (water, telephone, etc.) are also routed across the northern boundary.

\subsubsection{CONTROL BUILDING}

The equipment building is a $16^{\prime} \times 50^{\prime}$ concrete masonry structure. The building will be supported on a continuous reinforced concrete wall footing and a 5 " monolithic concrete floor slab. The soil under the building will be compacted to $95 \%$ of modified proctor density. A plan view of the building layout is shown on Figure 3-31.

Incoming 480-volt power cables from the utility company transformer will terminate in a facility junction box. From the junction box, the cables are extended to a 480,3-phase distribution panel board having a main circuit breaker. This panel will serve supportive equipment (cooling tower, pumps, etc. ) and also by means of a 480-volt, 3-phase delta primary to a 208/120 Volt, 3-phase wye type transformer ahead of a branch circuit panel will serve plant lighting.

DC cabling from the turntables will enter the building into a field junction box. From this point, they will be routed in conduit to the input of the inverter. Output cables from the inverter will connect to the line side of a 600 ampere, 3-phase, 600-Volt AC non-fused disconnect switch. From the load side of the disconnect switch, the cables will terminate at the interface 600 Ampere circuit breaker at the power company's transformer.

Equipment (inverter, reactor, voltage regulator and UPS) interconnecting cabling will be routed in overhead cable trays.

Office areas will be fully air conditioned while the equipment areas will only be heated and ventilated. 


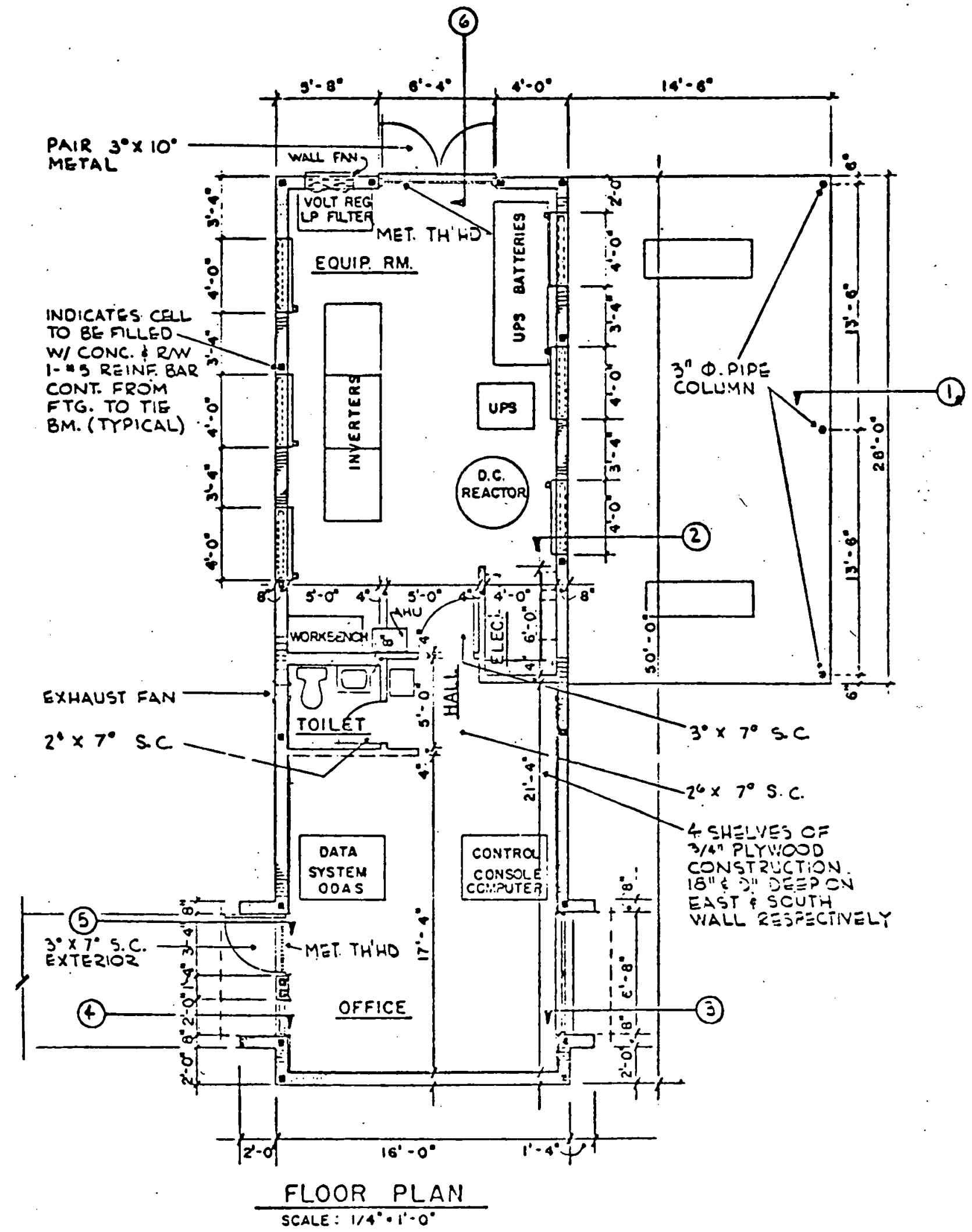

Figure 3-31. Control Building Layout 


\section{SECTION 4}

\section{SYSTEM AND DESIGN ANALYSIS}

\subsection{INTRODUCTION}

This section presents system performance and economic analyses. Simulation models for solar cells, system optics, thermal characteristics, hydraulics, and power conditioning are described. Performance predictions are presented for the two principal heat removal options: (1) use of the hot water produced by solar cell cooling for domestic hot water that would be used in a planned Sea World hotel complex; (2) use of the hot water for operating an absorption chiller for the production of chilled water for air conditioning the Sea World shark exhibit.

\subsection{SYSTEM PERFORMANCE}

\subsection{SIMULATION MODELS}

\subsubsection{Subsystem Analytical Models}

\section{2. 1. 1. 1 Solar Array Optical Model}

The optical model computer routine utilized for both parametric analysis as well as annual performance studies is based on the product of the following factors:

- Solar direct normal insolation level $\left(\mathrm{W} / \mathrm{m}^{2}\right)$

- Geometric concentration ratio (33.4X)

- Surface reflectivity $(\rho=0.80)$

- Receiver intercept factor $(\gamma=0.97)$

- Optical enhancement factor of the cell cover material compared to a bare cell $\left(\tau_{c}=1.04\right)$

- Effective absorptivity of the bare cell ( $\alpha_{\text {eff }}=0.82$ )

The geometric concentration ratio is simply defined as the ratio of the effective aperture width (excludes inactive blockage of solar cell receiver) to the sum of the active width of the two cells mounted opposite one another (See Figure 4-1). Since in the case of the thermal model, an energy balance is performed on an axial increment of length equal to a single cell length $(4 \mathrm{~cm})$, obstructions from trough structural partitions and series gaps are of no concern; that is, they do not af-: fect the concentration ratio. These obstructions do, however, alter the overall effective length of an installed collector row.

The surface reflectivity of 0.80 is generally consistent with values obtained for polyester aluminized films (See data on Table 3-5). As described in subsequent paragraphs, the receiver intercept factor and optical enhancement factors are based on analytical estimates. The overall optical efficiency of the concentrator is represented by the product of the reflectivity and the 


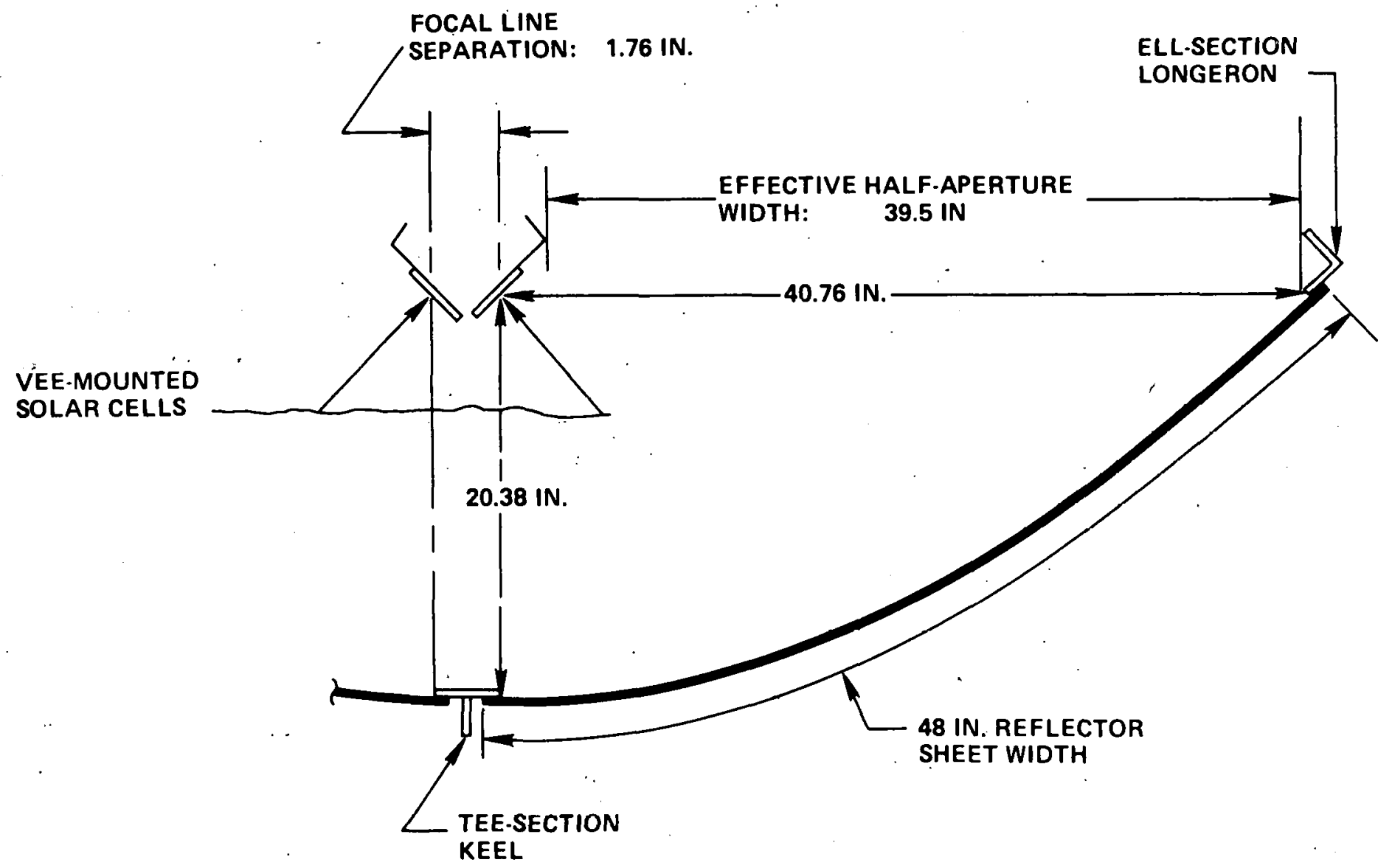

Figure 4-1. Collector Geometry

intercept and enhancement factors. Actual measurements with prototype hardware show an overall optical efficiency of 0.74 (see later discussion in Section 5 ) whereas the values cited above would produce an optical efficiency of 0.807 , representing a projected improvement of 9 percent. Evaluation of the test hardware indicates that such improvements are valid, and therefore performance analysis based on the projected factors is considered to be realistic.

The receiver intercept factor was calculated for the particular geometry of Figure 4-1 as a function of the width of the cell with RMS slope error and surface specularity of the reflector as a composite parameter. In addition, the sensitivity of the energy fraction intercepted by the cell mutual half angle, $\alpha$, was determined. The results given in Figures 4-2 and 4-3, respectively, indicate that a $3 \mathrm{~cm}$ active cell width will intercept 0.97 of the energy incident predicated on a slope error of $1 / 8^{\circ}$ and a 4 milliradian reflective specularity. The optimum cell configuration appears to be determined by a mutual half angle $\alpha=35^{\circ}$ independent of cell width (concentration ratio) over the range studied. 


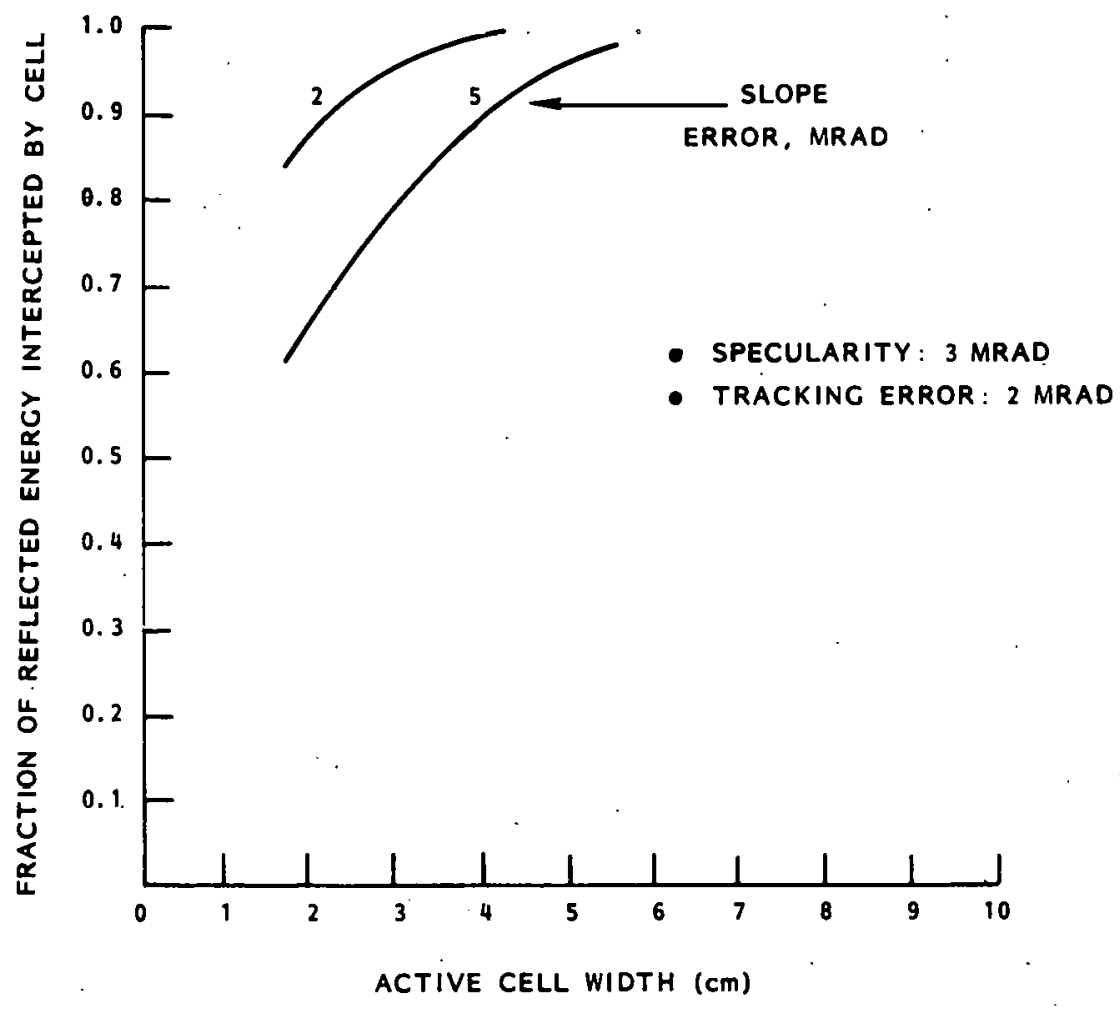

Figure 4-2. Energy Intercepted by Cell Versus Cell Width \& Slope Error

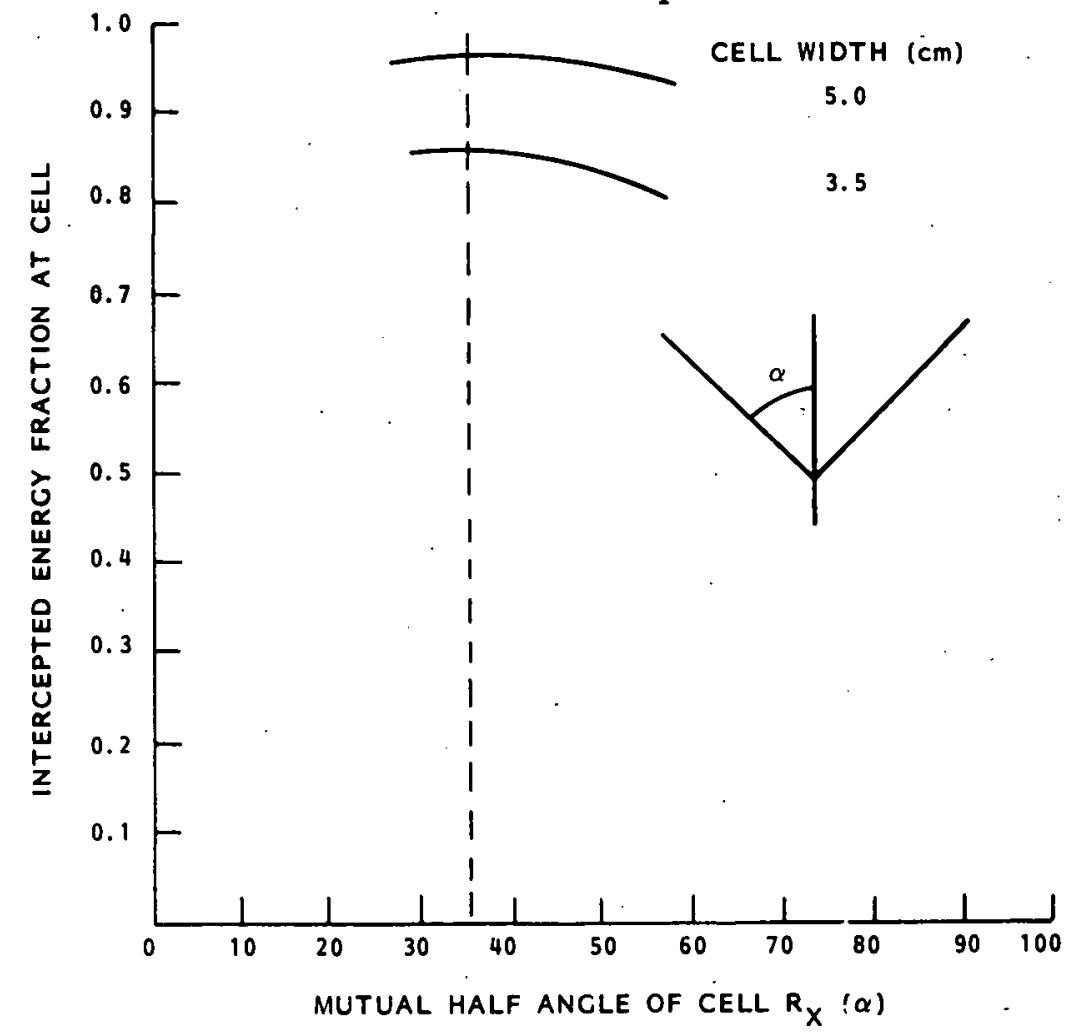

Figure 4-3. Cell Mutual Half Angle Dependence on Energy Interception 
The optical enhancement factor is associated with the improvement in output when optically matched cover windows are bonded to solar cells with transparent materials, in this case, RTV 615 silicone gel. The results of an analysis on the optical enhancement provided by the cover window and bond is shown in Figure 4-4. Sketch (a) indicates a reflection loss of 18 percent for light impinging on a bare cell coated with a tantulum pentoxide layer. Sketch (b) shows a total reflection and absorption loss of 15 percent for the system employing a bonded cover window. Thus, the cover window bond system provides an optical enhancement of $(1-.15) \div(1-.18)$ which equals 1.04. An anti-reflection coating on the exterior surface of the cover window would about halve the reflection loss and would result in an enhancement of about 1.06. This was not included since the incremental output benefits did not appear to offset the cost of the coating.

\subsection{1.2 Solar Array Electrical Model}

The synthesis of solar array electrical characteristics is based on the performance evaluation of Spectrolab's E3-2 solar cells (Reference 1). In order to determine the overall performance of the electrical system, the solar cell was first modeled in terms of its maximum power point conversion efficiency as a function of concentration and temperature. Figure 4-5 shows the normalized conversion efficiency as a function of normalized concentration ratio which is defined as the actual intensity incident on the cell divided by the design intensity. To account for a cell operating temperature $\left(\mathrm{T}_{\mathrm{c}}\right)$ which differs from the standard $28^{\circ} \mathrm{C}$ reference condition, the efficiency was adjusted by factor $\left|1-\beta\left(T_{c}-28\right)\right|$ where $\beta$ is the efficiency temperature coefficient. "Figure 4-6 shows the $\beta$ characteristics versus normalized concentration ratio (Reference 1 ).

The radiation flux that reaches the solar cell was calculated using the following collector array design parameters:

- Geometric Concentration Ratio

- Specular Reflectance of Concentrator

- Intercept Factor on Cell Active Area

- Glass Cover Optical Enhancement Factor
33.4

0.80

0.97

1.04

Combining these design parameters with cell efficiency and temperature coefficient, the maximum power output can be expressed as:

$\mathrm{PWR}_{\max }\left(\mathrm{kW} / \mathrm{m}^{2}\right)=\mathrm{I}_{\mathrm{DN}} *(33.4) *(0.80) *(0.97) *(1.04) *\left(\eta / \eta_{\mathrm{o}}\right) *\left|1-\mathrm{B}\left(\mathrm{T}_{\mathrm{c}}-28\right)\right|$ 


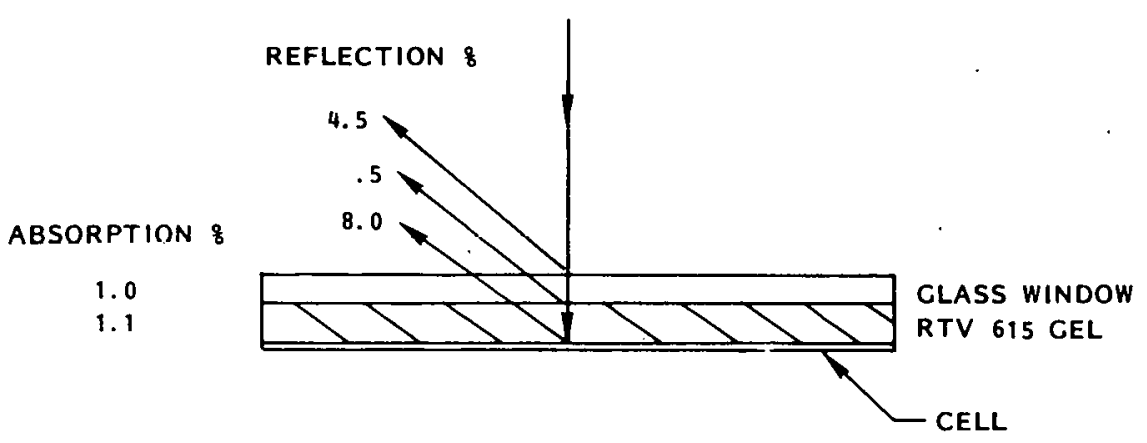

(B) FILLED WITH SILICONE GEL: $\alpha_{\text {EFF }}=.85$

REFLECTION \&

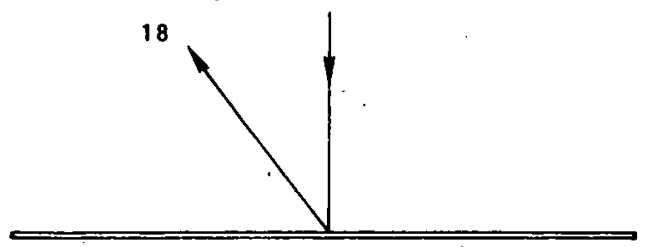

(A) COATED CELL IN AIR: $\alpha_{\text {EFF }}=.82$

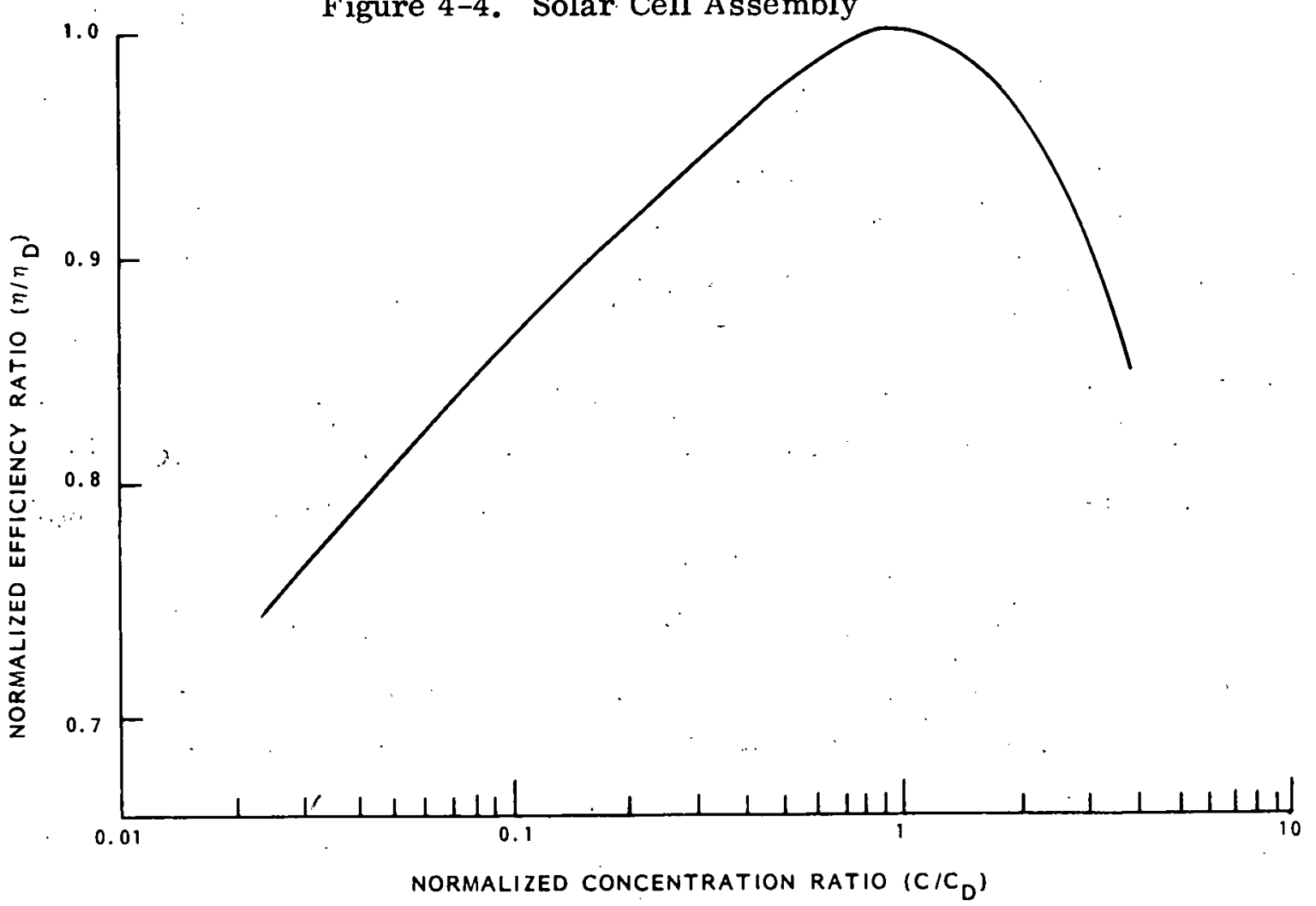

Figure 4-5. Normalized Performance of Spectrolab's E3-2 Solar Cell 


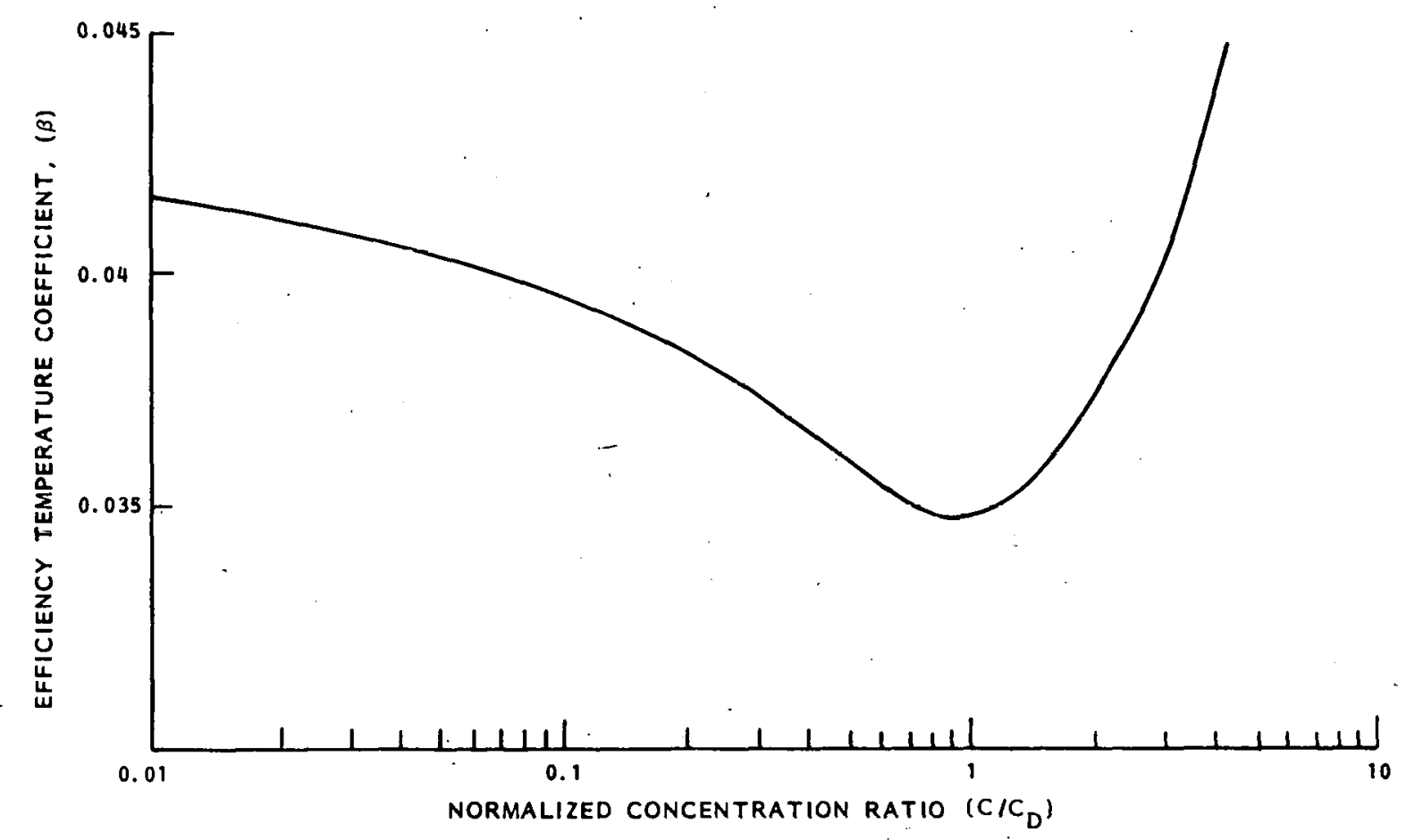

Figure 4-6. Cell Efficiency Temperature Coefficient Versus Concentration Ratio

where

$\mathrm{I}_{\mathrm{DN}}=$ Direct Normal solar isolation $\mathrm{kW} / \mathrm{m}^{2}$

$\eta_{\mathrm{D}}=$ Cell efficiency at design solar intensity

$\eta_{\mathrm{D}}=$ Cell efficiency at instaneous solar intensity

For a total active solar cell area of $111.974 \mathrm{~m}^{2}$ and a cell efficiency $\left(\eta_{\mathrm{D}}\right)$ of 0.16 at the design concentration ratio $\left(C_{D}\right)$ of 20 (or $20 \mathrm{~kW} / \mathrm{m}^{2}$ intensity), Figure $4-7$ shows the maximum power output characteristics of the solar array as function of cell temperature and direct normal solar insolation.

The array maximum power output is further reduced by the inefficiency of the inverter in transforming $\mathrm{DC}$ to $\mathrm{AC}$ power, and by the $\mathrm{I}^{2} \mathrm{R}$ dissipation in the cable. Figure 4-8 shows the inverter efficiency as a function of the inverter operating point in percent full load which is rated at $300 \mathrm{~kW}$. The $\mathrm{I}^{2} \mathrm{R}$ cable losses were assumed to be $2 \%$ at full load condition.

Solar cell maximum power point voltage was derived from the $I-V$ performance curves in Reference 1 by correlating the cell maximum power voltage with open-circuit voltage as shown 


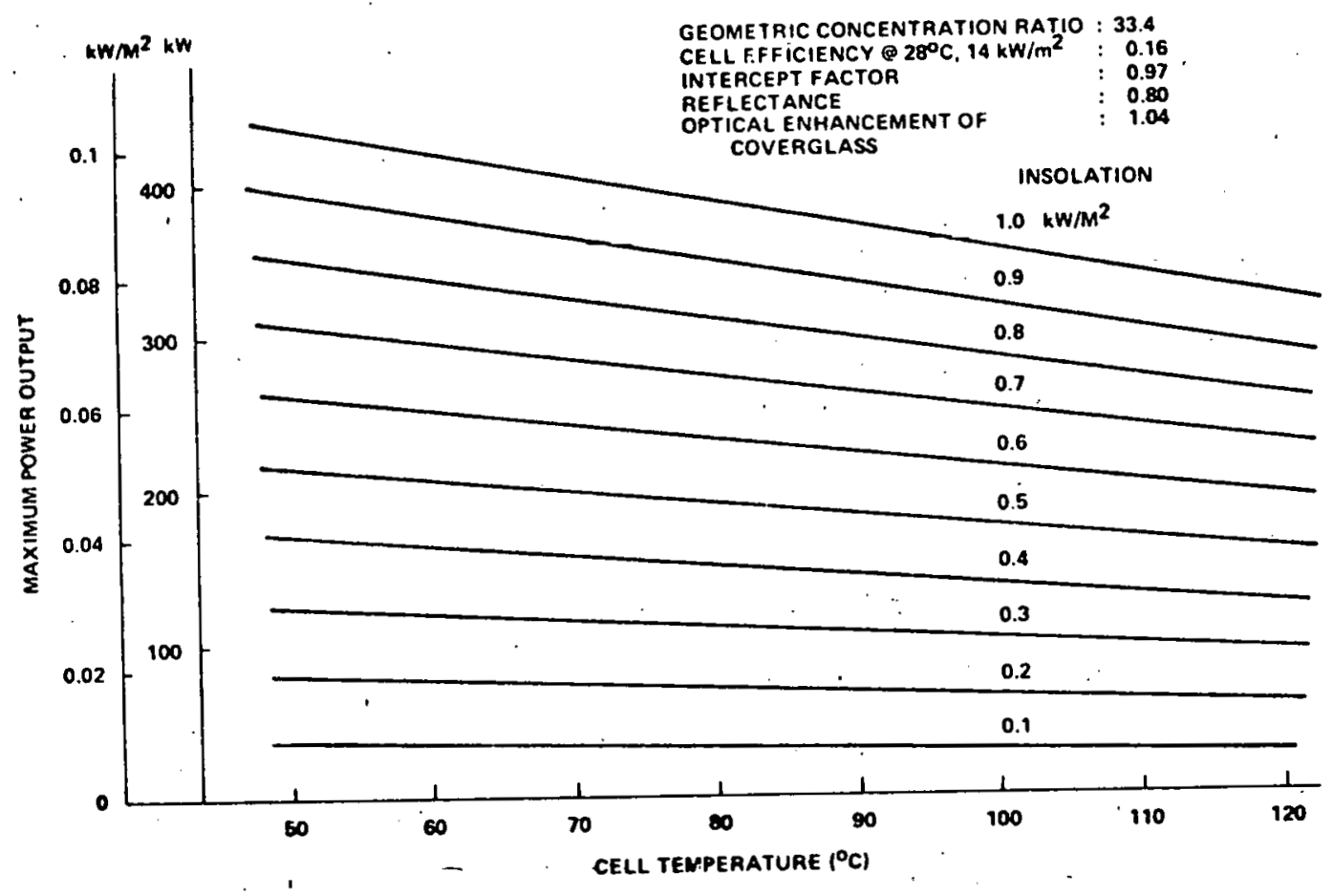

Figure 4-7. PV Array Maximum Power Output Characteristics

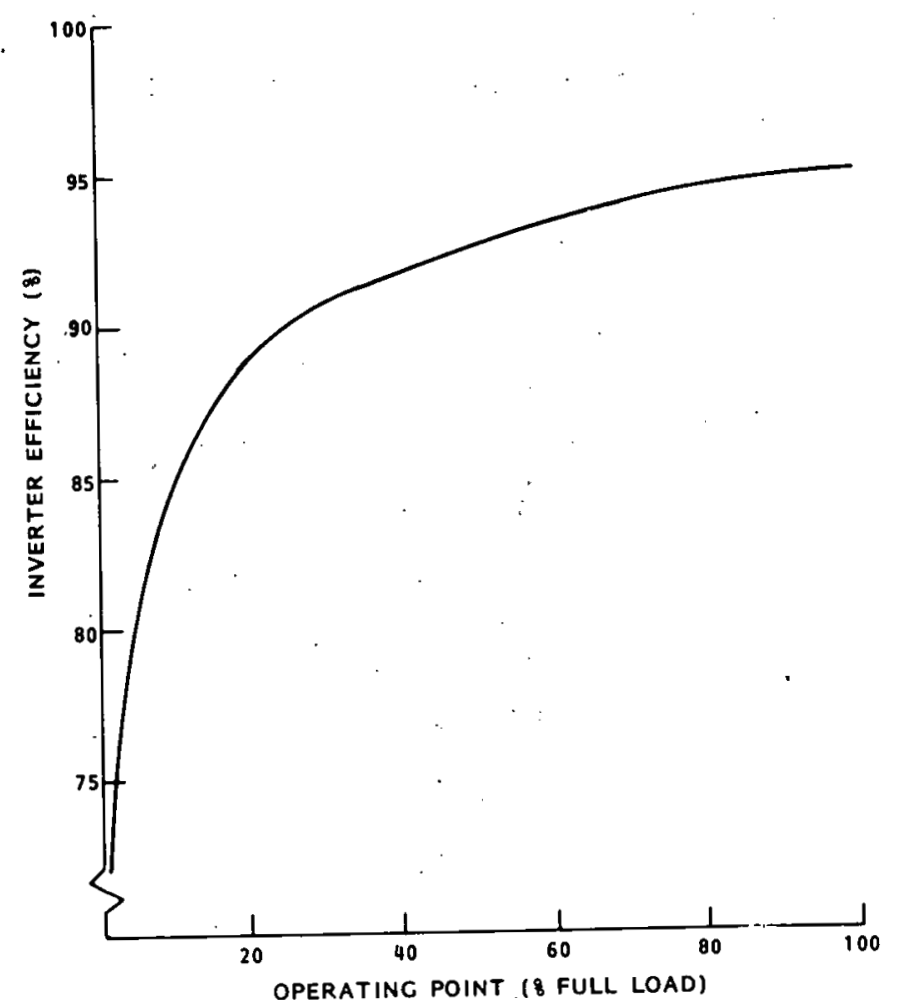

Figure 4-8. Typical $300 \mathrm{~kW}$ Inverter Efficiency Characteristics 
in Figure 4-9. The open-circuit voltage can be expressed empirically as a function of cell temperature $\left(T_{C}\right)$ and normalized concentration ratio $\left(C / C_{D}\right)$ as:

$$
\mathrm{V}_{\mathrm{OC}}=\left(0.000243 * \mathrm{~T}_{\mathrm{c}}+0.0467\right) * \mathrm{LOG}_{10}\left(\mathrm{C} / \mathrm{C}_{\mathrm{D}}\right)+0.7336-0.0017117 * \mathrm{~T}_{\mathrm{c}}
$$

Figure 4-10 presents the sensitivity of array maximum power output voltage to cell temperature and solar insolation.

\section{2. 1. 1. 3 Solar Array Thermal Model}

The thermal model created to approximate the heat transfer from the solar cells to the water coolant is based on incremental, energy balances at each cell along the four series-connected collectors comprising one of the hydraulic circuits on each turntable. The model receives inputs of fluid inlet temperature, flow rate, solar insolation level, ambient temperature, and mean wind speed. Outputs are expressed in terms of cell temperatures, fluid outlet temperature, and specific intermediate material temperatues. Parametric summaries of thermal energy, electrical energy, and parasitic pump power were generated from this model for use in the annual model which utilized the SOLMET '67 Miami weather tape to predict performance for the entire field of turntables. Control logic for the hydraulic loop was built into this latter program.

Figure 4-11 depicts the energy balance parameters used in the solar cell receiver thermal model. Radiation and convective losses occur along the cell faces together with similar losses on the skin of the top insulation. Conduction through the various materials from the cell to the coolant fluid is modeled according to the data given below:

$$
\begin{aligned}
\mathrm{KB} & =0.266 \mathrm{w} / \mathrm{m}^{\circ} \mathrm{C} \\
\mathrm{TB} & =5.09 \times 10^{-5} \mathrm{~m} \\
\mathrm{KI} & =0.036 \mathrm{w} / \mathrm{m}^{\circ} \mathrm{C} \\
\mathrm{TI} & =0.019 \mathrm{~m} \\
\mathrm{KS} & =180 \mathrm{w} / \mathrm{m}^{\circ} \mathrm{C} \\
\mathrm{TAL} & =0.0138 \mathrm{~m} \\
\mathrm{KEI} & =0.210 \mathrm{w} / \mathrm{m}^{\circ} \mathrm{C} \\
\mathrm{TEI} & =1.271 \times 10^{-4} \mathrm{~m} \\
\mathrm{CW} & =0.035 \mathrm{~m} \\
\mathrm{CL} & =0.040 \mathrm{~m} \\
\mathrm{SW} & =0.051 \mathrm{~m} \\
\mathrm{AFC} & =0.857
\end{aligned}
$$

Bond conductivity

Bond thickness

Insulation conductivity

Insulation thickness

Substrate conductivity

Substrate (aluminum) thickness

Electrical insulation conductivity

Electrical insulation thickness

Cell width

Cell length

Substrate width

Active area correction factor of cell (applies to CW) 


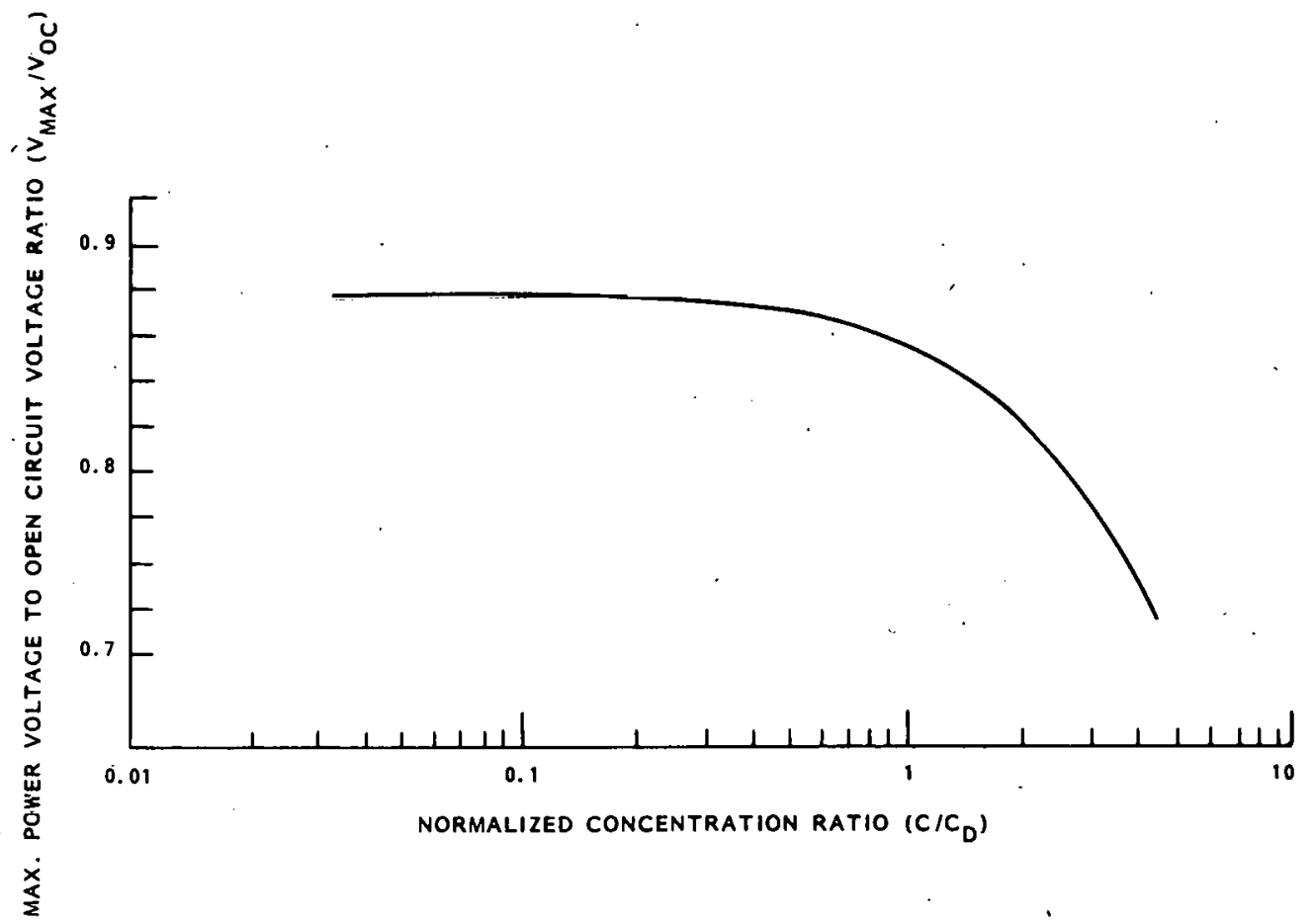

Figure 4-9. Maximum Power Point Voltage and Open Circuit Voltage Correlation

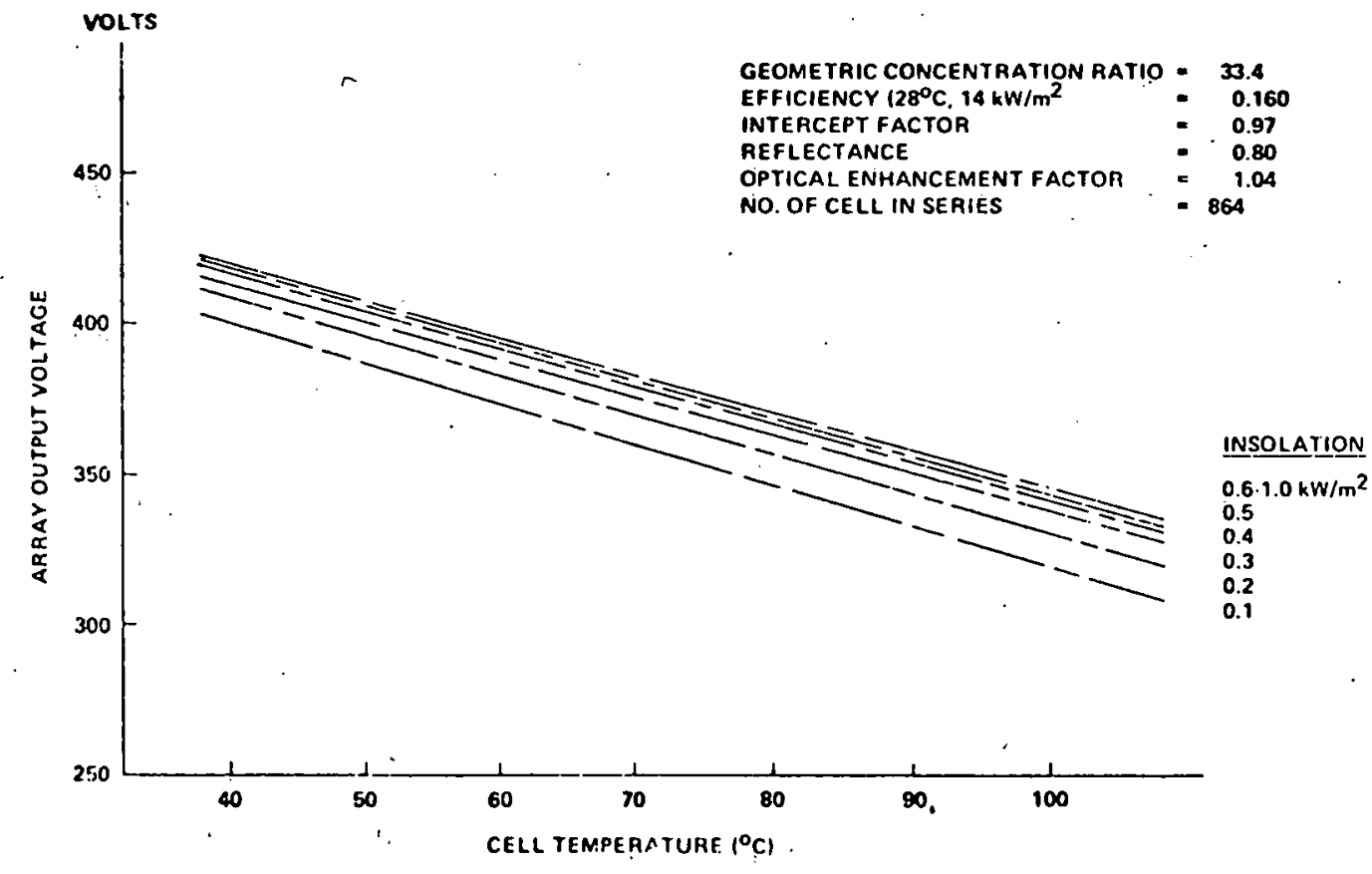

Fi gure 4-10. Array Maximum Power Output Voltage Characteristics 


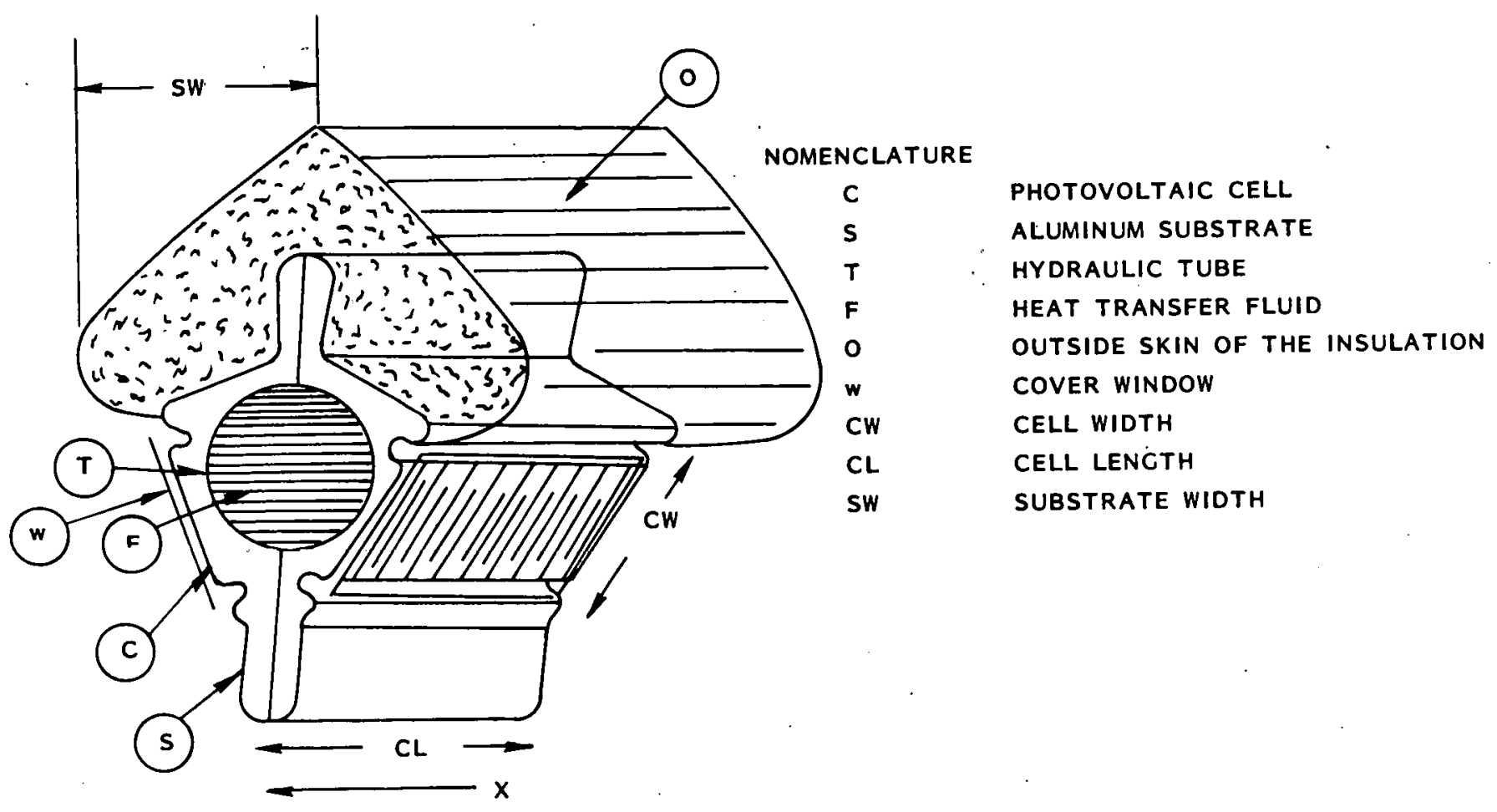

Figure 4-11. Thermal Energy Balance Model for Sea World Receiver

Heat transfer into the fluid (water) is determined by calculating the Reynold's number, and from its magnitude, determining the flow regime and appropriate Nusselt number at the bulk fluid temperature of the increment. Figure 4-12 shows the predicted temperatue thermal drops rise distribution at one station along the receiver as a function of solar insolation level for a flow of 160 GPM.

At a direct normal insolation of $1 \mathrm{~kW} / \mathrm{m}^{2}$, the plot predicts a cell-to-aluminum substrate temperature drop of $5^{\circ} \mathrm{F}$, an aluminum-to-copper tube temperature drop of about $10^{\circ} \mathrm{F}$, and a copper-to-fluid drop of about 6 to $8^{\circ} \mathrm{F}$ depending on flow rate. The comparison of predicted and actual results is discussed later in Section 5.

\subsubsection{System Analytical Models}

\section{2. 1.2.1 Domestic Hot Water System}

The thermal energy generated by the active cell cooling system was utilized in the system performance analysis studies to provide domestic hot water heating to a planned hotel and food complex at Sea World. Figure 4-13 shows the simplified schematic diagram of the system. To minimize pumping losses, the system is designed for low and high flow rates in both primary solar 


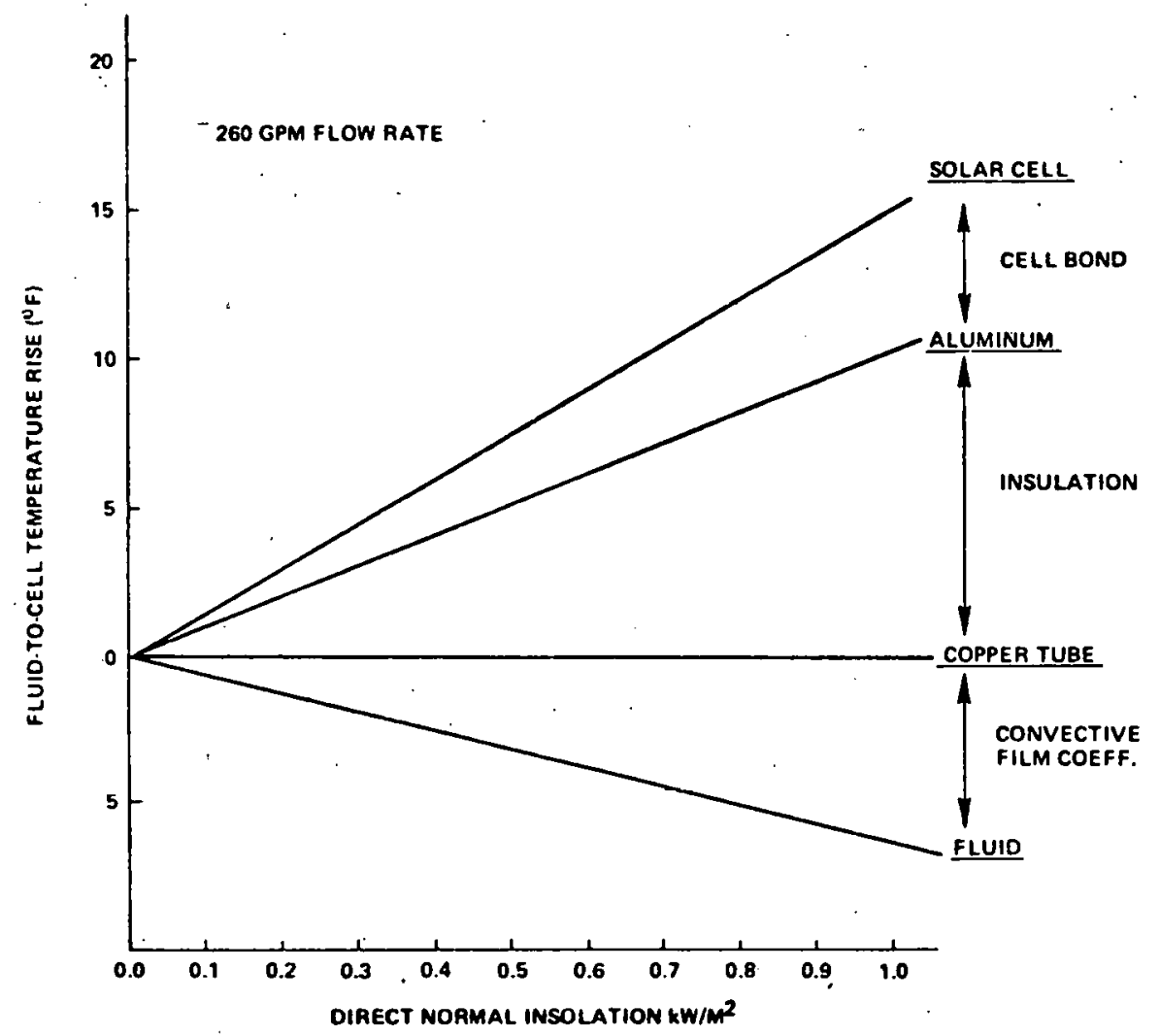

Figure 4-12. Fluid-Cell $\Delta \mathrm{T}$ Versus Solar Insolation Level

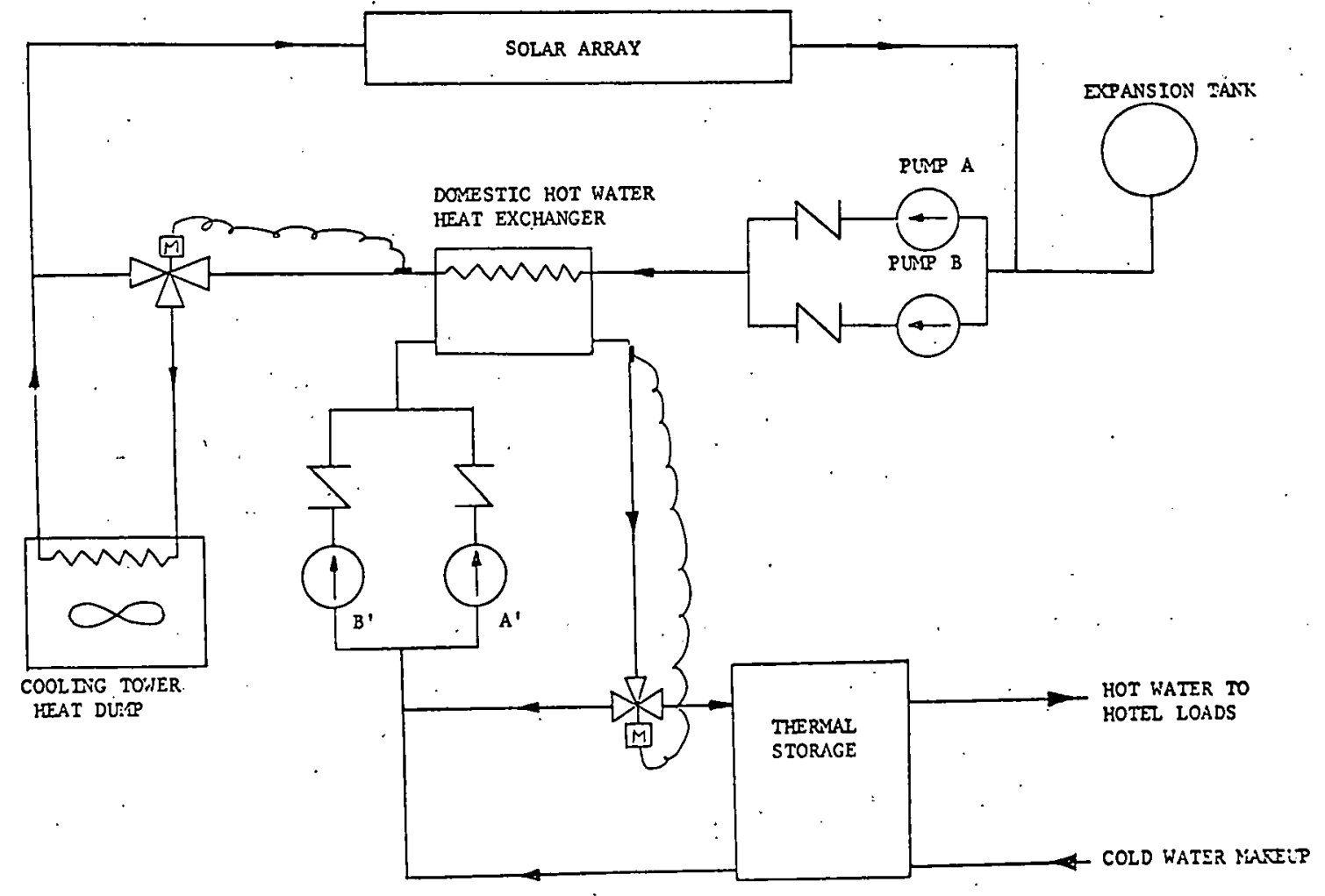

Figure 4-13. Domestic Hot Water System Schematic Diagram 
array loop and the secondary heat delivery loop. As illustrated on Figure 4-14, the low rate (160 gpm, 1 BHP pump power in the primary loop; $80 \mathrm{gpm}, 1 \mathrm{BHP}$ pump power in the secondary loop) is used until an array coolant temperature rise of $30^{\circ} \mathrm{F}$ is reached. When this occurs, the high rate $(340 \mathrm{gpm}, 5$ BHP pump power in the primary loop; $170 \mathrm{gpm}, 5 \mathrm{BHP}$ pump power is the secondary loop) is activated for a possible temperature rise up to $37^{\circ} \mathrm{F}$, corresponding to a direct normal insolation of $1 \mathrm{~kW} / \mathrm{m}^{2}$. The system reverts to the low rate when the solar array temperature rise drops to $10^{\circ} \mathrm{F}$.

To maintain the desired hot water temperature inlet to the thermal storage tank, a threeway modulating valve is utilized in the storage loop. As the heat exchanger outlet fluid temperature begins to decrease or increase due to a change in the collector fluid temperature, the valve will divert more or less return fluid to the heat exchanger, mixing with cold water makeup from the storage, to maintain the desired heat exchanger outlet temperature. The heat exchanger was modeled as a gasketed plate heat exchanger with an effectiveness of 0.79 at high fluid flow and 0.94 at low flow.

The collector fluid absolute temperature level is allowed to swing according to the solar insolation level and thermal energy demand on the system until a preset upper limit is reached. A three-way valve, sensing the fluid temperature above the limit at the heat exchanger outlet side, will direct the fluid to a cooling tower for heat dissipation. The cooling tower was sized with the capacity to cool $340 \mathrm{gpm}$ of water from $165^{\circ} \mathrm{F}$ to $130^{\circ} \mathrm{F}$ corresponding to peak solar insolation conditions.

The daily domestic hot water demand profile for the planned hotel and food complex is shown in Figure 4-15. The daily energy demand based on $75^{\circ} \mathrm{F}$ ground temperature and $140^{\circ} \mathrm{F}$ supply temperature is $4705 \mathrm{kWh}$ : Performance of this domestic hot water system was analyzed using hourly weather data for Miami. Results are discussed in Section 4.2.2.

\section{2.1.2.2 Absorption Chiller Cooling System}

Another option for thermal by-product utilization is to provide chilled water cooling by driving an absorption chiller at elevated temperature. Figure 4-16 shows a simplified schematic diagram of this concept. After energy pickup on the solar array, the fluid is introduced directly into the chiller generator, eliminating the need for a thermal storage tank. Thus, the operation of the chiller depends largely on the instantaneous solar insolation level.

Since the absorption chiller is designed for a single flow rate, only one collector fluid pump $(260 \mathrm{gpm}, 3 \mathrm{BHP})$ is utilized in the system. In order to reach a steady state condition, the generator of the chiller must absorb all of the solar array thermal energy; i. e., the temperature 


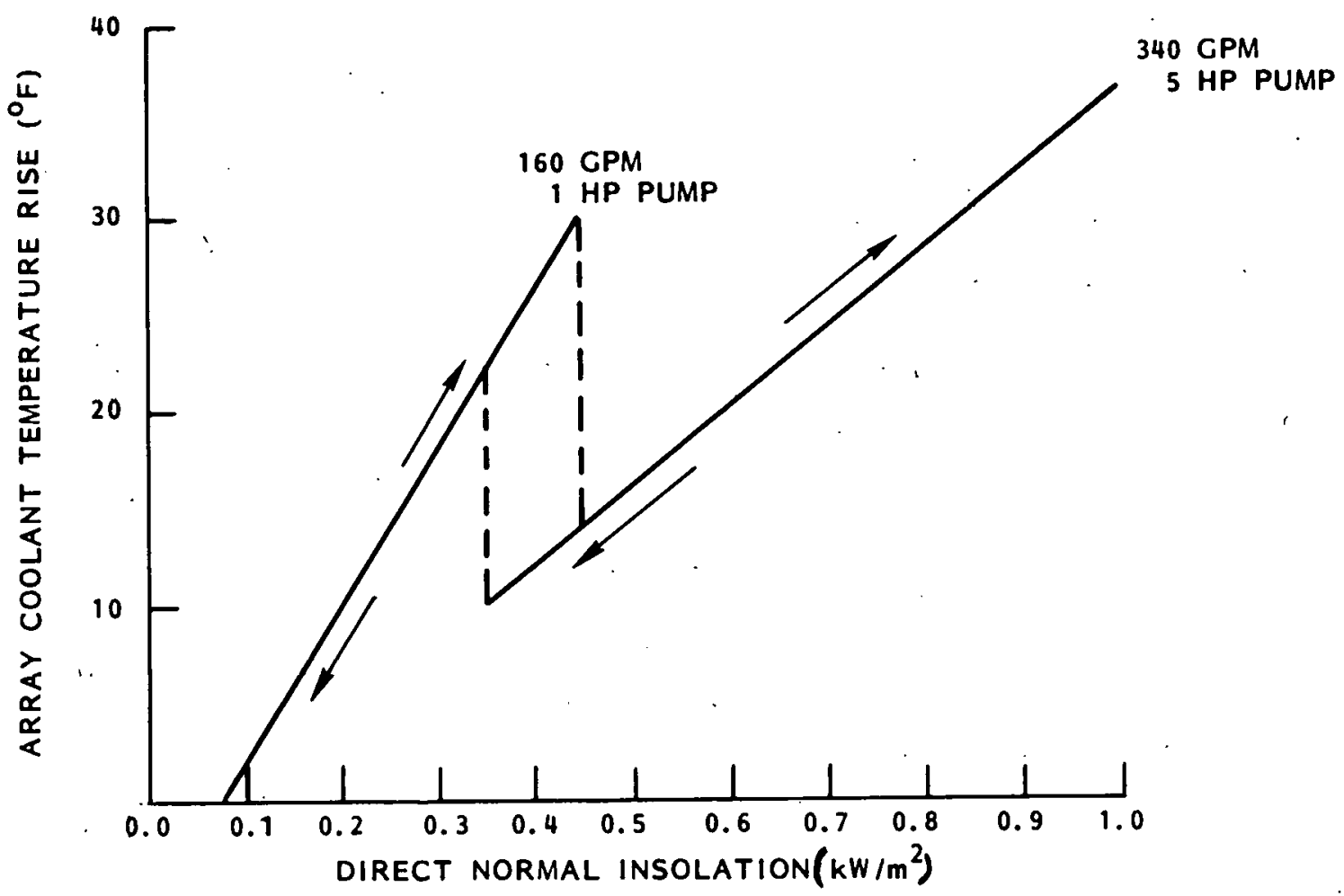

Figure 4-14. Two Pumps Control Scheme for Domestic Hot Water System GALI

HR $\quad k W$

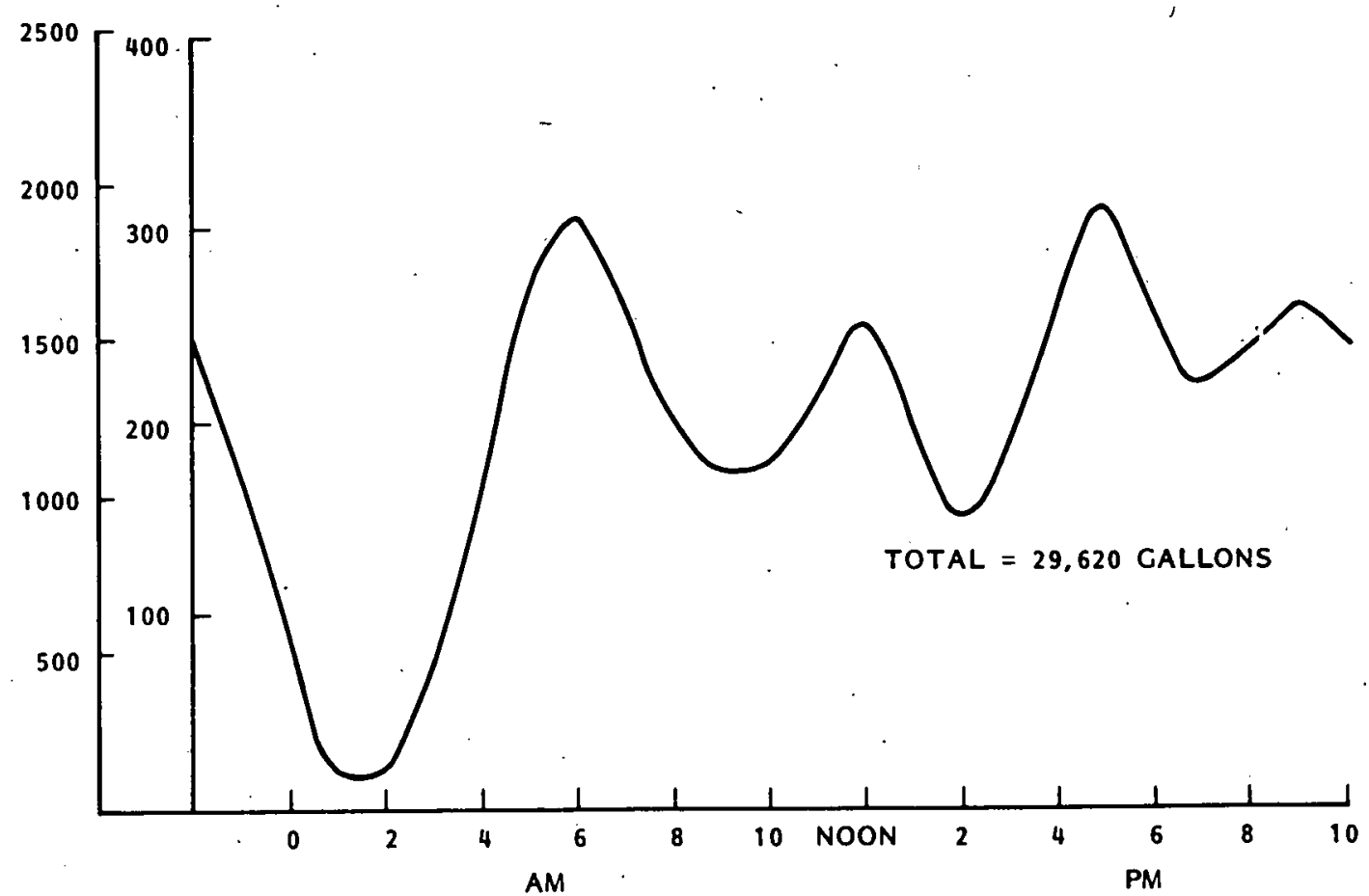

Figure 4-15. Daily Domestic Hot Water Demand Profile 


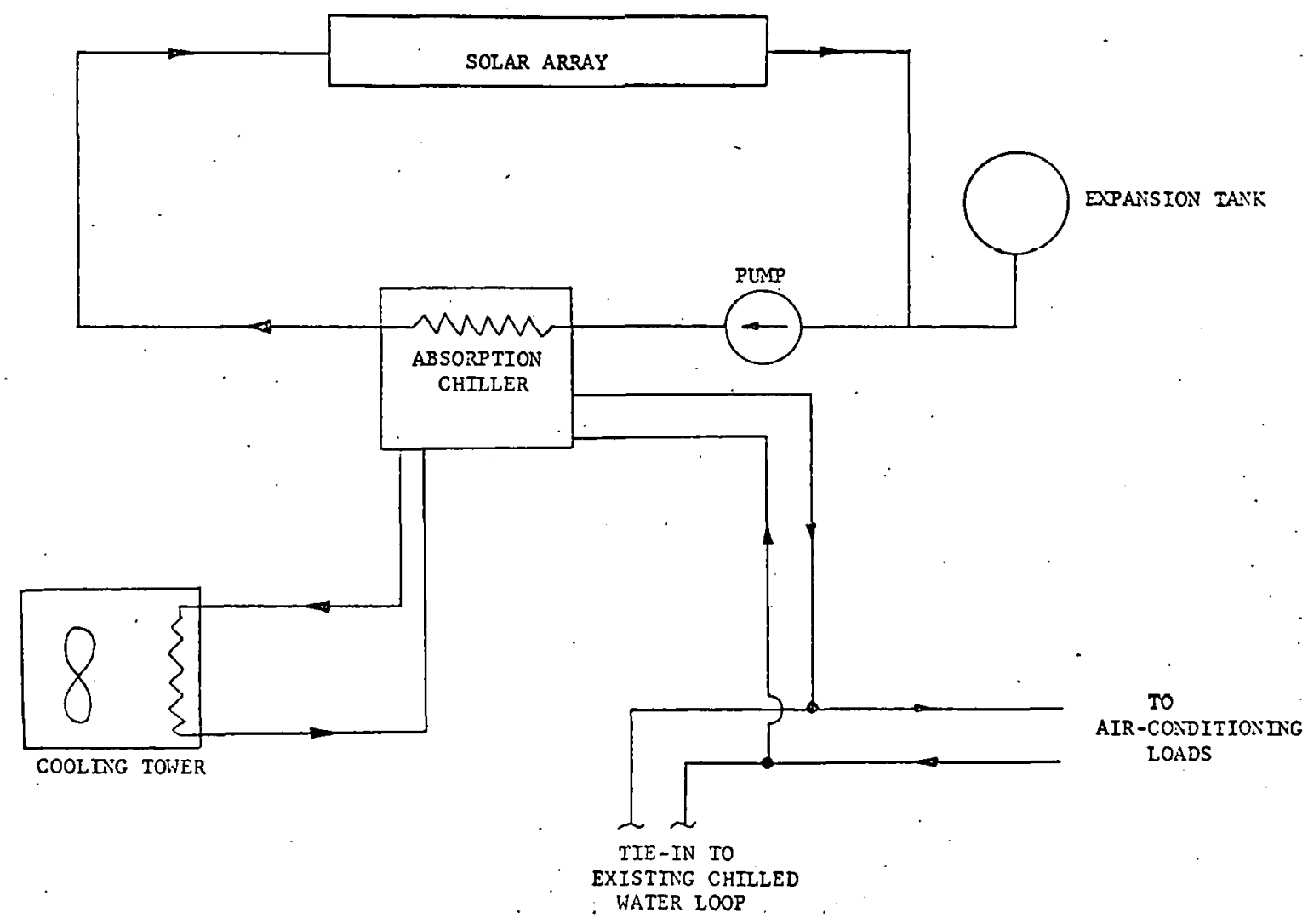

Figure 4-16. Absorption Chiller System Schmeatic Diagram

drop across the generator must equal the temperature rise across the collector field. Thus, the absolute fluid temperature is allowed to vary until equilibrium is reached. The absolute temperature level of the fluid will be determined by the specific design of the chiller chosen and solar insolation level.

To predict the overall performance of the system, a York ES7D2 absorption chiller was modeled in the simulation. The performance characteristics of the chiller are shown in Figures 4-17 and 4-18. The data was obtained from the manufacturer based on the following design parameters :

- Generator - 2 pass, $260 \mathrm{gpm}$, varying inlet temperature

- Evaporator - 2 pass, $1500 \mathrm{gpm}, 51^{\circ} \mathrm{F}$ water out

- Condenser - 2 pass, $1500 \mathrm{gpm}, 85^{\circ} \mathrm{F}$ water in

For a given instantaneous insolation level, the fluid temperature rise across the collector field can be determined from Figure 4-19 which is the result of a parametric analysis using the array thermal model as delineated in Section 4.2.1.1.3. Given the fluid temperature rise, the 


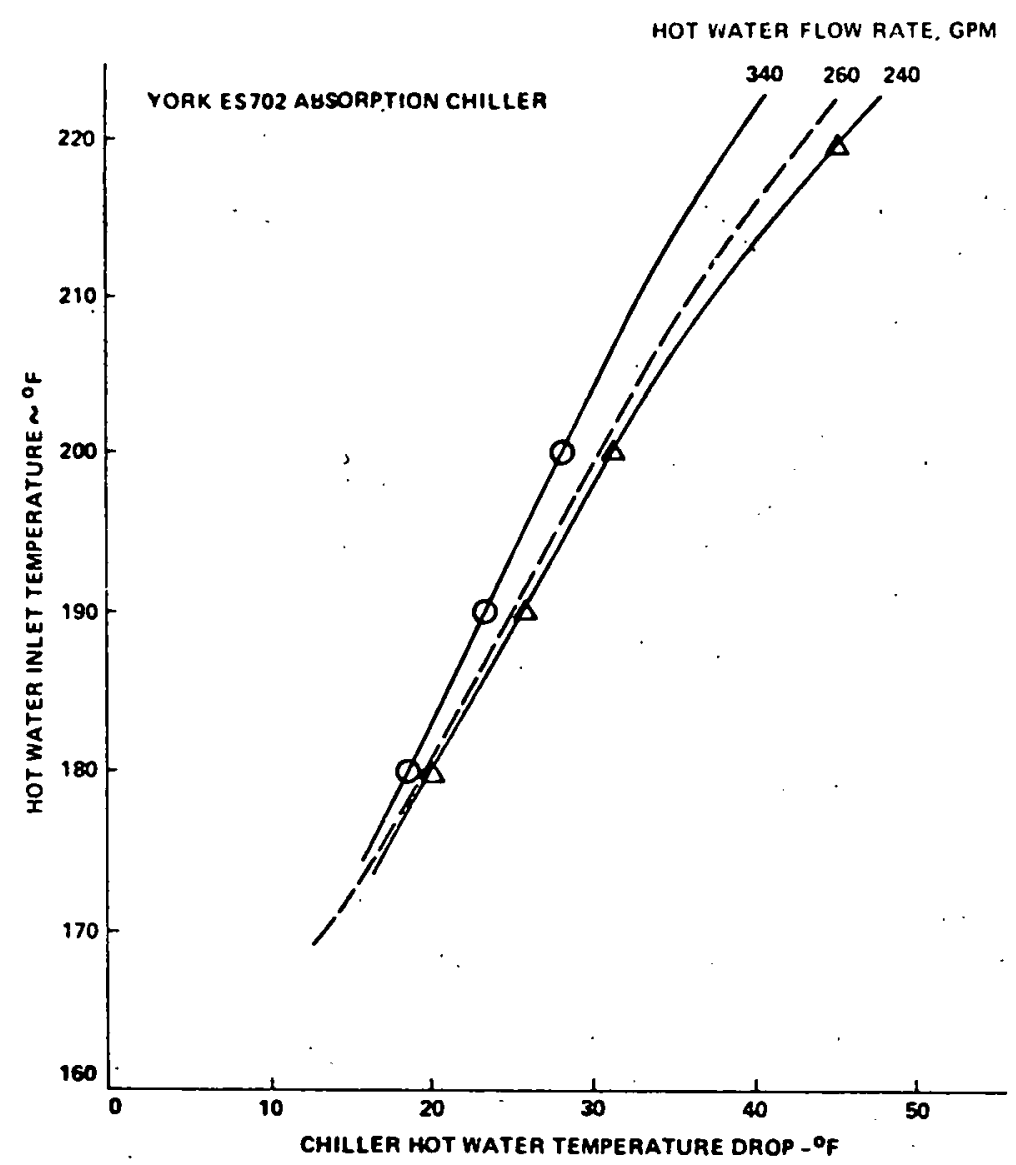

Figure 4-17. Chiller Generator Inlet and Outlet Temperature Correlation

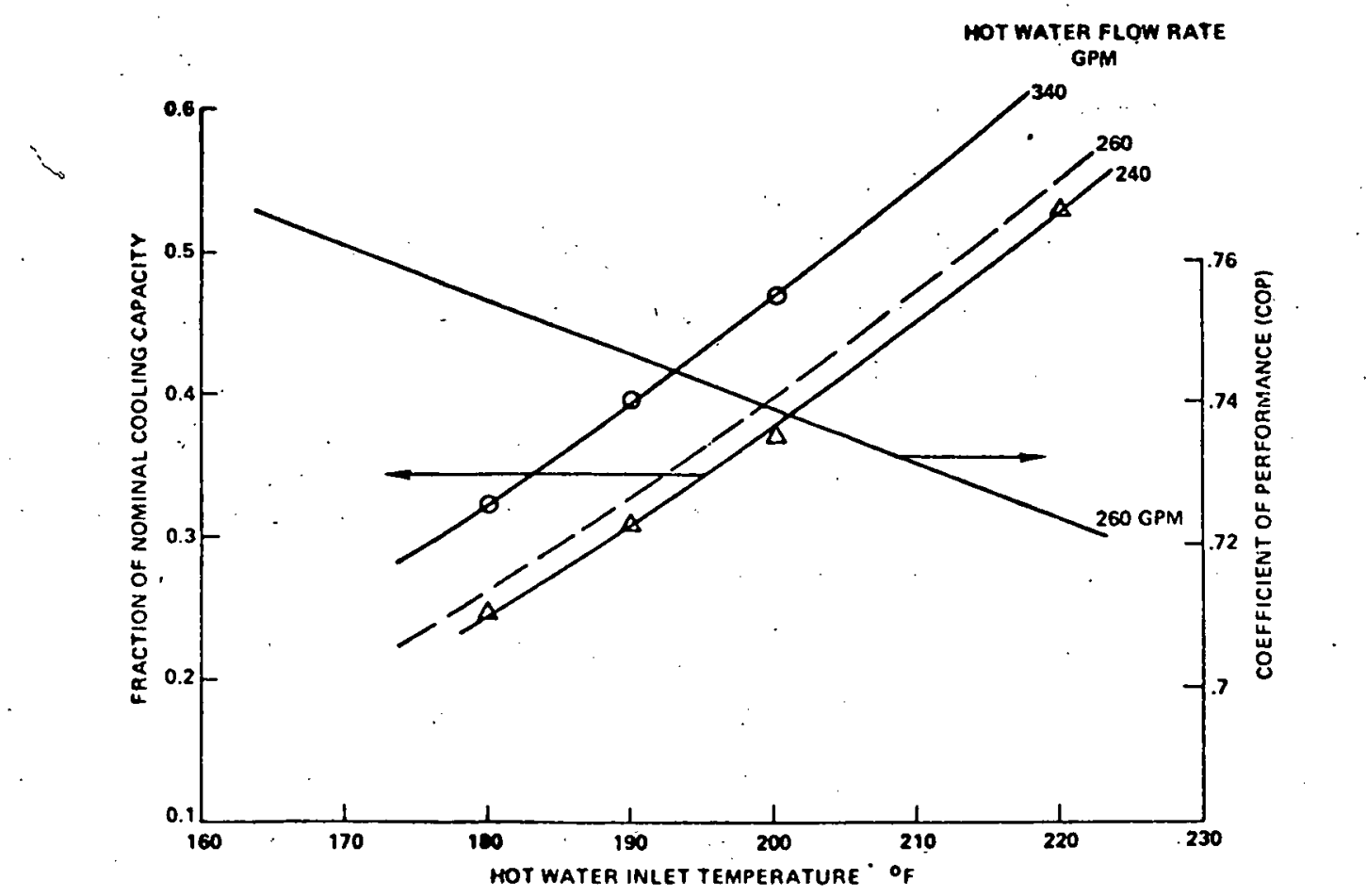

Figure 4-18. Cooling Capacity Versus Water Inlet Temperature for ES7D2 York Chiller 


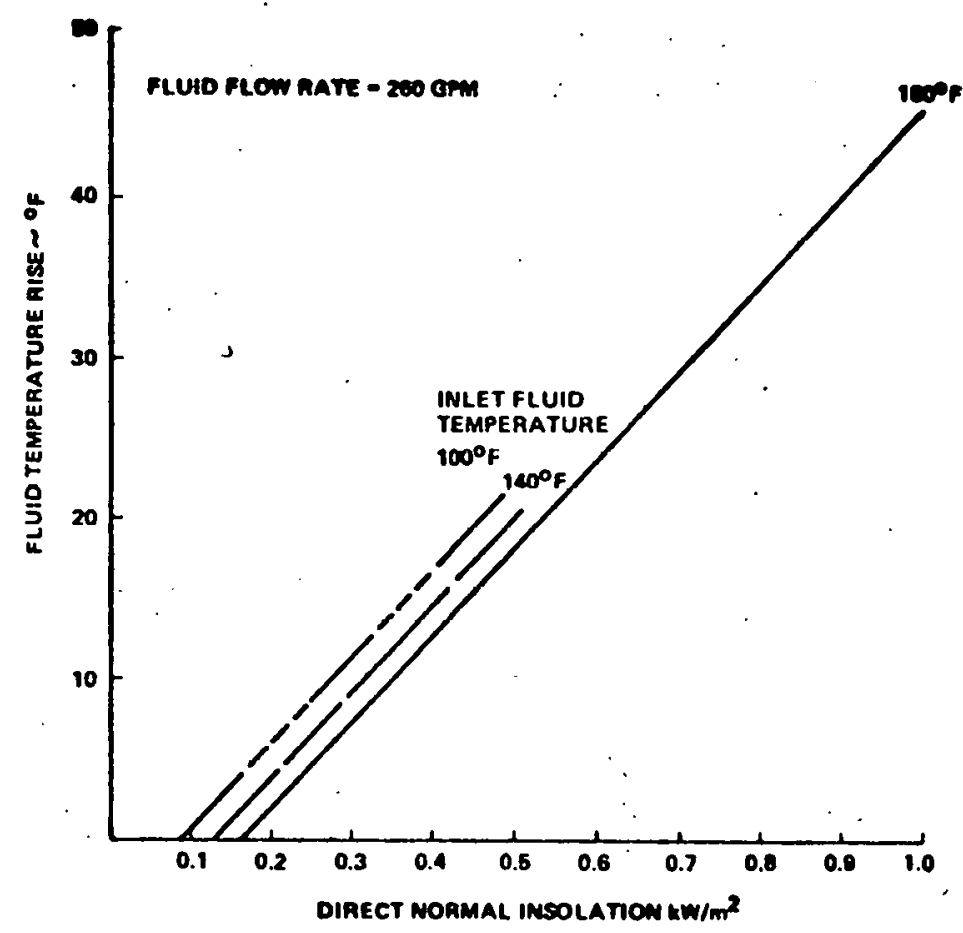

Figure 4-19. Collector Fluid Temperature Rise As Function of Solar Insolation

absorption chiller performance can be predicted from Figure 4-17 and 4-18 assuming steady state conditions. The transient period in the morning during collector loop fluid warmup is also taken into account in the performance model.

\subsection{SYSTEM PERFORMANCE RESULTS}

The electrical and thermal performance of the domestic water heating system and absorption chiller cooling system were analyzed using a SOLMET weather tape for Miami as the data most closely approximating conditions at Orlando, FL. The tape was obtained from the National Climatic Center with 1967 weather data chosen from the 23 available years as being the most representative. The monthly summary of direct normal insolation is listed in Table 4-1. Also shown in the table for comparison is the direct normal insolation from the recently obtained synthetic Typical Meteorological Year (TMY) tape. The TMY tape was prepared by Sandia based upon a selection of the most typical January, February, etc., available in the years of record for each of the 26 SOLMET sites. Typical months were selected by a weighting technique for insolation, temperature and wind speed. The table indicates that the 1967 SOLMET insolation values are lower by 3.3 percent compared with the TMY data. 
Table 4-1. Monthly Direct Normal Insolation for 1967 SOLMET and TMY Miami Location

\begin{tabular}{|l|r|r|}
\cline { 2 - 3 } \multicolumn{1}{c|}{} & \multicolumn{2}{c|}{ Direct Normal Insolation $\left(\mathrm{kWh} / \mathrm{m}^{2}\right)$} \\
\hline Month & 1967 SOLMET & T MY \\
\hline Jan. & 84.7 & 112.3 \\
Feb. & 114.1 & 122.1 \\
Mar. & 140.7 & 140.7 \\
Apr. & 139.2 & 150.6 \\
May & 155.3 & 113.6 \\
June & 89.4 & 95.7 \\
July & 111.8 & 106.2 \\
Aug. & 88.8 & 116.3 \\
Sept. & 95.8 & 93.8 \\
Oct. & 106.3 & 119.3 \\
Nov. & 114.5 & 129.2 \\
Dec. & 134.8 & 121.2 \\
\hline Annual Total & 1375.5 & 1421.1 \\
\hline
\end{tabular}

\subsubsection{Domestic Hot Water (DHW) System}

Using the domestic hot water load profile in Figure 4-15 as input, the overall sytem performance was evaluated parametrically for various domestic hot water supply temperatures and thermal storage sizes. Figure 4-20 shows the sensitivity of system performance to domestic hot water supply temperature. As the hot water temperature decreases, the gross electrical output increases due to lower fluid temperature, and consequently lower cell temperature and higher cell conversion efficiency. However, the gain in electrical output is more than offset by the increase in parasitic power required to dissipate the excess thermal energy. The cooling tower heat dump scheme has a two-speed fan with 20/6 BHP ratings. The auxiliary energy requirement also increases with decreasing water temperature as more auxiliary heat is needed to bring the water up to its useful temperature of $140^{\circ} \mathrm{F}$.

- Figure 4-21 shows the system performance tradeoff with varying thermal storage sizes for $140^{\circ} \mathrm{F}$ hot water supply temperature. As the storage volume increases, more useful thermal energy is available to meet the nighttime domestic hot water demand, while less excessive heat 


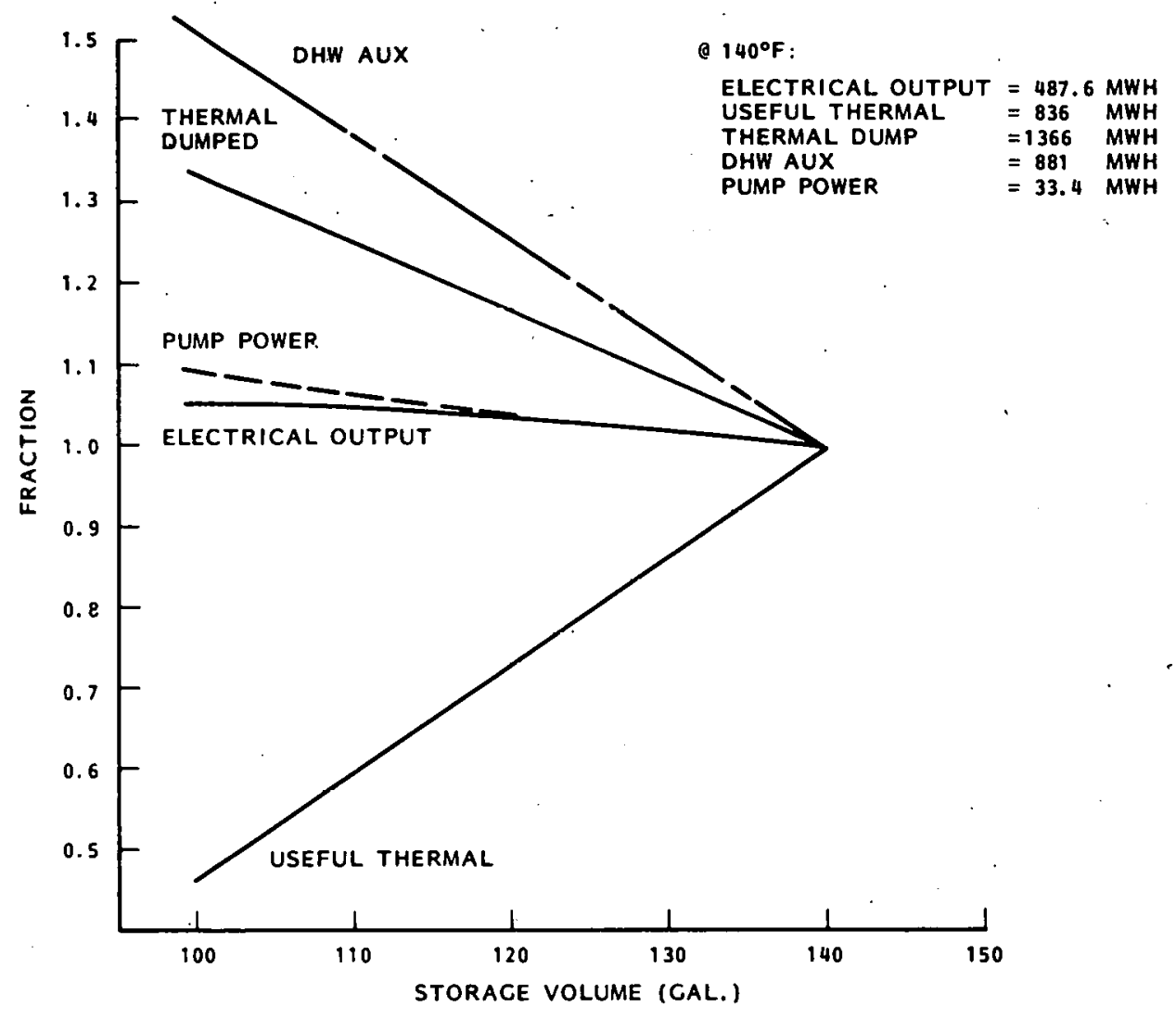

Figure 4-20. Sensitivity of System Performance to Domestic Hot Water Temperature

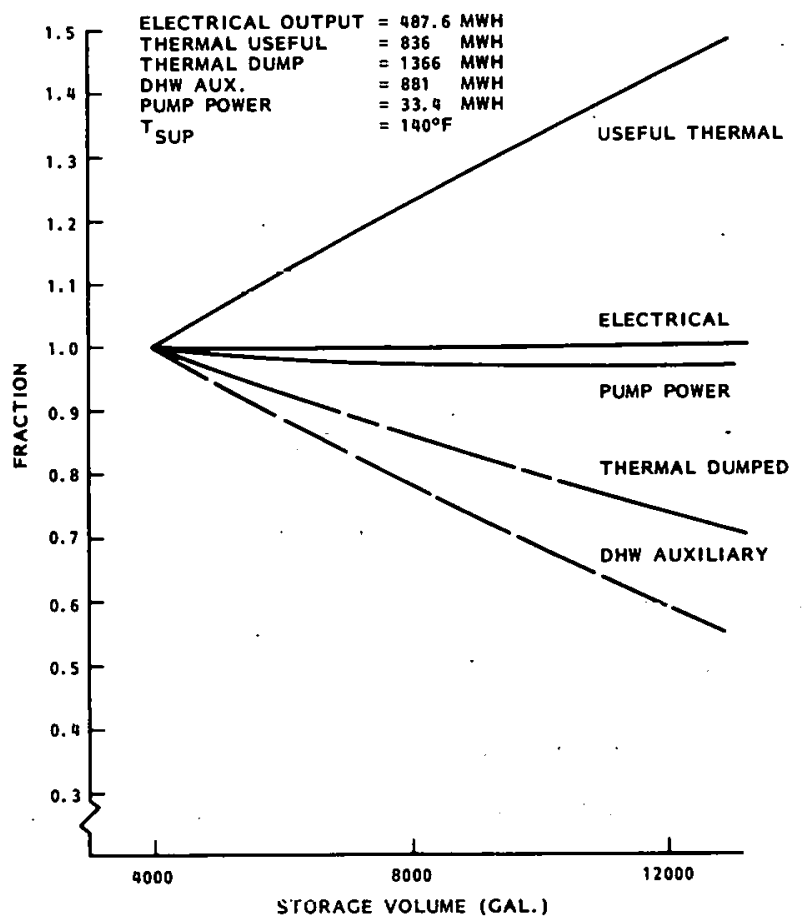

Figure 4-21. Sensitivity of System Performance to Storage Volume 
dump and the associated parasitic power are required. Figure 4-22 shows the monthly electrical and thermal output profiles for the $140^{\circ} \mathrm{F}$ DHW case.

The system output voltage and maximum power point characteristics are shown in Figures 4-23 and 4-24. For a range of hot water temperature between $100^{\circ} \mathrm{F}$ and $180^{\circ} \mathrm{F}, 99.5$ percent of the electrical energy generated are within \pm 15 percent of $360 \mathrm{VDC}$, thus establishing the operating requirement of the inverter. Figure 4-24 presents the maximum power output duration plot.

\subsubsection{Absorption Chiller Cooling System}

The actively cooled concentrating PV system utilizing a 617-ton York absorption chiller was analyzed to predict the overall electrical and thermal performance characteristics. Figure 4-25 shows the monthly energy output profiles for such a system. Over 90 percent of the thermal energy collected was utilized to supply cooling through the chiller with the remaining energy used in collector loop warmup each morning. For the relatively high chilled water operating temperature $\left(51^{\circ} \mathrm{F}\right)$ requirement at the Sea World complex, an average thermal COP of 0.817 was achieved. The gross electrical energy output at $460 \mathrm{MWH}$ is 6 percent less than the output from the $140^{\circ} \mathrm{F}$ domestic hot water system as the solar cells operate at higher temperatures most of the time. Figure 4-26 shows the duration plot for the maximum solar cell temperature which is the cell temperature at the end of a 120-foot receiver trough. The curve indicates that the majority of the cells will operate between $150^{\circ} \mathrm{F}$ and $220^{\circ} \mathrm{F}$ most of the time well within acceptable cell assembly operating temperatures.

The parasitic power required to operate the chiller system is considerably higher than the domestic hot water system. Table 4-2 shows the comparison in pump power requirements between the two systems.

Yearly system simulation indicates that total parasitic losses in the chiller system is $105 \mathrm{mWh}$ which equals approximately $24 \%$ of the gross electrical output, as compared to $33.4 \mathrm{mWh}$ for the hot water system. However, the decrease is net electrical output gain is offset by full utilization of the thermal by-product for cooling.

Figure 4-27 shows that the system operating voltage is between 330 and 425 VDC for $99.5 \%$ of the electrical power generated. Figure 4-28 presents the maximum power point output duration plot of the system.

\section{3 ECONOMIC ANALYSIS}

An economic comparison of the chiller and domestic hot water approaches analyzed in the previous section shows that, for their application at Sea World, the chiller approach yields a 


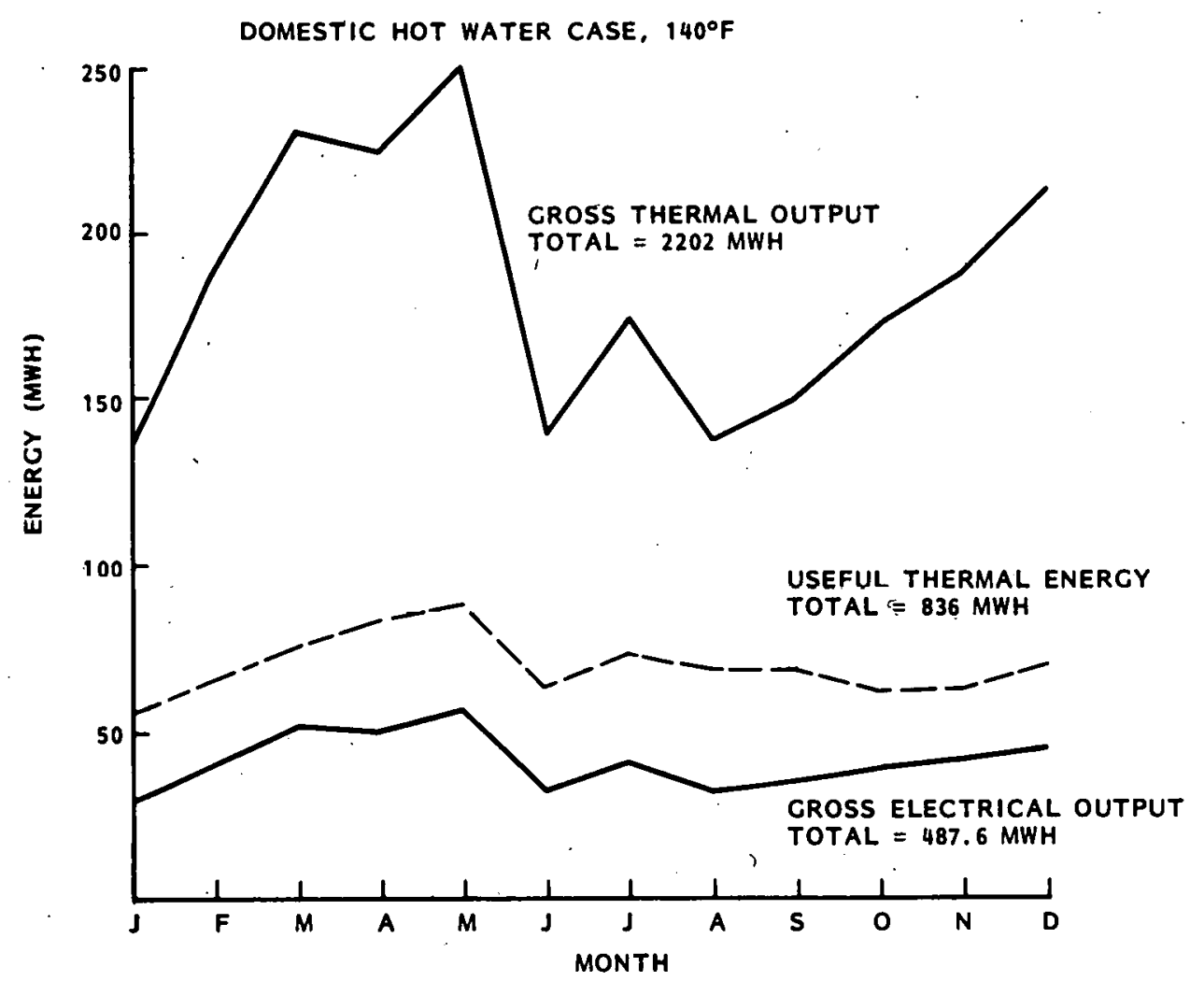

Figure 4-22. Monthly System Energy Output Profiles

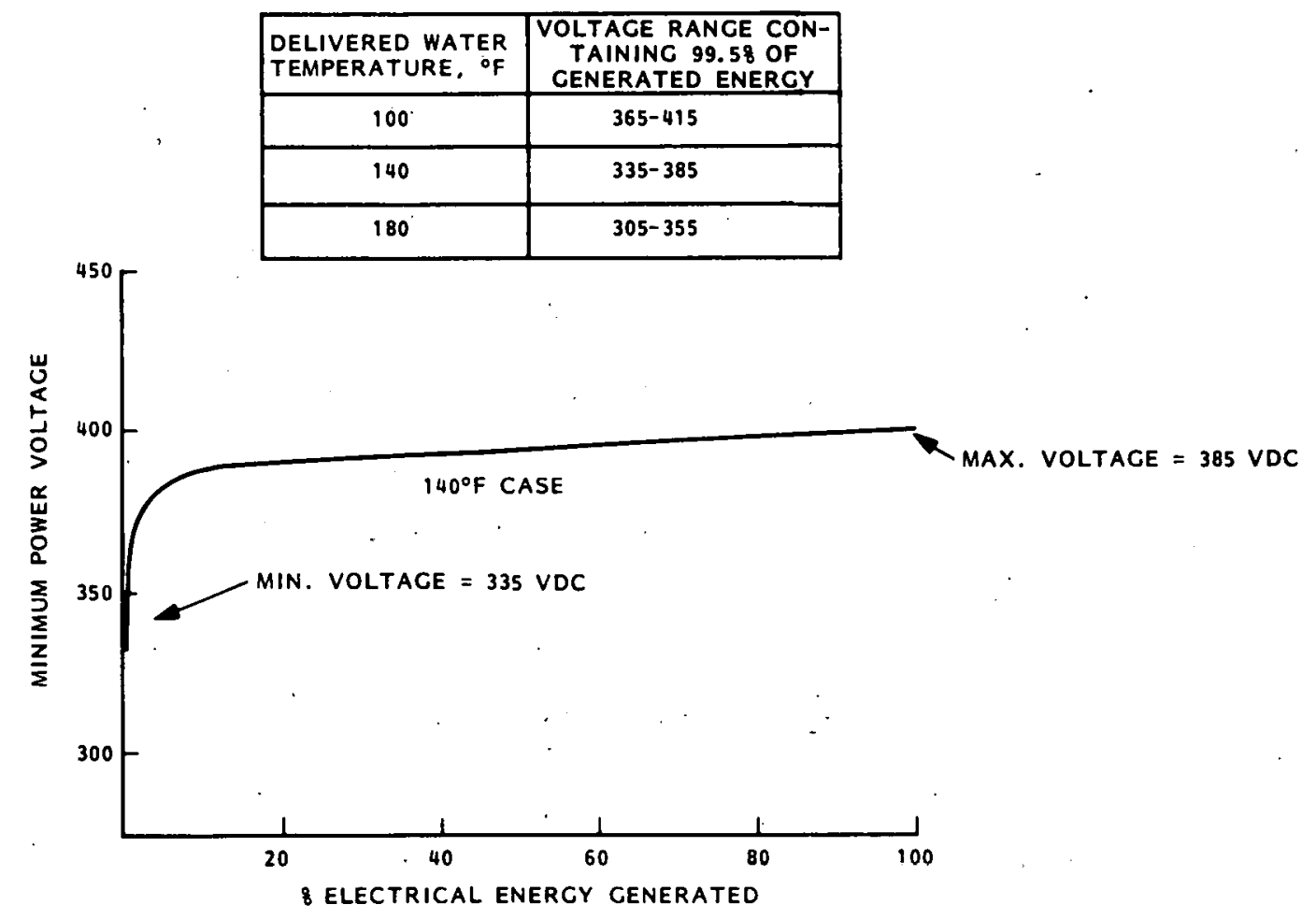

Figure 4-23. Maximum Power Output Voltage Operating Range 


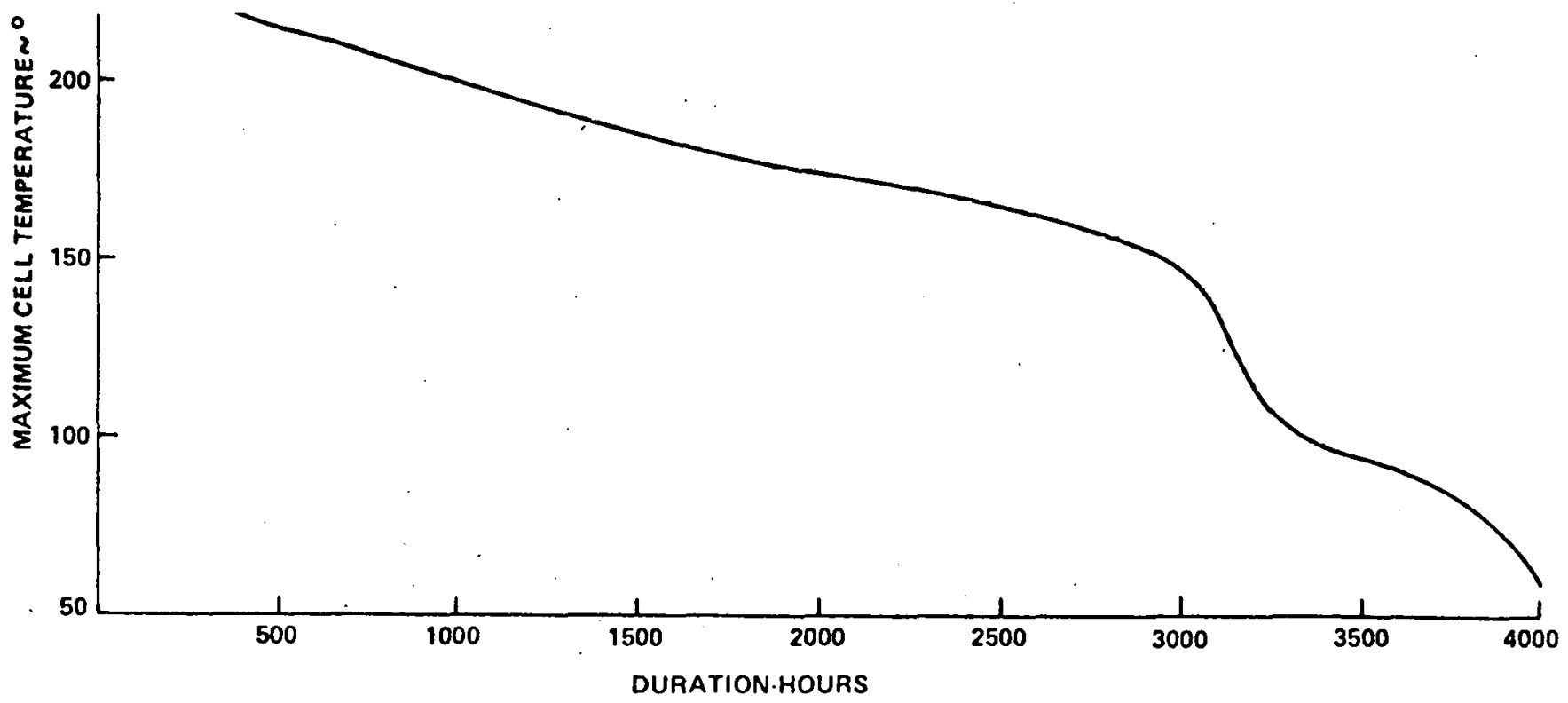

Figure 4-26. Solar Cell Temperature Duration Plot

Table 4-2. Parasitic Power Requirements Comparison

\begin{tabular}{|c|c|c|}
\hline \multicolumn{2}{|c|}{ Absorption System (BHP) } & Hot Water System (BHP) \\
\hline Collector Pump & 3 & 6 \\
\hline Storage Pump & - & 6 \\
\hline $\begin{array}{l}\text { Cooling Tower Fan } \\
\text { (2-Speed) }\end{array}$ & $20 / 6$ & $20 / 6$ \\
\hline Condenser Pumps & $20 / 20$ & - \\
\hline Absorption Unit Pumps & 6.83 & - \\
\hline
\end{tabular}

higher margin of benefits over costs. The principal factors contributing to this result are the greater utilization by the chiller of the solar array thermal energy, and the high expense of transporting the domestic hot water to its point of use at the planned hotel complex. 


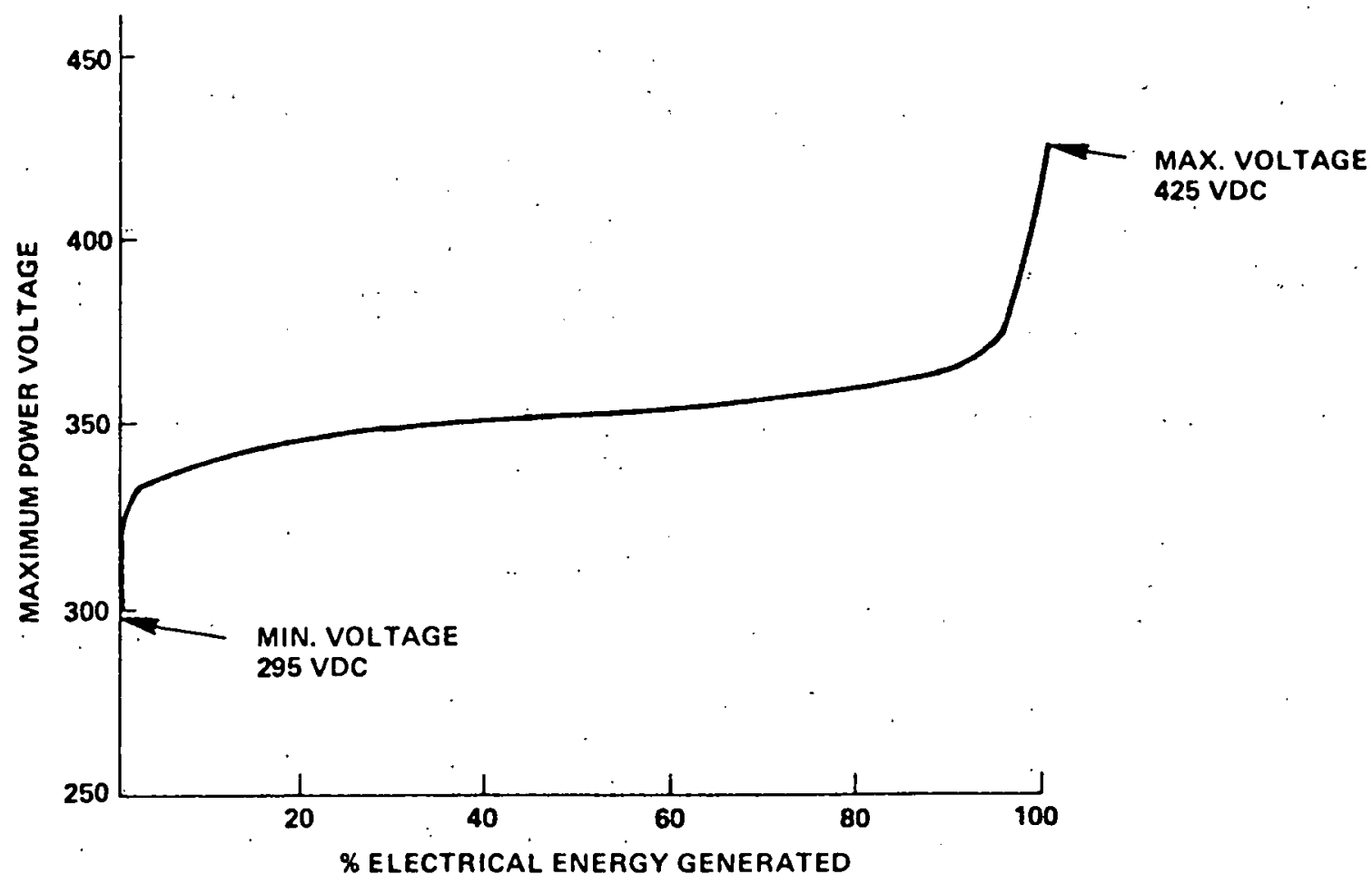

Figure 4-27. Maximum Power Output Voltage Operating Range

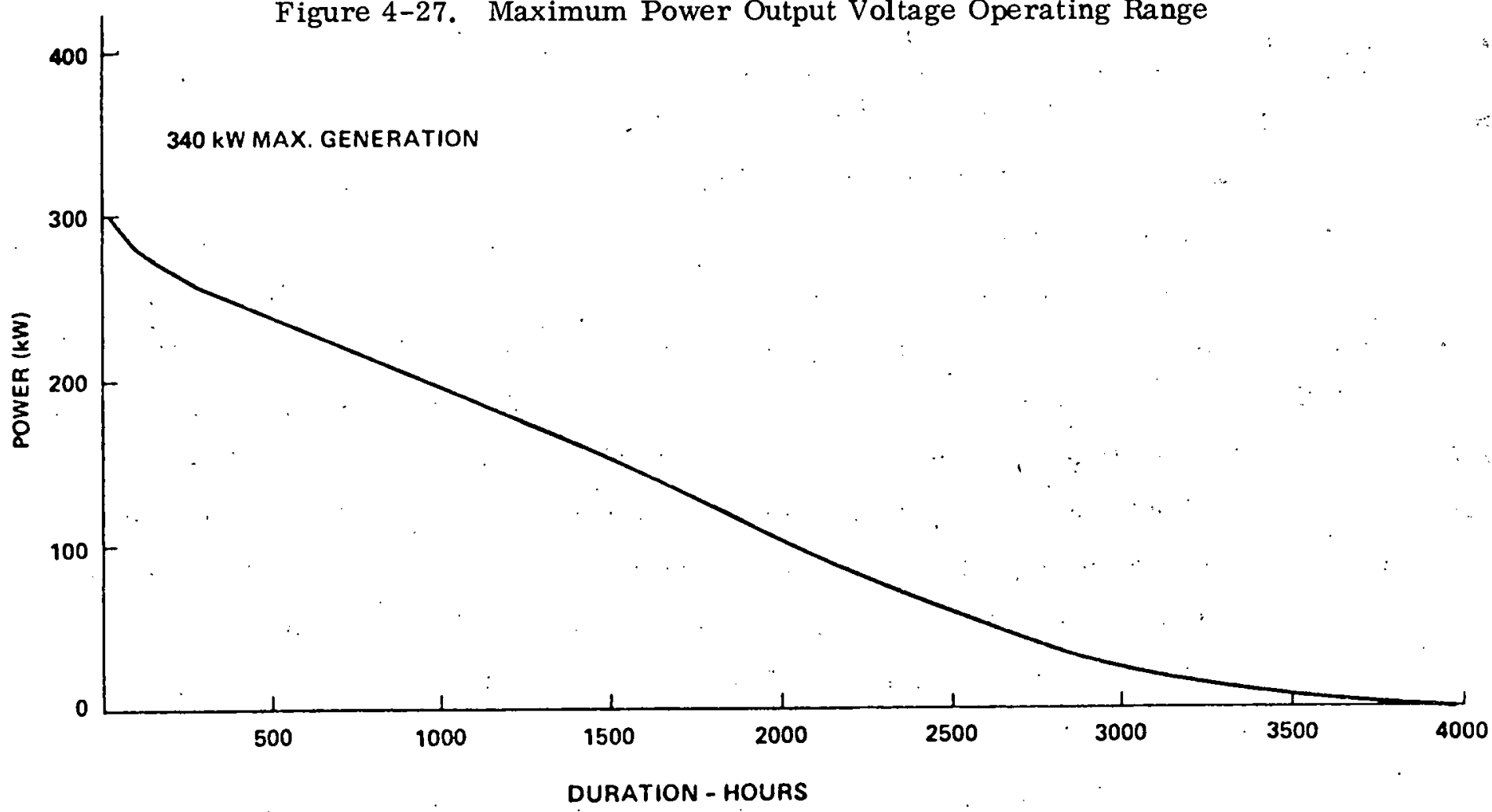

Figure 4-28. Electrical Power Output Duration 
The annual benefits for the chiller and domestic hot water approaches are summarized in Table 4-3.

Table 4-3. PV/Thermal Benefits

\begin{tabular}{|c|c|c|c|c|c|c|c|}
\hline \multirow{2}{*}{$\begin{array}{l}\text { System } \\
\text { Approach }\end{array}$} & \multirow{2}{*}{$\begin{array}{c}\text { Supply } \\
\text { Temperature } \\
\left({ }^{\circ} \text { F) }\right.\end{array}$} & \multirow{2}{*}{$\begin{array}{l}\text { Net PV } \\
\text { Output } \\
\text { (mWh) }\end{array}$} & \multirow{2}{*}{$\begin{array}{c}\text { Useful } \\
\text { Thermal } \\
\text { Output } \\
\text { (mWh) }\end{array}$} & \multirow{2}{*}{$\begin{array}{c}\text { Energy } \\
\text { Displaced } \\
\text { by } \\
\text { Thermal }\end{array}$} & \multicolumn{3}{|c|}{$\begin{array}{l}\text { Levelized Annual Benefits } \\
\text { Constant } 1975 \$^{\prime} \text { s }\end{array}$} \\
\hline & & & & & $\mathrm{PV}$ & Thermal* & Total \\
\hline Domestic & 100 & 465 & 386 & $\begin{array}{l}\text { Natural } \\
\text { Gas: } \\
22,000 \\
\text { Therms }\end{array}$ & $\$ 17,700$ & $\$ 3,600$ & $\$ 21,300$ \\
\hline Hot & 120 & 465 & 614 & $\begin{array}{l}35,000 \\
\text { Therms }\end{array}$ & 17,700 & $\cdots, 5,-800$ & 23,500 \\
\hline Water & 140 & 454 & 836 & $\begin{array}{l}47,600 \\
\text { Therms }\end{array}$ & 17,300 & 7,800 & 25,100 \\
\hline Absorp- & 160 & 355 & 1661 & $\begin{array}{l}\text { Electrici- } \\
\text { ty: } \\
290 \mathrm{mWh}\end{array}$ & $\$ 13,480$ & $\$ 19,300$ & $\$ 32,780$ \\
\hline tion & to & & & & & & \\
\hline Chiller & 200 & & & & & & \\
\hline
\end{tabular}

*Includes Allowance for $60 \%$ burner efficiency

The PV benefits are based on a monthly demand charge of $\$ 1.85 / \mathrm{kW}$ and an energy charge of $2.47 \mathrm{~d} / \mathrm{kWh}$ (both in 1975 \$'s) using data from the. Florida Power Corporation for large commercial users. The thermal benefits are based on a natural gas rate of $\$ .107 /$ therm $(1975 \$$ 's) using data from the Florida Gas Company, also for large commercial users. The levelized annual benefits shown in Table 4-3 are calculated in constant $\$ 1975$ using the method described in Appendix $B$ and the factors listed in Table 4-4. The resulting levelizing factor is 1. 53757.

The benefits for the chiller approach are similarly obtained except that they are expressed in terms of the electricity required to operate a.vapor compression chiller which produces an equivalent amount of cooling. The absorption chiller produces an annual cooling of $1357 \mathrm{mWh}$ with a $244 \mathrm{~kW}$ power capacity requirement. Therefore, the levelized annual energy savings of the vapor compressor is obtained as follows using the electric rates cited earlier:

$\begin{aligned} & \text { Levelized Annual Savings } \\ & \text { Due to Thermal Output }\end{aligned}=[12 \times 1.85 \times 244+.0247 \times 290,000] \times 1.537=\$ 19,300$ 
Table 4-4. Economic Analysis Factors

\begin{tabular}{ll}
\hline System Operating Lifetime, N & 20 years \\
Annual "other taxes" as a fraction of & 0.02 \\
Capital Investment, $\beta_{1}$ & \\
Annual Insurance Premiums as a & 0.0025 \\
Fraction of Capital Investment, $\beta_{2}$ & 0.50 \\
Effective Income Tax Rate, $T$ & 0.50 \\
Ratio of Debt to Total Capitalization, D & 0.40 \\
Ratio of Common Stock to Total Capitalization, C & 0.10 \\
Ratio of Preferred Stock to Total Capitalization, $P$ & 0.10 \\
Annual Rate of Return on Debt, $r_{D}$ & 0.12 \\
Annual Rate of Return on Common Stock, $r_{C}$ & 0.10 \\
Annual Rate of Return on Preferred Stock, $r_{P}$ & 0.07 \\
Rate of General Inflation, $g$ & 0.07 \\
Escalation Rate for Capital Costs & 0.07 \\
Escalation Rate for Operating Costs & 0.07 \\
Escalation Rate for Maintenance Costs & 0.10 \\
Escalation Rate for Electricity/Fuel Costs; f & 1975 \\
Base Year for Constant Dollars & 1980 \\
First Year of Commercial Operation &
\end{tabular}

The annual useful energy output of the PV system is reduced to $355 \mathrm{mWh}$ due to the larger auxiliary power required to operate the absorption chiller. The levelized annual savings for the PV output is then:

$$
\begin{array}{ll}
\begin{array}{l}
\text { Levelized Annual Savings } \\
\text { Due to PV Output }
\end{array} & .0247 \times 355,000 \times 1.53757 \\
& =\$ 13,480
\end{array}
$$

The total levelized annual benefits (LAB) for this system then become:

$$
\begin{aligned}
\mathrm{LAB} & =\$ 19,300+13,480 \\
& =\$ 32,780
\end{aligned}
$$

in constant 1975 dollars. 
The economic tradeoff between the hot water and absorption chiller approaches can be determined by comparing the difference of their levelized annual benefits (LAB) and levelized annual costs (LAC). The preferred system will have the larger positive difference between benefits and costs. The comparison can be expressed as follows:

$$
\text { Comparison }=\left(\mathrm{LAB}_{1}-\mathrm{LAC}_{1}\right)-\left(\mathrm{LAB}_{2}-\mathrm{LAC}_{2}\right)
$$

where the subscripts 1 and 2 refer to the chiller and hot water approaches, respectively. If the comparison is positive, then system 1 is preferred and vice versa. This equation can be rearranged as follows:

$$
\text { Comparison }=\left(\mathrm{LAB}_{1}-\mathrm{LAB}_{2}\right)-\left(\mathrm{LAC}_{1}-\mathrm{LAC}_{2}\right)
$$

This form is convenient since only differences in equipment costs and benefits need be considered rather than treating total costs and benefits.

The levelized annual cost in constant base year dollars is obtained from the methods described in Reference 1. Using the economic factors listed in Table 4-4, a levelizing factor of 09829 is obtained which is the multiplier against the capital investment which yields the levelized annual cost. Based on recent estimates, the capital costs (including shipping and installation) of the components in the hot water approach are listed below (in 1975 dollars):

$\begin{array}{lc}\text { Heat Exchanger } & \$ 4,500 \\ \text { Cooling Tower } & 18,470 \\ \begin{array}{l}\text { Piping from HX to } \\ \text { point of use }\end{array} & 40,000(2500 \text { feet at } \$ 16 / \mathrm{ft}) \\ \text { Total } & \$ 62,970\end{array}$

Therefore,

$$
\mathrm{LAC}=.09829 \times 62,970=\$ 6190
$$

The estimated capital costs for the chiller approach are listed below (in 197j dollars):

$\begin{array}{lr}\text { Heat Exchanger } & \$ 4,500 \\ \text { Absorption Chiller } & 62,240 \\ \text { Cooling Tower } & 26,390 \\ & \$ 93,130\end{array}$

Therefore,

$$
\mathrm{LAC}=.09829 \times \$ 93,130=\$ 9,150
$$


The levelized benefits and costs for the two systems are summarized in Table 4-5.

Table 4-5. LAB and LAC for Two Systems

\begin{tabular}{|c|c|c|}
\cline { 2 - 3 } \multicolumn{1}{c|}{} & Chiller System & $\begin{array}{c}\text { Domestic Hot Water } \\
\text { System }\left(140^{\circ} \text { F Case }\right)\end{array}$ \\
\hline LAB & $\$ 32,780$ & $\$ 25,100$ \\
LAC & $\$ 9,150$ & $\$ 6,190$ \\
\hline
\end{tabular}

Applying these values to Equation (1) gives:

$$
\text { Comparison }=(32,780-25,100)-(9150-6190)=+\$ 4720
$$

By the sign convention of Equation 1, this shows the chiller system to be the more attractive approach. 
SECTION 5

\section{HARDWARE DEVELOPMENT AND TEST}

\subsection{INTRODUCTION}

Several hardware development projects were carried out under the Phase I effort:

- Specification, procurement, and test of concentrator solar cells

- Solar cell receiver fabrication

- Receiver thermal impedance tests

- Reflective surface evaluation

- 30-Foot prototype collector

- 5-Foot collector segment fabrication and performance test

The significant results of these projects are described below.

\subsection{SOLAR CELLS}

A group of 100 concentrator-type silicon solar cells were purchased from Optical Coating Lab, Inc. , (OCLI) to be used in the fabrication of a prototype solar cell receiver. The cells were procured in accordance with General Electric Specification 295A8176. As shown on Figure $5-1$, the cells are approximately $3.5 \times 4 \mathrm{~cm}$ in size. Deducting for the two conducting side bars $\left(0.25 \mathrm{~cm}\right.$ each), the active cell width is $3 \mathrm{~cm}$ providing an active area of $12 \mathrm{~cm}^{2}$. A sampling of 11 of the 100 cells were tested under GE's flash illuminator at 1-sun using a JPL-supplied secondary solar cell standard. With a Swedlow Fresnel lens, the 10-cells were also tested at approximately 13.6 suns using the ratio of short-circuit currents as the basis for determining the concentration ratio. Limitations of the flash illuminator measurement circuitry prevented tests at higher concentrations. Table 5-1 summarizes the test data. Figure 5-2 shows the typical 1-sun and 13. 6 sun I-V plots obtained for Cell No. 008. An independent evaluation of cell performance was also obtained in tests conducted by Dr. C.E. Backus of Arizona State University.

The tests covered a wide range of concentration and temperature and are continuing at this writing. Several of the original 100 cells were furnished to Dr. Backus for this purpose. One cell (No. 17) was tested using sunlight which was concentrated by a $1.08 \mathrm{~m}$ diameter fresnel lens. The incident energy was determined by assuming a linear relation between short circuit current and incident energy. The relation was determined by measuring the short circuit current under direct normal sunlight, using a collimating tube, and comparing it to the incident energy flux as measured by an Eppley NIP pyrheliometer. The temperature of the cell was measured using two different thermocouples which were placed through holes in the copper substrate and touched the back of the cell. 


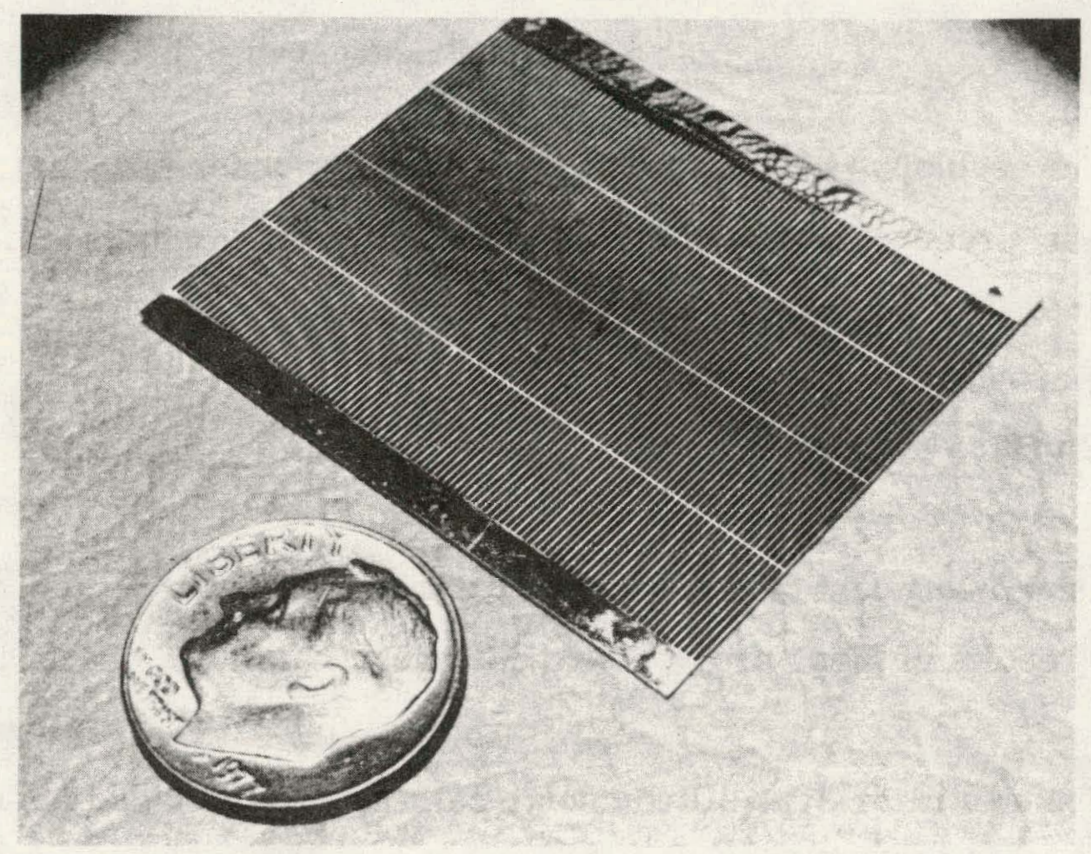

Figure 5-1. $3.5 \times 4 \mathrm{~cm}$ Concentrator-type Silicon Solar Cell

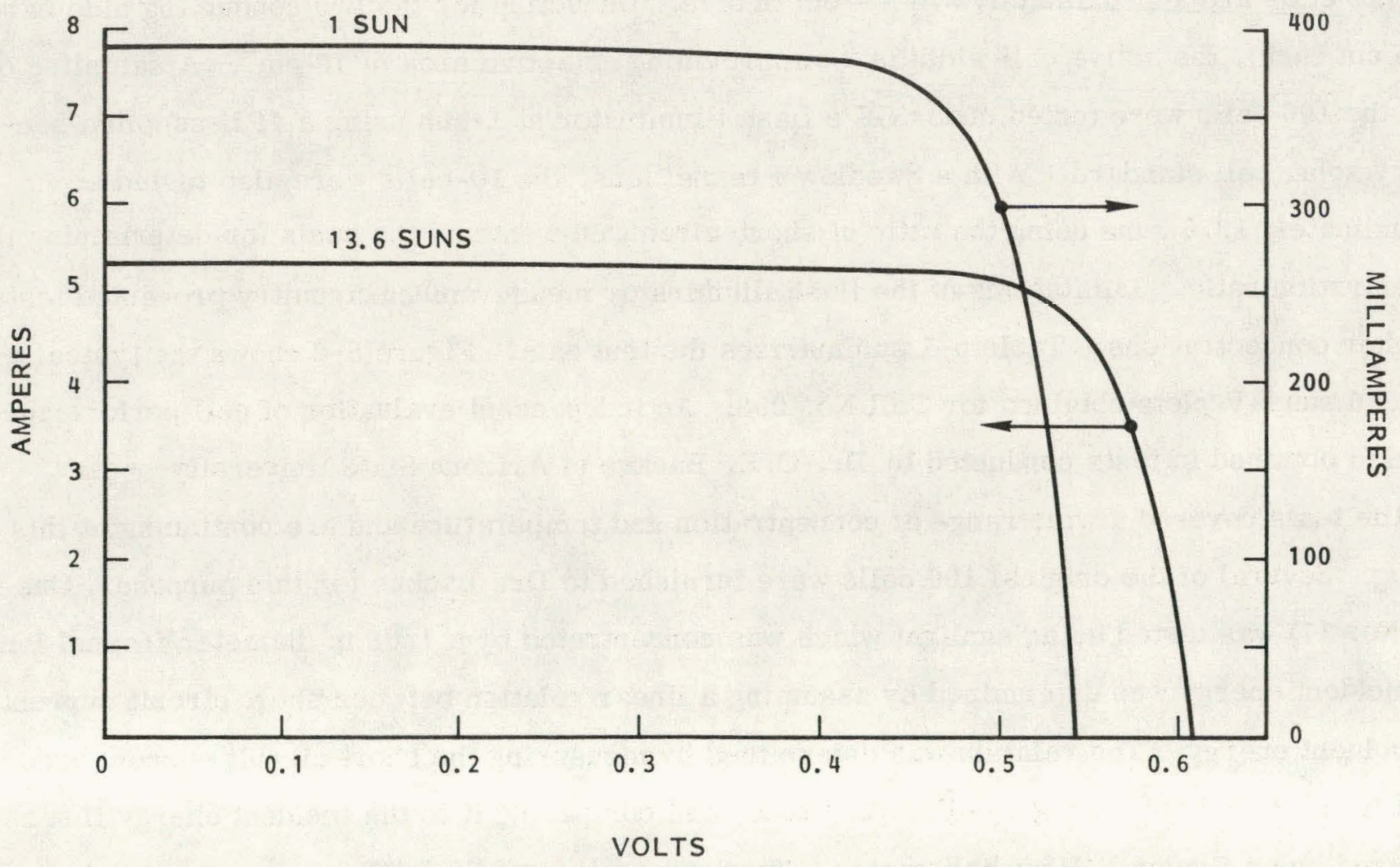

Figure 5-2. I-V Plots at 1 \& 13.6 Suns for Cell No. 008 
Table 5-1. Concentrator Cell Test Data

(Cell Temperature: $28^{\circ} \mathrm{C}$ )

\begin{tabular}{|c|c|c|c|c|c|c|c|c|c|c|c|}
\hline \multirow[b]{2}{*}{$\begin{array}{l}\text { Cell } \\
\text { Serial } \\
\text { No. }\end{array}$} & \multicolumn{5}{|c|}{$\begin{array}{c}\text { GE } \\
1 \text { Sun }\end{array}$} & \multicolumn{6}{|c|}{$\begin{array}{c}\mathrm{GE} \\
\text { Concentration }\end{array}$} \\
\hline & $\begin{array}{c}\mathrm{I}_{\mathrm{Sc}} \\
(\mathrm{MA})\end{array}$ & $\begin{array}{c}\mathrm{V}_{\text {oc }} \\
\text { (Volts) }\end{array}$ & $\frac{\mathrm{V}_{\mathrm{mp}}}{\text { (Volts) }}$ & $\begin{array}{l}P_{\max } \\
(\mathrm{MW})\end{array}$ & $\begin{array}{c}\text { Efficiency } \\
\text { at } 1 \\
\text { sun }(\%)\end{array}$ & $\begin{array}{c}\mathrm{I}_{\mathrm{Sc}} \\
(\mathrm{Amp})\end{array}$ & $\begin{array}{c}\mathrm{V}_{\text {oc }} \\
\text { (Volts) }\end{array}$ & $\mathrm{V}_{\mathrm{mp}}$ & $\begin{array}{l}F_{\text {max }} \\
\text { (Watts) }\end{array}$ & $\mathrm{CR}$ & $\begin{array}{l}\text { Efficiency } \\
\text { at CR (\%) }\end{array}$ \\
\hline 032 & 396 & 0.540 . & 0.46 & 167 & 13.9 & 5.35 & 0.605 & 0.51 & 2.55 & 13.5 & 15.7 \\
\hline 042 & 400 & 0.539 & 0.46 & 165 & 13.8 & 5.40 & 0.604 & 0.50 & 2.55 & 13.5 & 15.7 \\
\hline 044 & 401 & 0.552 & 0.46 & 174 & 14.5 & 5.73 & 0.618 & 0.53 & 2.86 & 14.3 & 16.7 \\
\hline 086 & 385 & 0.548 & 0.47 & 165 & 13.8 & 5.20 & 0.612 & 0.51 & 2.56 & 13.5 & 15.8 \\
\hline 008 & 390 & 0.550 & 0.46 & 169 & 14.1 & 5.32 & 0.614 & 0.53 & 2.64 & 13.6 & 16.2 \\
\hline 083 & 394 & 0.550 & 0.47 & 169 & $14: 1$ & 5.35 & 0.615 & 0.52 & 2.65 & 13.6 & 16.2 \\
\hline 005 & 396 & 0.547 & 0.46 & 170 & 14.2 & 5.37 & 0.610 & 0.52 & 2.65 & 13.6 & 16.2 \\
\hline 018 & 393 & 0.550 & 0.47 & 169 & 14.1 & 5.37 & 0.613 & 0.53 & 2.68 & 13.6 & 16.4 \\
\hline 012 & 400 & 0.537 & 0.46 & 167 & 13.9 & 5.38 & 0.601 & 0.50 & 2.55 & 13.5 & 15.7 \\
\hline 098 & 384 & 0.540 & 0.45 . & 161 & 13.4 & 5.31 & 0.603 & 0.51 & 2.55 & 13.8 & 15.4 \\
\hline 017 & 385 & 0.536 & 0.45 & 158 & 13.2 & 5.20 & 0.600 & 0.51 & 2.45 & 13.5 & 15.1 \\
\hline
\end{tabular}


Tests were conducted for a range of concentrations from 1 to 75 suns and for cell temperatures of $28^{\circ} \mathrm{C}, 40^{\circ} \mathrm{C}$, and $60^{\circ} \mathrm{C}$. Figure 5-3 shows a typical result of efficiency versus concentration for a $28^{\circ} \mathrm{C}$ cell temperature. The test results produced with GE's flash illuminator for Cell No. 17 are included on the plot indicating excellent correlation with the results obtained by Dr. Backus.

A review of the data on Table 5-1 indicates that Cell No. 17 has an efficiency significantly lower than the average for the cells tested (15.1\% versus $15.9 \%)$. For this reason, the test data obtained for Cell No. 17 was upgraded by the ratio $15.9 \div 15.1$ to make it more indicative of average cell performance. The summary plots shown on Figure 5-4, 5-5, and 5-6 include this adjustment. The $28^{\circ} \mathrm{C}$ plot on Figure 5-4 indicates a peak efficiency of 16 percent at 20 suns. This value verifies the 16 percent nominal efficiency selected for the performance simulation analysis described in Section 4.

\subsection{SOLAR CELL RECEIVER FABRICATION}

A prototype solar cell receiver was built to develop the manufacturing processes and to use in conjunction with testing a 5-foot segment of the solar collector. The segment tests are reported later in Paragraph 5.7.

Concentrator solar cells from the group of 100 described earlier were used in the prototype receiver. Two strings of 36 cells each were first assembled,by joining the cells with preformed copper interconnection strips along the two edge contacts of each cell. As shown on Figure 5-7, the interconnection strips are formed with extended tabs to achieve maximum flexibility for accommodating differential expansions. The tabs are then folded with respect to the main conductor strip to keep the overall solar cell receiver as narrow as possible thereby minimizing blockage of the concentrator aperture. Since the cell-to-cell interconnections are joined from the underside of one cell to the top edge contact of the adjacent cell, overlapping of the copper interconnections occurs. To prevent electrical contact of the overlappingtportions, an insulating tape is introduced as indicated on Figure 5-7. A simplification of this approach uses a similar but shorter interconnection strip in which the overlapping is avoided and the insulating tape eliminated. However, it is anticipated that this approach would result in higher ohmic losses.

Following their interconnection, the strings were bonded to each extruded aluminum receiver half with GE silicone adhesive RTV-511. Anodization of the aluminum surface insured that adequate electrical insulation was provided. A single glass strip over the 5-foot receiver length was secured by glazing strips and the gap between the cells and glass backfilled with clear silicon rubber RTV-650 using a combined pressure-vacuum technique. Appropriate electrical terminations 


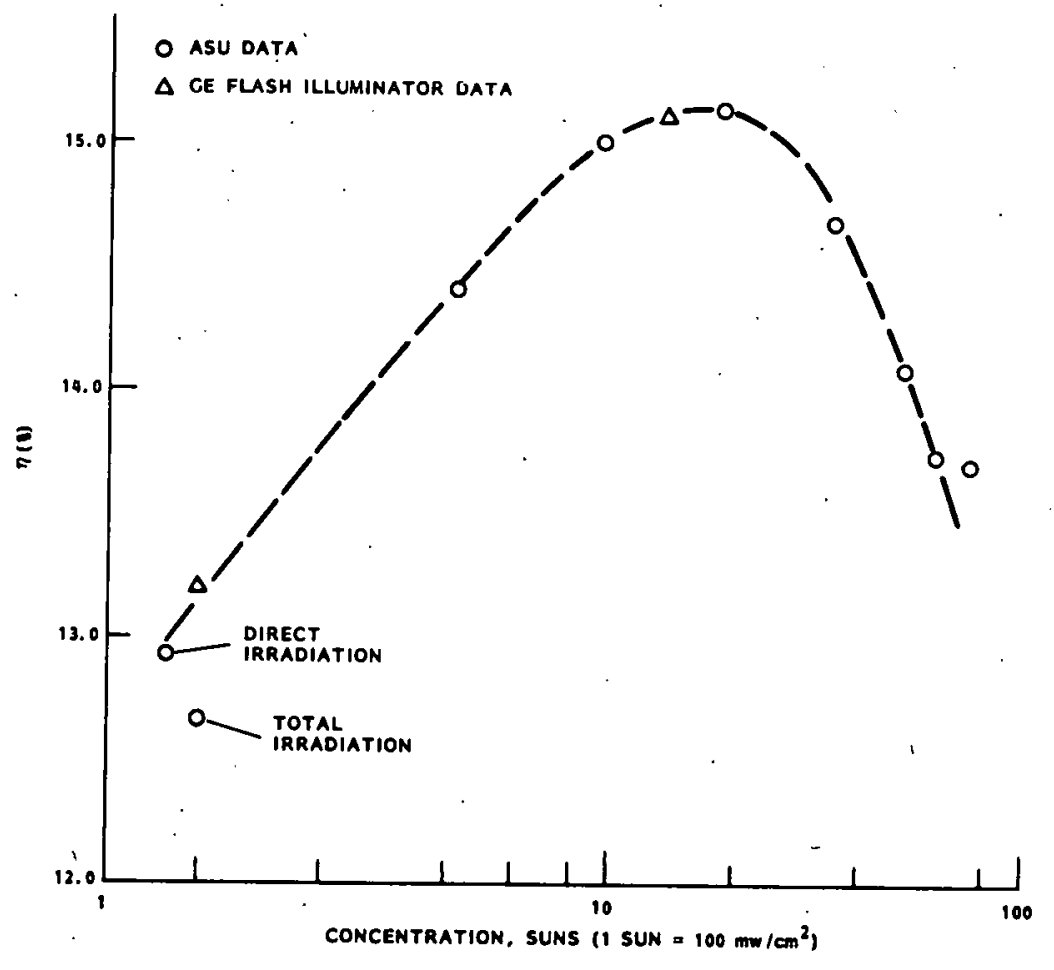

Figure 5-3. Efficiency vs Concentration for General Electric Cell 17 ( $3 \times 4 \mathrm{~cm}-12 \mathrm{~cm}^{2}$ Active Area) Tested at $28^{\circ} \mathrm{C}$

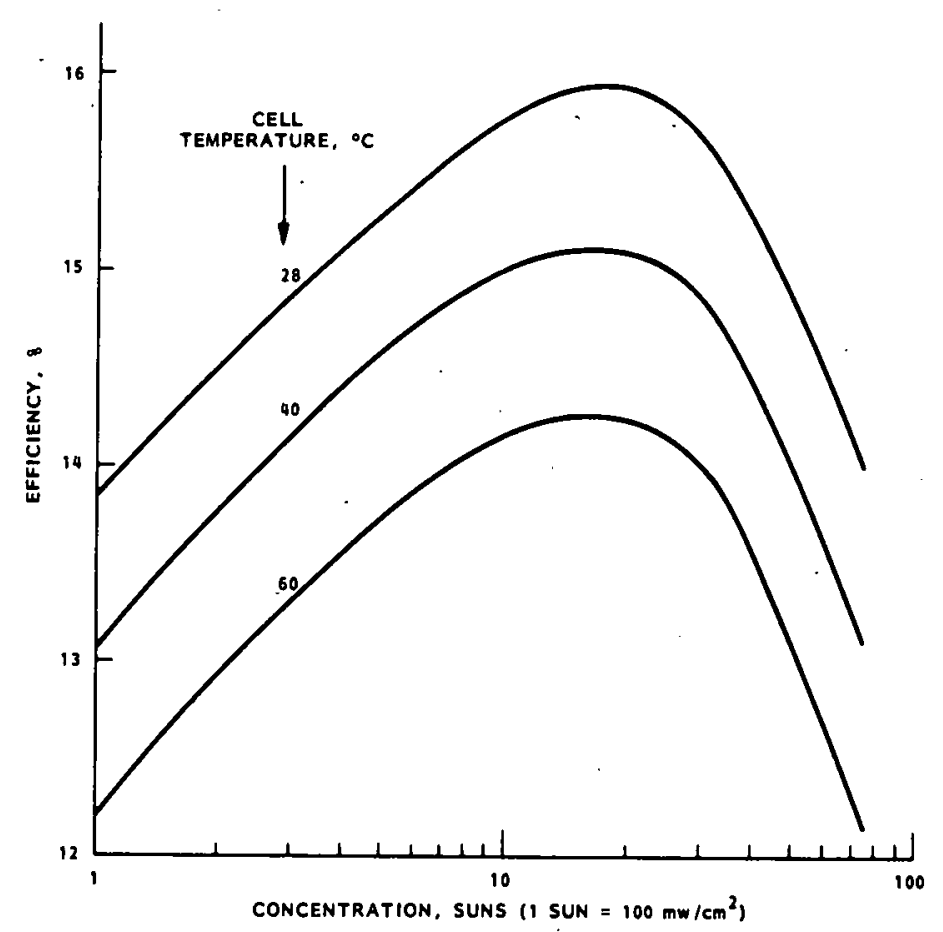

Figure 5-4. Efficiency vs Concentration for OCLI, $3 \times 4 \mathrm{~cm}$ Concentrator Cell 


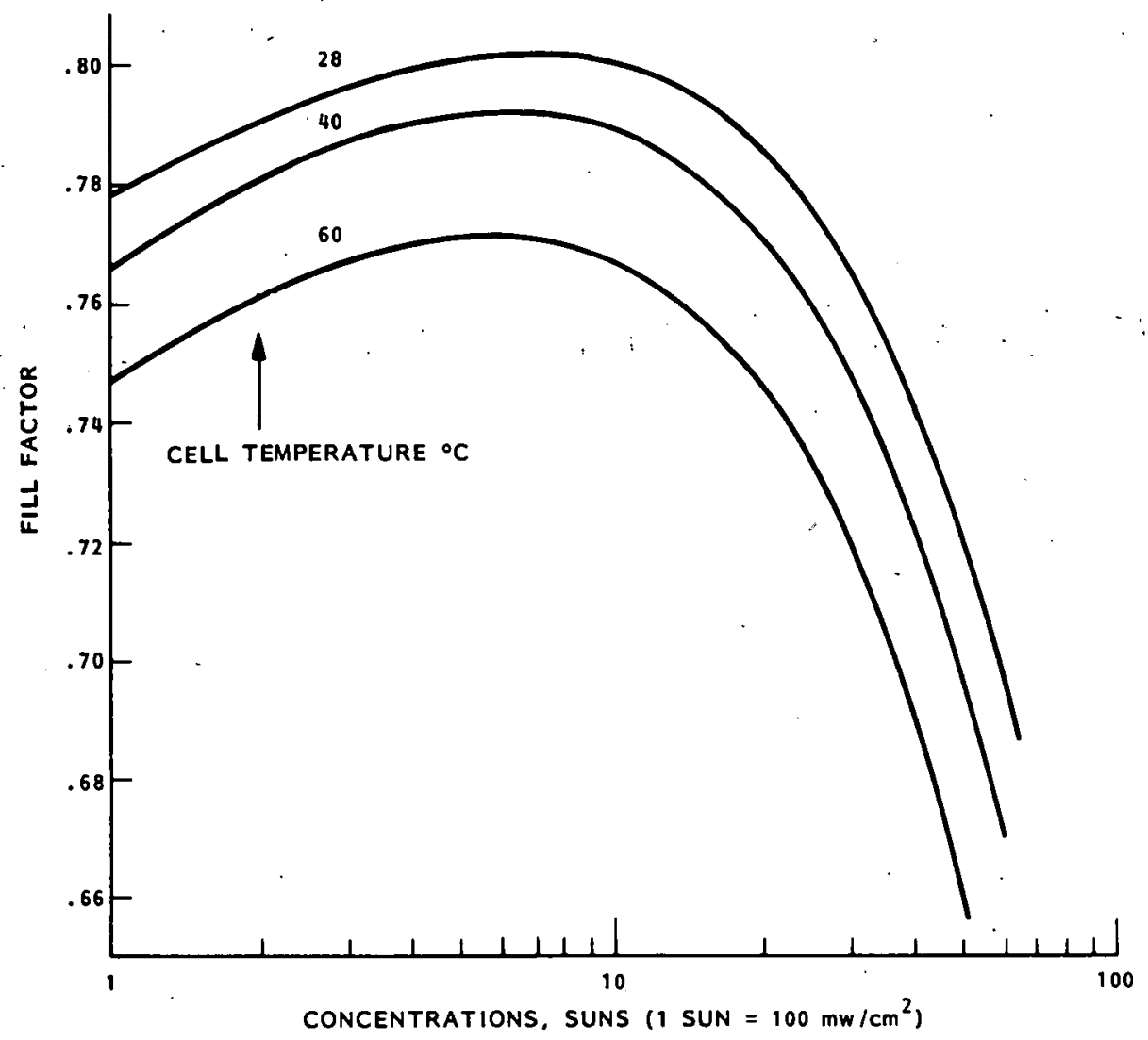

Figure 5-5. Fill Factor vs Concentrations for OCLI, $3 \times 4 \mathrm{~cm}$ Concentrator Cell

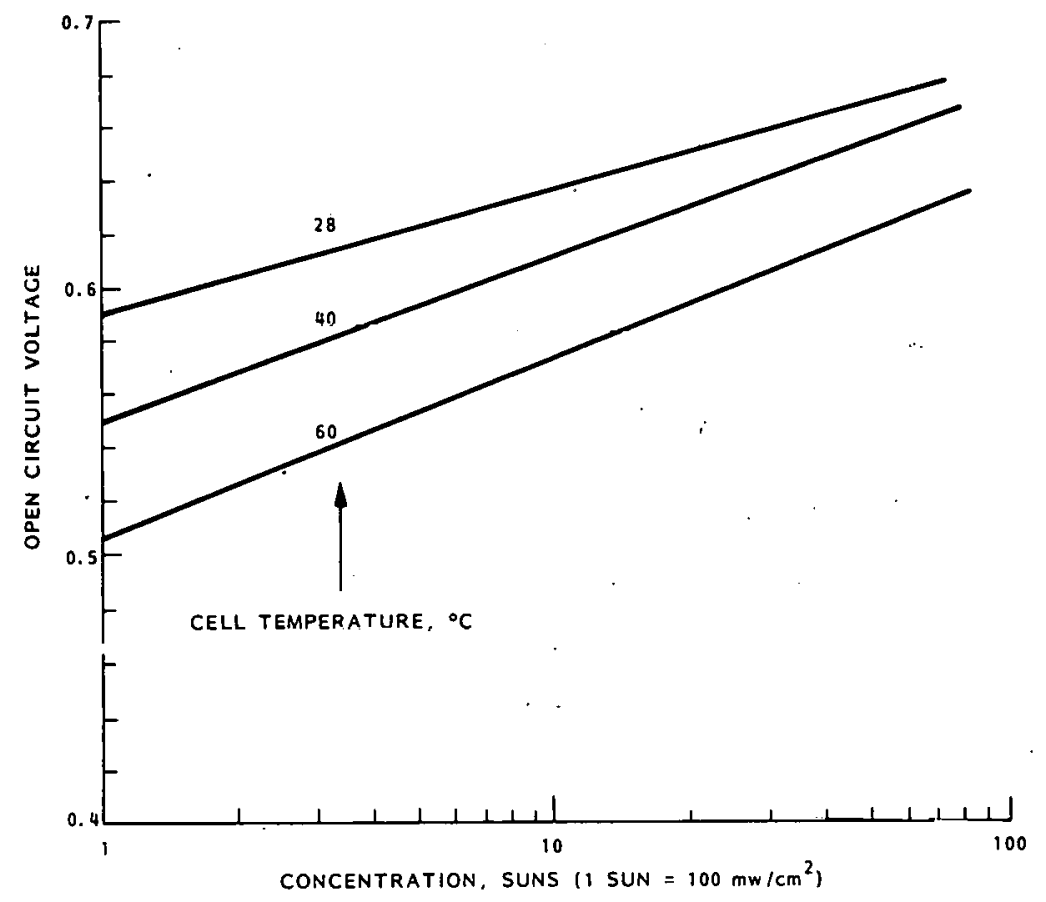

Figure 5-6. Open-Circuit Voltage for OCLI, $3 \times 4 \mathrm{~cm}$ Concentrator Cell 
were then made at each receiver end, and an insulating teflon-coated fiberglass tape applied to the surfaces which mate with the copper coolant tube. Figure 5-8 shows a segment of the receiver with the above identified elements.

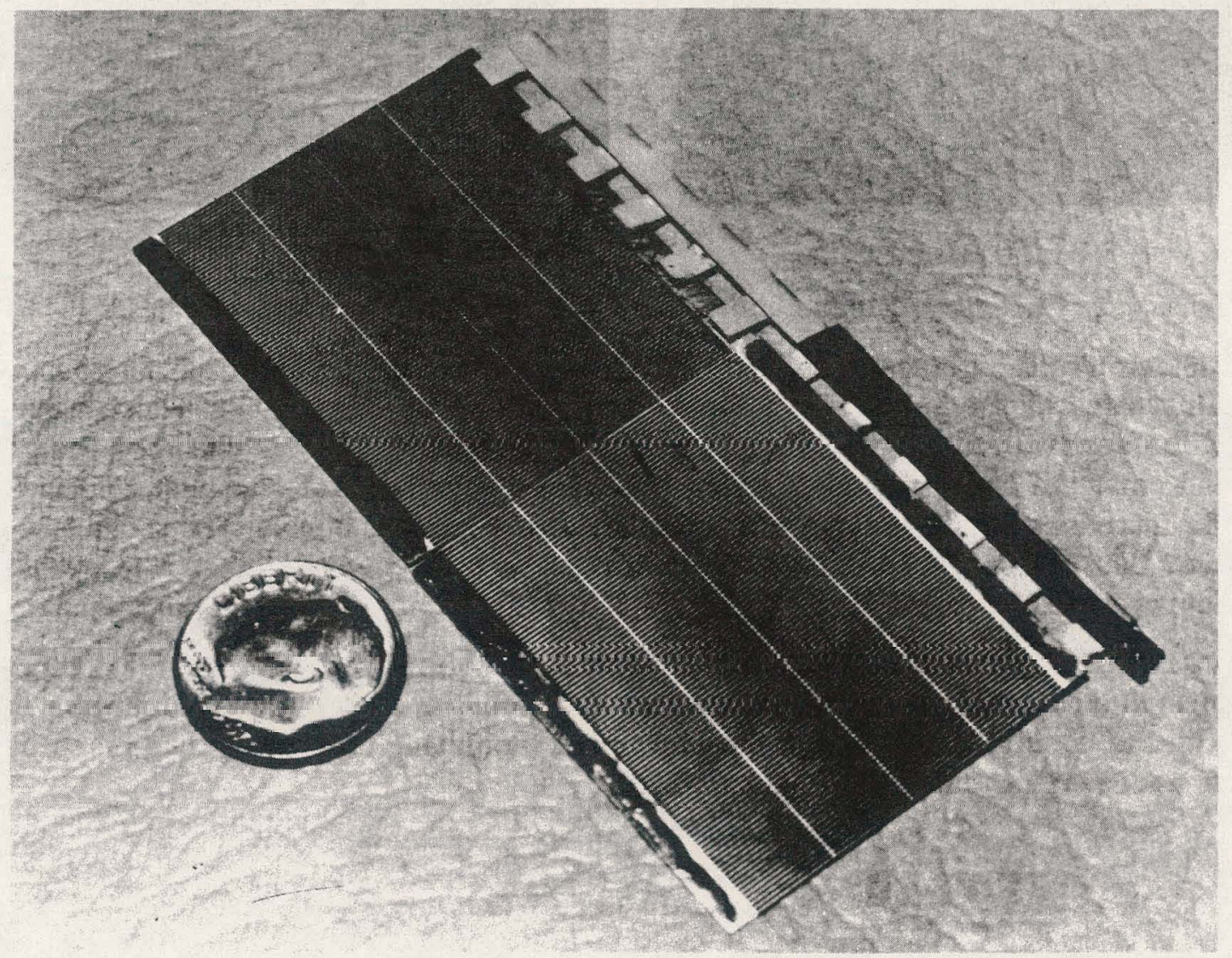

Figure 5-7. Solar Cell Interconnection

Fabrication and subsequent testing of the prototype receivers yielded important data relevant to design refinement and production manufacturing procedures. Foremost among these were the following:

1. Control of the cell-to-substrate bond thickness is critical in order to minimize the temperature drop. The design was based on a 3-mil thickness but the method of bonding (by spreading the bond with a doctor blade) made it difficult to control the thickness. Film adhesives are an attractive alternate (See earlier discussion, Paragraph 3.2.2). 

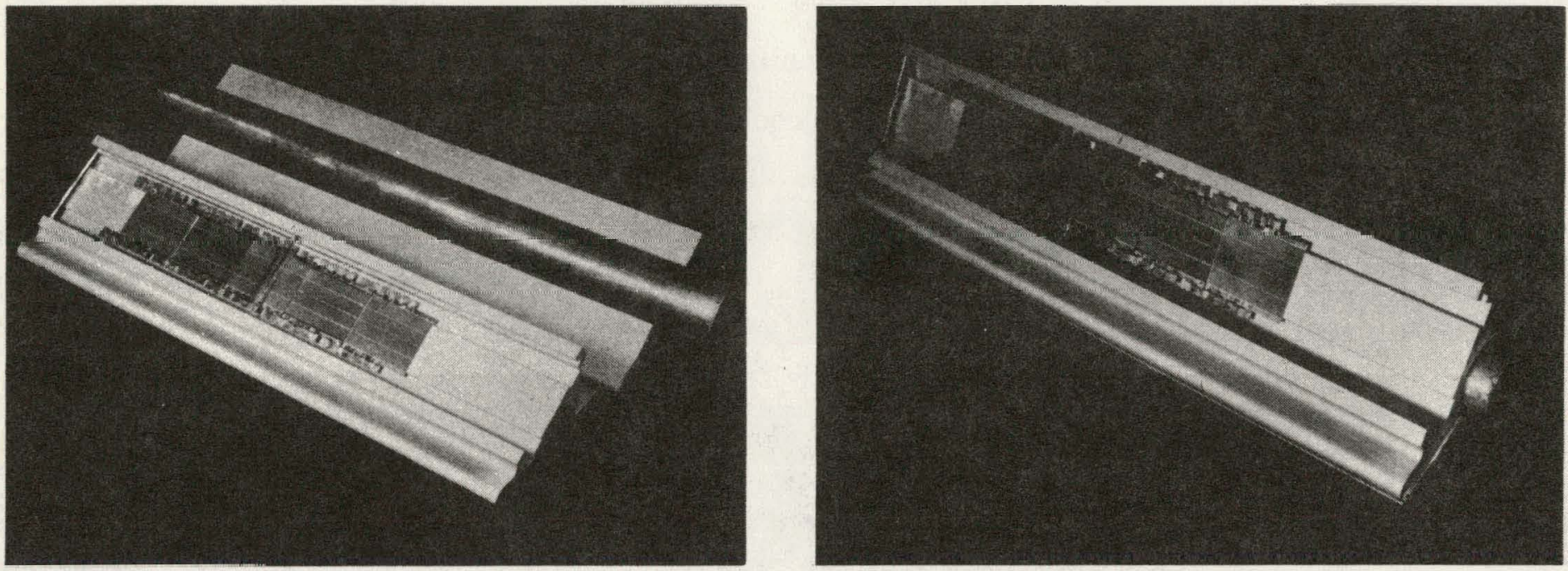

Figure 5-8. Receiver Details

2. Adhesion of the glass-to-cell bond is important for the best optical performance as illustrated by the 1-sun I-V measurements shown on Figure 5-9 which were taken at the several stages of assembly indicated. Without the bond between the glass and cell, the short-circuit current decreases below that of uncovered cells, whereas the introduction of the bond improves the short-circuit current by about 4 percent over that of uncovered cells. Delamination, which occurred over a few cells, is equivalent to having no bond in terms of its effect on decreasing the output.

3. Extrusion dimensional control is important for effective heat transfer. Slight irregularities existed at both the solar cell bonding surface and the mating surface with the coolant tube through the electrical insulating tape. Cleanup machining may be necessary to maximize heat transfer.

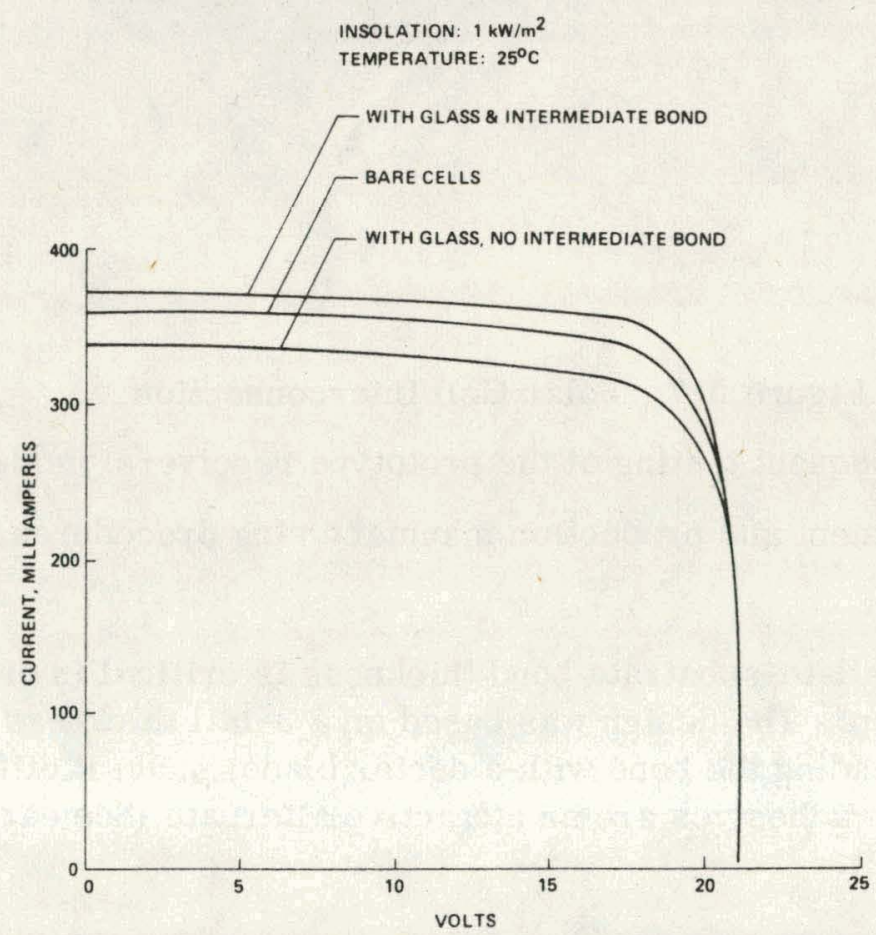

Figure 5-9. Solar Cell Receiver 1-Sun Test Results 


\subsection{RECEIVER THERMAL IMPEDANCE TESTS}

A critical feature of the solar cell receiver design pertained to the thermal impedance at the clamping interface with the copper coolant tube. As pointed out earlier in Paragraph 3.2.2, this design was adopted for its advantages in permitting easy removal and replacement of receivers without interrupting fluid lines, use of copper as a fully qualified material for plumbing systems, use of this clamping interface for voltage insulation purposes thereby reducing the cell mounting insulation requirements and, finally, use of the aluminum material of the receiver itself as a current bypass to obviate the effects of shaded or open-circuited solar cells.

To evaluate the thermal impedance characteristics of the clamped joint between the receiver and coolant tube, tests were conducted using several types of electrical insulating tapes. As shown on Figure 5-10, the test set up consisted of mounting several heater strips on machined blocks simulating the solar cell receivers, clamping the blocks to a 1-1/4-inch copper tube, introducing a flow of $3.3 \mathrm{gpm}$, and making appropriate temperature measurements. Figure 5-11 summarizes the test results for several types of insulating materials and shows that a temperature drop of approximately 15 to $20^{\circ} \mathrm{F}$ might be expected at an insola-

tion of $1 \mathrm{~kW} / \mathrm{m}^{2}$. The data shows that silicone thermal grease is effective in minimizing the temperature drop. The use of $2.5 \mathrm{mil}$ polymide film resulted in the lowest temperature drop and is tentatively selected as the preferred material. Additional durability testing is required to ascertain this selection.

One important feature of the mating surface design is that the insulating film is applied to the receiver halves rather than the coolant tube. This provides two important advantages: (1) it avoids the complication of having to apply the film to the long 30 -foot coolant tube with the attendant difficulties of process control and handling; (2) any insulation breakdown problems are easily handled by the removal and repair of the affected receiver assembly only.

Several minor problems in the design of the mating surface have been uncovered which can be easily rectified. In particular, there is vulnerability to insulation breakdown at both ends of the receiver where the insulating tape is terminated. Introduction of insulating endcaps (needed also to simplify the silicone gel filling operation) should adequately solve this problem. 


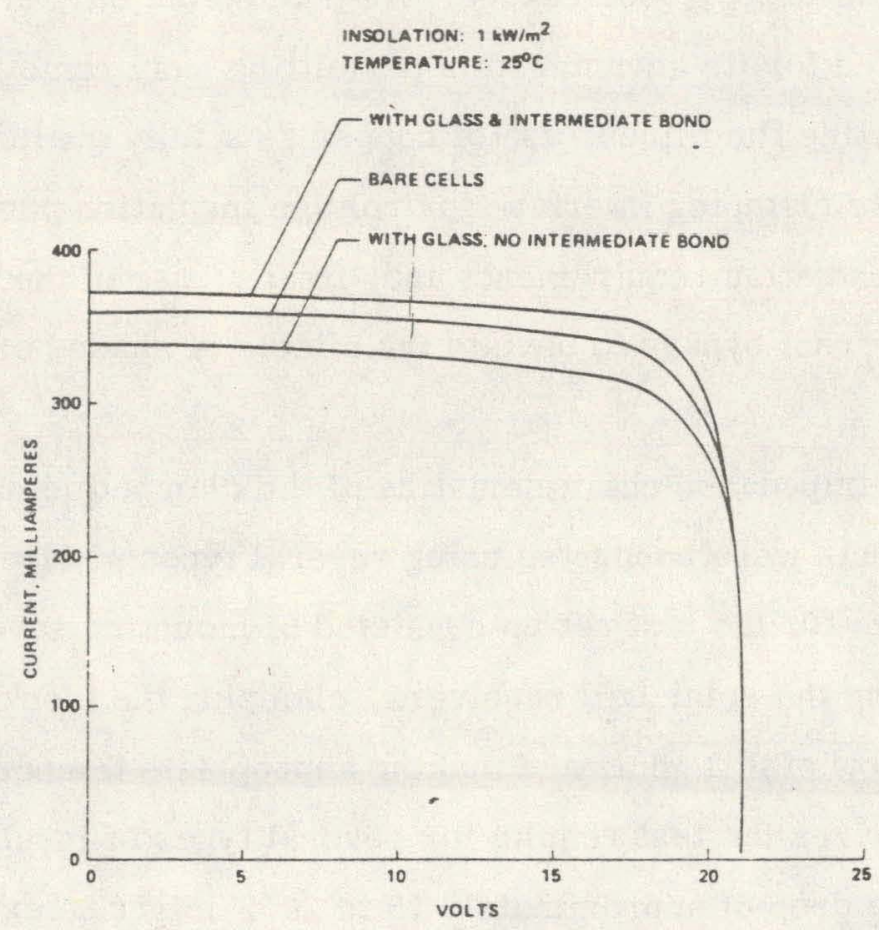

Figure 5-10. Solar Cell Receiver Thermal Impedance Test

\subsection{REF LECTIVE MATERIAL EVALUATION}

A number of reflective surface materials were obtained and tests performed to screen out the more promising candidates. Because of the potential for low-cost, the candidates were limited to film materials produced in high-volume. A description of the candidate materials and the tests to which they were subjected was presented earlier in Paragraph 3.2.1 and need not be repeated here. In general, reflective surfaces consisting of the class of aluminized U-V stabilized polyester films laminated to adequately smooth substrate sheet metals provides an adequate near-term approach. These materials appear to exhibit extended-life durability although they are deficient in certain regards, particularly to abrasion. Such materials as a silicone hard coat developed by GE's Lexan Division could potentially increase abrasion resistance, although further work is required to establish its compatibility with the polyester reflective materials.

With regard to improved reflective surface materials that may be developed over the coming years, a convenient feature of the collector design is the means by which the reflector is clamped to the framework permitting easy replacement or refurbishment. 

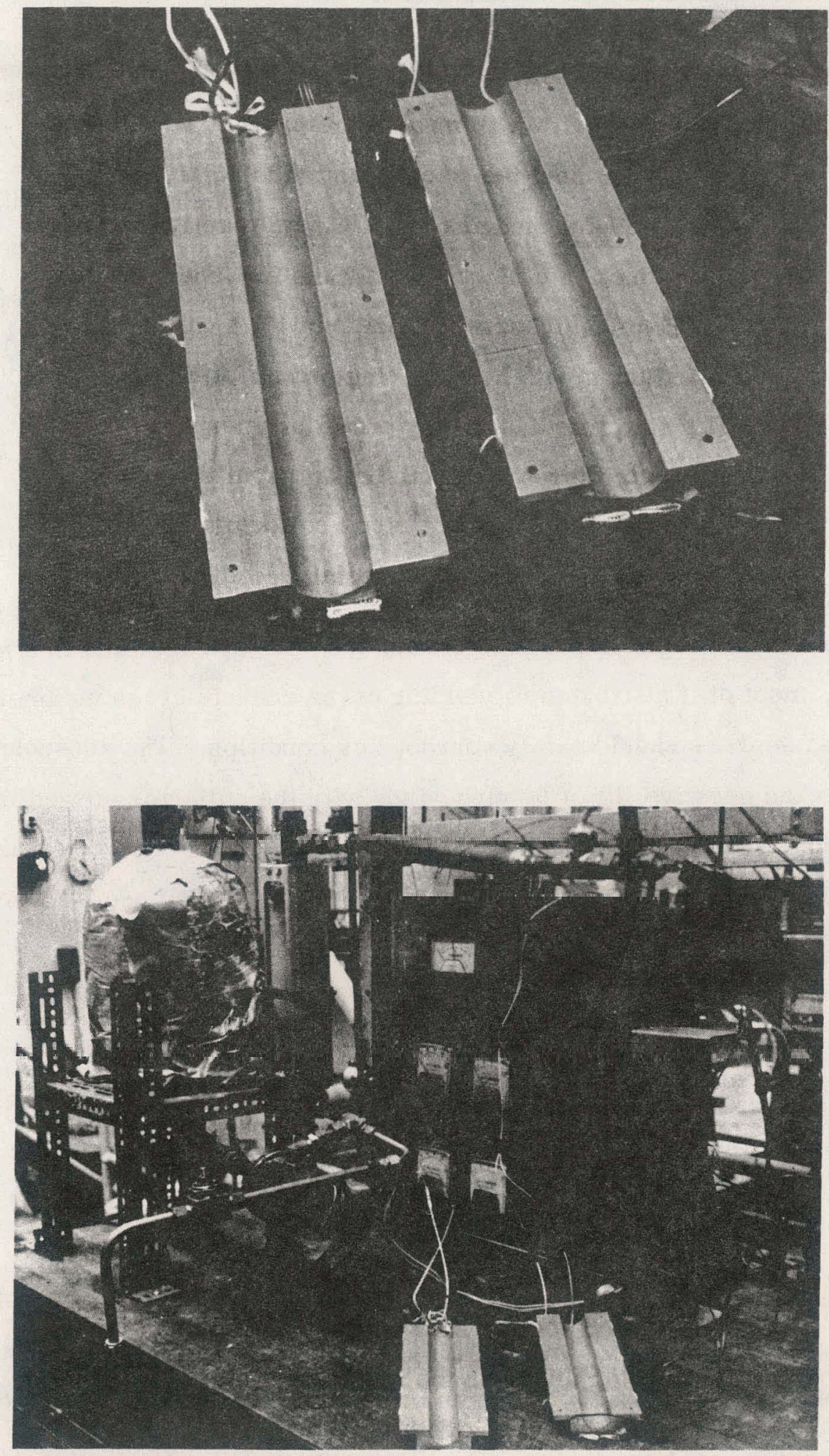

Figure 5-11. Results of Solar Cell Receiver Thermal Impedance Tests 


\subsection{0-FOOT PROTOTYPE COLLECTOR}

A prototype collector unit was completed as part of the Phase I activities. Figure 5-12 shows the unit in various stages of assembly. The seven-rib sections were stretch-formed over an accurate mandrel and were within 10 mils of the prescribed parabolic coutour. Standard sections were used for the keel tee-section and side rails although splicing was necessary because the required 30 -foot lengths could not be readily obtained. Full 30-foot lengths will be used for the production collectors in Phase II. The reflector skin consists of six 4 × 10-foot steel sheets (25-mil thickness) laminated with 4-mil aluminized polyester film. The unit is essentially self-fixturing with hole spacing and sheet-metal squareness providing the required alignment. The simplified assembly procedure permits the assembly of the collectors near the Sea World site thereby minimizing transportation costs.

Preliminary structural evaluation of the prototype collector indicates the design is exceptionally stiff in both bending and torsion. Simple static loading by placing 400 pounds of distributed dead weight on planks spanning the aperture resulted in a mid-point deflection of $1 / 4$ inch, most of it attributed to yielding of the end-rib cross members. Deeper sections for these members should easily correct this condition. The 400-pound distributed load simulates the negative lift of $90 \mathrm{mph}$ winds with the collector stowed in a horizontal position. A qualitative check of torsional stiffness by suspending weights on diametrically opposite corners indicated extremely small angular deflections. These preliminary tests indicate that winds of high velocity and shear will have little effect on the optical integrity of the collector.

The geometrical characteristics of the collector show excellent ability to focus the solar energy along the solar cell receivers. Using wooden mockup solar cell receivers, the photo of Figure 5-13 shows the interception of the solar energy along the receivers. A simple spirit level placed across the aperture was used to align the collector by adjusting the lengths of the diagonal braces.

Solar cell receiver tests described later used a reflector representing a segment in all respects, of the collector described above. The test results showed an optical efficiency of 74 percent. Since the full collector achieves the necessary interception of the solar energy along the solar cell receivers, this level of optical efficiency can be confidently predicted for the full unit. 

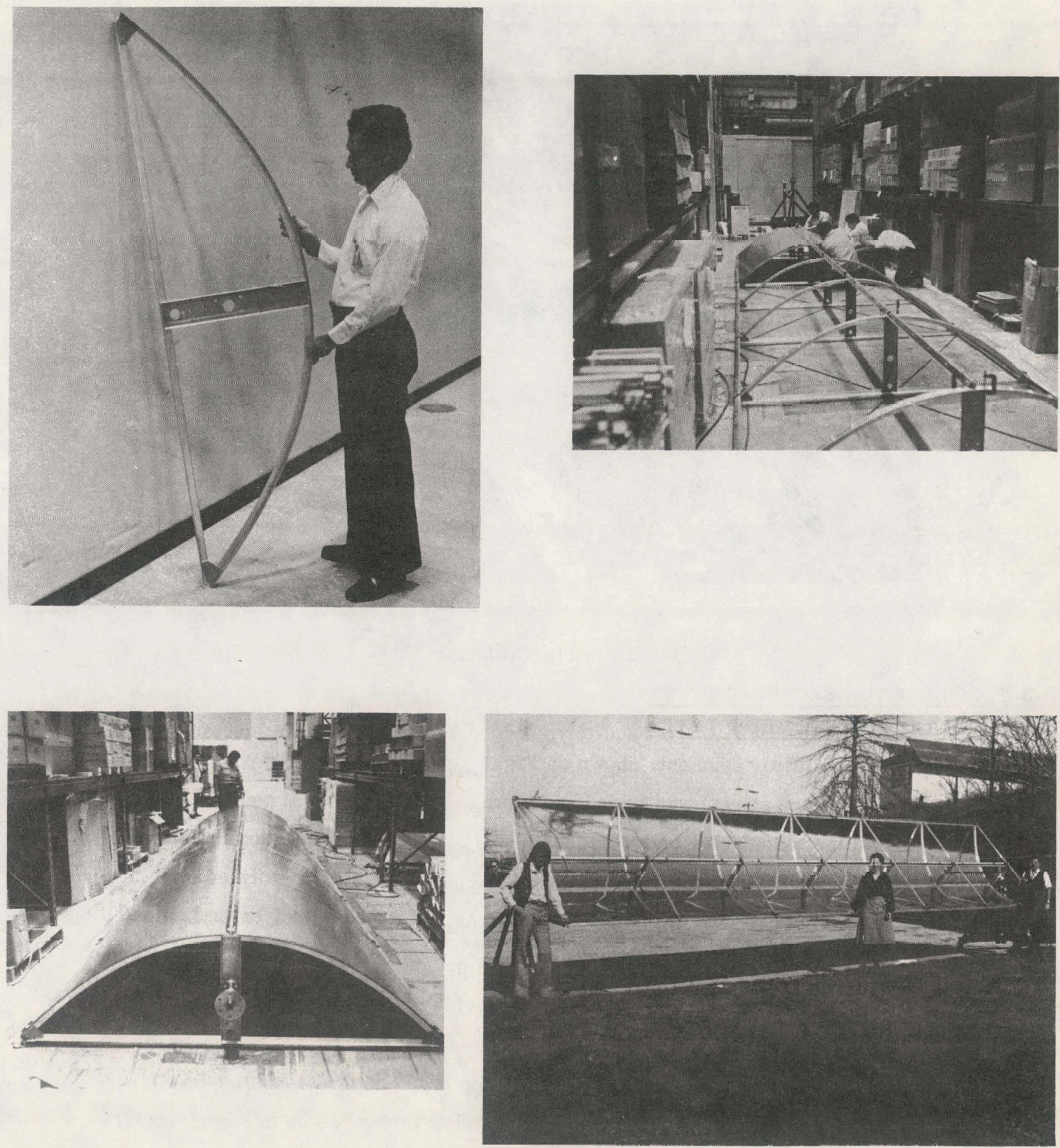

Figure 5-12. Prototype Collector 


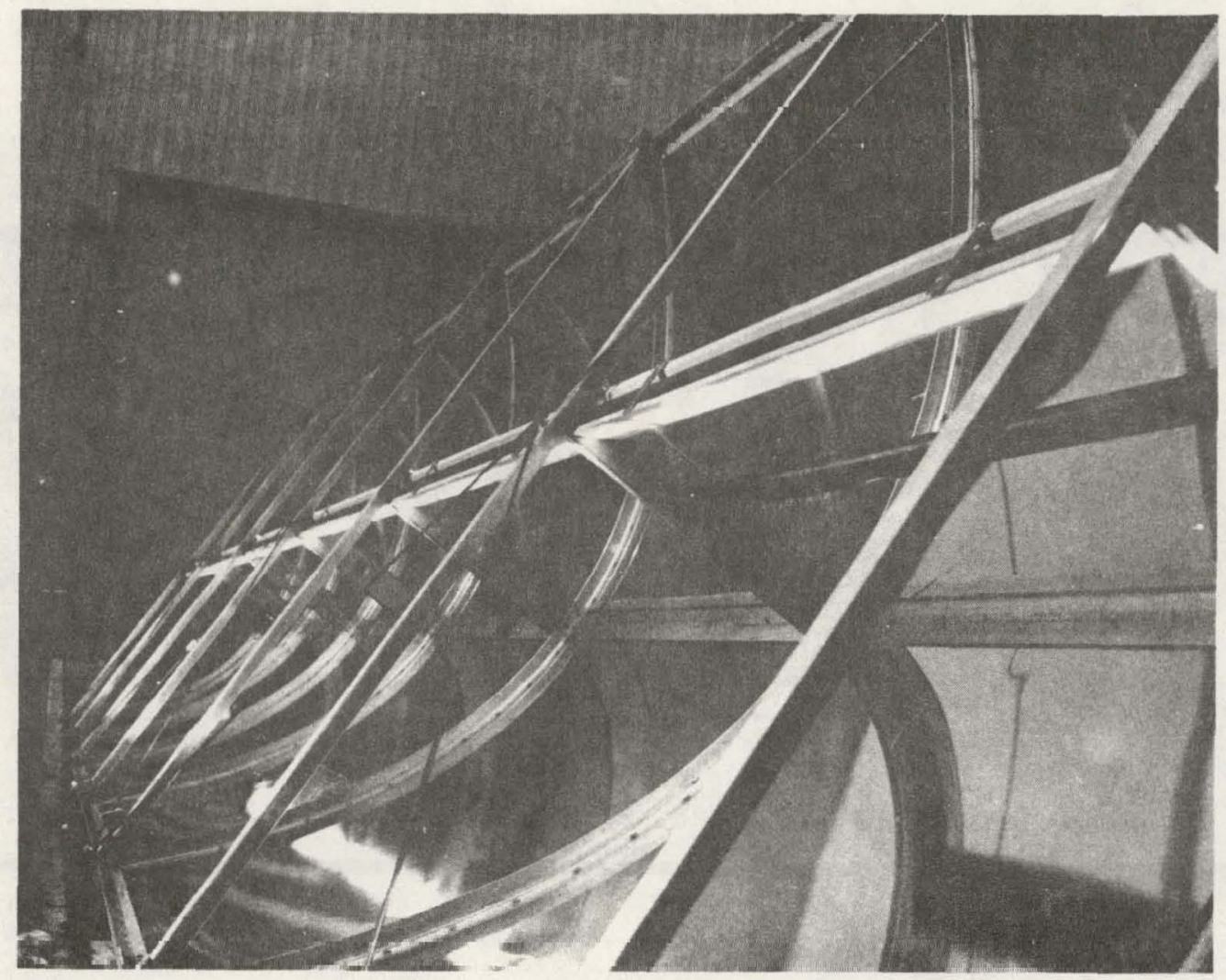

Figure 5-13. Collector

\subsection{COLLECTOR SEGMENT TESTS}

The five-foot collector segment, shown on Figure 5-14, including the prototype solar cell receivers described above, was tested and monitored for electrical and thermal performance. All of the manufacturing techniques planned for high-volume production were utilized in the buildup of this unit. For example, the ribs were stretch-formed on a mandrel using production equipment, and the reflector surface was formed by polyester laminated to the substrate with heat and pressure at process speeds of 20 feet per minute by the Raymond Engineering firm. The solar cell receivers were clamped to the copper coolant tube with 6-mil Teflon-coated fiberglass tape introduced to provide electrical insulation.

The collector was mounted on a frame which allowed the collector to be manually aimed at the sun in both azimuth and elevation. The test loop provided active cooling of the receiver at a controlled inlet temperature of $120^{\circ} \mathrm{F}$ to $180^{\circ} \mathrm{F}$ and at flow rates up to $3 \mathrm{gpm}$. RTD's (resistance thermometers accurate to $1 / 10^{\circ} \mathrm{F}$ ) measured the inlet and outlet temperatures. Together with flow measurements, these were used to determine thermal efficiency. Each series string of solar cells (one on each side of the receiver) was connected to a variable 

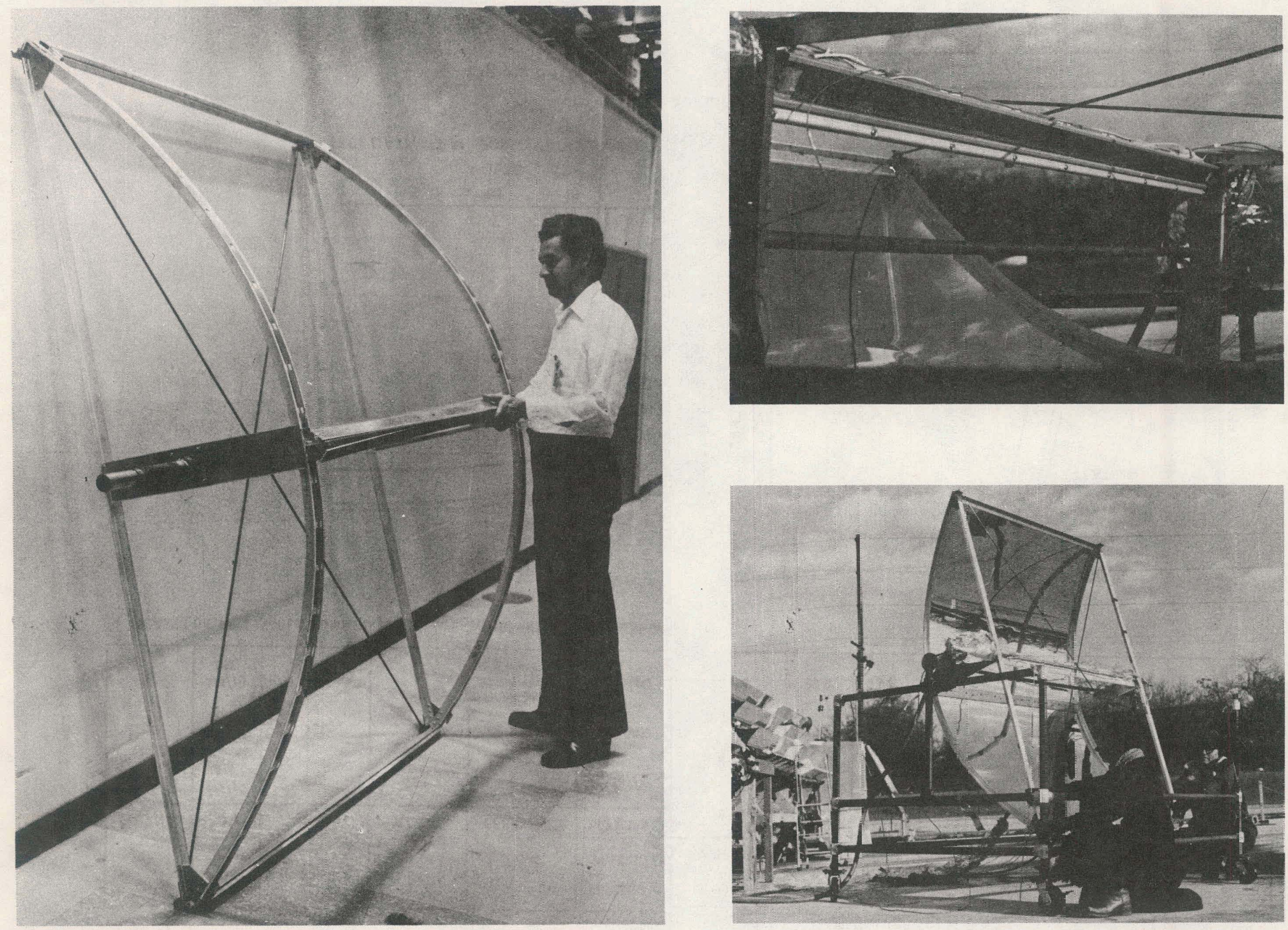
- FLOW: 3.1 GPM

- APERTURE AREA (PER RECEIVER HALF): $1.491 \mathrm{~m}^{2}$

\begin{tabular}{|c|c|c|c|c|c|c|c|c|c|c|c|c|}
\hline \multirow[b]{2}{*}{ TEST NO. } & \multirow[b]{2}{*}{ TIME } & \multirow[b]{2}{*}{$\begin{array}{l}\text { INSOLATION } \\
\mathrm{kW} / \mathrm{m}^{2}\end{array}$} & \multirow[b]{2}{*}{$\begin{array}{l}\text { PV OUTPUT } \\
\text { WATTS }\end{array}$} & \multirow[b]{2}{*}{$\begin{array}{c}\text { PV } \\
\text { EFFICIENCY }\end{array}$} & \multirow[b]{2}{*}{$\begin{array}{l}\text { PREDICTED } \\
\text { PV } \\
\text { EFFICIENCY* }\end{array}$} & \multicolumn{6}{|c|}{ TEMPERATURE, ${ }^{\circ} \mathrm{C}$} & \multirow[b]{2}{*}{$\begin{array}{l}\text { THERMAL } \\
\text { EFFICIENCY }\end{array}$} \\
\hline & & & & & & AMBIENT & $\begin{array}{l}\text { FLUID } \\
\text { IN }\end{array}$ & $\begin{array}{l}\text { FLUID } \\
\text { OUT }\end{array}$ & $\begin{array}{l}\text { ALUM. } \\
\text { SUBSTRATE }\end{array}$ & CELL & $\begin{array}{l}\text { WIND } \\
\text { SPEED, } \\
\text { KPH }\end{array}$ & \\
\hline 1 & $\begin{array}{c}1 / 3 / 79 \\
A M\end{array}$ & .846 & 104 & $8.24 \%$ & $8.87 \%$ & -10 & 46.9 & 47.4 & 63 & 89 & 35 & $16.2 \%$ \\
\hline 2 & $\begin{array}{c}1 / 3 / 79 \\
P M\end{array}$ & .738 & 89 & $8.09 \%$ & $8.54 \%$ & -9 & 64.3 & 65.2 & 72 & 102 & 18 & $33 \%$ \\
\hline 3 & $\begin{array}{c}1 / 4 / 79 \\
A M\end{array}$ & .825 & 88 & $7.13 \%$ & $7.64 \%$ & -4 & 80.9 & 82.0 & 91 & 125 & 4 & $37 \%$ \\
\hline
\end{tabular}

*BASED ON TEST INSOLATION AND CELL TEMPERATURE INPUTS TO FIGURE 2-10.

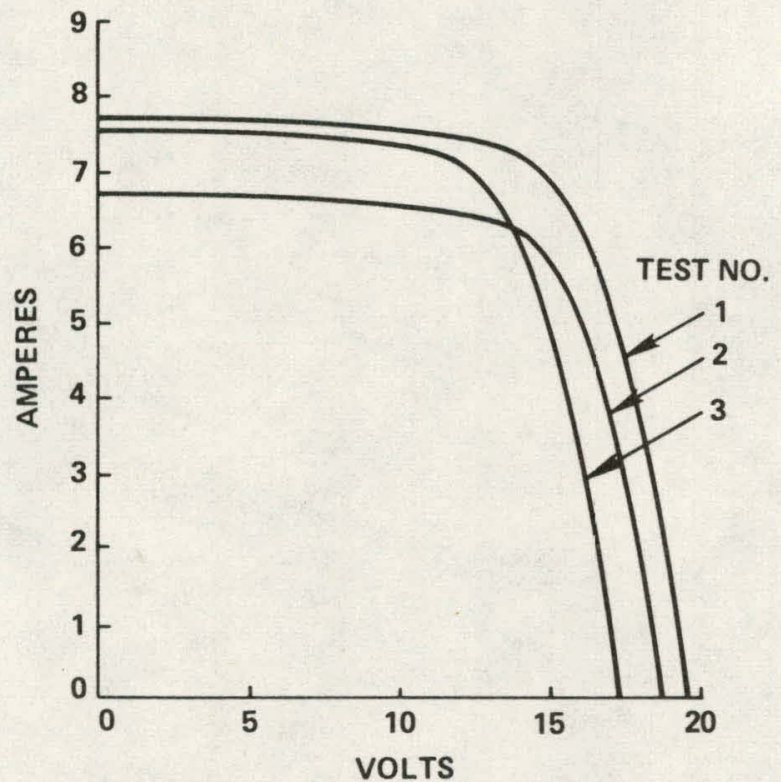

(a) TEST DATA (TRANSPOSED FROM X-Y PLOTTER)

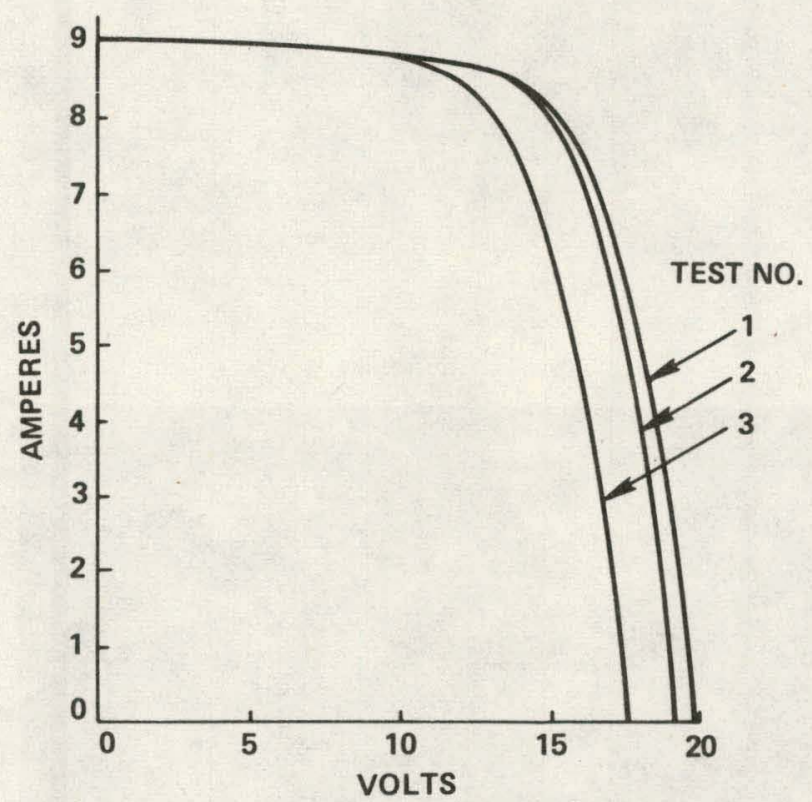

(b) TEST DATA ADJUSTED TO $1 \mathrm{~kW} / \mathrm{m}^{2}$ INSOLATION

Figure 5-15. Collector Segment Test Results 
electronic load. As the electronic load was varied, the I-V curve of each string was recorded on an X-Y plotter. Six thermocouples monitored the receiver substrate temperature and a pyroheliometer measured direct normal insolation.

Figure 5-15 (a) shows the I-V curves obtained for one receiver half transposed from recorder data, with the voltage adjusted upward to account for the fact that only 34 series cells were used instead of the nominal 36. This was the result of inadvertent damage to two cells during the fabrication of this prototype. Figure 5-15(b) normalizes the I-V plots to an isolation of $1 \mathrm{~kW} / \mathrm{m}^{2}$ by translating the plots along the current axis in proportion to the insolation ratio. Figure 5-15 also lists pertinent test and performance data.

Solar cell temperatures were determined as a function of open circuit voltage $\left(V_{\text {oc }}\right)$ using the following technique. The collector was defocused. The coolant through the receiver was controlled to a selected temperature and the entire receiver including the solar cells allowed to reach this steady state temperature. When equilibrium was reached, the trough was abruptly pointed at the sun and the instantaneous open circuit voltage recorded. This instantaneous peak represents the open circuit voltage at the initially known cell temperature. The several test points recorded in this fashion were correlated with the insolation level resulting in the plot shown on Figure 5-16. Solar cell temperatures were then determined using the open-circuit voltages and insolation data shown on Figure 5-15. Review of the data of Figures 5-9, and 5-15 leads to the following observations:

1. For the cell temperatures reached, the comparison of measured and predicted efficiency on Figure 5-16 shows an average relative difference of about 6.4 percent. The difference is mainly due to the partial delamination of the transparent silicone rubber. As illustrated earlier on Figure 5-9 delamination can account for a difference as high as 9 percent.

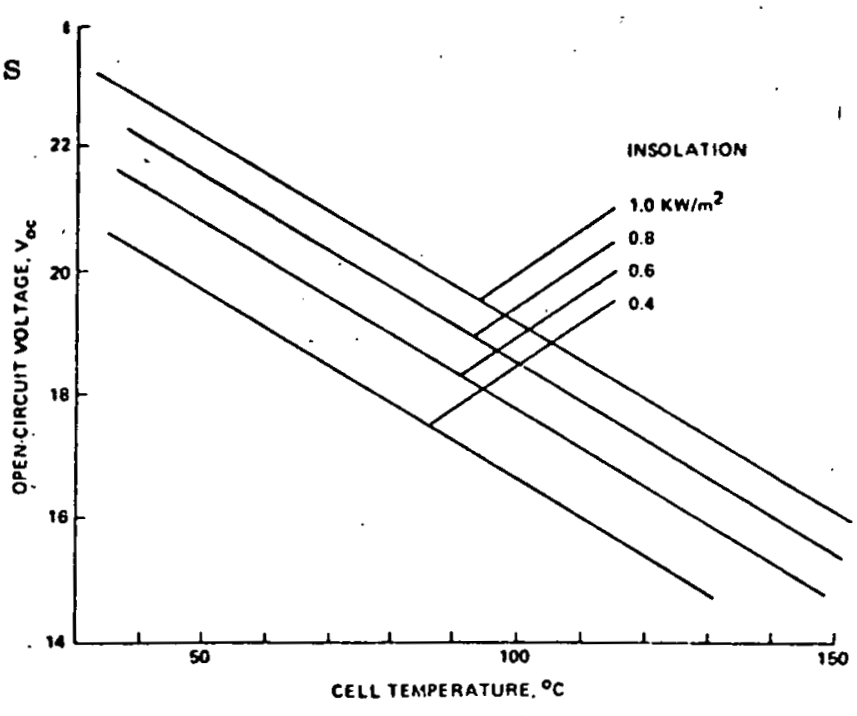

Figure 5-16. Correlation of Solar Cell Temperature with Open-Circuit Voltage 
2. Averaging the test results shows that cell temperatures are $30_{2}^{\circ} \mathrm{C}$ hotter than the aluminum substrate temperature at an insolation of $0.80 \mathrm{~kW} / \mathrm{m}^{2}$. This compares with a design $\Delta \mathrm{T}$ of about $2.5^{\circ} \mathrm{C}$ for that insolation. The higher than normal $\Delta \mathrm{T}$ acounts for an 11 percent loss of output. A variable bond thickness is suspected as the source of the high $\Delta \mathrm{T}$ and corrective action has been identified to eliminate this (see earlier discussion in Paragraph 3.2.2.) Even with the higher than normal temperatures reached, the receiver operated without adverse effects such as glass cracks or other physical damage. Delamination of the transparent silicone rubber which occurred at the time of manufacture remained unchanging during testing.

3. The measured optical efficiency of the reflector was $\mathbf{7 4}$ percent as determined by comparing the short-circuit current ratio of the concentration and non-concentration tests, at identical insolation levels, with the geometrical concentration ratio. Included in this efficiency are the following factors: reflectance, intercept factor (percentage of reflected light intercepted by cells), spectral response mismatch of cells with sunlight, and focal line uniformity. Considering all of these factors, the measured optical efficiency is excellent and consistent with the values used in the performance prediction analyses.

4. Fill factor (max. power divided by the short-circuit current $x$ open-circuit voltage product) ranged from 65 to 70 percent for the concentration tests indicating small interconnection losses.

5. The average temperature drop from the aluminum substrate to the coolant fluid was approximately $11^{\circ} \mathrm{C}$, consistent with earlier predictions and breadboard tests.

6. An average thermal efficiency of 29 percent was obtained. This compares with the value of 33 percent assumed in performance analysis.

\subsection{SOLAR ARRAY ANNUAL EFFICIENCY}

Based on the collector segment test results and the analytical predictions developed in Section 4.0, performance for the system used in conjunction with an absorption chiller is shown on Figure 5-17 as a function of annual insolation.

Performance, based on present test results, is shown by the solid line and is reduced with respect to the predicted performance by two factors: (1) a 6.4 percent penalty associated with reduced photon efficiency due to bond delamination in the solar cell receiver; (2) a 6.6 percent penalty associated with higher than normal cell temperatures. This value was developed by considering that the average insolation is about $0.5 \mathrm{~kW} / \mathrm{m}^{2}$ and therefore temperature drops are smaller in comparison with the higher values measured in the tests reported in Section 5.7 . 
For comparison purposes, Figure 5-17 includes the performance prediction considering an array outlet coolant temperature of $100^{\circ} \mathrm{F}$.

Projected thermal performance is presented on Figures 5-18 and is in close agreement with the test results described in Paragraph 5.7.

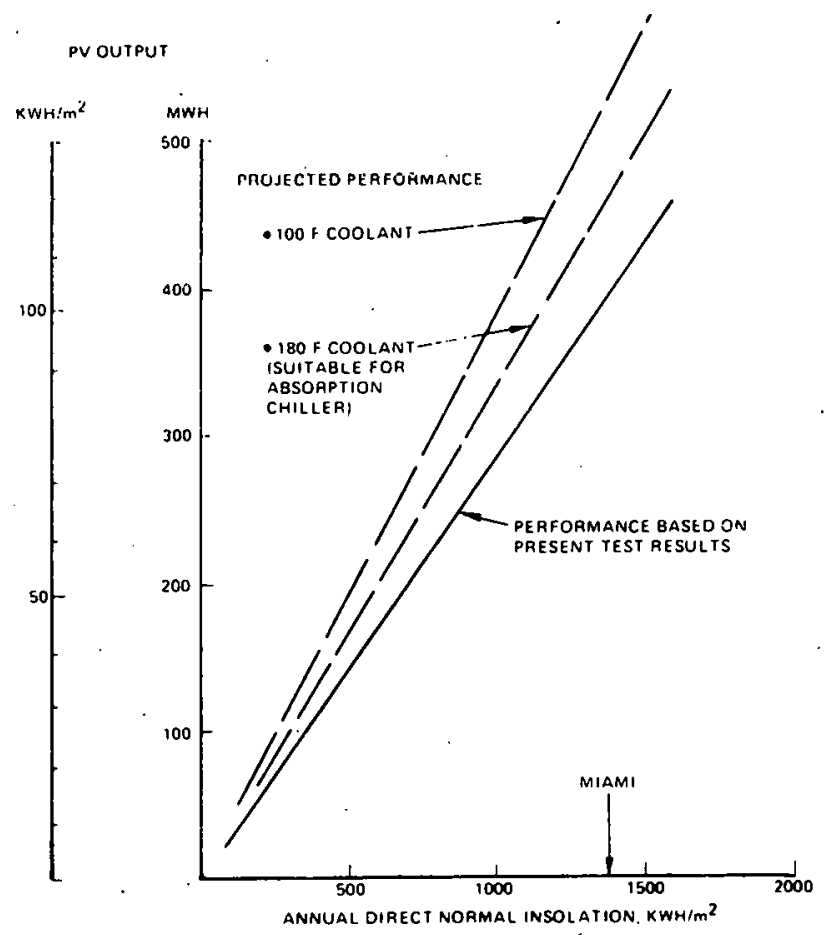

Figure 5-17. Solar Array Annual Electrical Performance

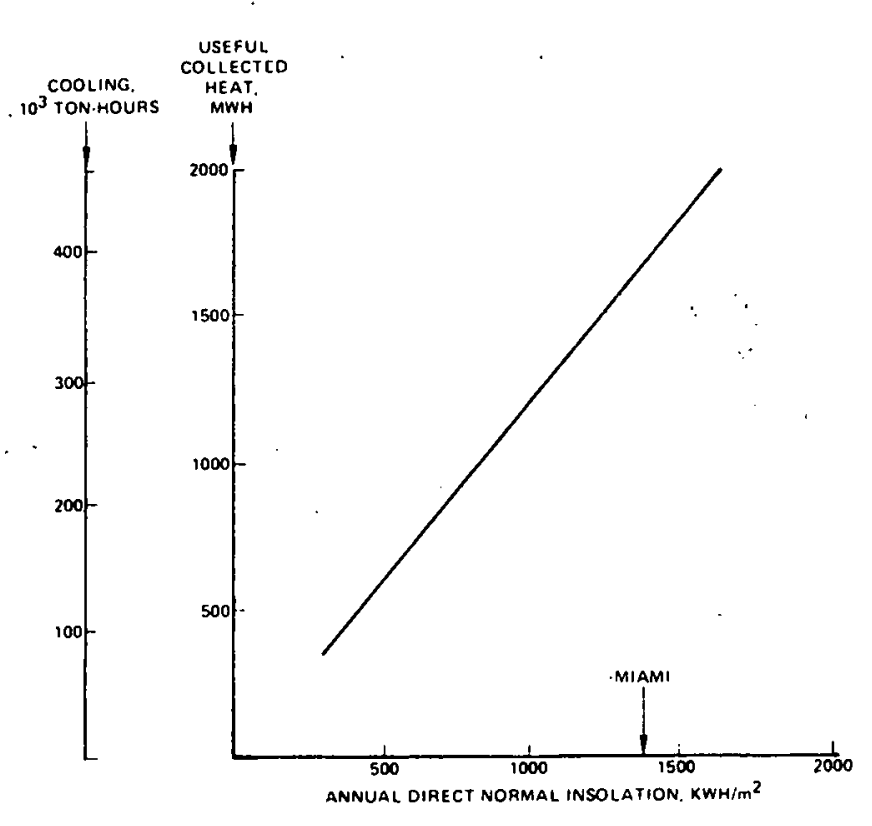

Figure 5-18. Annual Thermal and Cooling Performance 


\section{SECTION 6}

\section{NONTECHNICAL ISSUES}

As a result of the various considerations encountered during the course of this Phase I study, several nontechnical issues have been identified which may be of special interest relative to installing and operating PV power plants. Some of the more significant of these issues are discussed below:

\section{1 PLANNING IMPACT}

Presently, the State of Florida is highly dependent on fossil fuels for the source of electrical energy generation. Sea World of Florida is a relatively high consumer of electricity. 1978 expenditures for electricity have averaged nearly $\$ 75,000$ per month. Demonstrating a spirit of environmental consciousness, Sea World chose to participate in the PVCAE program with the hope that this particular experiment would be designed as a total energy approach to photovoltaics and that it would optimize both the thermal and electrical contribution to the Theme Park's energy budget.

The decision to participate in this experiment has had a major impact on Sea World's Master Development Plan. Relative to energy output, the experiment is area intensive and will provide only about $50 \mathrm{~kW}$ per allocated acre. Incorporation of this project into the Master Plan has caused Sea World to modify previously programmed land-uses and area allocations. This, in turn, has had an impact on land takedown schedules and the subsequent allocation of land costs to capital projects.

This project has also required re-opening of dialogues with local jurisdictional agencies. Sea World's land holdings are contained within an approved Planned Unit Development (P. U. D. ). All proposed land-uses within this P. U. D. have been well defined since 1973. Substantial changes in proposed land-uses must be approved by the Orange County Board of Commissioners. The unusual nature of this experimental project made its land-use classification difficult to establish. In the initial submittal to the County, Sea World assumed that the experimental and environmental nature of this project would allow its development to occur in a designated area of open space: This petition was denied by the County and subsequently the proposed site was relocated. The new site has been tentatively approved by the County and the process for final approval will be initiated during Phase II of the project. 


\subsection{OPERATIONAL IMPACT}

If selected for construction and testing phases, the project will also have a significant impact on operations and maintenance programs as they presently exist at the Theme Park. The PV facility will be sited outside, but adjacent to the Theme Park's perimeter fence, thus allowing unrestricted access to the general public from outside and controlled access to paying guest from inside the Theme Park.

Unquestionably, the operation and maintenance of the PV facility itself will require development of technical expertise not required by existing O\& M programs.

\section{3 ECONOMIC IMPACT}

From a cost-sharing viewpoint, some Sea World owner costs are readily apparent. These would include costs associated with land take-down, increased insurance premiums, increased taxes, new operating and maintenance costs, back-up system costs, potential costs for down stream retrofits to combat obsolesence and, finally, costs for developing a Visitor Information Center. Conservatively, these costs will be in excess of $\$ 1$ million.

Realistically, the cost-to-benefit ratio for the project does not appear to be advantageous to Sea World if based solely on an analysis of the energy end product. It is hoped that the attraction value of the experiment will help alleviate some of the cost burden of the project by attracting visitors to the Theme Park.

\section{4 INSURANCE COVERAGE}

Review of the PCAE design with insurance specialists at Sea World has not identified any problems of an unusual nature relative to insurance coverage. The facility will be located in a secure, protected area with access limited to authorized personnel. The system is essentially benign with a small likelihood of causing injury. The possibility of injury by reflected sunlight is low since the focus of light occurs within the collectors themselves along their focal lines.

During construction, insurance will be covered by the construction contractor in the manner of normal construction projects. Upon completion, the facility will be assessed by insurance underwriters and appropriate insurance coverage defined at that time.

\section{5 VISITOR DEMOGRAPHICS}

\section{5. 1 VISITOR SCOPE}

One of the most attractive aspects of siting this experiment at Sea World of Florida will be the public exposure derived from its proximity to the Theme Park.

In 1977, over 31 million tourists visited Florida. Of these, 24 million spent visitor time in the Central Florida Corridor, and 11 million visited Disney World, six miles west of the proposed 
site for the PV facility. In this same year, 2.4 million people visited the Sea World Theme Park.

Sea World's 1978 attendance is running $20 \%$ above 1977 and $10 \%$ above projection for 1978 . Indications are that Sea World will see 2.75 million visitors in the Orlando Park this year. In this event, projections for 1979 will probably be 3 million visitors, all of whom will get some exposure to the planned PV facility.

\section{5. 2 VISITOR CHARACTER}

A pproximately $70 \%$ of Sea World's annual attendance is comprised of domestic and international tourists. The group generally consists of individuals on economic, political and social levels that correlate to collective influence on policy decisions in those respective levels. At the proposed site, the goals and objectives of DOE relative to the experiment can be exposed in a window to America from a single focal point. This site can provide a universally based statistical sample for use in assessing any aspect of the experiment. 
APPENDIX A

DC/AC INVERTER

THEORY OF OPERATION 


\title{
I IOIITIIHS PROTECTION \\ OF A \\ PHOTOVOLTAIC CONCENTRATOR \\ APPLICATION EXPERIMENT
}

AT

1. SEA WORLD

ORLANDO FLORIDA

$$
\text { FOR }
$$

GENERAL ELECTRIC COMPANY

ADVANCED ENERGY PROGRAMS

P. O. BOX 8661

PHILADELPHIA, PENNSYLVANIA 19101

SUB-CONTRACT A28000-W20163

\author{
BY \\ J.A. PLUMER \\ K.E. CROUCH
}

8 FEERUARY 1979

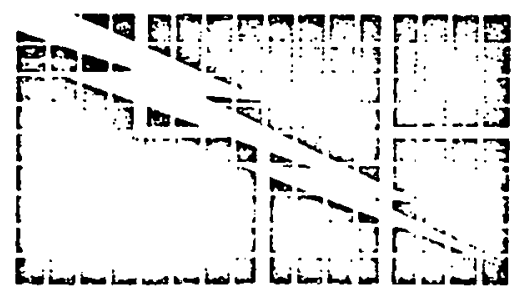

LIGHTNING

TECHNOLOGIES, INC.

560 Hubbard Avenue

Pittsfield, Massachusetts 01201 
TABLE OF CONTENTS

Page

Introduction . . . . . . . . . . . . . . . 1

1.0 Lightning Protection Requirements........... 2

1.1 Number of Expected Strikes to the PV Plant... 2

-1.2 The Electrical Environments ......... 4

1.2.1 From Direct Strikes........... 4

1.2.2 From Nearby Strikes.......... . 5

1.3 Surges Induced in Cables by Magnetic Fields . . 8

1.4 Surges Produced by Earth Voltages . . . . . . . 12

2.0 Analysis of Lightning Effects . . . . . . . . . 15

2.1 Direct Strike Damage . . . . . . . . . . 15

2.2 Analysis of Cable Transients . . . . . . . . . . 17

2.3 Lightning Effects on the Photovoltaic Receiver. 23

2.4 Summary . . . . . . . . . . . . . . . . 33

3.0 Protection Design . . ... . . . . . . . . . 34

3.1 Turntable Direct Stroke Protection. . . . . . . . 34

3.2 Protection of Cable Circuits . . . . . . . . . . 35

3.2.1 AC Power Cables........... . 35

3.2.2 DC Power Cable . . . . . . . . . 35

3.2.3 Signal Cable . . . . . . . . . . 36

3.2.4 Protection of the Equipment Building . . 37

3.2.5 Summary of Protection Recommendations . . 37

References . . . . . . . . . . . . . . . . . 39 
INTRODUCTION

The inverter system proposed for the Sea World Photovoltaic Concentrator Application Experiment is a 6-pulse, line-commutated unit. This inverter system has been successfully applied for many years in steel-rolling mills to drive and control DC motors. The accumulated experience predates the invention of silicon-controlled rectifiers.

The discussion of the theory of inverter operation begins with a description of rectifier operation because it is easier to visualize the operation of a rectifier.

When a bridge unit is suitable for either rectifier or inverter operation, it is usually called a converter unit. The converter terminology is used in the following discussion, but the Sea World bridge will be an inverter only; it will not be suitable for rectifier operation.

Voltages are designated by the symbol $U$ in the following discussion because this is the generally acceoted international symbol for voltage. 


\section{Eigure: 1 CONVERTER UNIT}

Converter unit is an operative unit comprised of converter bridge, converter transformer, associated control equipment and switching devices.

Solid-state valves are the basic heart of the converter unit. They consist of series-parallel combinations of high jöwer silicon Control Rectifiers (thyristors).

The name thyristor defines any semiconductor switch whose bi-stable action depends on $p-n-p-n$ regenerative feedback. The Silicon Controlled Rectifier (SCR) is by far the best known of all thyristor devices. Because it is a unidirestional device - current flows from anode to cathode only - and has three terminals (anode, cathode and control gate), the SCR is classified as a reverse blocking triode thyristor.

Converter transformers are the link between the $A C$ power system and the HVDC valve. They are specifically designed to withstand the insulation requirements of DC application and to step up or down the AC system voltage to appropriate levels for optimum valve design. During operation the associated induction voltage regulator adjusts the valve voltage according to loading. 


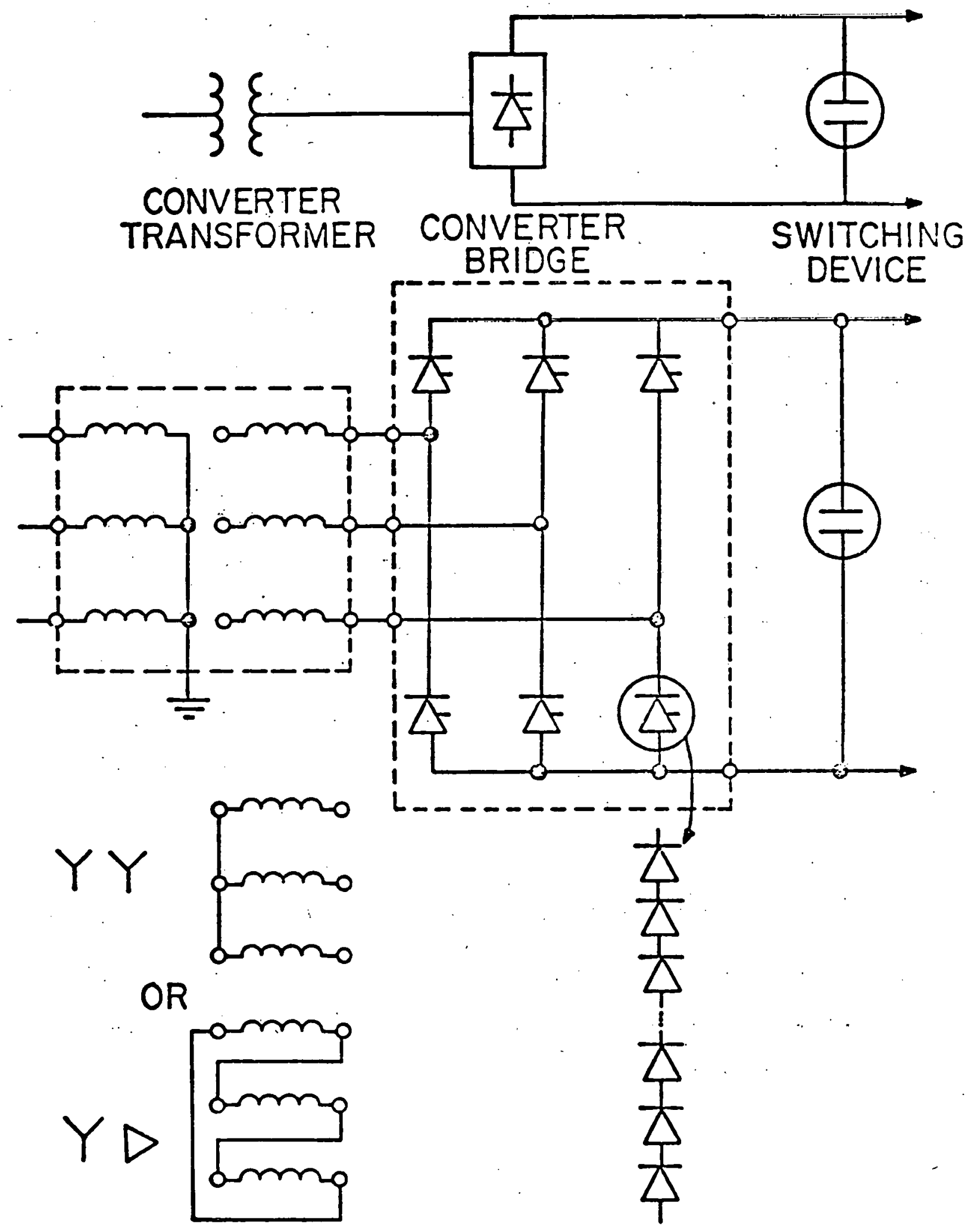

FIGURE 1 CONVERTER UNIT 
FIgure: 2 CONVERTER OPERATION

Converter bridge is the building block of the HVDC transmission system. A typical bridge is shown, where the valves are represented by ideal and "Intelligent" switches.

The principles of rectifier operation are based on the generation of DC voltages by utilizing segments of the sinusoidal AC voltage waves.

One set of switches $(1,3$ and 5$)$ is connected to the $+C$ output terminal and furnishes a voltage $U_{C-O}$ above the zero reference line (solid curve) while a second set of switches $(2,4$ and 6$)$ is connected to the -A terminal and furnishes a voltage $U_{-A-O}$ below the reference line (broken curve). Thus a load connected between C-A is supplied with the sum of two voltages. Since the two groups of switches operate with opposite polarity voltages, their ripple voltages are displaced and the total voltage shows a so-called 6 pulse ripple.

Note that this figure presents the alternating and direct voltages with respect to the neutral (0) point of the transformer. 


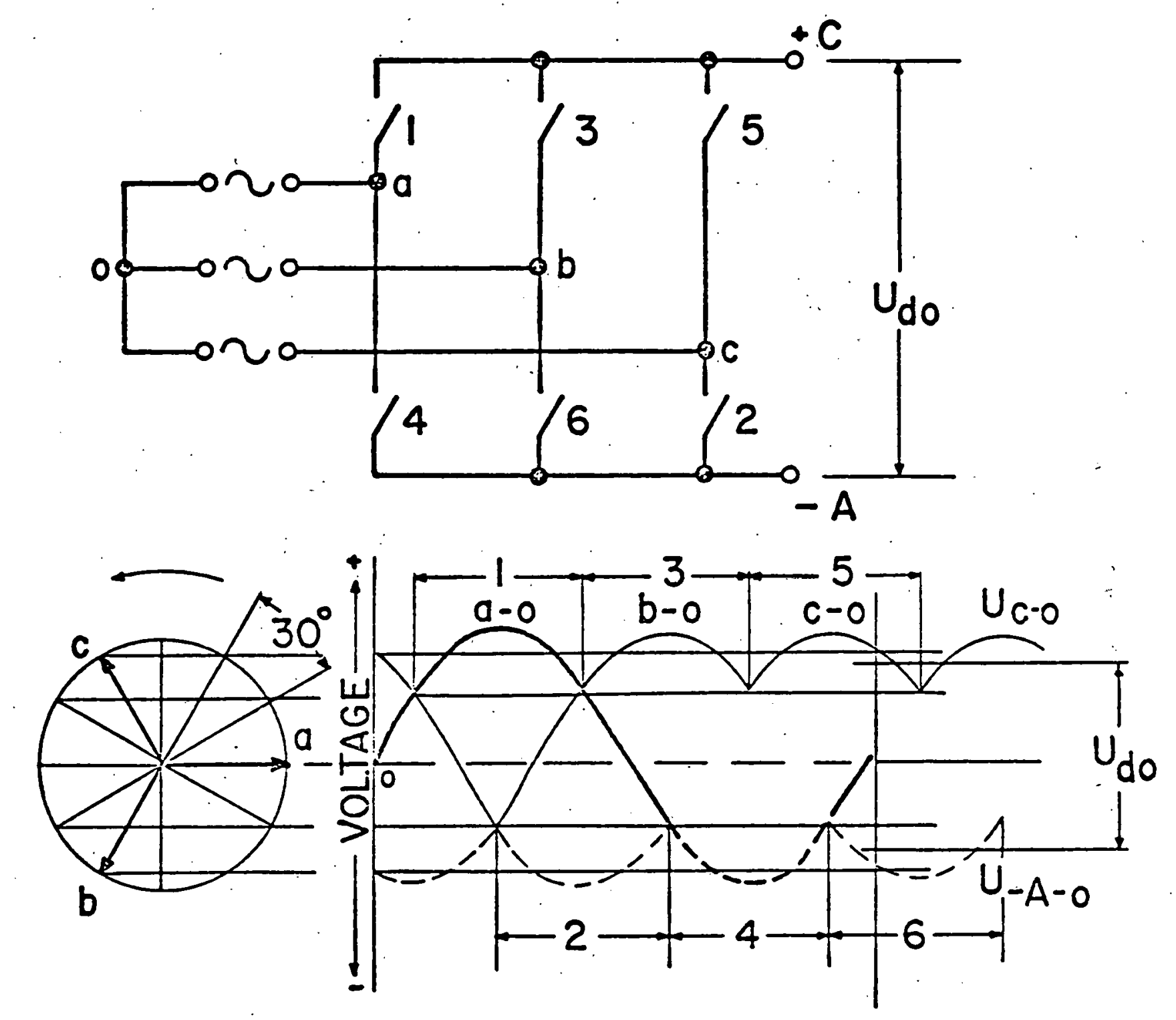

FIGURE 2 CONVERTER OPERATION 


\section{Eigure: 3 IDEALIZED RECTIFIER}

The functions of the "intelligent" switch can be performed with the SCR which is a unidirectional current switching device. The current can only flow in one direction, from anode to cathode.

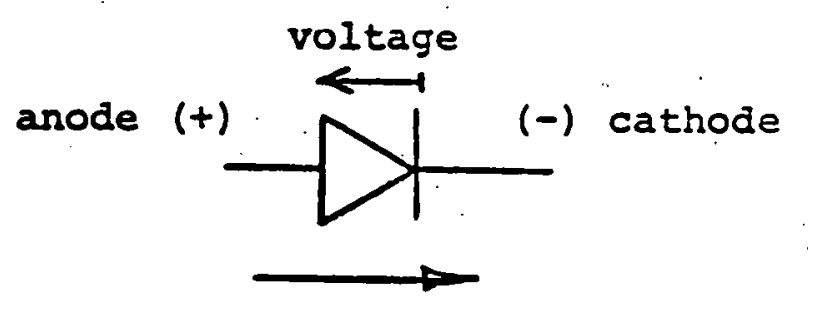

Direction of Current Flow

The SCR switch will normally conduct only when the anode is more positive than the cathode, and it has been switched on by application of positive voltage to the gate.

A double wye, six (6) pulse converter circuit is shown. Three valves $(2-6-4)$ have a common anode connection and three valves $(1-3-5)$ have common cathode connection.

The idealized rectifier concept implies a transformer without leakage reactance and an AC supply system without impedance. Uncer these conditions we have instantaneous commutation in the rectifier which means instantaneous transfer of current from one phase and valve to the consecutive phase and valve. If all gates were maintained positive, the current at any given moment would flow through the anode with the highest positive potential.

$$
A-6
$$


Figure: 3 IDEALIZED RECTIFIER (cont'd)

Beginning at time $x$ in the figure it is seen that phase a, which is connected to valves 1 and 4 is positive, phase $b$ is zero and phase $c$ is regative but equal to phase a in magnitude. The anode of valve I is therefore at the highest potential among the common cathode connected valves and so phase a feeds current through valve 1 to the DC load circuit. At the same time; valve 2 of the common anode connected valves has the highest positive anode to cathode potential across it because its cathode is at the greatest negative potential. Therefore, the current from the DC load returns through valve 2 , thus completing the circuit.

As we advance along the time scale, the potential of phase a decreases while the potential of phase b increases. At time $Y$, the rising voltage of phase $b$, which is connected to valves 3 and 6 becomes more positive than the decreasing voltage of phase a. Therefore, the current transfers instantaneously from valve 1 to valve 3. At the same time, valve 2 continues to conduct since its anode continues to be at the highest potential relative to its cathode compared to valves 4 and 6 . 
EIgure: 3 IDEALIZED RECTIFIER (cont'd)

Advancing still further along the time scale, we reach time $z$ where the increasing negative potential of valve 4 becomes greater than the decreasing negative potential of valve 2. At this point the positive anode to cathode voltage of valve 4 becomes greater than the anode to cathode voltage of valve 2 and the current transfers from valve 2 to valve 4. The current continuous to flow through valve 3 of the common cathode connected valves. In this manner the phases $a, b$ and $c$ of the AC. system feed power in cyclic fashion to the DC system.

The result of this behavior is to generate. a DC voltage with ripple having the wave shape indicated by the heavy line labeled $U_{C-A}$.

The DC voltage across the rectifier DC terminals is defined as positive when the cathode terminal is more positive than the anode terminal. This is the case for the rectifier which can be considered as a generator. For the inverter, the cathode will be more negative than the anode. 

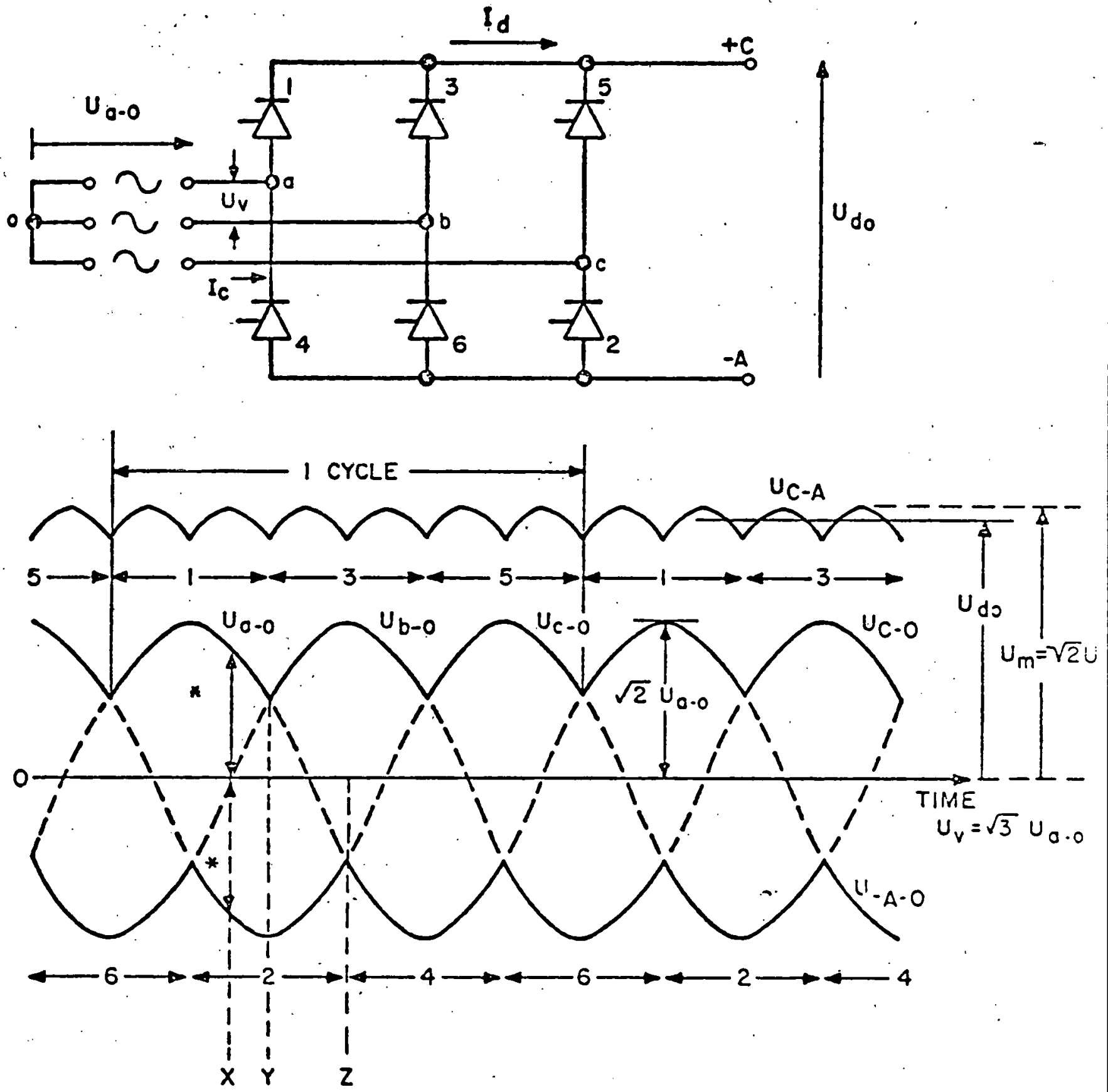

* Indicates equal magnitudes 
Figure: 4 IDEALIZED RECTIFIER - CURRENTS

In the idealized case' the conduction period of each valve is $1 / 3$ of a cycle or $120^{\circ}$ electrical on a $60 \mathrm{~Hz}$ basis. A new valve is being switched in every $60^{\circ}$ electrical which is $1 / 6$ of a cycle. Thus in one cycle there are 6 switchings which give 6 pulses; hence the name " 6 pulse converter".

$U_{m}$ is defined as the crest value of the $D C$ voltage at no load and zero phase control. It is equal to the crest value of the phase to phase voltage of the AC transformer valve winding.

$U_{\text {do }}$ is the average value of the ideal no load DC voltage when there is zero phase control. All other voltage quantities are preferably expressed in terms of $\mathrm{Udo}$. 


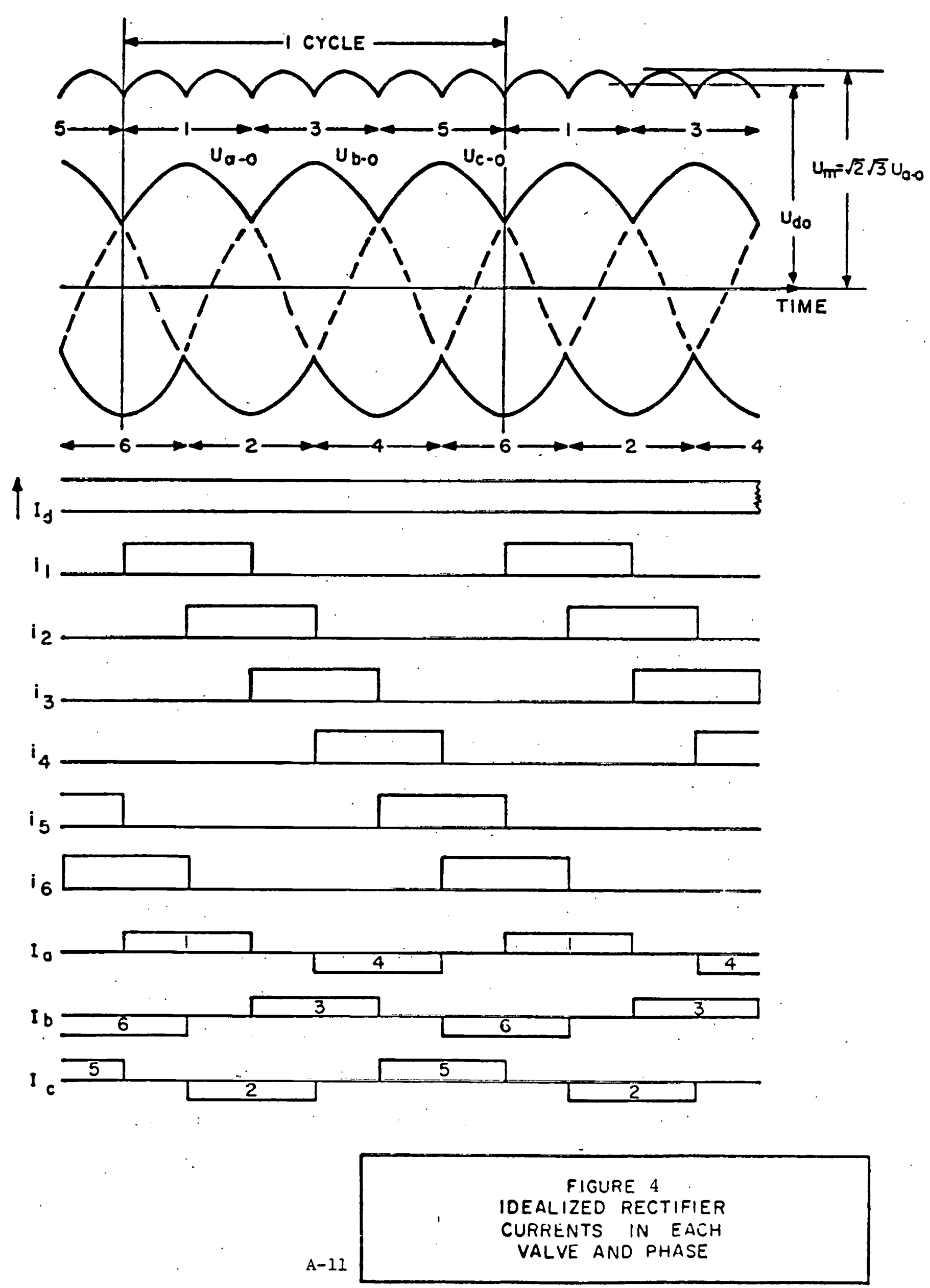




\section{Eigure: 5 NO LOAD VOLTAGE}

The direct voltage of a rectifier connection with zero phase control and no internal voltage drop is clearly defined by the alternating voltages and is therefore selected for a general voltage reference. A formula for computing this fundamental value will be derived.

In a rectifier connection the DC circuit is periodically "switched around" among points of alternating potential. With open output there is no current and consequently no voltage drop. Hence the direct voltage at no load must equal at any instant a certain combination of the alternating voltages as, for example, the sum or the difference of the alternating voltages of two phases. We assume that the alternating voltages are undistorted, the sum or the difference is also a sinusoidal voltage so that, during each interval of operation, the direct voltage is described by a sine function. During one cycle there are several intervals of operation, depending upon the rectifier connection. Thus the curve of the direct voltage at no load consists of as many identical sections of sine curves per cycle as there are intervals of operation, and if the transition from one sine curve to the other is not delayed by phase control, each section is symmetrical with respect to the crest point of the sine curve. 
Figure: 5 NO LOAD VOLTAGE (cont'd)

The number of sections is called the Pulse Number, designated by $q$. For various pulse numbers the curves of the direct voltage are shown. Since the shape of these curves is so simple and is only a function of the pulse number, and since the magnitude is. clearly defined by the alternating voltages, the average value of the direct voltage at no load and zẹo phase control is úsed as a general voltage Reference. Its symbol is $\mathrm{U}_{\mathrm{CO}^{\prime}}$ and all other voltage quantities are preferably expressed in terms of $\mathrm{u}^{\circ}$

The quantity $U_{d o}$ is a theoretical figure. Therefore $U_{\text {do }}$ should be understood as the value computed from the alternating voltages, ignoring any voltage drop.

For computing $U_{d o}$ the direct voltage at no load and zero phase control must be integrated over a certain period of time, and the result must be divided by the length of this period. Since there are $q$ identical intervals per cycle, and each interval is symmetrical by itself, the range of integration can be reduced to one half-interval, and the average value can be determined from the crosshatched area.

$$
\text { Crosshatched area }=U_{m} \int_{0}^{\pi / q} \cos (\omega t) d(\omega t)=U_{m} \sin \frac{\pi}{q}
$$
where $U_{m}=$ crest value of direct voltage at no load and zero phase control. Provided the sections of the sine curves follow each other continuously, which excludes $q=1$, the crosshatched area also equals $\frac{\pi}{q} U_{\text {do }}$. 
Figure: 5 NO LOAD VOLTAGE (cont'd)

The direct voltage ratio is a fundamental relationship

$\frac{U_{d o}}{U_{m}}=\frac{q}{\pi} \sin \left(\frac{\pi}{q}\right)$ where $q$ is the number of pulses

but $q \neq 1$. The direct voltage ratio is exclusively

based on the shape of the DC voltage curve.

Example: for a 6 pulse converter, $q=6$ and

$\frac{v_{d o}}{\sigma_{m}}=\frac{6}{\pi} \sin \frac{\pi}{6}=\left(\frac{6}{\pi}\right) \sin 30^{\circ}=\frac{3}{\pi}$

$v_{d o}=\frac{3}{\pi} v_{m}$ but $u_{m}=\sqrt{2} v_{v}$ or $\sqrt{2} \sqrt{3} u_{a-0}$

$=\frac{3}{\pi} \sqrt{2} U_{v}=1.35 U_{v} \begin{aligned} & \text { in terms of valve } \\ & \text { phase-to-phase voltage }\end{aligned}$

$=\frac{3}{\pi} \sqrt{2} \sqrt{3} U_{a-0}=2.34 U_{a-0} \begin{aligned} & \text { in terms of valve } \\ & \text { phase-to-netural }\end{aligned}$ voltage.

Example:

The converter transformer valve winding is rated

$U_{v}=44.4 \mathrm{~V}$ phase-to-phase or $U_{a}=25.63$ phase-to-neutral.

$\mathrm{v}_{\mathrm{v}}=44.4 \mathrm{~V}$. or $\mathrm{U}_{\mathrm{a}}=25.63 \mathrm{~V}$

$U_{d_{0}}=\frac{3}{\pi} \sqrt{2} U_{v}=\frac{3}{\pi} \sqrt{2} 44.4=59.95 \mathrm{~V}$

$u_{d o}=\frac{3}{\pi} \sqrt{2} \sqrt{3} U_{a} \frac{3}{\pi} \sqrt{2} \sqrt{3} 25.63=59.95 \mathrm{~V}$ 


$$
k=\frac{U_{d o}}{U_{m}}=\frac{q}{\pi} \sin \frac{\pi}{q}
$$

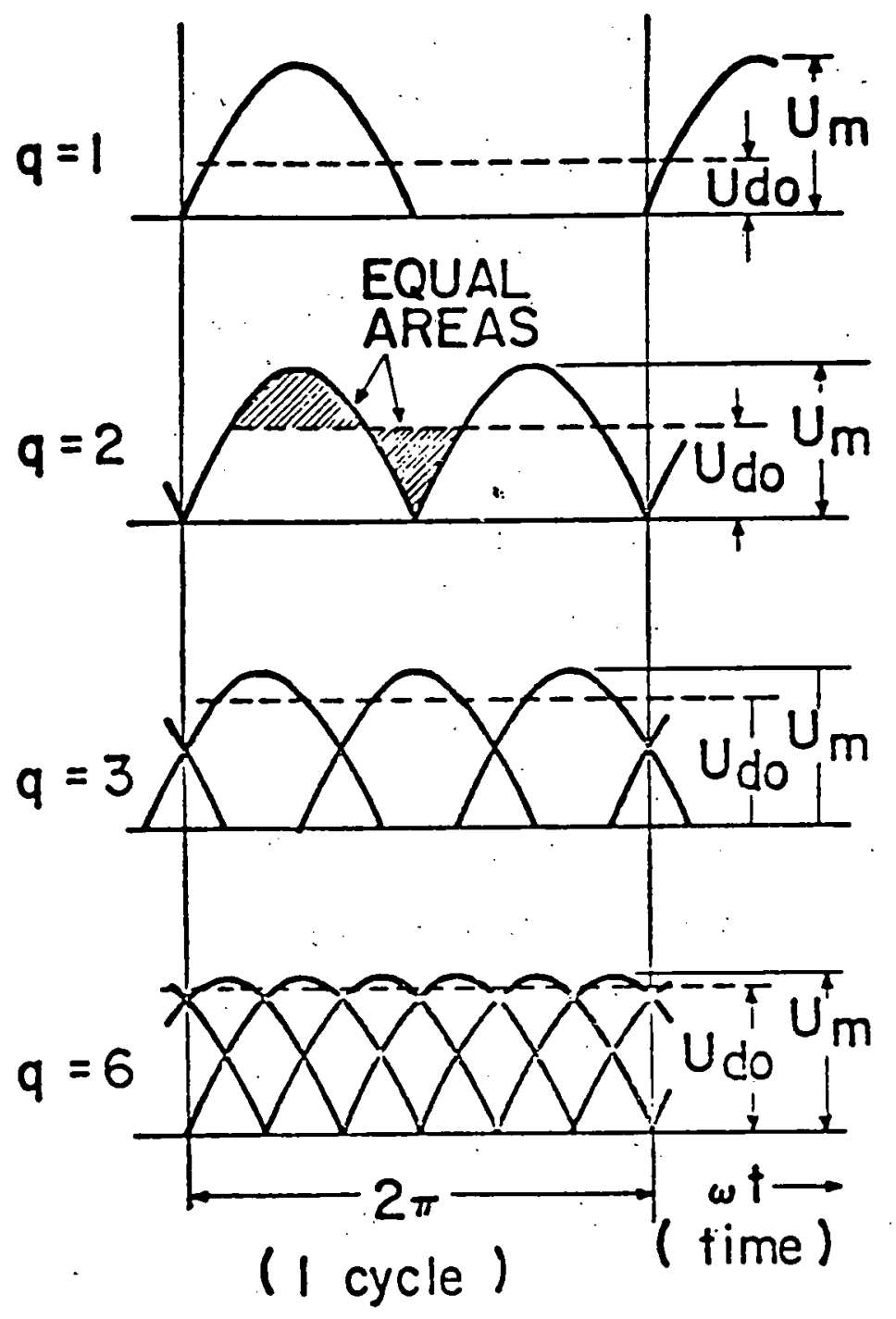

$q=12$ $\frac{2}{\pi} \underbrace{\sin \frac{\pi}{2}}_{1.0}=\frac{2}{\pi}=0.637$

$\frac{3}{\pi} \frac{\sin \frac{\pi}{3}}{\frac{\sqrt{3}}{2}}=\frac{3 \sqrt{3}}{2 \pi}=0.827$ $\frac{12}{\pi} \sin \frac{\pi}{12}=\frac{6 \sqrt{2}}{\pi(\sqrt{3}+1)}=0.559$

$$
U_{\text {do }}=k \underbrace{\sqrt{2} U_{v}}_{U_{m}}
$$

FIGURE 5

IDEAL NO LOAD VOLTAGE 
Figure: 6 EFFECT OF COMMUTATING REACTANCE

In the real life circuit the current cannot rise or fall instantaneously because it is flowing through the transformer leakage reactance and the AC source reactance. There must be a time interval beginning at time $Y$ in the figure when the current in valve 1 is falling while the current in valve 3 is rising. The current transfers only gradually from one phase " $a$ " and valve to the consecutive phase " $b$ " and valve. This means that commutation in the rectifier requires a certain time period. During this time, which is called the overlap period, two valves are simuitaneously conducting current. The current of the "outgoing" valve steadily declines until zero is reached when current conduction naturally ceases, and the current of the "incoming" valve steadily rises until full value-is reached at the instant the outgoing valve ceases to conduct and the commutation process is completed.

Starting at time $Y$, the potential of "b" phase exceeds that of "a" phase. This causes valve 3 to conduct (still assuming continuous positive gating). Valve 1 is also conducting because it still carries the load current. Thus the potential difference between " $b$ " and " $a$ " phases is suddenly forced to be absorbed in a pircuit that contains only the reactance of the transformer windings and the very small reactance of the bus bars of phases " $a$ " and " $b$ ". 
Figure: 6 EFFECT OF COMMUTATING REACTANCE (cont'd)

This condition is comparable to a'short time, short circuit between phases " $a$ " and " $b$ ".

The short circuit current $\left(i_{c}\right)$. flows from phase " $b$ " through valve 3 in the forward direction, while it opposes the load current $\left(i_{1}\right)$ in valve 1 . The current in valve 1 becomes zero when the short circuit current $\left(i_{c}\right)$ becomes equal to the load current $\left(i_{1}\right)$. Because of the unidirectional characteristic of the valves, valve 1 will block, thereby clearing the short circuit and the transfer of the load current from "a" phase, valve 1 to "b" phase, valve 3 is completed.

The resulting current wave shapes are shown in the figure for valves 1,3 and 5 . A similar action exists between valves 2,4 and 6 but it is not shown.

When both valves 1 and 3 are operating simultaneously, DC output voltage assumes a mean value between the two phase to neutral voltages. This reduces the average DC voltage by $U_{x}$ which is proportional to the transformer reactance $\left(X_{T}\right)$ and to the magnitude of the DC current ( $\left.I_{d}\right)$. The shaded area in the $A C$ voltage waves in the figure is the volt seconds we lost in the commutating reactance. The larger the DC current, the longer it takes to commutate and hence the greater the volt second area will be. 
Figure: 6 EFFECT OF COMMUTATING REACTANCE (cont'd)

It can be derived mathematically that

$$
\nabla_{x}=1 / 2 x_{T} \frac{I_{d}}{I_{d N}} U_{d o}
$$

where $X_{T}$ is expressed in per unit, $I_{d}$ is the DC current at any particular load and $I_{\mathrm{dN}}$ is the rated DC current (one per unit current).

Example:

The rated transformer impedance at EPRI Station 1s 22.48. The impedance value can be used as transformer reactance with only slight error. Therefore, the "reactive voltage drop" for rated current is: $\nabla_{x}=1 / 2 \times .224 \times 59.95=6.714 \mathrm{kV}$

It can be seen from the figure that this moves the center line of the current block to the right by an engle $\mu / 2$ and gives an inherently lagging power factor of $\cos \mu / 2$. 

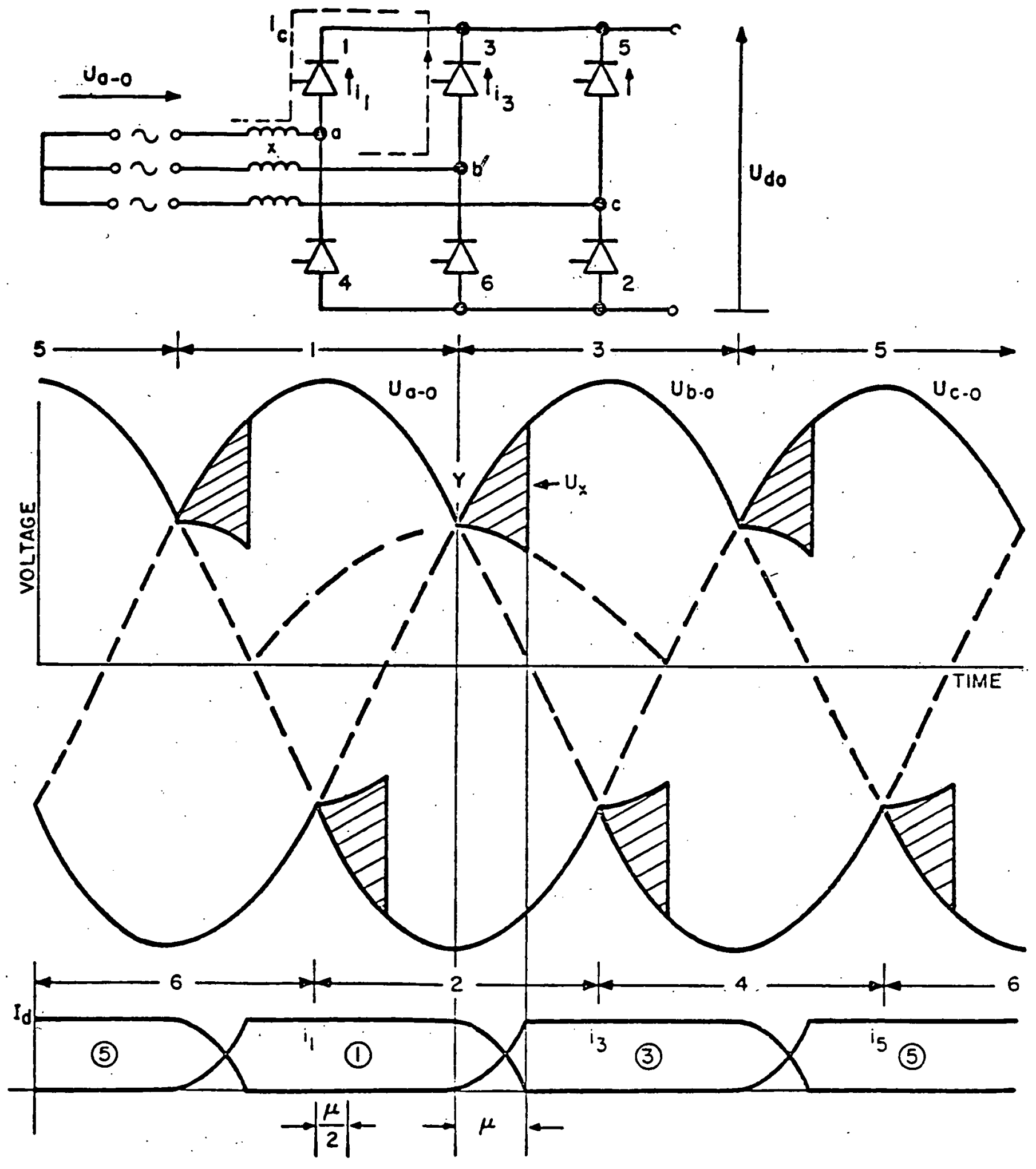

FIGURE 6

EFFECT OF

COMMUTATING REACTANCE 
Figure: 7 EFFECT OF PHASE CONTROL

Without gate control delay, the current transfer between two valves and the corresponding phases starts as soon as the potential of the "incoming" phase exceeds the potential of the "outgoing" phase. Thus, the DC circuit has the highest possible potential at any instant and the DC voltage is at maximum.

With suitable gate cortrol we can hold back the turn on of the incoming valve thereby delaying the transfer of load current from the "outgoing" valve to the "incoming" valve. This is illustrated in the subject figure where at time $Y$ the potential of phase "b" begins to exceed the potential of phase "a". If by means of gate control the turn on signal is given at time " 2 ", the start of valve 3 conduction has been delayed by the angle a (alpha).

By delaying the gate turn on, each $1 / 3$ conducting section of the $A C$ voltage will be slid off the crest of the voltage wave. By delaying the instant of gating, the magnitude of the rectifier output voltage can be controlled.

It can be observed that gate control will move the center line of the current block to the right by the angle $\alpha$ and gives an inherently lagging power factor of approximately $\cos \alpha$. 
Figure: 7 EFFECT OF PHASE CONTROL (cont'd)

Mathematically the following expression can be obtained :

$$
\begin{aligned}
& u_{d}=u_{d_{0}}-u_{\alpha}=u_{d_{0}} \cos \alpha \\
& u_{\alpha}=u_{d_{0}}(1-\cos \alpha)
\end{aligned}
$$

where $U_{d}=D C$ voltage output

$$
\begin{aligned}
& U_{\alpha}= \text { Reduction of DC voltage caused by } \\
& \text { gate control. } \\
&=\text { Delay angle (also called gating angle) } \\
& U_{d o}=\text { Ideal no load DC voltage }
\end{aligned}
$$

Example:

For the EPRI Terminal $U_{d o}$ is $59.95 \mathrm{kV}$ with $\alpha=18^{\circ}$.

$$
v_{\alpha}=59.95(1-.9511)=2.93 \mathrm{kV}
$$



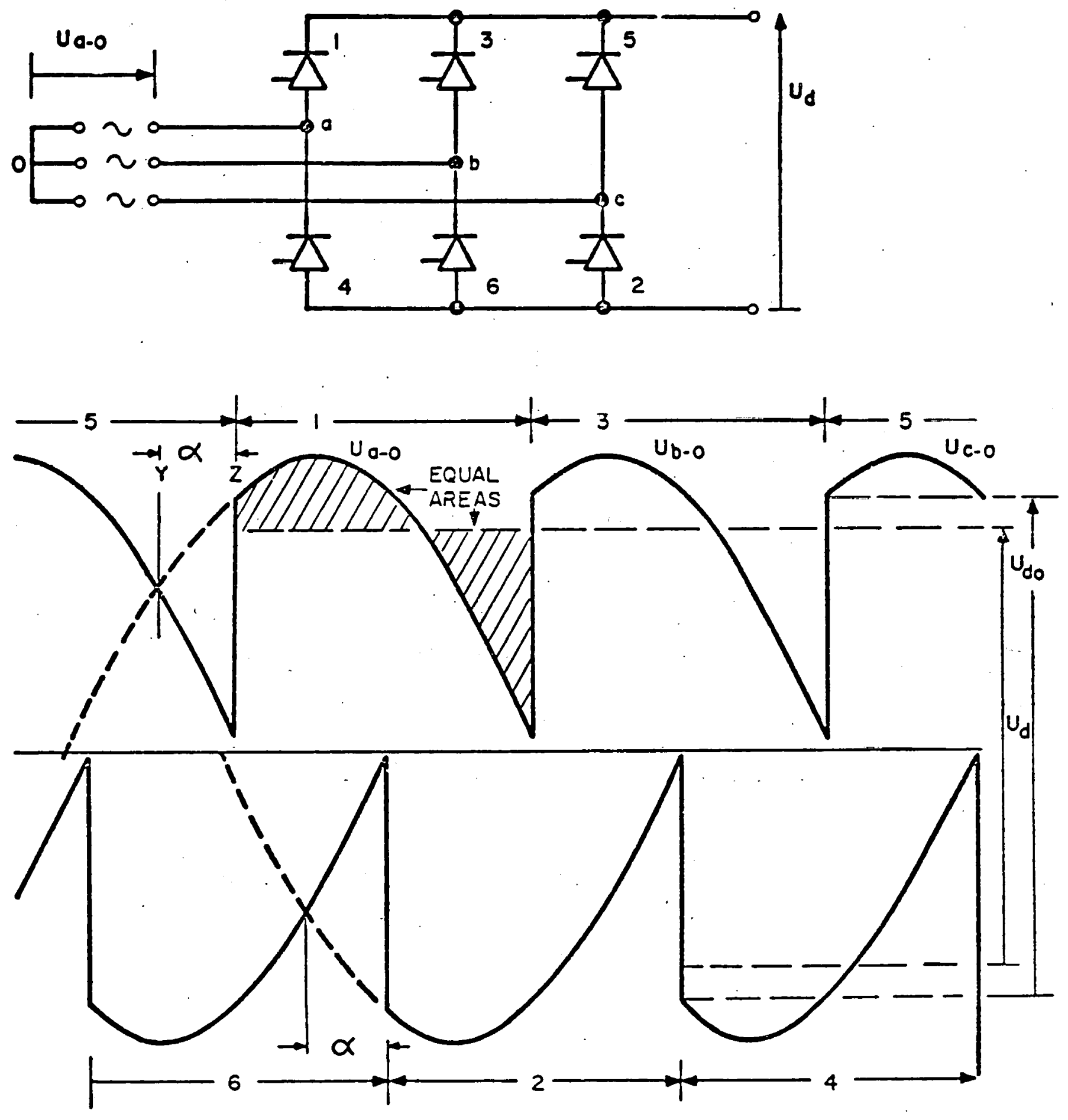

\section{(5)}

(1)

(3)

(5)

FIGURE 7

EFFECT OF PHASE CONTROL IDEAL RECTIFIER CIRCUIT 
FIgure: 8 OPERATING CONDITION - RECTIFIER

Under load and with phase control the direct voltage differs from the theoretical value $U_{\text {do }}$. It is reduced as, a consequence of commutation and phase control, and by the resistive voltage drop. The reductions caused by phase control and commutation are denoted by $U_{\alpha}$ and $U_{x}$, whereas the resistive voltage drop is usually conceived as part of the direct voltage and is combined with the voltage across the load circuit in the theoretical quantity $U_{d}$. Furthermore, all voltages and voltage reductions are represented by their average values and can therefore be added according to

$$
u_{d o}=u_{x}+u_{\alpha}+u_{d}
$$

where $\mathrm{U}_{\mathrm{do}}=$ theoretical direct voltage with zero phase control and no voltage drop. avg value.

$u_{x}=$ reduction of direct voltage caused by commutation, avg value.

$u_{\alpha}=$ reduction of direct voltage caused by phase control, avg value.

$\mathbf{u}_{\mathbf{a}}$ = direct voltage including resistive voltage drop, avg value. This component is normaliy neglected because of the relatively small value. 
Figure: 8 OPERATING CONDITION - RECTIFIER (cont'd)

For rectifier operation:

$u_{d}=v_{d o}-v_{\alpha}-v_{x}$

Substituting we get:

$$
\begin{aligned}
& \tilde{U}_{d}=U_{d o} \cos \alpha-U_{d o} \frac{X_{T}}{2} \frac{I_{d}}{I_{d N}} \\
& \tilde{v}_{d}=U_{d o}\left(\cos \alpha-\frac{X_{T}}{2} \frac{I_{d}}{I_{d N}}\right)
\end{aligned}
$$

Example:

For normal full load operation at the EPRI Terminal

$$
\begin{aligned}
& \left(\alpha=18^{\circ}\right): U_{x}=6.714 \mathrm{kV} ; U_{\alpha}=2.93 \mathrm{kV} \\
& \mathbf{v}_{\mathbf{d}}=59.95-6.71-2.93=50.31 \mathrm{kV}
\end{aligned}
$$

or using the derived formula

$$
\sigma_{d}=59.95\left(\cos 18^{\circ}-\frac{.224}{2}\right)=50.30 \mathrm{kV}
$$

Subtracting the valve voltage drop and the resistive voltage drop we will get an $U_{d}$ which is close to $50 \mathrm{kV}$.

Since the EPRI terminals have two 6 pulse groups in series, the total DC voltage is $2 \times 50 \mathrm{kV}=100 \mathrm{kV}$. The rectifier output voltáge for a 6 pulse bridge is shown in Figure 8 . 

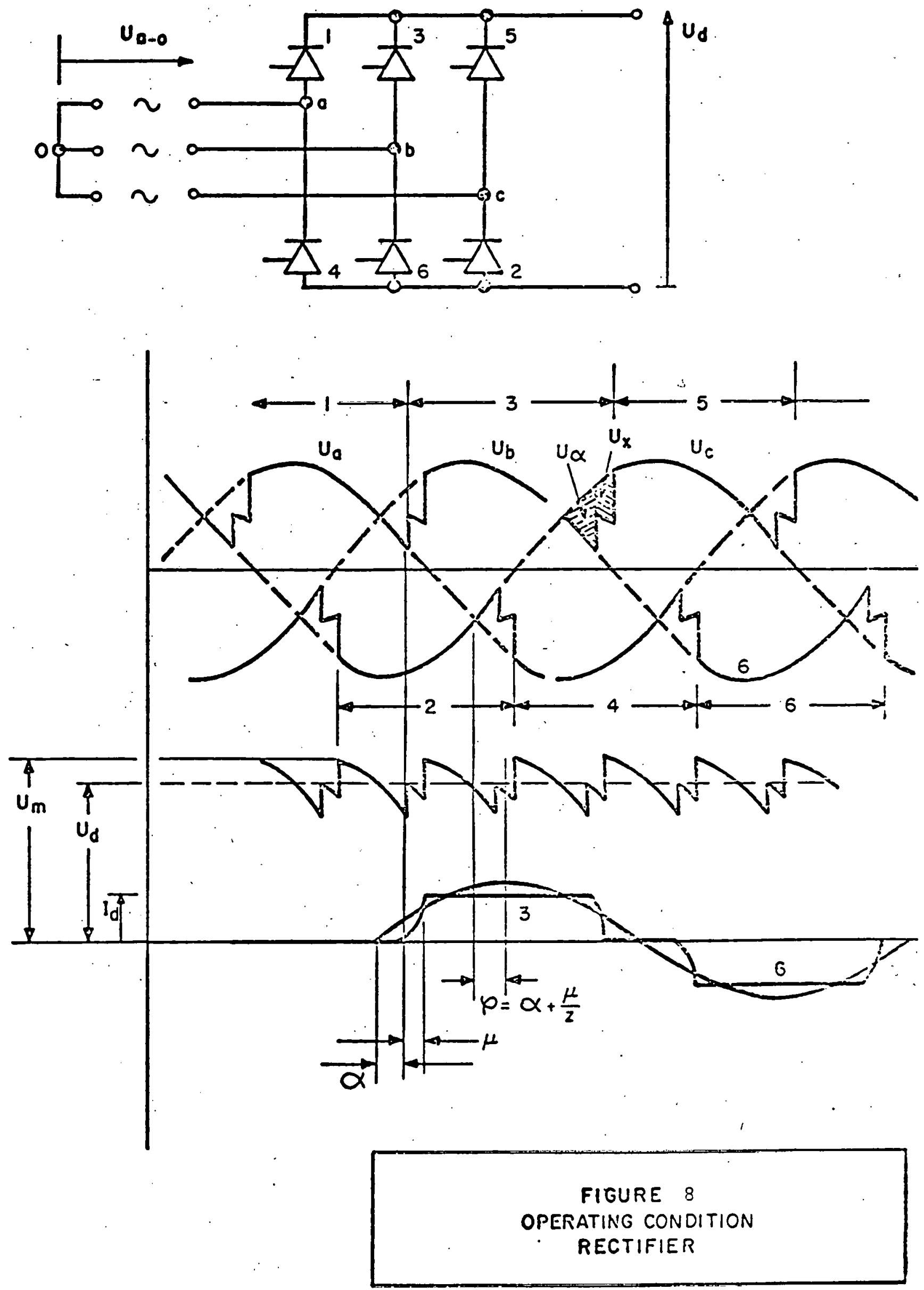


\section{Figure: 9 INVERTER OPERATION}

Delaying the gating further and further will reduce the magnitude of the DC output voltage until at a gating angle $\alpha=90^{\circ}$ the output voltage averages zero. Further increase of a will reverse the polarity of the DC output voltage and will gradually increase it in the opposite polarity. Therefore, any gate controlled converter can be used as an inverter by. increasing the gating angle beyond $90^{\circ}$.

The equation for $U_{d}$ remains

$$
U_{d}=U_{d o} \cos \alpha(a t, \text { no load) }
$$

for inverter operation. However, since $\cos \alpha$ is a negative value for $90^{\circ}<\alpha \leq 180^{\circ} \mathrm{U}_{\mathrm{d}}$ becomes a negative guantity.

In inverter operation we generally substitute the margin angle $\gamma$ (gamma) for the angle where

$$
Y=180^{\circ}-\alpha
$$

for the ideal condition. (no circuit impedance and infinite DC reactance).

For the realistic operating condition with finite reactive voltage drop in the converter (see Figure b).

$$
\begin{aligned}
& \beta=\gamma+\mu=180-\alpha \\
& \beta=\text { angle of advance for the inverter } \\
& \mu=\text { angle of overlap (duration of commutation) } \\
& \gamma=\text { margin of commutation } \\
& \alpha=\text { delay angle for rectifier }
\end{aligned}
$$


Figure: 9

INVERTER OPERATION (cont'd)

The rectifier voltage during no load operation is:

$$
u_{d}=u_{d o} \cos \alpha
$$

This voltage becomes negative if $a$ is greater than $90^{\circ}$. Since valves can concuct current only in one direction (from anode to cathode), direct current can flow through an inverter only when the DC voltage applied to it exceeds in absolute value the no load voltage. Thus the no load voltage of an inverter always represents a counter electromotive force (emf) to the rectifier and DC line circuit. To insure current flow to the inverter valves, the anodes must always be at a higher potential than the cathodes. The potential of the cathode is reduced by connecting the negative terminal of the incoming DC circuit to the cathode. This means that all. anodes are always at a higher DC potential than the cathodes and will; therefore, tend to carry current all the time. This must be prevented by suitable gate control and the application of the: AC voltage. Gate control is a convenience with rectification, but it is a must for inversion.

Assume valve 1 is carrying current in Figure 9. After the crossover time $x$ in Figure $9 a$ it can be seen that the potential of phase a is becoming more positive than the potential of phase $b$ so that commutation from valve 1 to 3 cannot occur naturally at time $x$. Commutation must be forced to take place 
INVERTER OPERATION (cont'd)

before the crossover time $x$, when the potential of phase $b$ is still more positive than the potential of phase a. This is done by appropriate gate control. It is essential that before the time of the crossover (point $x$ ) is reached and the anode of valve 1 is assuming a more positive potential than valve 3 , that the current in valve 1 must be zero. Only then can its" gate regain full control and block the return of the current into valve 1. Current zero is forced in an inverter valve only when the inverter $\mathrm{AC}$ voltage can force an AC current greater than and in opposition to the DC current.

The AC voltage produced by the valve group during inverter operation is shown in Figure 9. If the delay angle $\alpha$ is greater than $90^{\circ}$. theoretically the converter voltage becomes negative. In practice it remains zero as current flow through. the valve in the reverse direction. If now the passive load of the converter is replaced by a DC supply voltage (a rectifier) greater than the theoretical negative voltage of the converter and is of such polarity that it is conducive to a flow of current from the anode to the cathode through the inverter valves, inversion will take place. The DC current will be flowing against the inverter AC counter emf and power will be transferred from the DC to the AC side of the converter. 
Figure: 9 INVERTER OPERATION (cont'd)

For inverter operation (i)

$$
\begin{aligned}
U_{d i} & =U_{d o} \cos \gamma-U_{d o} \frac{X_{T}}{2} \frac{I_{d}}{I_{d N}} \\
& =U_{d o}\left(\cos \gamma-\frac{X_{T}}{2} \frac{I_{d}}{I_{d N}}\right)
\end{aligned}
$$



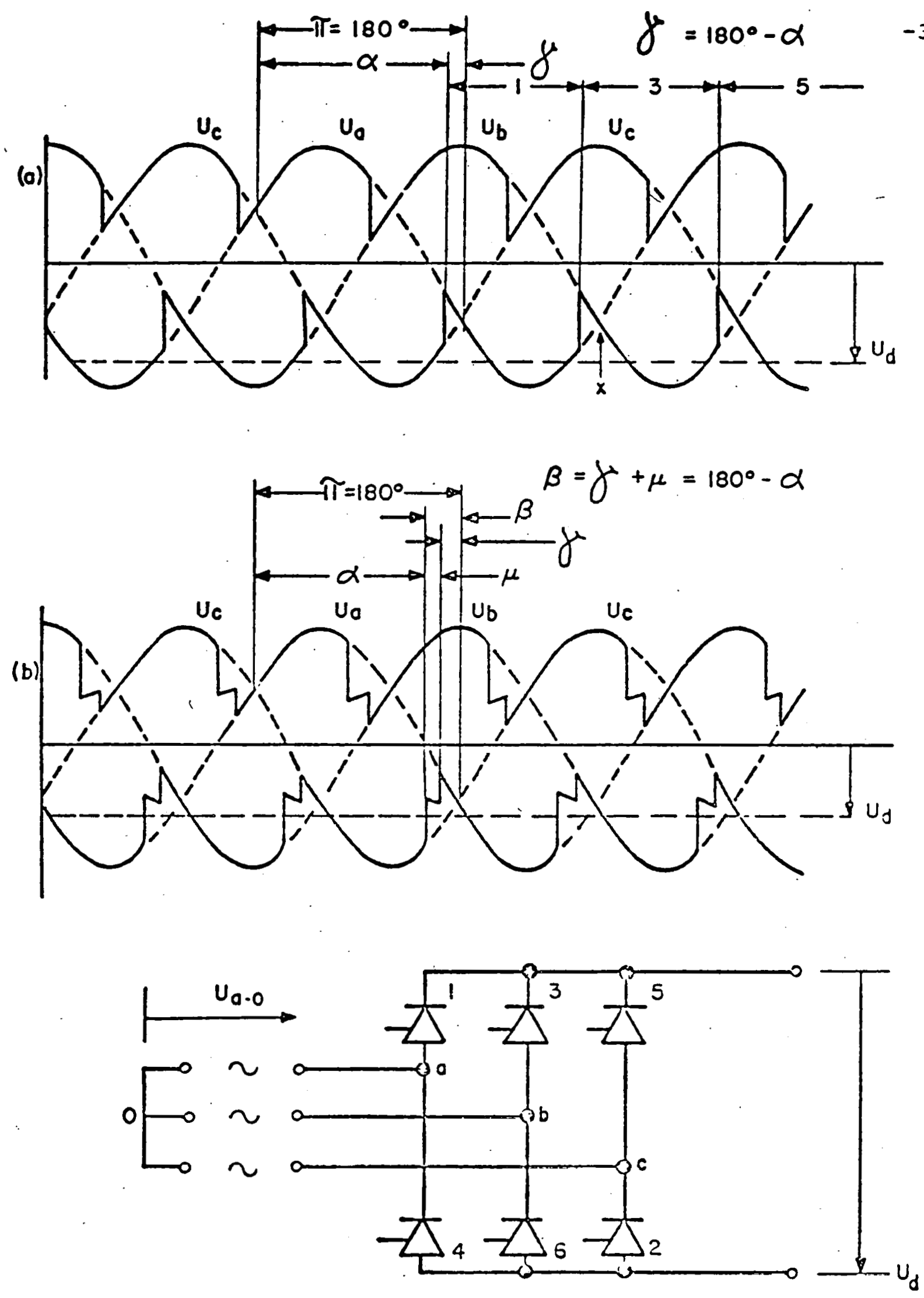

)

FIGURE 9 
MARMONIC GENERATION

The alternating currents of a rectifier connection are not sinusoidal. Therefore, we interpret them as combinations of a fundamental and harmonics. A method of analyzing a periodic function by means of Fourier's integral is used but only the results are given here: a) The amplitude of the harmonics decrease reciprocally to their order $1 / n$; b) There are only harmonics of the order nq \pm 1 (where $q$ is the pulse number).

fundamental $=1008$
5 th harmonic $=100 / 5=208$
7 th harmonic $=100 / 7=14.38$
11 th harmonic $=100 / 11=9.18$
13 th harmonic $=100 / 13=7.78$
17 th harmonic $=100 / 17=.98$
19 th harmonic $=100 / 19=5.38$
23 dd harmonic $=100 / 23=4.38$
25 th harmonic $=100 / 25=4.08$


Eigure: 10 POWER EXCHANGE

If we define the voltage as positive in the direction of the anode terminal, then we find that the active power at the converter terminals will be positive for the rectifier operation and negative for inverter operation. In other words, power is transmitted from the converter in rectifier operation and power is received into the converter in inverter operation.

This figure shows the power exchanged between the $A C$ system and converter under various degrees of 'phase control.

At the AC side figure (a) shows the line-to-neutral voltage $U_{a}$ and the line current $I_{a}$ of one phase of $a$ 6 pulse converter connection, assuming an $\alpha$ angle of phase control between zero and $90^{\circ}$. The product of both values is the instantaneous power, and it can be seen that the average value of the power is positive, indicating a flow of energy from the AC system to the DC circuit. With $\alpha=90^{\circ}$, illustrated in section (b), the positive and the negative values of power are in balance, so that no active, but reactive and distortion power are exchanged. Finally, with a further increased, the average power is negative, so that energy is transmitted from the DC circuit to the AC system (Figure c). 
Figure: 10 POWER EXCHANGE (cont'd)

The difference between rectification and inversion on the $A C$ side can also be seen in the above figures. During rectification, the positive half-cycle of the current $I_{a}$ coincides with the positive half of the alternating voltage $U_{a}$. During inversion, the positive half cycle of current $I_{a}$ coincides with the negative half of the alternating voltage $u_{a}$ ? 


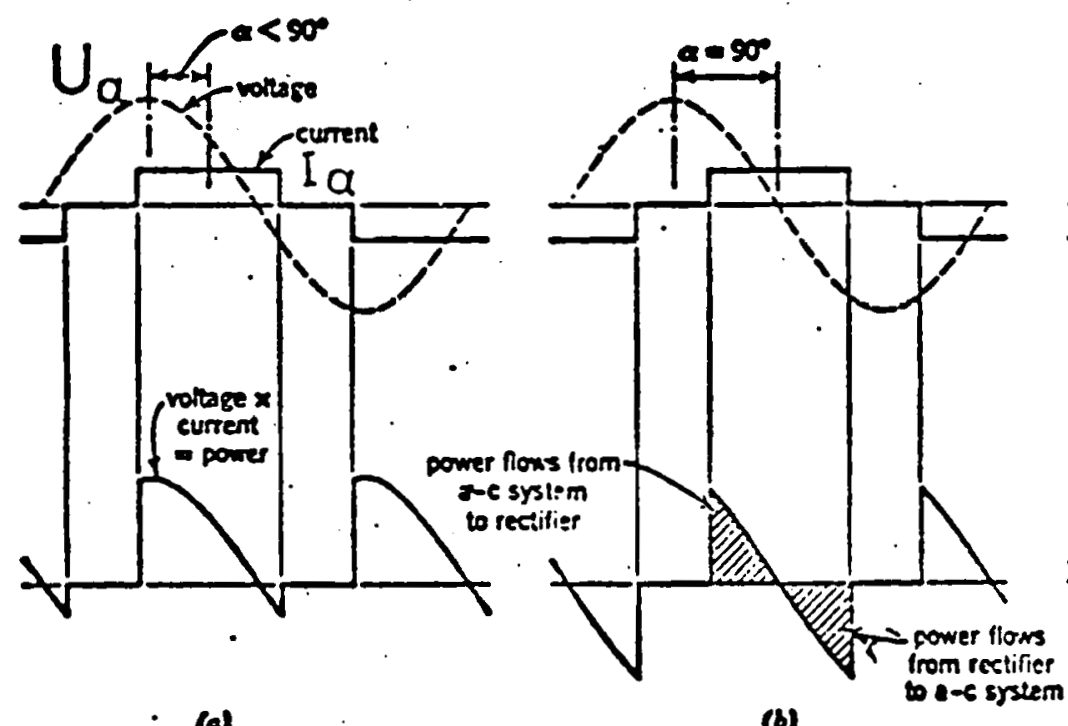

- (a)

Rectifler Opcration

Active power.

positive.

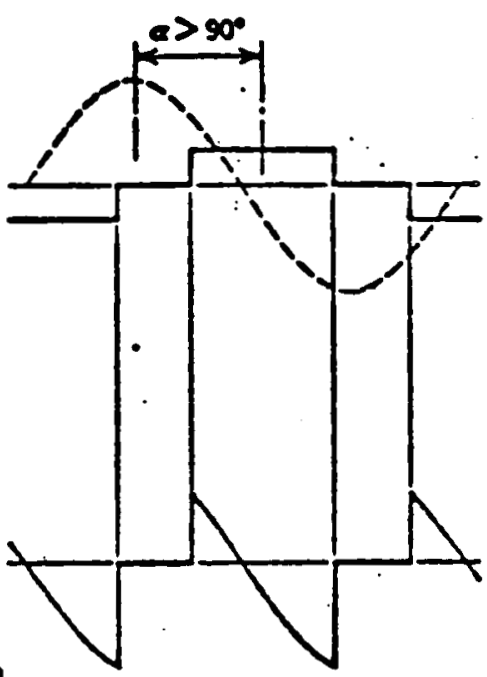

(c)

Inverter Operation

Active power =

negatlve:

\section{FIGURE 10}

POIER EXCHAilge 


\section{APPENDIX B}

\section{LIFE-CYCLE COST METHODOLOGY}




\section{APPENOIX 3}

\section{LIFE-CYCLE COST METHODOLOGY}

\section{B1.0 LEVELIZED AHIHUAL COST}

True life cycle cost analysis must necessarily consider the timing of costs and benefits as well as the niagnitude. A method employed in previous General Electric solar and wind encrgy prograns is to compare Levelized Annual Benefits (LAB), representing system energy savings, with the Levelized Annual Cost (LAC), the levelized dollar amount required to own, operate, and maintain a system during each year of the life of the system. Specifically, the levelized annual cost accounts for:
(a) "paying off" systen capital costs
(b) paying for operating and maintenance expenses
(c) paying taxes
(d) paying a return to investors and interest to creditors
(e) building a capital fund for periodic component replacement, overhaul, and retirement of debt.

The levelized annual cost, denoted by LAC, is given by:

$$
L A C=C R F \times P H
$$

where CRF is the capital recovery factor and PW is the present worth of the year by year revenue requirements throughout system life.

The following sections describe the analytics for computing LAC \& LAB as applied to photovoltaic systems for various user-types.

\section{B1.1 CAPITAL RECOVERY FACTOR, CRF}

The capital recovery factor is the uniform periodic payment, as a fraction of the origina) principal, that will fully repay a loan (including the interest rate). The interest rate used to calculate CRF is called the discount rate and represents the weighted average cost of capital.

Analytically, the capital recovery factor is given by:

$$
C R F=\frac{r(1+r)^{N}}{(1+r)^{2}}=1
$$

where $r$ is the appropriate arnual discount rate and $N$ is the system lifetime in years. The discount rate, $r$, varies with the alplication. Values of .09, .072, and .10 have veen used for the utility, residintial and incermediate applications, respectively. 


\section{B1.2 PRESENT HORTH, PW .}

The present worth is analogous to that anount which, if deposited in an interest bearing account at the discount rate, would permit annual withdrawals to pay all system costs and dirinish to zero at the end of system life. For the evaluation of PV jystems, the PIV is comprised of two components: (1) a component accounting for capital costs and (2) a component accounting for the cost of operation and maintenance (O\&M).

The total present worth is given by:

$$
\text { PW = PHFIXED CHARGE + PWO\&H }
$$

The fixed charge component is given by:

$$
\text { PWFIXED CHARGE }=\frac{I_{C} \cdot F C R \cdot C C F}{C R F}
$$

Here, $I_{C}$, is the total capital cost of the system and CCF is the construction cost factor accounting for interest during construction of the PV system.

The parameter FCR is the fixed charge rate and represents the yearly cost of ownership, expressed as a \% of the capital investment. IC. These costs consist of capital outlay, taxes and insurance. An explanation of the fixed charge rate and its derivation is given in the following subsection.

The second component in equation (3) accounts for system operation and maintenance. This is given by:

$$
\text { PWOEM }=\frac{A_{O M} \cdot M}{\text { CRF }}
$$

This is similar in form to equation (4), but with different parameters. AOH is the cost of operating and maintaining the system.

The parameter $M$; defined as the levelized value of an escalating cost stream, accounts for the fact that $A_{0,1}$ is increasing over the lifetime of the system because of inflation.

$$
H=\frac{r(1+q)}{r-g}\left[\frac{(1+r)^{N}-(1+g)^{H}}{(1+r)^{N}-1}\right]
$$

where $g$ is the annul inflation or escalation rate.

Substituting equations (4) and (5). into equation (3) yields:

$$
P H=\frac{1}{C R F} \cdot\left[I_{C} \cdot F C R \cdot C C F+H\left(A_{0.11}\right)\right]
$$




\section{BI. 3 FIXED CHARGE RATE}

The fixed charge rate (FCR) represents the yearly cost of ownership, expressed as a \% of the investment, IC. These costs consist of debt interest and principal payments, return on equity (where applicable), insurance, local taxes and the net effect of Federal taxes. The concept of the fixed charge rate comes from electric utility finaricial andysis, but has proven to be applicable and convenient in the . analysis of other sectors as well.

The residential energy user has one important difference from other energy consumers in that energy is not a tax deductible expense. The effect is best shown by example. Consider an industrial and a residential user in 48 and 20 percent tax brarkets, respectively. Assume each has $\$ 1000$ of before-tax income and is evaluating $\$ 100$ energy purchase:

Corporation

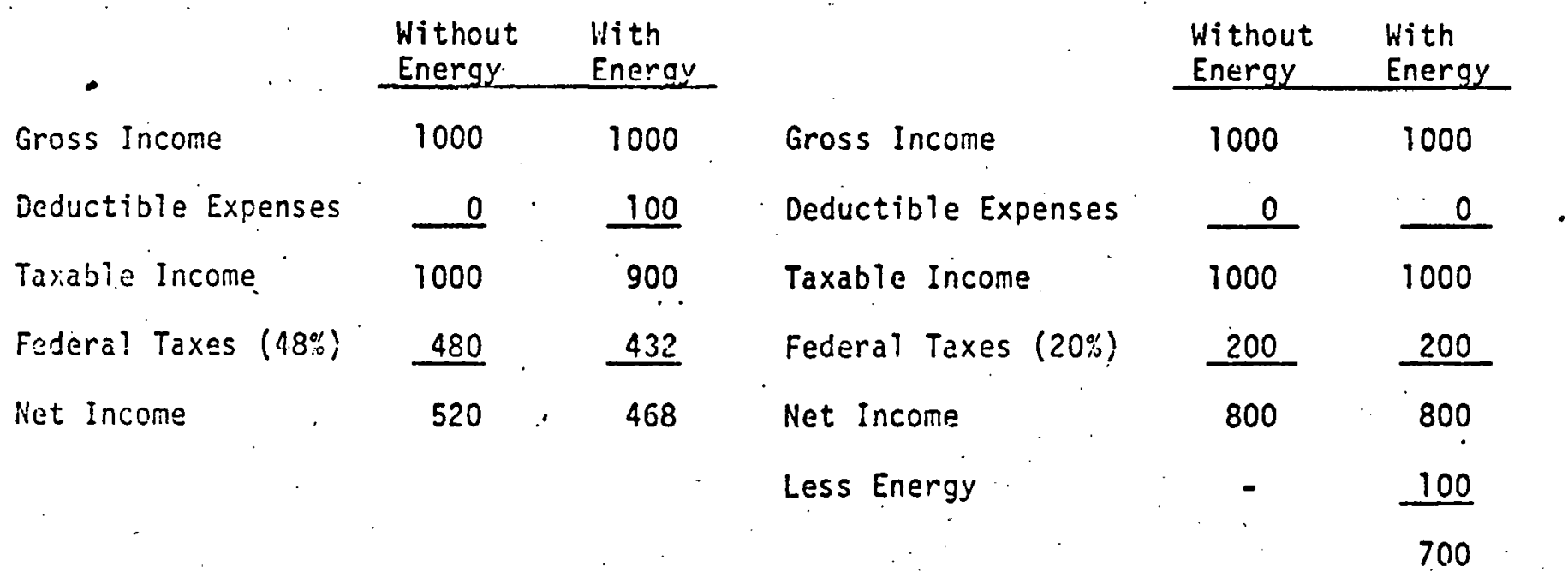

Homeowner

After Tax Energy Cost $=\$ 520-468=\$ 52$

Thus, while the homecwner pays the full $\$ 100$, the corporation effectively pays only $\$ 52$ (\$100 $\times(1$ - tax rate)) since taxes are reduced by $\$ 48$. It is due to this tax effect that costs of alternate cnergy systenis must be evaluated on an after-tax basis for the homcouner and on a before-tax basis for the corporation. Only in this way can systeni costs be conpared with prevailing energy costs.

A detailed discussicn of fixed charge rate, its various components, and corporate tax effects is preserited in "The cost of Energy from Utility-Owned Solar Electric Systcms" (Reforence $b-1)$. The residential sector presents a much simpier case. Assuming a $G$ percant loan for a homeowner in a 20 percent increniental tax bracket, the effective after-iax rate can be shown to be 7.2 percent $(.9 \times(1-.2))$. Computing the appropriate Caf and adding local taxes ald insurance yields the fixed charge rate. For cxarple, asstiuc a 10 year lire systeil and 2.3 percent for local taxes and insurance: 


$$
F C R=\frac{.072}{1.072}\left(\frac{1.072)^{10}}{-1}+.025=.1687 \cong .17\right.
$$

Typical fixed charge rates (FCR) as a function of system life $N$ and application are tabulated below:

\begin{tabular}{|c|c|c|c|}
\hline SYSTEN LIFE & \multicolumn{3}{|c|}{ FCR } \\
\cline { 2 - 4 }$N$ YRS. & UTILITY & RESIDEITIAL & INOUSTRIAL/COIMUERCIAL \\
\hline 10 & .23 & .17 & .27 \\
20 & .19 & .12 & .23 \\
30 & .18 & .10 & .22 \\
50 & .18 & .10 & .22 \\
\hline
\end{tabular}

81.4 LEVELIZED AINUAL COST IN CURRENT DOLLARS

If equation (7) is substituted into equation (1):

$$
-L A C=I_{C} \cdot F C R \cdot C C F+M \quad\left(A_{O M}\right)
$$

In this case, the levelized annual cost is expressed in terms of current doliars.

Expressing LAC in current' dollars establishes equal yearly costs over the system life. This is analogous to the case of a home mortgage. The homeowner borrows money at some interest rate. It is paid back in equal monthly (hence, yearly) installments over the life of the mortgage ( $i . e .$, he pays $\$ X / m o n t h$ in the first year and $\$ X /$ month in the 30 th year):

\section{B 1.5 LEVELIZED AMNUAL COST IH CONSTANT DOLLARS}

An alternative method of expressing levelized annual costs is to reference the costs. to a particular base year, e.g., 1976. The result is the levelized annual cost in constant (base year) dollars.

To calculate LAC in constant dollars, a discount rate that accounts for inflation over the system lije is deternined. This rate, denoted by $r^{\prime}$, is given by:

$$
r^{\prime}=\frac{(1+r)}{(1+9)}-1
$$

where $g$ is the annual inflaticn rate. This $r^{\prime}$ is then used in the CRF equation to 
yield a capital recovery factor in constant (base year) dollars:

$$
\mathrm{CRF}^{\prime}=\frac{r^{\prime}\left(1+r^{\prime}\right)^{N}}{\left(1+r^{\prime}\right)^{\prime \prime}-1}
$$

Substituting CRF' for CRF in equation (1) gives:

$$
\text { LAC (Constant } \$)=\text { CRF'. PW }
$$

Further substitution of equation (7) into (11) results in:

$$
\text { LAC (Constant } \$)=\frac{C R F^{\prime}}{C R F}\left[I_{C} \cdot F C F \cdot C R F+M\left(A_{O M I}\right)\right]
$$

Combination of equations (2), (6), and (b0) results in

$$
\frac{\text { CRF' }}{\text { CRF }} \cdot M=1
$$

provided that $g$, the annual inflation or escalation rate, is the same for OSH as for the general rate of inflation used in computing $r^{\prime}$. This expression, in turn, reduces equation (12) to:

$$
\text { LAC (Constant } \$)=\left(\frac{C R F^{\prime}}{C R F} \cdot I_{C} \cdot F C R \cdot C C F\right)+A_{O H}
$$

\section{B1.6 LEVELIZED ANNUAL BENEFITS}

The comparison of the energy cost savings of the PV system to the levelized annual cost is accomplished by computing the levelized annual benefits (LAB) for the energy savings. LAB is inherently a function of present and projected energy prices and may be expressed by

$$
L A B \text { (Constant } \$)=\frac{C R F^{\prime}}{C R F} \cdot M_{f} \cdot P_{0} \cdot E
$$

where E represents the annual energy saved by the solar system, $M$ is an energy savings multiplier which is defined as the levelized value of an escalating cost stream which accounts for the rate of energy price escalation over the lifetime of the systen, and $P_{0}$ is the energy price in year zero. In actual practice the appropriate utility rate. scheduie is appiied with the savings determined by the difference of the electric bills computed with and without. the PV system.

The multiplier $M_{f}$ is a function of energy price escalation rate ( $\left.f\right)$, system lifetime ( $N$ ), and discount rate $(r)$, and is expressed as*

$$
M_{f}=\frac{r(1+f)}{r-f}\left[\frac{(1+r)^{N}-(1+f)^{N}}{(1+r)}\right]
$$

* When $r:=f$ :

$$
M=C R F \cdot N
$$


The energy price in year zero $\left(P_{0}\right)$ is related to the energy price in constant (base year) dollars per ellergy unit (p) through the expression

$$
p_{0}=p\left(\frac{1+f}{j+g}\right)^{\Delta}
$$

where $\Delta$ is the number of years from the base year to year zero.

The economic viability of a system can be measured by comparing the levelized annual cost to the levelized annual benefits. If the levelized annual benefits exceed the levelized annual. cost, the system is economically viable. The break-even system cost ocsurs when $L A C$ and $L A B$ are equal.

\section{REFERENCE}

8-1. "The Cost of Energy from Utility-Owned Solar Electric Systems", Doane, J.H., et. al., June 1976, Report JPL 5040-29, Jet Propulision Laboratury 


\section{APPENDIX C}

LIGHTNING PROTECTION ANALYSIS 
The Sea World Photovoltaic (PV) Concentrator Application Experiment will be located in an area of the U.S. where thunderstorms and lightning strikes are most prevalent. In fact, there are an average of 90 days each year on which a thunderstorm is within earshot of Orlando. Consequently, lightning protection must be incorporated in the equipment design to assume satisfactory performance in this environment. Lightning Technologies, Inc. was engaged to assess the potential lightning hazard to the experiment and to recommend protection.

The site will receive about $I^{\prime}$ direct strike every six years. It can be adversely affected by about 26 strikes per year which fall within a 1 kilometer radius of the site. A direct strike to a receiver turntable can damage mechanical linkages and bearings as well as electrical/electronic systems. The nearby strikes will only affect electrical/electronic systems but occur much more frequently.

Protective measures recommended consist of shielding and suppression. Power and signal cables are shielded by locating return cables at the edges of the conduit. runs and grounding them at many points. The signal conductors are contained within an additional overall shield which is grounded at the ends. Each of the shields will reduce a lightning transient by about an order of magnitude ( 10 to 1 ) but the remaining transient must be removed by suppression devices to fully protect the equipment and electronics. Metal-oxide varistors and silicon zener diodes are recommended as suppressors because of their excellent protective characteristics.

Direct strikes to the turntable can induce currents in the receiver cells that are potentially destructive. Analysis of the silicon solar cells has shown that the cells should be able to tolerate the induced currents. However, no laboratory test data on solar cells is readily available to verify the analysis. The Sea World experiment offers an excellent opportunity to perform tests that will verify not only the silicon solar cell tolerance levels but obtain base line data on the hazard levels in typical array structures. This data could be obtained by performing simulated lightning tests on a relative geometric scale model of the turntable leading to full scale current level tests on receiver assemblies and solar cells.

Solar power generation facilities of the future will of ten be located in areas of high lightning activity and will require lightning protection. Data and experience derived from this project will be useful in the design of the protection for future systems which will be more extensive. 
1. I Iintwinn Drntrotinn Rrowirnments

This report summarizes expected susceptibility of the Photovoltaic (PV) Concentrator Application Experiment to lightning strikes, and the electrical environment that test strikes may be expected to apply to the system. The effects that this environment may have on the system are outlined and used as a guide for the subsequent tasks to follow the comprehensive lightning data compiled by Cianos and Pierce in Reference 1 will be utilized to establish severity levels for design purposes.

\subsection{Number of Expected Strikes to the PV Plant}

Thunderstorms and lightning flashes do not occur with uniform frequency throughout the world, but vary instead with the climate and topography. A parameter which can be utilized to estimate the number of flashes to an object and for which historical data exists is the thurderstorm day. This data is accumulated by the World Meteorological Organization (WMO) and is called the isokeraunic level. A thunderstorm day is defined as a 24-hour day on which thunder is heard. Thus, the parameter does not give information on the duration or intensity of the storm. For the United States, the isokeraunic level ranges between a low of 5 thunderstorm-days per year along the West Coast, to a high of 91 days on which thunder is heard at Orlando, Florida. When used in the analysis that follows, this parameter is designated at $\mathrm{T}_{\mathrm{y}}$.

Most observers agree that there are about 3 lightning flashes per minute in the average thundercloud and that a cloud covers about 500 square kiloreters of ground for an average of between 1 and 3 hours. This would work out to a flash density, $\tau_{y}$, of between 0.3 and 1.0 flashes per square kilometer on each thunderstorm day. Actually, flash density over a wide area has been shown (Reference 2) to be related more closely to the square of the isokeraunic level as follows:

$$
\tau_{y}=0.02 \mathrm{~T}_{\mathrm{y}}{ }^{1.7} \mathrm{flashes} / \mathrm{km}^{2} / \text { year }
$$

The flash density of equation ( 1 ) includes flashes between clouds and flashes to ground, but those that reach the ground would be of concern with respect to physical damage to structures. Pierce (Reference 3) has noted that the percentage, $P$, of flashes to ground varies with geographical latitude as follows:

$$
P=0.1\left[1+(\lambda / 30)^{2}\right]
$$

where $\lambda$ is the geographical latitude in degrees. For the U.S., the percentage of earth-bound flashes ranges between $20 \%$ (in the South) to $36 \%$ (in the North). Equation (2) may be used to estimate the average number of times lightning may be expected to strike the ground within a given area. 
Within a large area, Lightning wili strike higier objects such as rialio towers, utility poles and rooftops much more frequently than objects that are shorter than these, but if all of the objects within a region are of nearly the same height, as in a forrest, the height of any single object will not increase its lightning attractiveness.

This appears to be the situation at the PV plant. The PV turntables, converter station, perimeter fence, and wooded area surrounding much of the plant are all nearly the same height, and are not overshadowed by tall buildings or towers. Thus, the number of strikes expected to land within each square kilometer of area near the plant site can be determined by combining equations 1 and 2 as follows:

No. of Strikes

reaching earth $=\left(0.02 \mathrm{~T}_{\mathrm{y}}{ }^{1.7}\right)\left[0.1\left(1+\left(\frac{\lambda}{30}\right)^{2}\right)\right]$
per year

$$
=0.002 \mathrm{~T}^{1.7}\left[1+\left(\frac{\lambda}{30}\right)^{2}\right]
$$

The WMO (Reference 4) records an isokeraunic level ( $\mathrm{T}_{\mathrm{y}}$ ) of 91 thunderstorm days per year at Orlando, Florida, which is 1ocated at $28^{\circ} 33^{\prime}$ latitude. If this data is inserted in equation 4 ,

$$
\begin{aligned}
\begin{array}{l}
\text { No. of Strikes } \\
\text { reaching earth }
\end{array} & =\left[0.002(91)^{1.7}\left(1+\left(\frac{28.55^{2}}{30}\right)\right)\right] \\
\text { per year } & =8.16 \text { strikes per square kilometer }
\end{aligned}
$$

The PV plant covers 5 acres, or

$$
\begin{aligned}
(5 \text { acres })( & \left.4.047 \times 10^{3} \text { meters }{ }^{2} / \text { acre }\right) \\
& =2.02 \times 10^{4} \text { meters }^{2} \\
& =2.02 \times 10^{-2} \mathrm{~km}^{2}
\end{aligned}
$$

Thus, the number of strikes expected to fall within the $\underline{P V}$ plant each year are:

$$
\begin{aligned}
\begin{array}{l}
\text { No. of Strikes } \\
\text { to PV plant }
\end{array} & =\left(8.16 \mathrm{~km}^{-2}\right)\left(2.02 \times 10^{-2} \mathrm{~km}^{2}\right) \\
& =1.65 \times 10^{-1} \text { strikes per year }
\end{aligned}
$$

or about 1 strike every 6 years.

$$
c-3
$$


pacausc of this it might ho monc?uthd that lighrning will. he of little concern to the $\mathrm{PV}$ plant and that protective measures are not warranted. Lightning need not strike within the plant, however, for damaging surges to be coupled in the power or control circuits. Experience has shown that lightning strikes falling within 1 kilometer or more can cause damage to unprotected power and signal circuits in many types of systems. Thus, a more realistic measure of the number of strikes that may cause damage to an unprotected system is the number that fall within a radius of $1 \mathrm{~km}$ from the plant, or in this case,

$$
\begin{aligned}
\begin{aligned}
\text { No. of } \\
\text { damaging }
\end{aligned} & =\left(8.16 \text { strikes per } \mathrm{km}^{2}\right)\left(\pi \mathrm{km}^{2}\right) \\
\text { strikes } & =25.6 \text { strikes per year }
\end{aligned}
$$

The analysis to this point has considered only cloud-toground strikes. It is known that cloud-to-cloud flashes which do not contact the ground can also induce surges in electrical systems, especially when such systems involve elevated electrical wires or other apparatus exposed to thunderstorm electric fields. The sensitivity of the PV collectors to the rapid electric field changes produced at the earth by cloud-to-cloud flashes has not yet been assessed, so no judgment can yet be made as to the additional exposure presented by these flashes. It may turn out, however, that any increase in hazardous exposure due to intercloud flashes will be diminished by those strikes that fall within the $1 \mathrm{~km}$ radius that are too low in intensity to be harmful.

\subsection{The Electrical Environments}

\section{2 .1 From Direct Strikes}

For design purposes the electrical environment produced by direct strikes to the PV plant will be in accordance with the Severe Basic Model described by Cianos and Pierce in Reference 5. This model describes the currents reaching the earth, and recognizes that within any single strike, called a fiash, more than one stroke may occur in rapid succession. The model is show in Figure 1. Other critical parameters associated with this model, which are of importance to the PV system, are the number of strokes per flash, the peak current in the first and second strokes, and the total charge transfer. The scverity of these parameters is approximitly the 2 percent extreme of the statistical distributions of each paramter, determined by Cianos and Pierce from a study of all of the available electrical data on natural lightning. The lightning model thus consists of ten strokes with a peak current of $140 \mathrm{kA}$ in the first stroke and $70 \mathrm{kA}$ in the second stroke. The time interval between these strokes is 10 milliseconds. The remaining subsequent strokes are chosen as having a peak current of $30 \mathrm{kA}$; on the high side of the median but not so much so as to be 
timed severe. The time between strokes, except for a continuing current. interval, is taken as the typical value of $60 \mathrm{~ms}$.

TIME TO PEAK CURAENT - $1.5 \mu \mathrm{s}$ TIME TO HALF VALUE - $40 \mu \mathrm{s}$

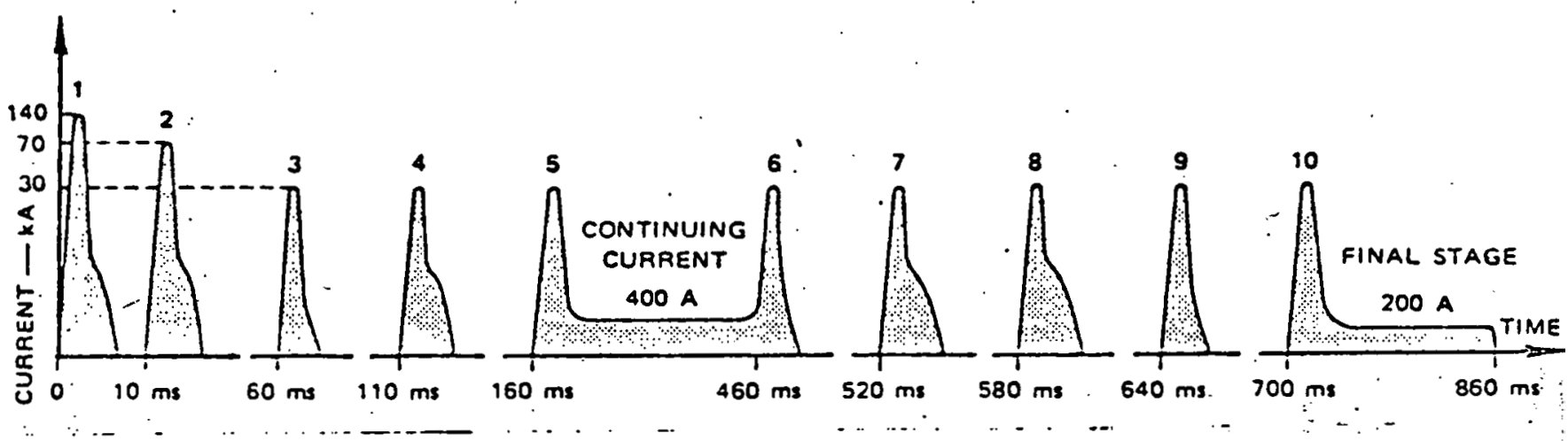

Figure 1 - Time History of the Severe (Basic) Lightning Model.

For all strokes, the time to peak is $1.5 \mu \mathrm{s}$. Hence, the average rate of rise is about $100 \mathrm{kA} / \mu \mathrm{s}$ for the first return stroke, $50 \mathrm{kA} / \mu \mathrm{s}$ for the second stroke, and $20 \mathrm{kA} / \mu \mathrm{s}$ for the remaining subsequent strokes. The fall time to half the peak current is chosen as the typical value, $40 \mu \mathrm{s}$, for each stroke. The total charge transferred in the flash is 200 coulombs.

The critical hardware such as the PV receiver assemblies, pintel bearing and control linkages should, wherever possible, be designed to tolerate the currents in the severe model.

\subsubsection{From Nearby Strikes}

Earth voltage rises and magnetic fields will be produced by nearby strikes (defined as occurring within a radius of $1 \mathrm{~km}$ from the plant). The magnitude of these effects must also be known if adequate protection is to be designed.

Figure 2 shows the equations from which the magnetic fields and earth voltages at various distances, D, from the place where a strike enters the earth can be estimated. The amplitude and rate of rise of the first stroke in the flash are utilized for this analysis, because they are the most severe. Thus Figure 2 shows a $140 \mathrm{kA}$ stroke entering earth of typical 1,000 ohm-meters resistivity. 


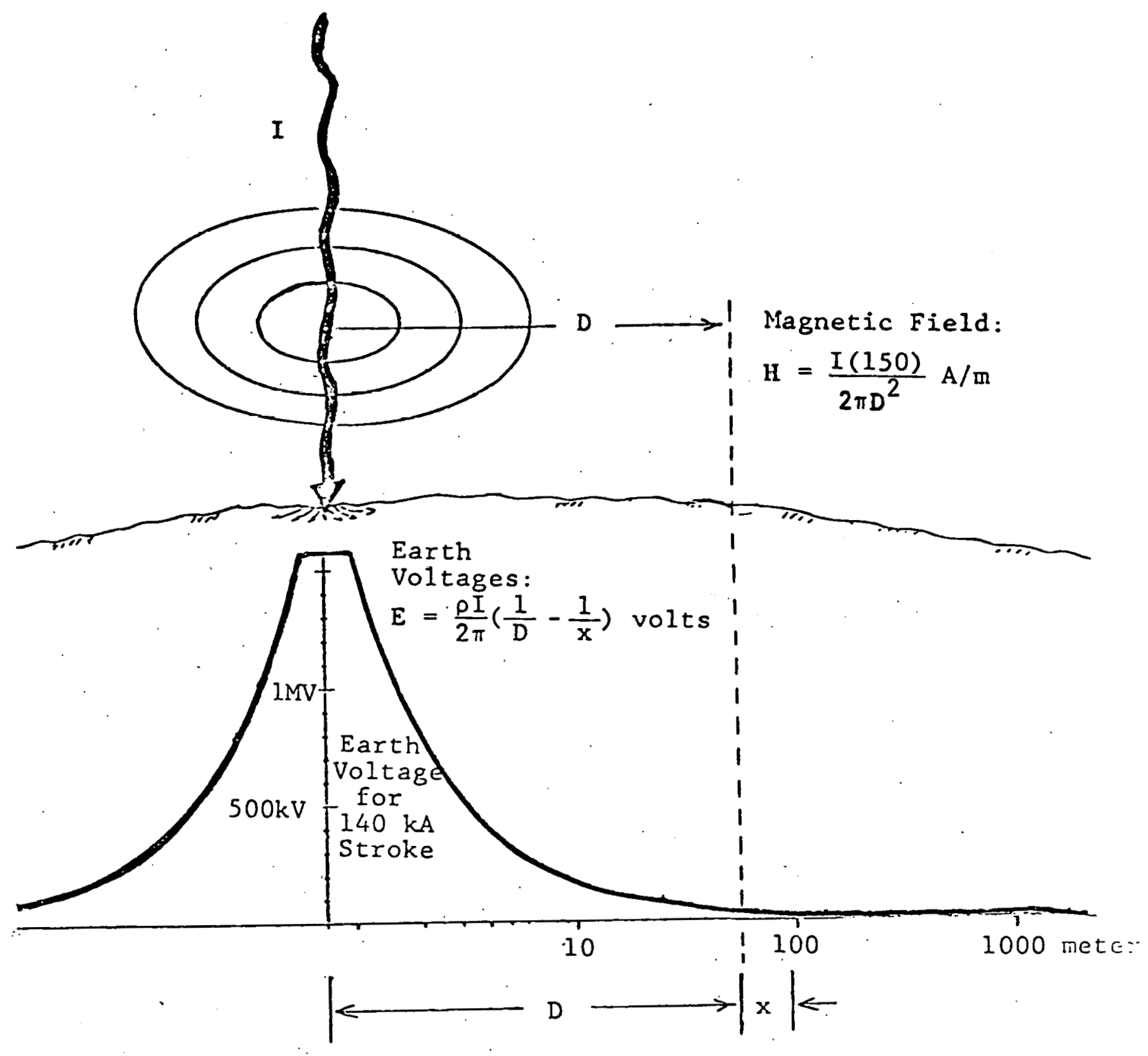

Figure 2 - Magnetic Fields and Earth Voltages

- Earth voltage profile is shown for a $140 \mathrm{kA}$ stroke into soil of $1,000 \mathrm{ohm}$-meters resistivity. 
The expression governing the earth voltage is:

$$
E=\frac{\rho I}{2 \pi}\left(\frac{1}{D}-\frac{1}{D+x}\right) \text { volts }
$$

where

$E=$ Voltage between two points $x$ meters apart on the earth surface due to current, $I$, entering the earth at an average distance, D, away from the point of interest. (volts)

$x=$ Radial distance outward to another point of interest from the reference point. (meters)

The expression for the magnetic field intensity is:

$$
\mathrm{H}=\frac{\mathrm{I}(150)}{2 \pi \mathrm{D}^{2}} \text { amps/meter }
$$

where

$$
\begin{aligned}
H= & \text { Magnetic field intensity a distance, D, } \\
& \text { away from the strike due to current, I, in } \\
& \text { the channel (amps/meter) } \\
D^{\prime}= & \text { Distance away from the flash channel (meters) } \\
I= & \text { Lightning current (amperes) }
\end{aligned}
$$

Table I shows examples of the magnetic field intensities and earth voltages determined from expressions (9) and (10) which would appear at three different distances, D, away from where a $140 \mathrm{kA}$ stroke entered earth of resistivity 1,000 ohm-meters.

TABLE I - Typical Magnetic Fields and Earth Voltages Produced by a $140 \mathrm{kA}$ Stroke

\begin{tabular}{|ccc|}
\hline $\begin{array}{r}\text { Distance, } \mathrm{D}, \text { from } \\
\text { Strike }\end{array}$ & $\begin{array}{c}\text { Magnetic Fields } \\
\mathrm{A} / \mathrm{m}\end{array}$ & $\begin{array}{c}\text { Earth Vol.tages for } \\
\rho=1000 \Omega-\mathrm{m} \\
\mathrm{x}=150 \mathrm{~m}\end{array}$ \\
\hline $100 \mathrm{~m}$ & $3.3 \times 10^{2}$ & $134 \mathrm{kV}$ \\
$1 \mathrm{~km}$ & $3.3 \times 10^{0}$ & $2.9 \mathrm{kV}$ \\
$10 \mathrm{~km}$ & $3.3 \times 10^{2}$ & 33 volts \\
\hline
\end{tabular}


The magnetic fields and earth voltages will cause surges to appear in the power and signal cables running between the turntable and the converter station. The voltages and currents induced by these effects can be estimated as follows:

\subsection{Surges Induced in Cables by Magnetic Fields}

The magnetic field, $H$, produced by the lightning stroke will pass through the loop formed by the cable and the earth, shown in Figure 3 , inducing a voltage in this loop or a current in it if a return path is present. The earth is represented by a distributed resistance, $R$, at some finite distance below the actual surface. In reality, the induced current flows throughout a wide volume between the two terminals, but it will be sufficient to lump this into a single resistance for the purpose of analysis.

The voltage induced by the magnetic field is:

$$
e(t)=\frac{d \phi}{d t}=\mu_{0} s \frac{d H}{d t} \quad \begin{aligned}
& \text { volts permeter } \\
& \text { of cable length }
\end{aligned}
$$

where;

$$
\begin{aligned}
e(t)= & \text { induced voltage in the cable - earth loop } \\
& \text { (volts/meter of cable length) } \\
\phi= & \text { magnetic flux passing through the loop (Webers) } \\
H= & \text { magnetic flux density (amperes/meter) } \\
\mu_{0}= & \text { permeability of free space }=4 \pi \times 10^{-7} \text { henrys/meter } \\
S= & \text { spacing between cable and earth return (meters) }
\end{aligned}
$$

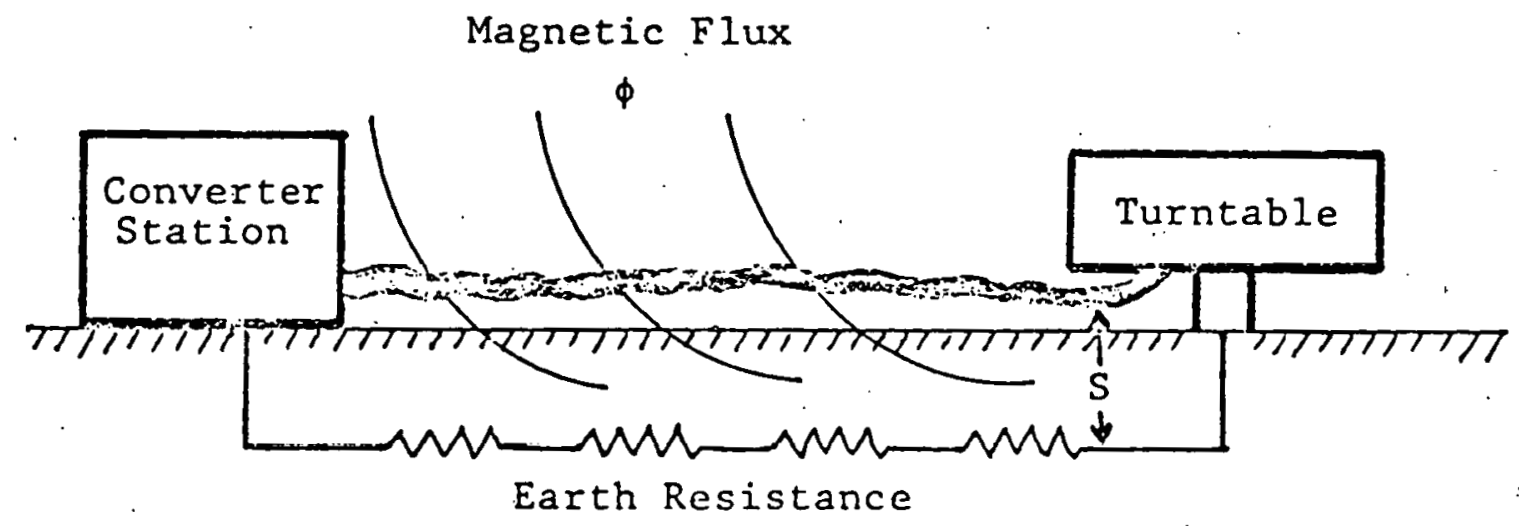

Figure 3 - Magnetic Field Interaction with Power Cables. 
The magnetic flux, $\mathrm{H}$; follows the same waveform as the ligintuing stroke current that produces it. Most natural lightning stroke currents are concave and can be represented best by a (1-cos) function reaching its peak (at $\pi / 2$ radians) in 1.5 microseconds in accordance with the severe model of Figure 1. This is shown in Figure 4.

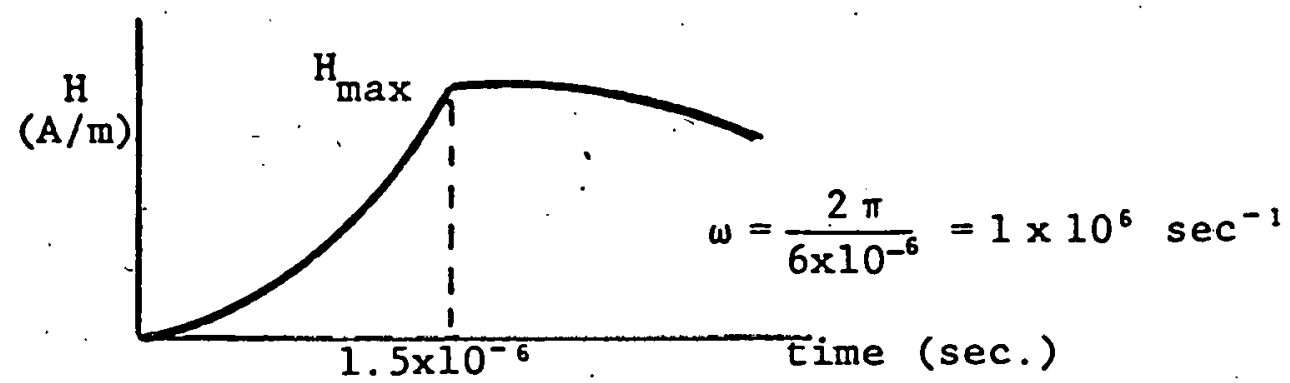

Figure 4 - Mathematical Representation of Return Stroke and Magnetic Field Wavefront.

If

$$
H=H_{\max }(1-\cos \omega t)
$$

then,

$$
\frac{d H}{d t}=H_{\max } \sin \omega t
$$

Inserting this expression into equation (11) for the voltage induced in the cable-earth loop and letting $\mathrm{S}=1$ meter, gives:

$$
e(t)=\mu_{0} \omega H_{\max } \text { sinwt } \begin{aligned}
& \text { volts per meter of } \\
& \text { distance between turntable } \\
& \text { and the converter station }
\end{aligned}
$$

Since the PV system is grounded at the converter station this voltage would appear between the PV receivers and earth-grounded structural hardware on the turntable. At $t=\frac{\pi}{2}$ sinwt is unity

$$
\mathrm{e}_{\mathrm{pk}}=\mu_{\mathrm{o}} \omega \mathrm{H}_{\max }
$$

For the same distances, D, from a $140 \mathrm{kA}$ lightning stroke as in Table $I$, equation 15 gives the voltages per meter length of cable shown in Table II. 
TABLE II - Voltages Induced by Magnetic Fields in PV System Cables

\begin{tabular}{|c|c|}
\hline $\begin{array}{c}\text { Distance, D, from } \\
\text { Strike }\end{array}$ & $\begin{array}{c}\text { Volts per meter } \\
\text { of Cable Length }\end{array}$ \\
\hline $100 \mathrm{~m}$ & 415 \\
$1 \mathrm{~km}$ & 4.15 \\
$10 \mathrm{~km}$ & 0.04 \\
\hline
\end{tabular}

The low level induced by'strikes beyond $1 \mathrm{~km}$ away illustrates why strikes farther than $1 \mathrm{~km}$ away from the plant need not be considered.

A strike 100 meters away from a 25 meter long cable may cause

$$
25(415)=10,375 \text { volts }
$$

to appear at the turntable between the PV receiver and grounded hardware, however. This voltage is probably sufficient to cause a sparkover across the insulation. When this happens a complete circuit may be formed with the earth as return. The induced voltage will then drive a surge current through the cable, returning through the earth as shown in the equivalent circuit of Figure 3. This current is limited by the earth resistance and the loop inductance. The equivalent circuit is shown in Figure 5 .

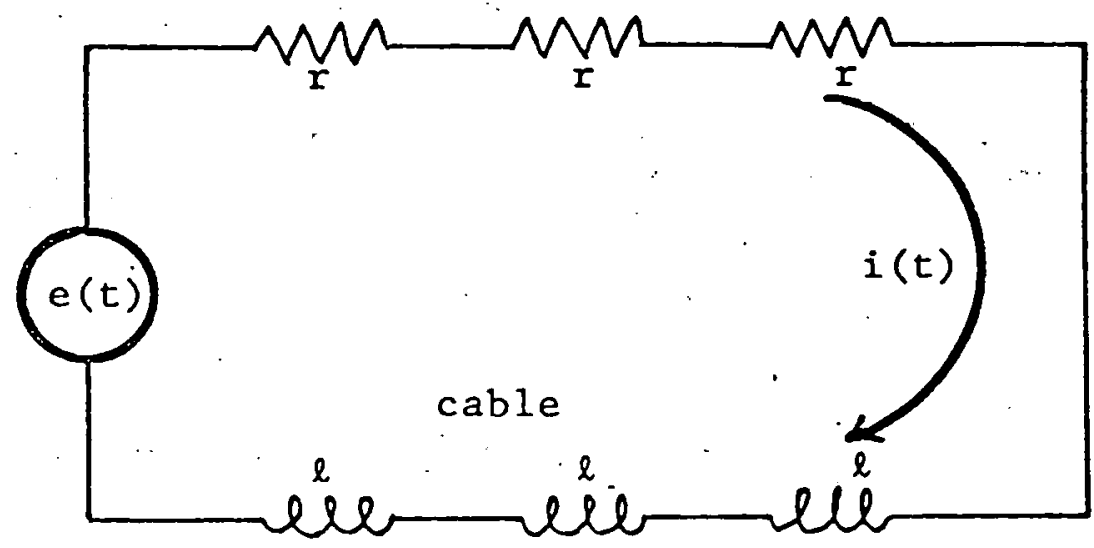

Figure 5 - Equivalent Circuit of Cable and Earth Return. 


$$
i(t)=\frac{\partial(t)}{r}\left(1-\varepsilon^{-\frac{r t}{l}}\right) \text { amperes }
$$

where,

$$
\begin{aligned}
& r=\text { earth resistance per unit length of cable (ohms/meter) } \\
& \ell=\text { circuit inductance " " " " " " " } \\
& e(t)=\operatorname{volts} " \text { " " " " (volts/meter) } \\
& i(t)=\text { loop current flowing in cable (amperes) }
\end{aligned}
$$

Substituting expression (14) for $e(t)$ in equation 16 gives:

$$
i(t)=\frac{\mu_{0} \omega H_{\max } \sin \omega t}{r}\left(1-\varepsilon^{-\frac{r t}{l}}\right)
$$

This expression and those that preceded it are valid until the stroke current reaches its crest (coswt $=\pi / 2$ ), assumed to be $1.5 \mathrm{\mu s}$ in accordance with the severe stroke model. $\omega$ is available from Figure 4 and the peak magnetic field strength, $H_{\text {max }}$, was calculated in Table I for the $140 \mathrm{kA}$ flash striking the earth at several distances, $D$, away from the plant. $r$ depends on the soil resistivity at the particular location, but $l$ is less dependent on such site factors and can be assumed to be 1 microhenry per meter of cable length. Values of $i(t)$ therefore can be calculated by equation 17 for various combinations of $D$ and $r$. Peak currents for several combinations of $D$ and $r$ are presented in Table III.

TABLE III - Peak Currents Induced in Cables by Magnetic Fields Passing between a Cable and Earth Return

\begin{tabular}{|ccccc|}
\hline $\begin{array}{l}\text { Distance, D, } \\
\text { from Flash }\end{array}$ & \multicolumn{4}{c|}{$\begin{array}{l}\text { Return Path Resistance } \\
\text { (ohms/meter) }\end{array}$} \\
\hline & 0.5 & \multicolumn{2}{c}{1.0} & 10.0 \\
\hline & & Peak Currents & (amperes) \\
$100 \mathrm{~m}$ & $\ddots$ & 471 & 322 & 18.6 \\
$1 \mathrm{~km}$ & $\ddots$ & 4.68 & 3.2 & 0.18 \\
$10 \mathrm{~km}$ & & 0.05 & 0.03 & 0.0023 \\
\hline
\end{tabular}

Table IV shows that the greater the return path resistance through the earth, the lower the currents which may be induced in the cable. This result illustrates the possibility that a low ground resistance (i.e. resistance between the hardware and "earth") may "sometimes aggravate lightning effects instead of 
mitigating them. While "grounding" has an important role to

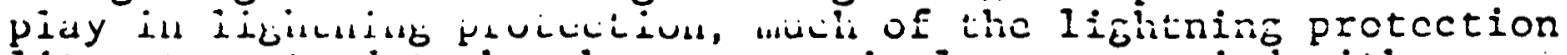
literature to date has been excessively preoccupied with grounding, while overlooking inductive effects which are at least as significant.

\subsection{Surges Produced by Earth Voltages}

The other indirect effect which may cause surge voltages and currents to appear in cables is the earth voltage rise.

The voltage, $E(t)$, between two shelters a distance, $x$, apart drives a current, $i(t)$, through any cable(s) that extend between them: This situation is shown in Figure 6 .

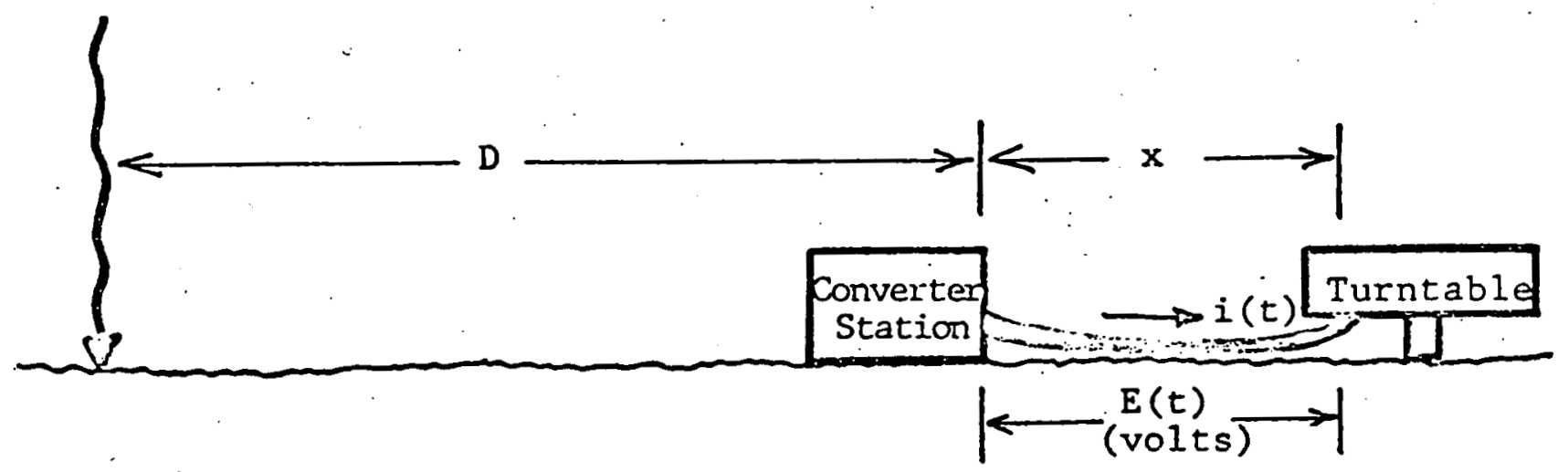

Figure 6 - Earth Voltage Drives Current through Cables.

Assuming that the lightning current wavefront is a. ( 1 -cos) function as before, the earth voltage will follow and drive a current through the cable inductance, as shown in equivalent circuit of Figure 7.
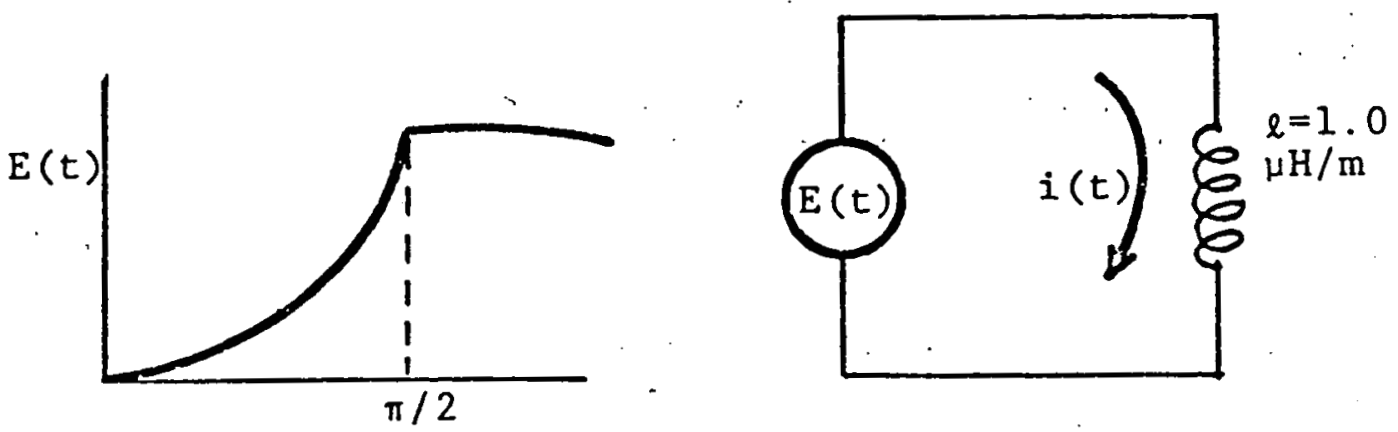

Figure 7 - Earth Voltage Waveform and Equivalent Circuit. 
The earth voltage is given by equation ( 9 ) and is:

$$
E(t)=\frac{\rho I(t)}{2 \pi}\left(\frac{1}{D}-\frac{1}{D+x}\right)
$$

Let $e(t)$ be the average earth voltage per meter of cable length between the two shelters, then:

$$
e(t)=\frac{E(t)}{x}(1-\cos \omega t), \text { for } 0<t<1.5 \mu s
$$

and

$$
\begin{aligned}
i(t) & =\frac{1}{l} \int_{0}^{1.5 \mu s} e(t) d t \\
& =\frac{1}{l} \int_{0}^{1.5 \mu s} \frac{E_{\max }}{x}(1-\cos \omega t) d t \\
& =\frac{E_{\max }}{l x}\left[t-\frac{1}{\omega} \sin \omega t\right] .
\end{aligned}
$$

If the cable inductance, $\ell$, is again assumed to be $1 \mu \mathrm{H} /$ meter and the cable length, $x$, is assumed to be 150 meters, the peak cable current, $i_{\max }$, can be calculated for various combinations of $\rho$ and $D$ by substituting the appropriate value of $E_{\max }$ obtained

\begin{tabular}{|c|c|c|c|c|}
\hline \multirow{2}{*}{$\begin{array}{c}\text { Soil } \\
\text { Resistivity } \\
(\Omega-m) \\
\end{array}$} & \multicolumn{4}{|c|}{ Stroke Distance from Buildings } \\
\hline & $D=$ & $100 \mathrm{~m}$ & $1 \mathrm{~km}$ & $10 \mathrm{~km}$ \\
\hline & & Peak C & ent $i_{m}$ & \\
\hline$p=10$ & & 6.4 & 0.16 & insignificant \\
\hline$\rho=100$ & & 64.0 & 1.4 & $"$ \\
\hline$\rho=1000$ & & 640.0 & 14.0 & $"$ \\
\hline
\end{tabular}
from equation ( 9 ) into equation (22). Peak cable currents resulting from a $140 \mathrm{kA}$ stroke are presented in Table IV.

TABLE IV - Peak Currents in Cables as a Result of Earth Voltages

Table IV shows that there are conditions under which earth voltages from a nearby flash can drive up to several hundred amperes through cables. 
Thus, there are at least two mechanisms whereby nearby lightning strikes can cause surge voltages and currents to appear in interconnecting cables, even when the strikes occur outside of the plant.

If surges of the magnitudes appearing in Tables III and IV appear in power or signal conductors they may damage some of the electronic components. If the cables are shielded, the induced currents will flow on the shields instead of the conductors. The shields will greatly attenuate the voltages that are induced upon the conductors but some voltage will still appear on the conductors due to the shield resistance and to magnetic flux leaking through the shield. Vulnerability of the PV system electrical and electronic components to surge voltages and currents of the magnitudes estimated in the foregoing paragraphs will be considered in Section 2. 


\section{A Angroic nf Tishtning Effects}

The analysis begun in Section 1 is continued in this section to develop specific recommendations for protection of the GE/Sea World Photovoltaic Concentrator Application Experiment. To. facilitate this; several protection concepts have been considered and evaluated. Those that appear promising are discussed in this section and included in the list of protective recommendations presented in Section 3 (Protective Recommendations).

\subsection{Direct Strike Damage}

In the analysis of Section 1 it. was determined that the 5-acre collector site would receive about one lightning strike every 6 years. The collector turntable structures cover approximately $62 \%$ of the 5 acres, but due to protrusions and sharp corners, it can be assumed that all strikes to the area will terminate on one of the nine turntables or the perimeter fence. Thus each turntable will be struck only about once every 55 to 60 years.

Very little information is available about the electrical transient capability of silicon solar cells and so it is not known whether the cells can survive the induced currents and voltages associated with a lightning strike directly to a collector. Such a stroke, which could be of either positive or negative polarity, would impose open circuit voltages of $10^{3}$ to $10^{4}$ volts and short circuit currents of $10^{2}$ to $10^{3}$ amperes on the system for time durations of $10^{-5}$ to $10^{-4}$ seconds. The cell bypass diodes, which typically have $I^{2} t$ ratings of 60 to 100 ampere ${ }^{2}$ seconds may survive the short circuit currents and are protected from the reverse voltages by the solar cells. The "or-ing" (blocking) diodes most likely wili be failed on reverse voltage unless protected by appropriate surge suppression devices such as varistors. Further discussion of possible lightning effects on the photovoltaic receivers is presented in Paragraph 2.3.

A direct lightning strike to the turntable structure would also cause possible mechanical damage to the turntable mechanisms. Pitting and arcing may take place in wheel and pintel bearings; craters may be blown in the concrete outer wheel path, and possibie welding of control rod and collector bearings could all result from a direct strike to a turntable.

Most of the mechanical damage can be minimized by using bonding straps around the bearings and providing adequate grounding paths from the turntables. However, protection of the mechanical system may not be justifiable, especially for a once in 55-year. anticipated strike level.

The only way to completely protect the solar cells and turntable system would be to intercept the lightning before it could strike a turntable. Twelve 30-foot tall lightning masts erected at 


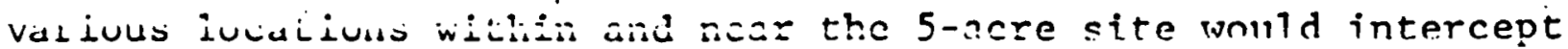
$99 \%$ of all of the lightning strikes that would otherwise fall within the site. These masts, however, would also attract more strikes than would normally occur and deposit their currents near the power and control cables, greatly aggravating the more important problem of protecting the electrical and electronic systems against indirect effects. This approach, therefore, is not recommended.

When lightning strikes a turntable, a significant portion of the lightning current will be carried by the cables interconnecting the turntables and the converter station building. The longest cable run is about 75 meters and AWG $13 / 0$ cables are being considered to carry the DC power from the turntable to the converter. Using the ground voltage rise equation from the previous section (equation No. 9):

$$
E=\frac{\rho I}{2 \pi}\left(\frac{I}{D}-\frac{I}{D+x}\right)
$$

and substituting

$$
\begin{aligned}
& D=1 \text { meter (a very close strike) } \\
& \mathbf{x}=75 \text { meters } \\
& \rho=100 \text { ohm-meters (an average value) } \\
& I=140 \times 10^{3} \text { amperes ( } 98 \mathrm{th} \text { percentile stroke) }
\end{aligned}
$$

a value

$$
E=2.2 \times 10^{6} \text {, volts is obtained }
$$

However, the resistance, $R$, of AWG 非 $2 / 0$ cable is $0.13 \times 10^{3}$ ohms per meter of cable length. Thus the resistance, $R_{75}$, of 75 meters of this cable is

$$
R_{75}=9.75 \times 10^{-3} \text { ohms }
$$

If the entire current $\left(140 \times 10^{3}\right.$ amperes) were conducted, the voltage drop along the cable would only be

$$
V=1365 \text { volts }
$$

So the cables are the path of least resistance and most of the lightning current will be conducted by the cables and not by the earth. However, not all of the current will be conducted by any one of the. interconnecting cables but will be distributed as a function of their respective impedances. The cable can essentially be represented by a series circuit consisting of cable resistance and self-inductance. The self-inductance, L, of large cables (AWG 非 3 and 2/0) is a function of cable diameter and will be between 0.5 and $1.0 \times 10^{-6}$ henries/ meter. The cable circuit time constant, $t_{c}$, is given by:

$$
t_{c}=L / R=\frac{0.75 \times 10^{-6}}{0.13 \times 10^{-3}}=5.8 \times 10^{-3} \text { seconds }
$$


Sincc this time crinstant is much lonper than the duration of a lightning stroke ( $1 \times 10^{-4}$ seconds) the inductance will govern the current.behavior and the conductors with least inductance will carry most of the lightning current.

\subsection{Analysis of Cable Transients}

Conduction of lightning stroke currents by the cables will not usually be detrimental to the cable. For instance, an AWG 非 6 wire will conduct a $2 \times 10^{5}$ ampere lightning stoke with an action integral (ability to deliver energy) of $2 \times 10^{6} \mathrm{~A}^{2}-\mathrm{s}$ without damage to the wire. However, unless protective devices are installed at the ends of the cable to provide current entry and exit paths, passage of lightning current through unprotected equipment may damage this equipment.

If two or more parallel cables are laid side by side, the inductance of both cables will be only slightly less than that of a single cable. However, if the cables are separated by a few meters, each cable will be unaffected by its companion and will exhibit the same inductance as if it were used alone. The paralleled system inductance will be reduced by the reciprocal of the number, $n$, of cables in the system $(1 / n)$. This phenomena is very similar to skin effect in large conductors; where short duration currents are concentrated on the outside edges of a conductor or conducting structure. Basically the current is following the path of the least impedance, which in this case is the path of least inductance.

As presently conceived, there will be five electrical cables extending from each turntable to the equipment building. These cables are as follows;

$$
\begin{aligned}
& \text { DC power positive cable, AWG 非 } 2 / 0 \\
& \text { DC power negative cable, AWG 非 } 2 / 0 \\
& \text { AC power supply cable, AWG 非 } 3 \\
& \text { AC power return cable, AWG 非 } 3
\end{aligned}
$$

Control cable, 3 pair - AWG 非2 with an overall shield.

The five cables are routed in a random pattern through polyvinylchloride (PVC) lined concrete conduits between the converter and the turntable. Fresently the negative DC power caole is grounded to the turntable structure and ground rod, and the AC power return cable is grounded at the transformer neutral in the equipment building. The control cable should be a telephone-type cable with folded continuous $0.005^{\prime \prime}$ thick copper shield.

To reduce the portion of lightning current which flows on the positive DC power cable, the AC power supply cable and the shield of the control cable, it is suggested that the $D C$ power negative and AC power return cables be replaced by AWG 非 $1 / 0$ cables which are grounded at both the turntable and equipment building ends. 
These cables should be routed along the edges of the conduit structure to minimize their inductance. Aduitionally, two ground rods should be driven at the bottom outside edges of each handhole with a vertical copper busbar attached to join and ground these lightning ground and return (LGR) cables at every handhole. A sketch of preferred conduit cable routing is shown in Figure 8. Typical handhole layouts are shown in Figure 9.
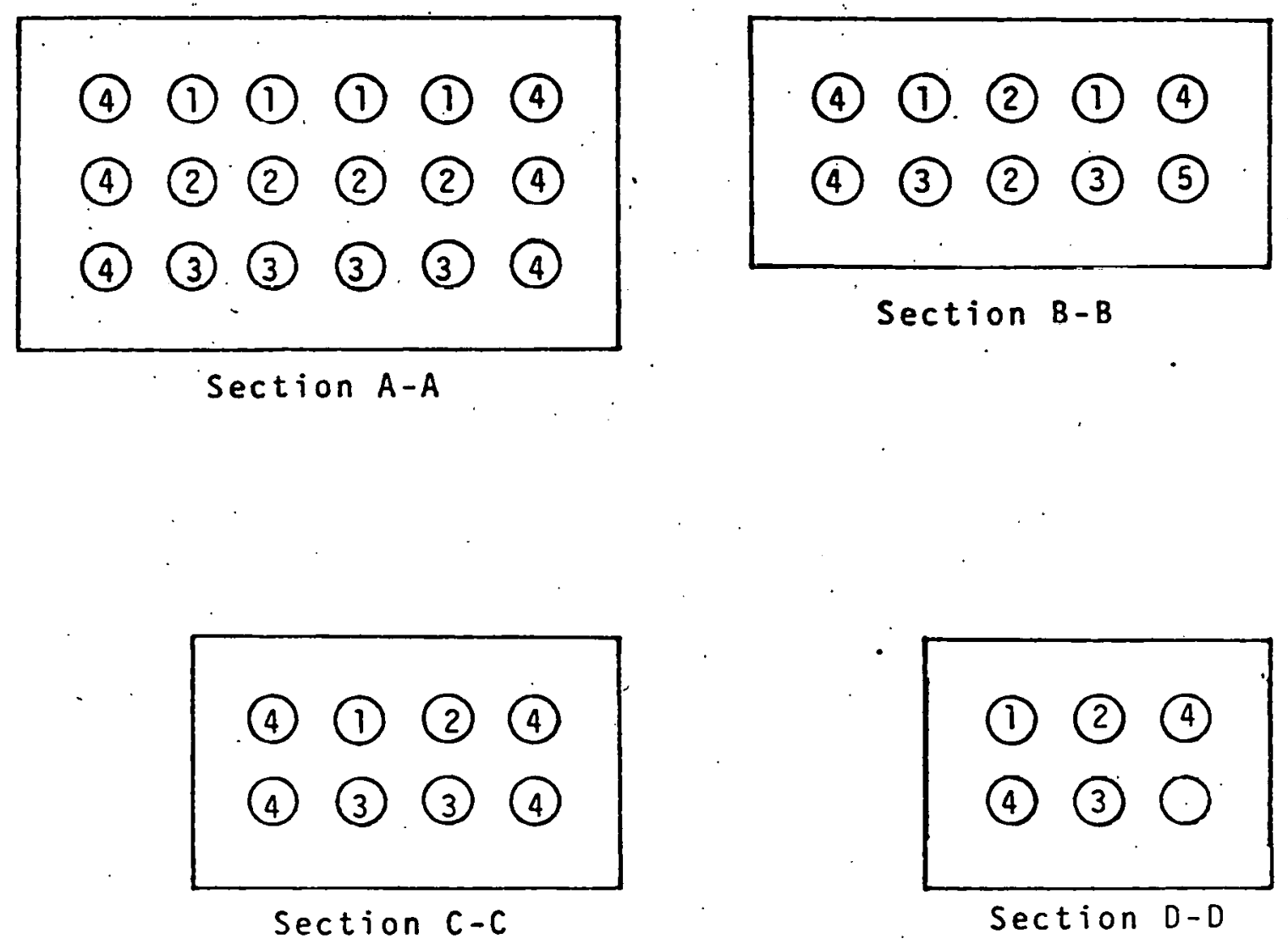

Key:

1 - Signal Cable
2 - AC Pwr Cable

3 - DC Pwr Cable

4 - LGR Cable

\section{(4) (1) (2) (4) \\ (4) (3) (3) (4)}

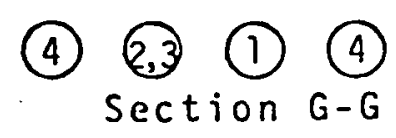

Section $E-E$

Figure 8 - Typical Conduit Cable Layout. See Rogers \& Lopatka Preliminary Plant Layout Dwg. 8/1/78. 
Typical Handhole

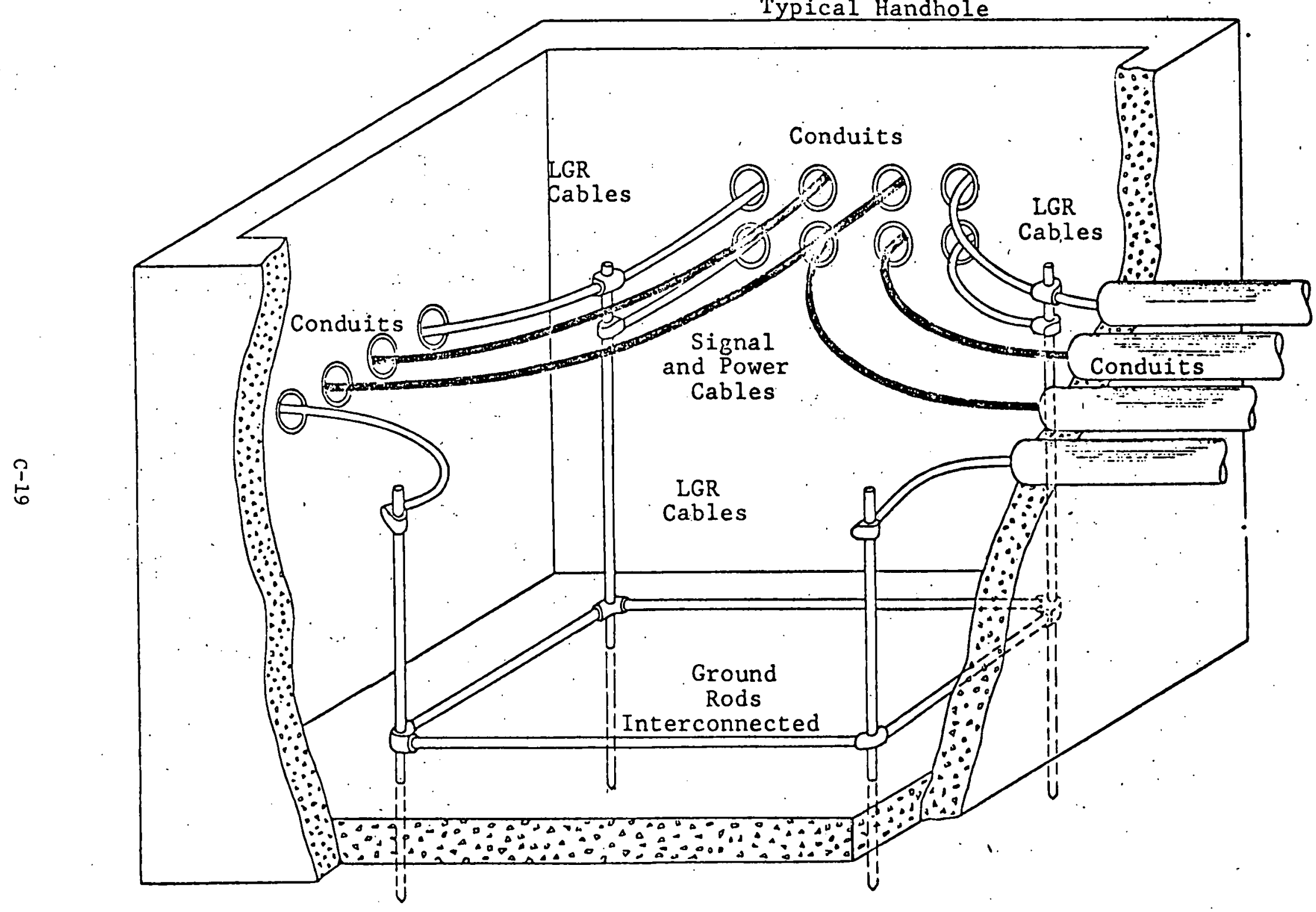

Figure 9 - Typical Handhole Grounding Configuration: 
Since the inductance of the path formed by the two outer cables is less than that of the three inner cables in the arrangement of Figures .8 and 9 (Reference 6 ) most (but not all) of the lightning current will want to flow on the outer cables. This will reduce the amount of lightning current flowing on the inner cables and minimize the requirements for protection of the electrical equipment at either ends of these cables. It is probable that this arrangement will result in $60 \%$ of the lightning current being carried by the two outer (grounded) cables and $40 \%$ on the inner cables. Under the worst case in which a $140 \mathrm{kA}$ stroke enters a turntable and all of this current leaves the turntable via the 5 cables, $60 \%$ of this current would be carried safely to ground via the two outer cables, $40 \%$ would enter the three inner cables. The division among these cables might be as follows:

$$
\begin{aligned}
& \text { control cable shield }-20 \mathrm{kA} \\
& \text { positive DC power }-18 \mathrm{kA} \\
& \text { AC power supply }
\end{aligned}
$$

Since the control cable shield has no openings or holes (as are present in braided shields) the voltage, $v(t)$, in internal conductors will be equal to the shield current, Is, multiplied by the shield resistance, $R_{S}$. A typical shield resistance is $2.5 \times 10^{-3}$ ohms per meter, so that the peak voltage, $V_{m}$, along the cable shield will be

$$
\begin{aligned}
V_{\mathrm{m}} & =I_{s} R_{s} \\
& =\left(20 \times 10^{3}\right)\left(2.5 \times 10^{-3} \text { ohms/meter }\right) \\
& =50 \text { volts per meter of cable length. }
\end{aligned}
$$

or

$$
\begin{aligned}
& 1250 \mathrm{~V} \text { for } 25 \text { meters of cable length and } \\
& 3750 \mathrm{~V} \text { for } 75 \text { meters of cable length }
\end{aligned}
$$

The amount of current that is induced in the internal conductors of the control cable is dependent upon the inductance and resistance of these conductors as well as the driving voltage. The resistance, $R_{c}$, of the conductors is that of AWG 22 wire, or $5.32 \times 10^{-3}$ ohms per meter of length: The inductance, $\mathrm{L}_{c}$, of these wires (with respect to their shield return path) may be derived from the surge impedance of the cables as follows:

$$
L=\frac{Z}{V}
$$

where

$$
\begin{aligned}
\mathrm{z}= & \text { cable surge impedance (ohms) } \\
& \text { typically, } 75 \text { ohms } \\
\mathrm{v}= & \text { velocity of propagation along } \\
& \text { the cable (meters/second) } \\
& \text { typically } 2 / 3 \text { the speed of } \\
& \text { light, or } 2 \times 10^{8} \mathrm{~m} / \mathrm{s} .
\end{aligned}
$$


Thus:

$$
L=\frac{75}{2 \times 10^{8} \mathrm{~m} / \mathrm{s}}=0.38 \times 10^{-6} \text { henries/meter }
$$

The time constant, $t_{c}$, of current buildup in a conductor circuit is :

$$
\begin{aligned}
t_{c} & =\frac{L_{c}}{R_{C}}=\frac{0.38 \times 10^{-6} \mathrm{H}}{5.32 \times 10^{-3} \Omega} \\
& =7.14 \times 10^{-6} \text { seconds }
\end{aligned}
$$

which is on the same order as the lightning strike time duration of 100 microseconds. This confirms that both inductance and resistance will govern the peak current that results in the conductors.

The peak conductor current, $I_{\mathrm{m}}$, can be calculated as a function of the shield (driver) voltage and shown in Figure 10 together with the driving voltage $V(t)$. Using straight line approximations for the voltage rise and fall introduces some small errors but greatly simplifies the calculations.

The rise and fall times of the shield voltage will be nearly identical with those of the lightning stroke current in the cable shield. For this analysis, the rise time will be assumed to be 2 microseconds (as in Figure 4), and the fall time will be 100 microseconds, as is typical of many lightning strokes.

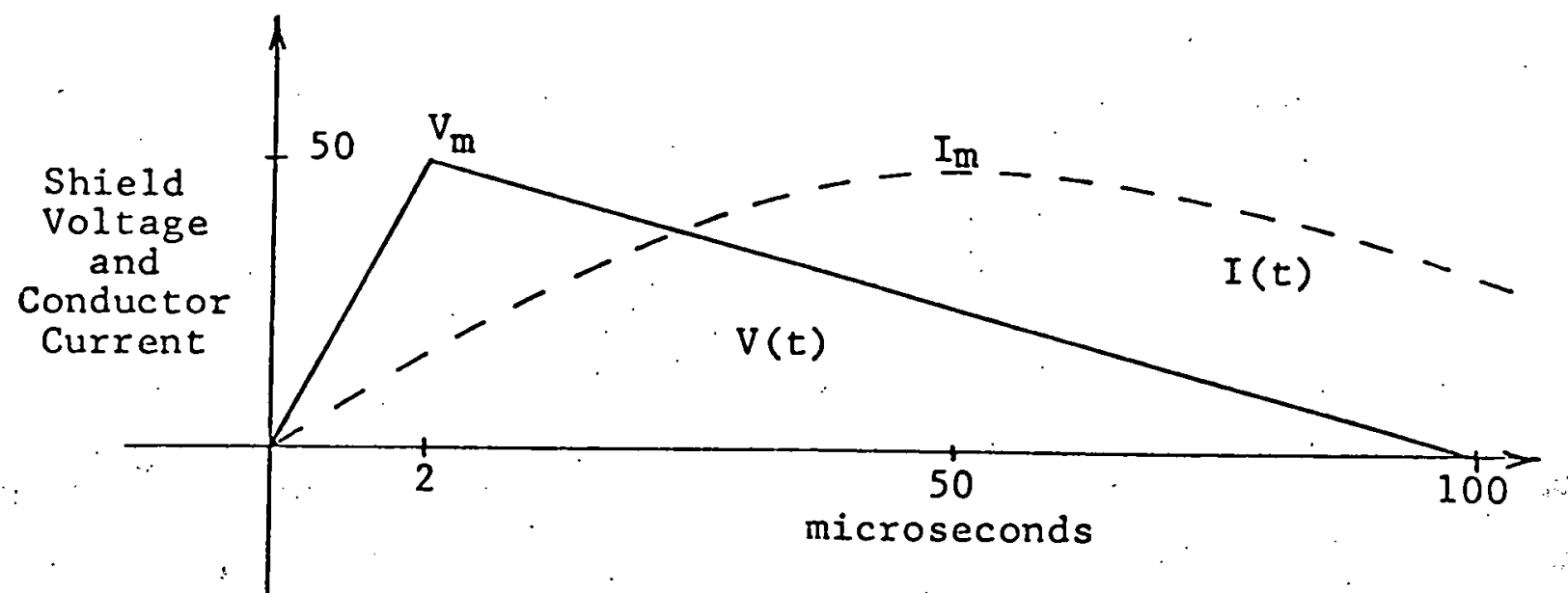

Figure 10 - Approximate Shield Voltage and Current Waveshape. where, $0 \leq t \leq 2 \times 10^{-6}$ seconds $V(t)=\frac{V_{m}}{2 \times 10^{-6}}$

$$
2 \leq t \leq 100 \times 10^{-6} \text { seconds } V(t)=V_{m}\left(-1.02 \times 10^{4} t+1.02\right)
$$


The current that this vollage will produce in the cable conductor will be out of phase with the voltage and peak at a later time determined by the circuit resistance when $I(t) R=V(t)$, as shown in Figure 10. Neglecting the resistance, $I_{m}$ will occur when $V(t)$ returns to zero, or:

$$
I_{m}=\frac{1}{L} \int_{0}^{2 \times 10^{-6}} V(t) d t+\frac{1}{L} \int_{2 \times 10^{-6}}^{100 \times 10^{-6}} V(t) d t
$$

Substituting equations (27) and (28) into (29) and simplifying gives:

$$
I_{m}=1.52 \times 10^{-4}\left(\frac{V_{m}}{L}\right)
$$

and if no resistance were present,

$$
I_{m}=2 \times 10^{4} \text { amperes. }
$$

On the other hand, if no inductance were present the conductor current would reach its maximum at the same time as the shield voltage. Its peak would. be:

$$
\frac{E_{\text {m }}}{R_{c}}=\frac{50 \mathrm{~V} / \mathrm{m}}{5.32 \times 10^{-3} \Omega / \mathrm{m}} \sim 1 \times 10^{4} \text { amperes }
$$

but at 2 microseconds, the conductor current is actually:

$$
I_{m}=132 \text { amperes and } V(t)=50 \text { volts }
$$

By choosing different times ( $t$ ) and determining the voltage at that time from Figure 10, the peak current can be determined by iteration.

When the voltage has decayed to $1 / 2$ crest:

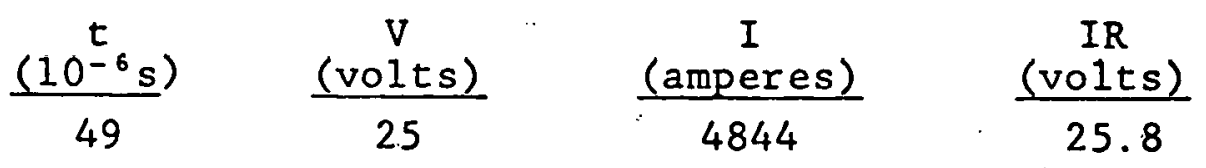

which is in close agreement with the actual driving voltage. So, $I_{\mathrm{m}}$ will be about 4700 amperes and will occur at about 45 microseconds.

This is the peak current if the shielded cable had only a single conductor in it. The actual-signal cable has 6 conductors. If each were to carry 4700 amperes, there would, hyopthetically, be a total of 28,200 amperes in the conductors which is more than the lightning current that was in the shield to begin with, an impossibility. The current carried by each conductor in the control cable will, however, be more than $1 / 6$ of the 4700 amperes since the parallel impedance of all of them is lower than that of a single 
conductor. An estimate for each wire of between 500 and 750 amperes seems reasunable since this represents a total of between 3000 and 4500 total amperes, leaving the balance to flow in the shield. Voltages of 50 volts per meter of cable length and currents of up to 750 amperes per conductor are thus the levels that must be dealt with by protective devices at the ends of the signal cables. Protective devices to suppress these surges are described in Section 3.0.

\subsection{Lightning Effects on the Photovoltaic Receiver}

The possibilities for lightning damage to the PV receivers are now considered in further detail. A typical receiver assembly is pictured in Figure 11.

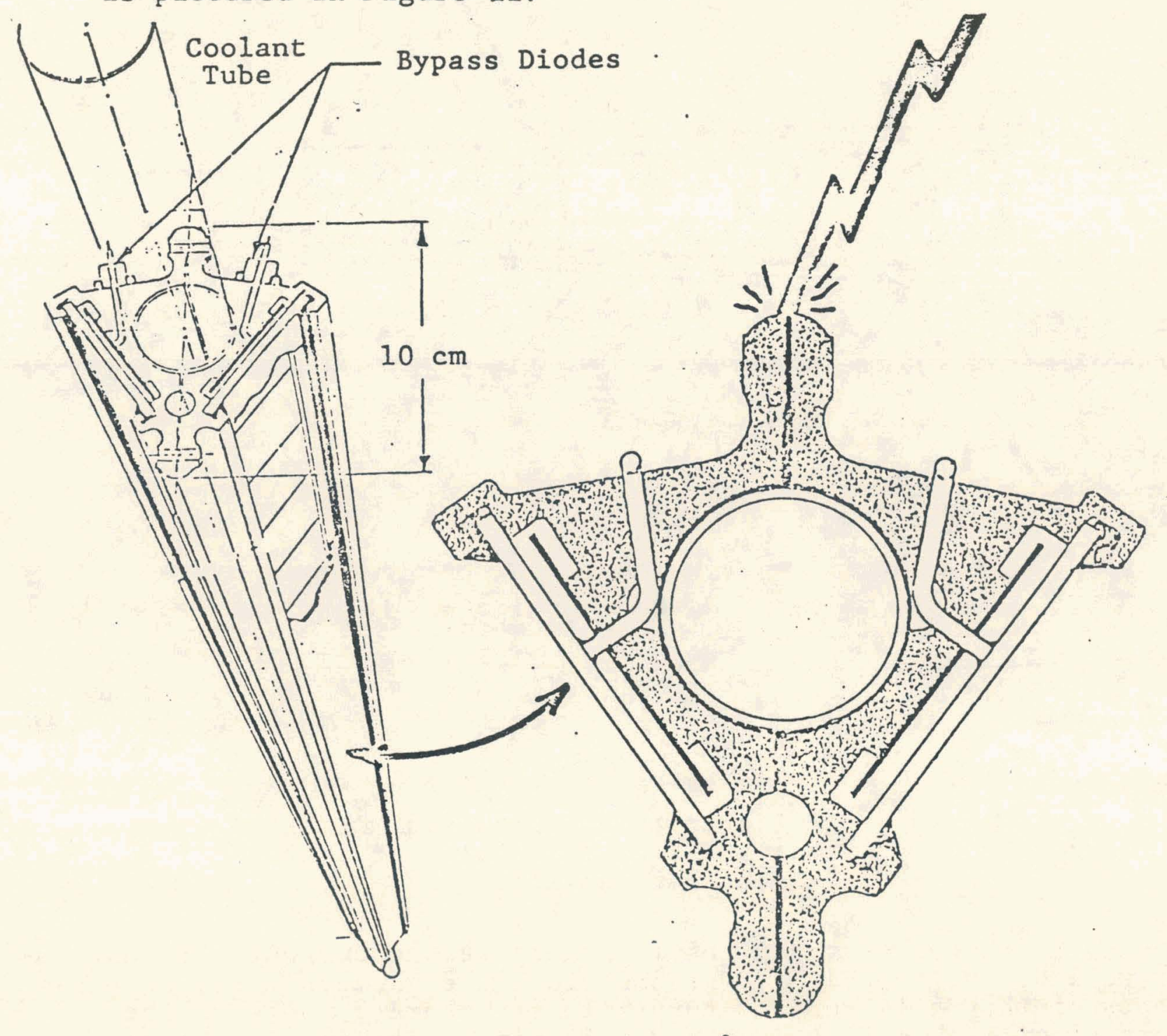

Figure 11 - Photovoltaic Receiver Assembly - A Lightning Strike Would Hit the Receiver Bar and Not the PV Cells Themselves. 
As shown in figure 11, the PV cells themselves are faced downward and will not be exposed to a direct lightning strike; but the receiver bars in which the cells are mounted may receive a direct strike. The probability of this happening is not great because the probability of a direct strike to a spot anywhere on any of the turntables, in the first place, is very low ( 1 strike every 6 years). Secondly, at most times of the day the edges of the reflectors would be higher than the PV receiver assemblies, making it likely that the reflectors, and not the receivers, would be struck as shown in Figure 12.

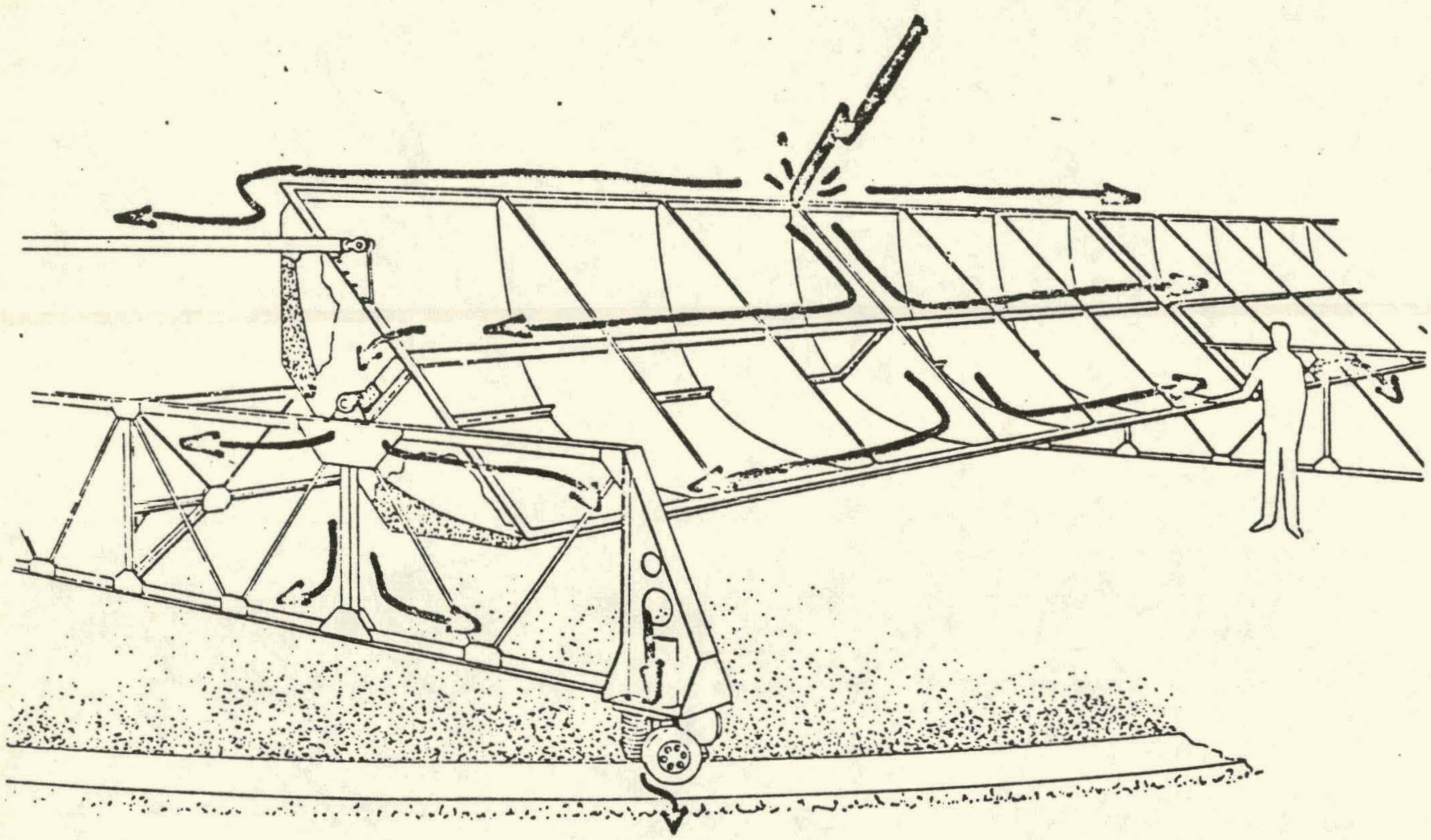

Figure 12 - A Lightning Strike Would Most Likely Hit the Edge of a Relector Instead of a Receiver Assembly.

When a reflector is struck the lightning stroke current that enters it will divide and flow to ground along the various metallic elements of the reflector and turntable structures. Some of the current will also flow in the reinforcing wires and in the copper coolant tubes. Due to its close proximity to the PV receivers, the portion of lightning current that flows in the coolant tubes 
will have the greatest affect upon the PV receivers. The amount of current that flows in the coolant tubes or any other structural member will depend upon its proximity to the strike point and its impedance to earth. Those elements that are in line with the shortest paths to earth will therefore conduct the highest portion of current.

Due to the number of structural paths available, it is probable that no more than $25 \%$ of the lightning stroke current can flow in any single coolant tube, and in most cases the percentage will be even less than this. Assuming, for design purposes, that $140 \mathrm{kA}$ is the maximum lightning stroke current that will occur, the amount of current in a coolant tube would be:

$$
i_{\text {tube }}=(0.25)(140 \mathrm{kA})=35 \mathrm{kA}
$$

This current produces a magnetic flux which will pass through loops formed by the PV receiver circuits mounted on the tube and induce surge voltages and/or currents in these loops. The induction mechanisms are the same as described in paragraph 1.3. of. Section 1 for magnetic fields passing through loops formed by cables and the earth, except that the loop areas involved are smaller. The largest circuit loops are Iikely to be those formed between power and return conductors and the coolant tube at the ends of each compartment, collector and string of receivers where these conductors run between one unit and the next. Along the receivers themselves the conductors are directly adjacent to each other and the loops formed are very small.

Figure 13 illustrates the several loops formed between the PV cells, receiver bars, return conductor and coolant tube, and the paths of surge currents that may be induced in these loops. There are six possible cases. Only two of the PV cell compartments are shown, but the surge current paths would be similar in all compartments in a string.

Figure 13 also includes a reverse bypass diode, a varistor and an additional "or-ing" diode. These devices, which are discussed in section 3 , were included to provide safe paths for all currents in the system.

An estimate of the magnitude of surge current induced in the loops and Figure 13 can be obtained by assuming an effective loop area through which flux may pass, and calculating the resulting loop current as follows: 
Equivalent Circuit of PV Receivers. Two Compartments Shown.

Case 1

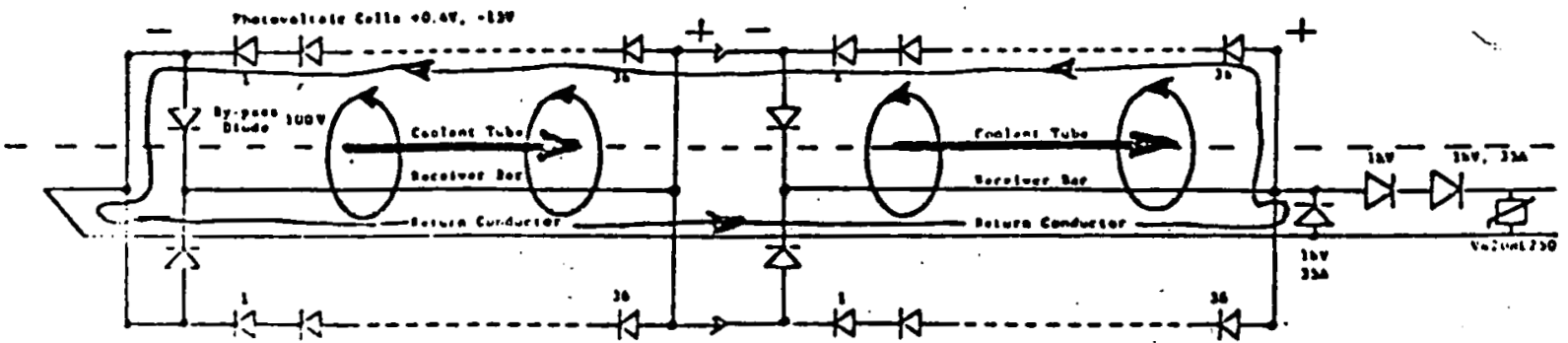

Magnetic flux passing between the return conductor and PV cells in this direction induces a voltage that immediately drives current through the PV cells in their reverse direction, of a magnitude possibly sufficient to destroy these cells.

\section{Case 2}

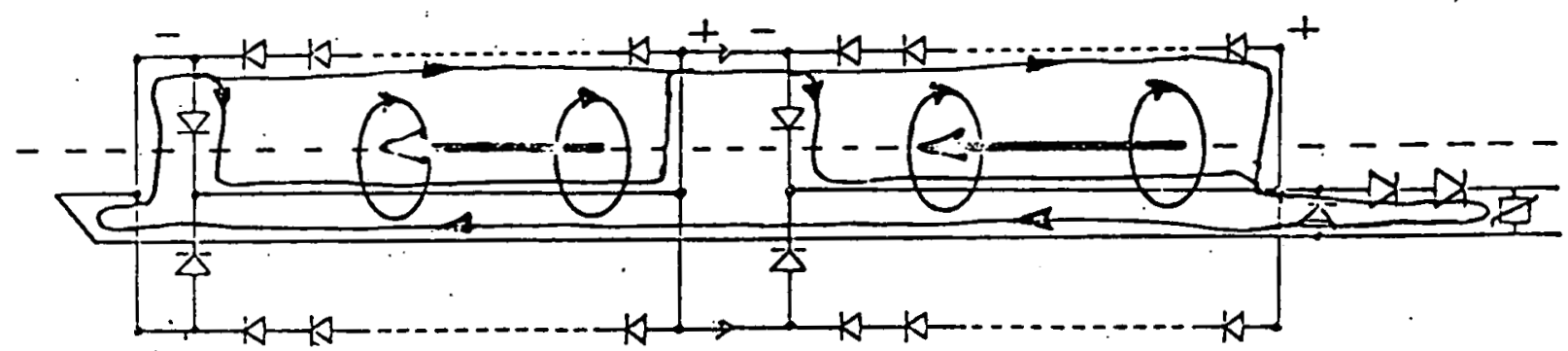

Magnetic flux passing between the return conductior and PV cells in this direction induces a voltage that drives current in the forward direction through the PV cells. (Path A) and the bypass diodes and receiver bars (Path $B$ ). The diodes and PV cells will probably tolerate this current.

\section{Case 3}

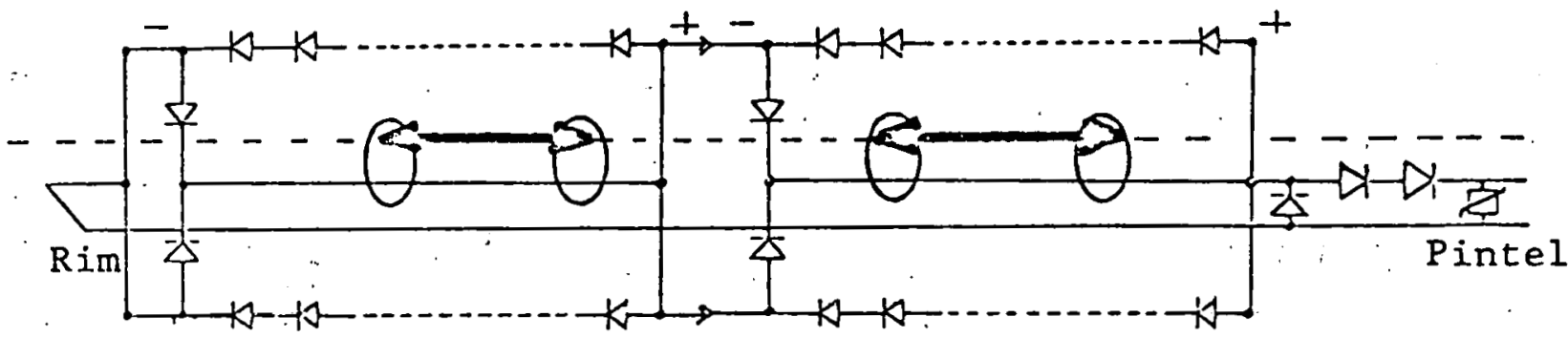

Magnetic flux (in either direction) passing between the coolant tube and the return conductor induces a voltage between the negative bus bar, return conductor and the coolant tube. This voltage will also cxist between the other elements of the receiver and the coolant tube, and will be maximum at the negative (rim) end of each string. No damage will result unless the insulation fails and a sparkover occurs.

Figure 13 - Possible Surge Current Paths Induced by Lightning Current in the Coolant Tubes.. Paths in Each Parallel Receiver Are Identical: Only One Side Shown. 
Equivalent Circuit of PV Receivers. Two Compartments Shown.

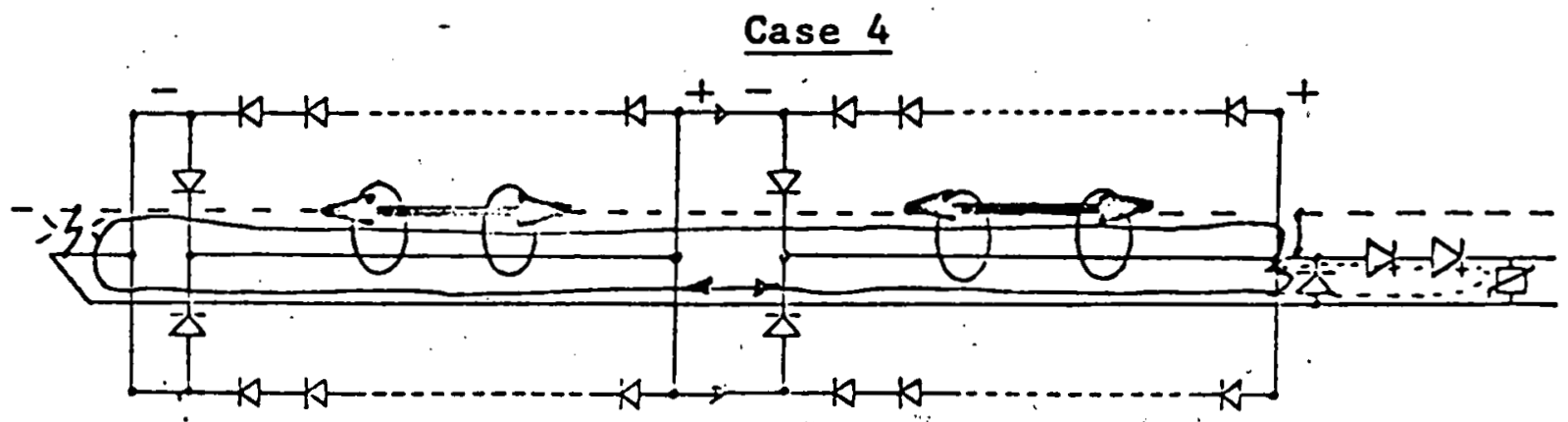

If the insulation breaks down in case 3 (above), the voltage will force current to circulate harmlessly between the return conductor and coolant. tube. Some power current may commute to the coolant tube also, but this should not be harmful.

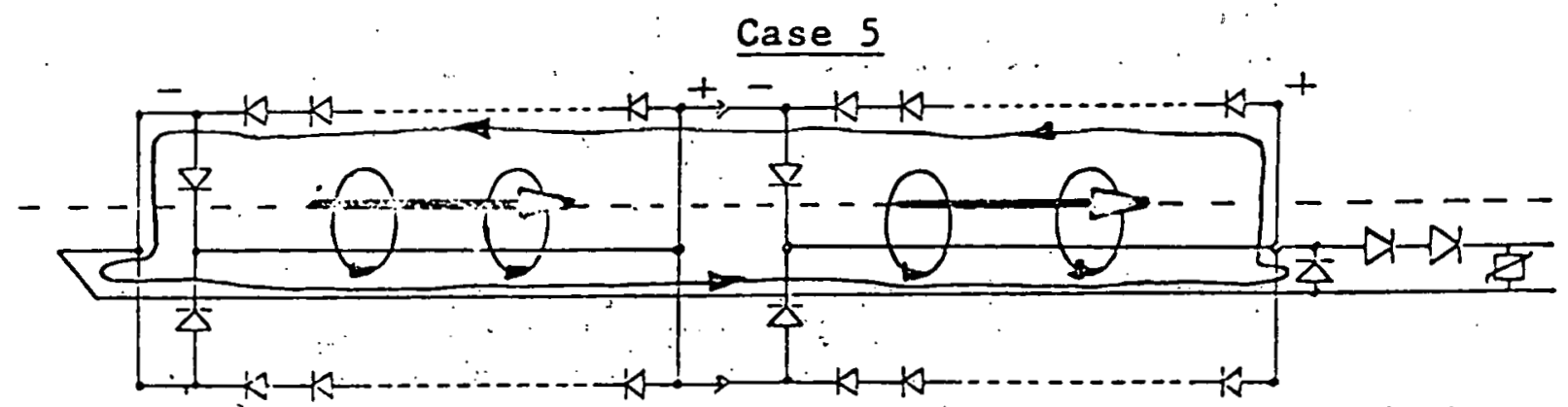

Magnetic flux passing between the return conductor and the receiver bar in this direction induces a voltage that appears across the bypass diodes and the PV celis in the reverse direction. The $\mathrm{PV}$ cells will conduct in the reverse direction at about 0.6 volts per cell or 22 volts per 36 cell string, which is less than the 100 volt reverse avalanch rating of the bypass diodes. Thus, the induced voltage will cause current to circulate in the PV cells as shown. The result is similar to Case 1.

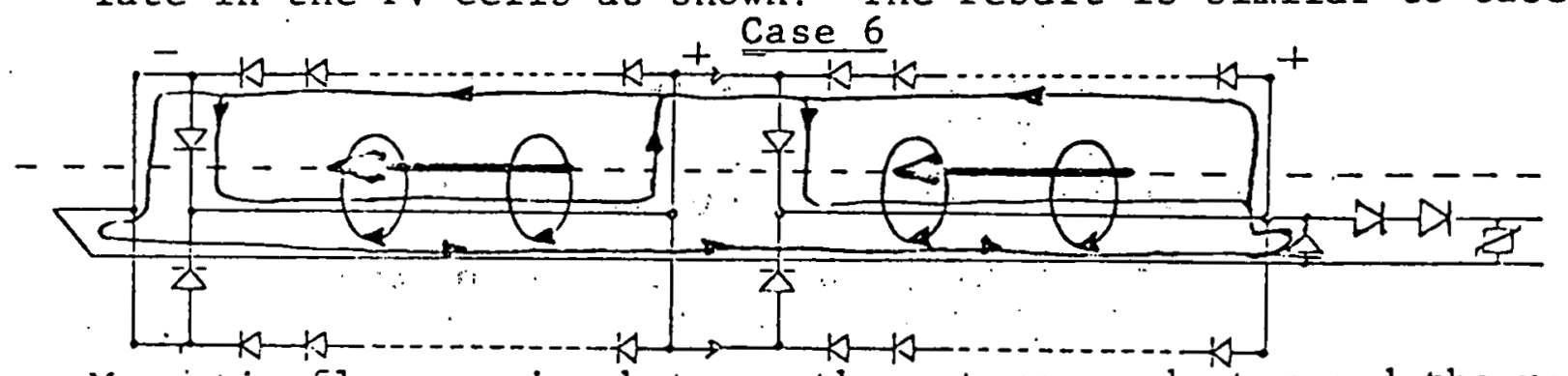

Magnetic flux passing between the return conductor and the receiver bar in this direction induces a voltage that drives current the PV cells and the bypass diodes in the forward direction as shorin. The result is similar to Case 2 , and the diodes and cells will probably tolerate this current.

Figure 13 - Concluded. 
Assumc that the PV cells and the return conductor are between and 2 and 4 centimeters away from the coolant tube respectively, and the cell compartments are separated by 0.5 meters as shown in Figure 14:

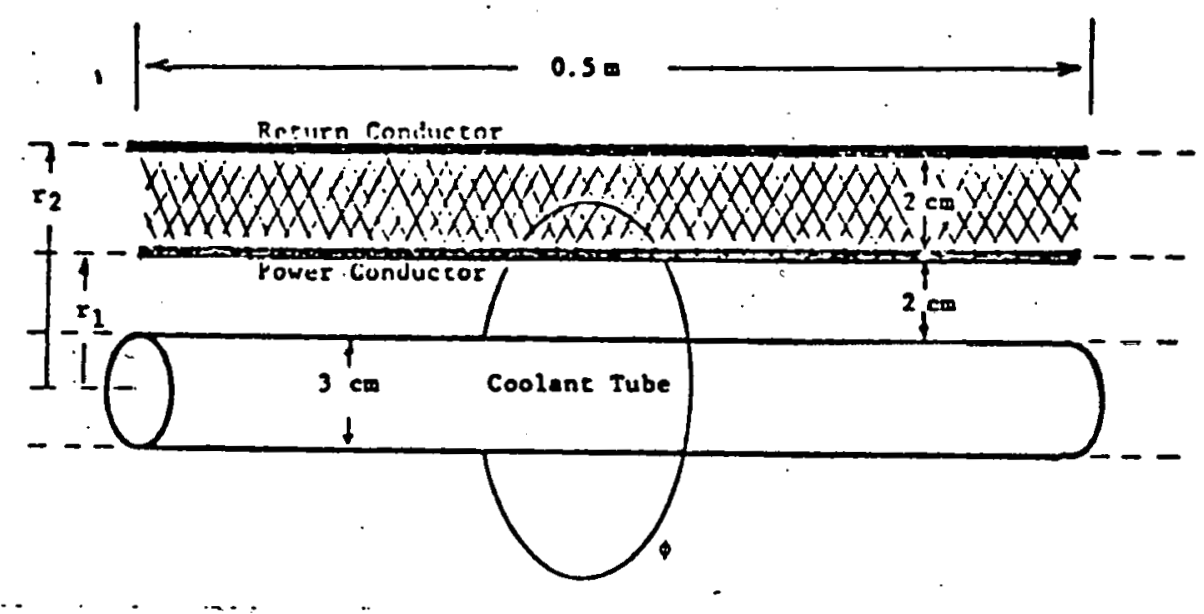

Figure 14 - Transition Area between Two PV. Cell Collectors, Showing Loop Area between Return and Power Conductors.

Then the rate of change of magnetic flux passing through the loop area shown in Figure 14 is (Reference 7):

$$
\frac{\mathrm{d} \phi}{\mathrm{d} t}=20 \times 10^{-8} \ell \frac{\mathrm{di}}{\mathrm{dt}} \operatorname{Ln}\left(\frac{\mathrm{r}_{2}}{\mathrm{r}_{1}}\right)
$$

where,

$$
\begin{gathered}
\phi=\begin{array}{l}
\text { the magnetic flux passing through the } \\
\text { loop (webers) }
\end{array} \\
\ell=\begin{array}{l}
\text { length of the loop (meters) }=0.5 \mathrm{~m} \\
i= \\
\text { the lightning current in the coolant } \\
\text { tube (amperes) }=35 \mathrm{kA}
\end{array} \\
r_{1, r_{2}=} \text { dimensions as shown (meters) } \\
r_{1}=3.5 \mathrm{~cm} . \\
r_{2}=5.5 \mathrm{~cm}
\end{gathered}
$$


linus,

$$
\begin{aligned}
\frac{\mathrm{d} \phi}{\mathrm{dt}} & =\left(20 \times 10^{-8}\right)(0.5 \mathrm{~m}) \frac{\mathrm{di}}{\mathrm{dt}} \operatorname{Ln}\left(\frac{5.5}{3.5}\right) \\
& =4.52 \times 10^{-8} \frac{\mathrm{di}}{\mathrm{dt}} \text { webers/second }
\end{aligned}
$$

and the peak voltage induced by the magnetic flux passing through this loop would be:

$$
e_{\text {loop }}=\mathrm{N} \frac{\mathrm{d} \phi}{\mathrm{dt}}
$$

where $\mathrm{N}$ is the number of turns in the loop, $=1$.

Thus,

$$
e_{100 p}=4.52 \times 10^{-8} \frac{d i}{d t}
$$

The waveform of the loop voltage will be the derivative of the lightning current that produces it. For this analysis it will be assumed that the lightning current has a. $\left(1-\cos \omega_{1} t\right)$ rise in 2 microseconds and a cosine wave decay over a period ten times as long. The waveforms of this current and the voltage it induces in the loop are shown in Figure 15.

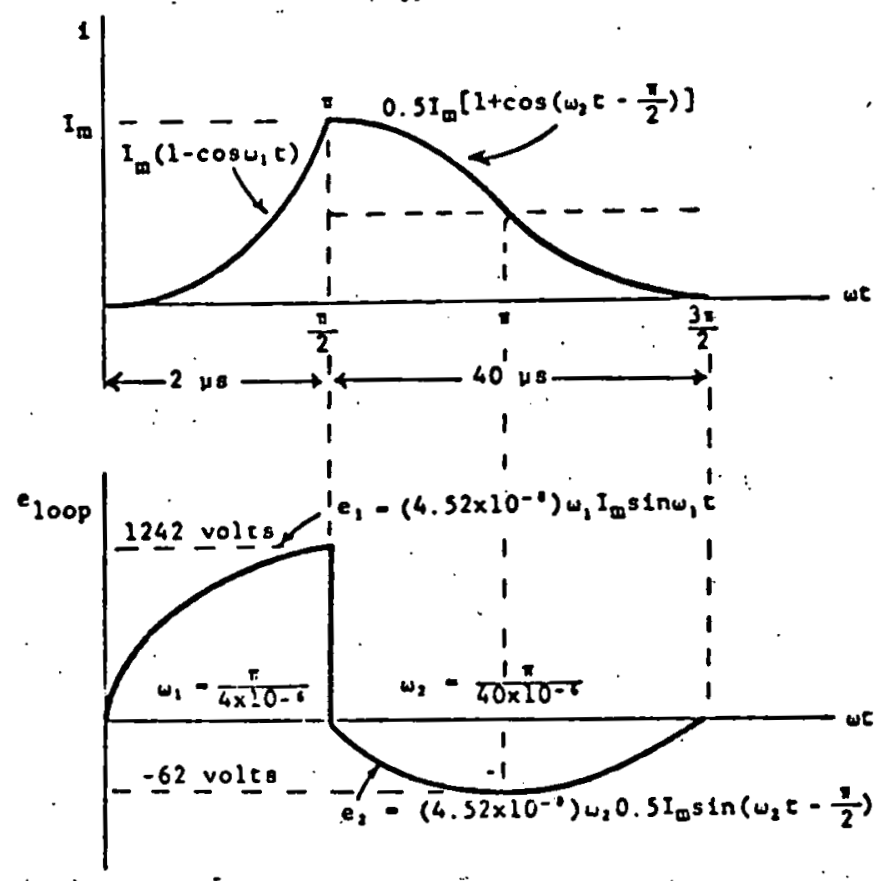

Figure 15 - Lightning Current Waveform and the Voltage It Induces in the Loop. 
The current that is $\dot{u}_{L} i_{w i} i j: h a$ loon voltage is limited by the loop resistance and inductance. Neither of these parameters is presently. avililable, but an estimate of the maximum surge current. may be made if the loops are assumed to have no resistance and the inductance is taken to be that of the entire compartment loop. The loop inductance can be estimated from the formula (Reference 8):

$$
L=0.004 \ell\left[\ln \frac{d}{p}+\frac{1}{4}\right]
$$

where, $\quad \mathrm{L}=$ the loop inductance (microhenrys)

$$
\begin{aligned}
\ell= & \text { the length of the loop (centimeters) } \\
d= & \text { the distance apart of the two } \\
& \text { conductors (centimeters) } \\
\rho= & \text { the radius of the conductors (centimeters) }
\end{aligned}
$$

The length of each compartment is 144 centimeters. The average separation of conductors in a loop will be assumed to be one centimeter and the radius of each conductor, on the average, 0.5 centimeters. The inductance of a loop would then be:

$$
\begin{aligned}
I & =0.004(144)\left[\ln \frac{1}{0.5}+\frac{1}{4}\right] \\
& =0.004(144)(0.943) \\
& =0.543 \text { microhenrys }
\end{aligned}
$$

and the current in the loop would be:

$$
i_{\text {loop }}=\frac{1}{L} \int_{0}^{\pi / 2} e_{1}(t) d t+\frac{1}{L} \int_{\pi / 2}^{2 \pi} e_{2}(t) d t
$$

where $e_{1}$ and $e_{2}$ are the separate induced voltage functions before and after the transition at $\omega_{1} t=\pi / 2$. The loop current flowing before $\pi / 2$ will be designated $i_{i}$ and is determined by integrating $e_{1}$ to $\pi / 2$ as follows:

$$
\pi / 2
$$

$$
\begin{aligned}
i_{1} & =\frac{1}{L} \int_{0}^{\pi / 2} e_{1}(t) d t \\
& =\frac{1}{0.543 \times 10^{-8}} \int_{0}^{\pi / 2}\left(4.52 \times 10^{-8}\right)\left(\frac{\pi}{4 \times 10^{-6}}\right)\left(35 \times 10^{3}\right)\left(\sin \omega_{1} t\right) d t \\
& =2.29 \times 10^{\circ}:\left[\frac{-\cos \omega_{1} t}{\omega_{1}}\right]_{0}^{\pi / 2} \quad \cdots
\end{aligned}
$$




$$
i_{1}=2.20: 10^{3}[?]=2900 \text { amperes at } \pi / 2 \text {. }
$$

After $\pi / 2$, the current is determined by integrating the voltage, $e_{2}$, as follows:

$$
\begin{aligned}
i_{2} & =\frac{1}{L} \int_{\pi / 2}^{2 \pi} e_{2}(t) d t \\
& =\frac{-1}{0.543 \times 10^{-6}} \int\left(4.52 \times 10^{-8}\right)\left(\frac{\pi}{40 \times 10^{-6}}\right)(0.5)\left(35 \times 10^{3}\right) \sin \left(\omega_{2} t-\frac{\pi}{2}\right) d t \\
& =-1.14 \times 10^{8}\left[\frac{-\cos \left(\omega_{2} t-\pi / 2\right)}{\omega_{2}}\right]_{\pi / 2}^{2 \pi} \\
& =-1.45 \times 10^{3}[0-(-1)] \\
& =-1450 \text { amperes }
\end{aligned}
$$

This is the amount by which $i_{1}$ will diminish 40 microseconds after the lightning current has reached its crest. It means that, due to the inductance of the loop, $(2920:-1450)=1450$ amperes: will still be flowing in the loop when the lightning current itself has decayed to zero. Another 40 microseconds would be required for the loop current to decay to zero.

The waveform of the loop current is shown in Figure 16. Since lightning currents may be expected to flow in either direction in the coolant tubes, the induced current may also flow in either direction in the PV receiver loops.

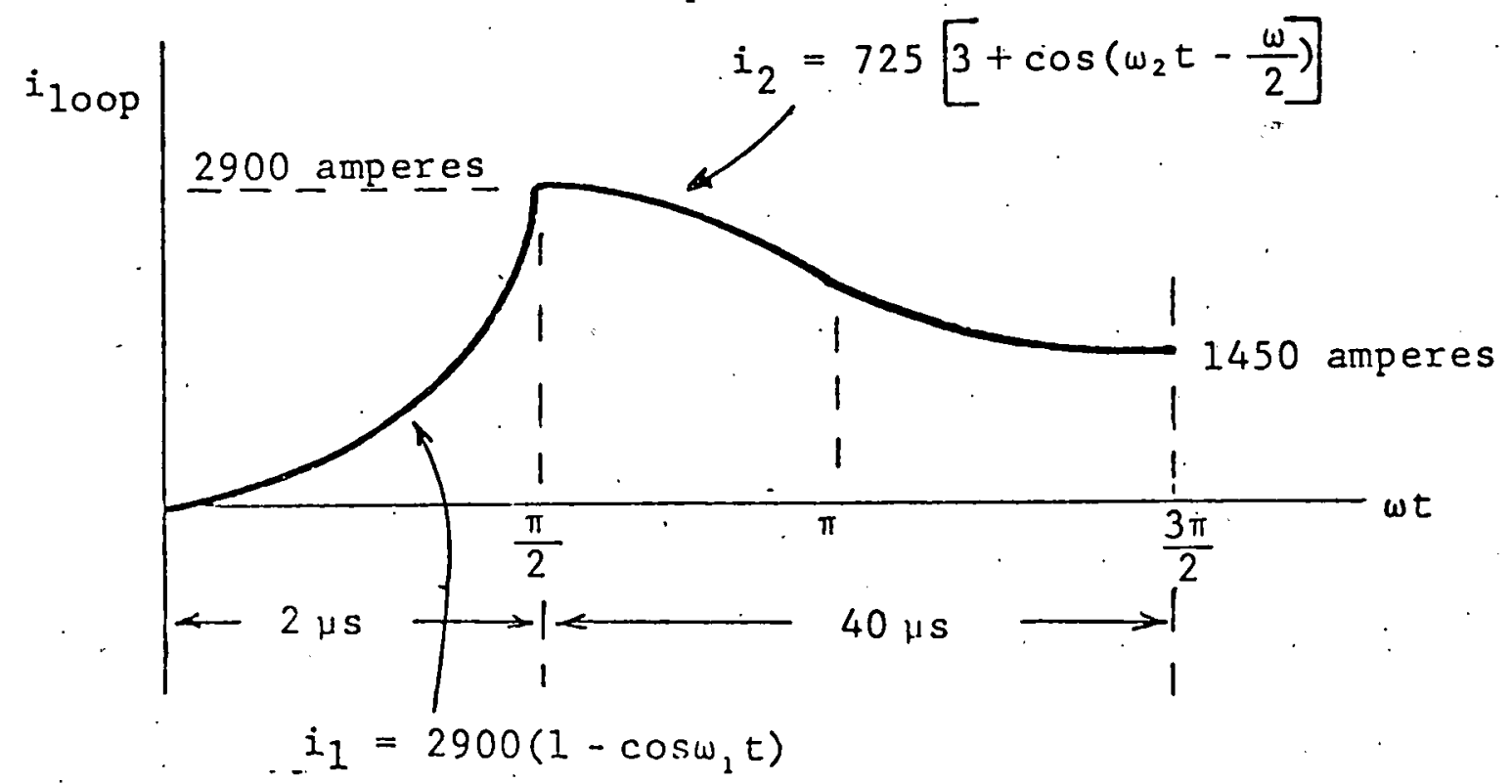

Figure 16 - Current Induced in a PV Cell Compartment Joop. 
The resistance of the solar cells, diudis and any other components in the loops will diminish this current somewhat from. the values calculated above, so that the peak surge current of 2900 amperes should be considered a maximum.

The ability of this current to damage the PV cells and diodes in the system depends not only on the amplitude of the surge current but also its action integral $\left(\int 1^{2} d t\right)$. This is a measure of the amount of energy that can be delivered by the surge. The action integral of the sine wave currents of Figure 16 requires a complex derivation, but can be estimated from the triangular approximation shown in. Figure 17.

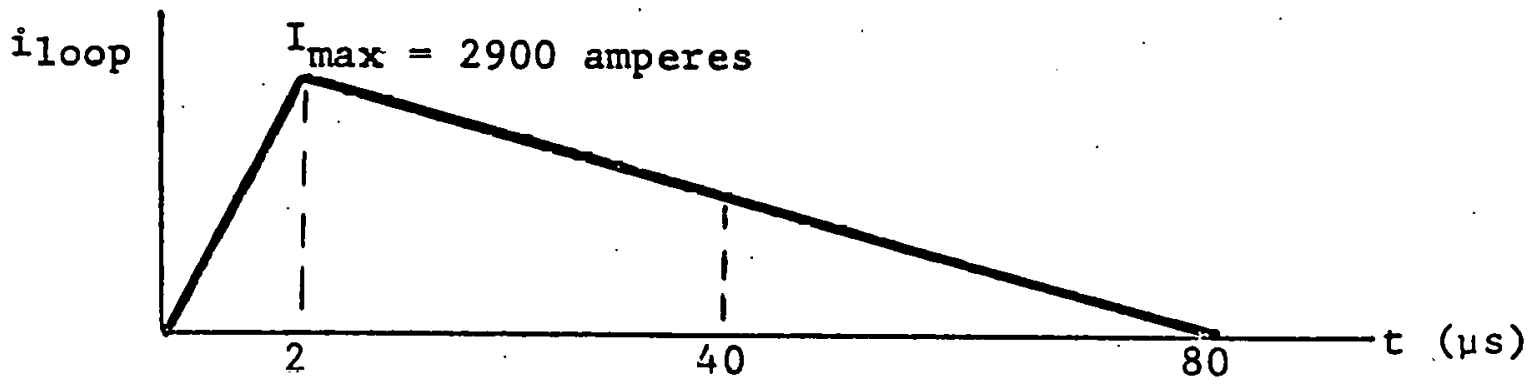

Figure 17 - Triangular Approximation of Loop Surge Currents.

Here,

$$
i_{100 \mathrm{p}}=\left.\left(\frac{I_{L(\max )}}{2 \times 10^{-6} s}\right) t\right|_{0} ^{2 \times 10^{-6} s}+\left.\left(\frac{I_{L(\max )}}{78 \times 10^{-6} s}\right) t\right|_{2 \times 10^{-6}} ^{80 \times 10^{-6} s}
$$

and

$$
i_{100 p}=\left.\frac{I^{2} t^{2}}{4 \times 10^{-12}}\right|_{0} ^{2 \times 10^{-6} s}+\left.\frac{I^{2} t^{2}}{6.1 \times 10^{-9}}\right|_{2 \times 10^{-6}} ^{80 \times 10^{-6} s}
$$

and the integrals are:

$$
\int i^{2} d t=\left.\frac{I^{2}}{4 \times 10^{-12}}\left(\frac{t^{3}}{3}\right)\right|_{0} ^{2 \times 10^{-6} s}+\left.\frac{I^{2}}{6.1 \times 10^{-9}}\left(\frac{t^{3}}{3}\right)\right|_{2 \times 10^{-6} s} ^{80 \times 10^{-6} s}
$$

Letting $I=2900$ amperes (the peak surge current) and solving the above expression gives:

$$
\int \dot{i}^{2} d t=241 \text { ampere } e^{2}-\text { seconds } .
$$


Some diodes can withstand action integrals of this order, but others can not. Here again, the tolerance of the particular PV cells and bypass diodes utilized in the system must be known before the probability of damage can be assessed.

The foregoing analysis, of course, was based on the severe but infrequent case in which a $140 \mathrm{kA}$ stroke current directly enters a reflector on one of the turntables. Surge currents of lower magnitude will also circulate through the PV circuit loops when nearby strikes occur, so the PV cells and other components will experience surge currents an order of magnitude lower in amplitude much more often. Before a valid estimate of damage potential can be made, it is necessary to know the surge current withstand capability of the PV cells to be utilized in this system.

The literature provides no meaningful information on this point, so surge withstand tests will have to be made to obtain this information. Recommendations for performance of such tests are provided in Section 3.

\subsection{Summary ,}

The foregoing analyses have shown that the AC and DC power return conductors between turntables and equipment building should be replaced by two AWG 非/0 cables located in the outside spaces in the conduits and grounded to turntable structural ground, converter building ground and to 8 foot ground rods in each handhole. These lightning ground return (LGR) cables will conduct about $60 \%$ of the lightning current that results from a very near or direct strike to a turntable, thereby reducing the amount of lightning current that could get into the AC or DC power cables or the shield of the control cable. Recommendations for this are presented in Section 3.

Analysis of the possible surge voltages and currents that may appear in PV receiver loops shows that up to 1300 volts may be induced in a typical PV circuit, and that this voltage may be able to circulate up to 3,000 amperes through these circuits which include the PV cells. The amount of damage which may occur to these cells is not known. Recommendations for additional bypass diodes and a varistor to minimize the possibility of such damage are made in Section 3. 


\subsection{Protection Design}

The analyses reported in Section 1 and 2 have shown that direct and nearby lightning strikes may damage the PVAC electrical and electronic systems. In this section, protective measures aimed at minimizing the possibility of this damage are described. These measures include modification of cable routing and grounding provisions, and the addition of surge suppressors and lightning arresters at critical roints throughout the system. The ratings of these devices have been selected to provide protection against the levels of surge voltage and current expected in the system as a result of a nearby lightning strike, as determined from the analyses of Sections 1 and 2. These devices will protect many parts of the system from the effects of a direct strike to a turntable as well, although it is expected that some damage may occur to the PV cells as a result of such a strike.

The protective recommendations are described in the following paragraphs and were illustrated by red-line markings on several GE drawings delivered during the project.

\subsection{Turntable Direct Stroke Protection}

The voltages and currents induced in turntable electrical wiring by a direct stroke may destroy many of the silicon solar cells. The ability of the cells to survive under these conditions, as discussed in the previous section, depends on their abiiity to sustain high forward diode currents (reverse solar cell currents). If the cells have forward diode current ratings similar to rectifier diodes with $I^{2} t$ numbers of 100 to $500 \mathrm{~A}^{2} \mathrm{~s}$ they will probably survive; if not, they could fail. In either case, it is not practical and may not be possible to provide any additional protection for the cell itself. A reverse bypass diode connecting the negative lead to the output lead behind the "or-ing" or blocking diode. This diode will provide a path for induced currents to circulate in the forward diode direction (reverse solar cell direction) without causing a reverse overvoltage on the. blocking diodes.

Electrical power lines on the turntable should be protected at motors, etc. with suppressors such as GE V130LA20 varistors. The wiring cables do not need to be shielded if suppressors are installer: The varistor may fail under some rare conditions (i.e. as when a strike attaches directly to the AC power wires) but will protect the motor in any event. The 120 volt return wire should be connected to structure at both ends.

Other turntable electronic wires should be shielded with both ends of the shield grounded. Thermocouple wires usually cannot have the shield grounded at both ends so a varistor or diode should be connected between the shield and ground at the thermocouple end. 
Small chains ( $1 / 2^{\prime \prime}$ link) should be hung from the structure to provide low inductance paths for lightning to reach ground without flashing over the wheels or being conducted through the pinte1. Four to six chains should be hung around the outer diameter of the turntable with a small spacing, ( $1 / 2^{\prime \prime}$ or less) between their ends and ground. The chains should be positioned over earth to prevent arcs from cratering the concrete wheel path.

\subsection{Protection of Cable Circuits}

In section 2 it was shown that the present $A C$ and $D C$ return cables should be replaced by lightning and ground return (LGR) cables of AWG $1 / 10$ size. These cables will be-connected to structure and the ground rod at the turntable pintel. The present design calls for these return lines to be carried up the flexible connection to the electronics box on the turntable together with the shielded signal cable. It would be preferable to bundle the AC power, DC power and signal cable in an overall shield in this area. The shield could be made of enough layers of copper overbraid to contain the equivalent copper in two AWG 非 $1 / 0$ cables: and still remain somewhat flexible. With large conduit or pipe fittings on the ends, this flexible shield will conduct lightning currents from the turntable to ground without damage or large induced voltages on the cables contained within it.

\subsubsection{AC Power Cables}

At the pintel electronics box, the 120 VAC power line from the equipment building should be protected by connecting a suppressor such as V130HE150 varistor with short leads between line and structure.

At the equipment building, the AC power for all turntables is supplied by a 480: 120/208 3-phase transformer. Three suppressors, as above, should be connected line to ground on each of the three, 120 volt phases at the junction service box for this transformer. Under very rare circumstances, it would be possible for a lightning strike to occur during a time when the circuit breakers feeding the turntables were opened. Under such conditions, the lightning induced voltage could cause a sparkover in the service box. Usually it takes less voltage to spark between the wiring and ground $(4-8 \mathrm{kV})$ then to spark across the switch contacts $(15-20 \mathrm{kV})$. Such an induced voltage surge will not usually contain enough energy to cause much damage in the service box and without any 120 volt power applied, it will extinguish very quickly.

\subsubsection{Power Cable.}

At the pintel electronics box, the DC power line between the equipment building and the turntable should be protected with a suppressor such as a V420HE250 connected from positive terminal 
to structure wilh siort leads. At the peak current of $18 \mathrm{kA}$ proierted. for this rahle the varistor condiction voltage will exceed the 1000 volt reverse voltage rating of the system "or-ing" or blocking diodes. A 2000 volt rating, which can be obtained by putting two diodes in series, will overcome this problem.

At the equipment building, another suppressor must be installed to protect the inputs to the inverter. The smoothing inductor will help to prevent transients from entering the inverter from the DC side of the system.

\subsubsection{Signal Cable}

The signal cable pairs should be contained in a standard telephone type cable which has a single corrugated shield applied longitudinally with an overlap of $1 / 8$ to $1 / 4$ inch. Shield material shall be fully annealed solid copper, 0.005 inches thick or copper clad stainless steel.. Such cable is available from Clifford of Vermont (1-800-451-4381); specify 3 pair, 22 gauge, Direct Burial Distribution wire, copper shield per REA PE-54. The shield should be solidly grounded by short leads to structure and ground at both ends.

The six wires ( 3 pair) should all be treated identically and be protected to a voltage level of 6 to 8 volts peak to minimize damage to the TTL solid state circuitry present at either end.

The protection design for both ends of the signal cable is shown in Figure 18. Each wire is clamped by a varistor which conducts the 750 ampere surge at about 100 volts. The resistor limits the current to the zener protector which conducts 20 amperes at 7.5 volts.

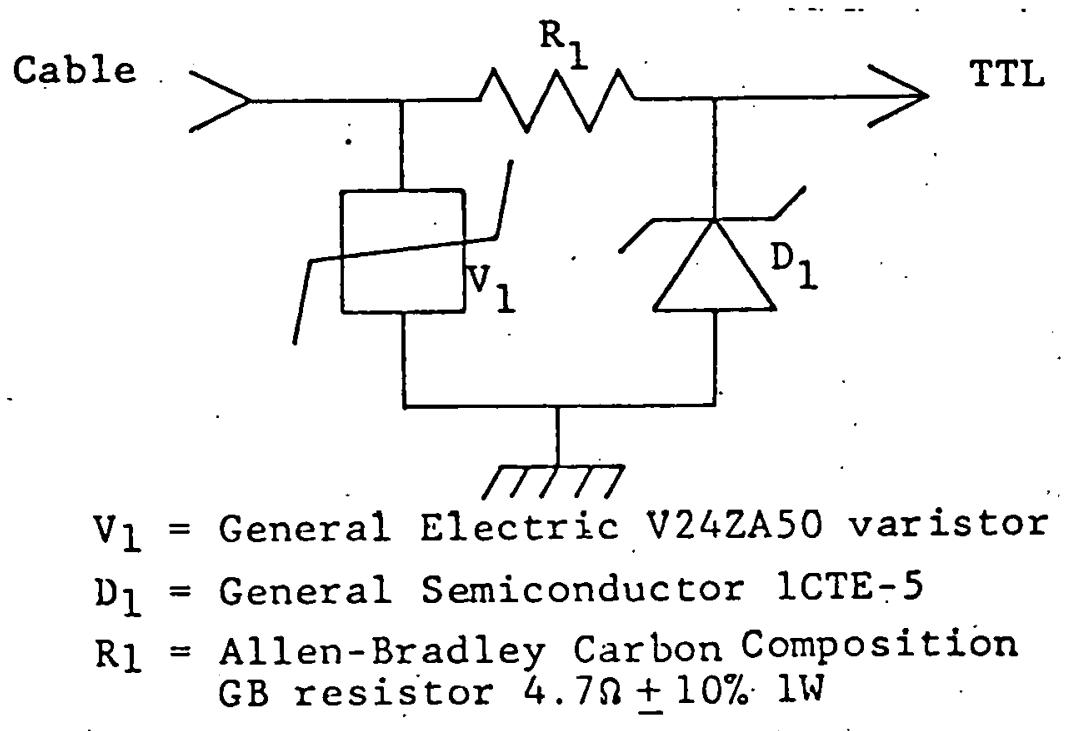

Figure 18 - Typical Signal Conductor Protection Schematic. 


\subsubsection{Protection of the Equipment Building}

Some means for structural protection of the cement block building, (i.e. a conductive roof with down conductors, or lightning rods). must be provided by the A\&E firm responsible for the building design.

The 480 volt, 3-phase AC power connection between the power company and the building should be protected with arresters or suppressors at the building and the transformer site. Because sensitive electronic monitoring devices are connected to the power system in the equipment building, GE Type V480HE450 varistors are recommended for protection of the main three phase 480 volt power at the building entrance. The equipment at the transformer is standard distribution gear and a GE Model 9L15BCCOO3 surge arrester is recommended to protect this equipment. If lightning does strike the array system substantial lightning current will be present in these circuits because the utility system presents an ultimate ground for the lightning current. The pump motors are generally quite close to the building and will need no additional protection.

All electronic sensing circuits entering the building, except those associated with the turntables, come from nearby sources and require only shielded cables which are grounded at both ends.

\subsubsection{Summary of Protection Recommendations}

In most cases where the distances involved are short, protection can be afforded through the use of shields grounded at both ends. Where the distances are greater (such as between the turntable and the equipment building) additional suppression is required to remove potentially damaging transients from the conductors. All recommended protection has been incorporated on the red-lined GE drawings delivered earlier. Specifically those drawings were:

1. $147 \mathrm{D} 9785$

2. $919 \mathrm{~J} 232$

3. $919 \mathrm{~J} 233$

4. $919 \mathrm{~J} 233 \mathrm{SH}$ SH
Schematic - Plant Electrical

Schematic - Equipment Building

Schematic - Turntable (Operational)

Schematic - Turntable(Experimental)
Rev $12 / 4 / 78$

Rev. $12 / 4 / 78$

$11 / 30 / 78$

$11 / 30 / 78$

The termination and grounding methods used for overall shields (OAS) are very important and when done improperly can degrade the effectiveness of the shield. Figure 19 shows various methods and rates their effectiveness. As shown in the figure, a $360^{\circ}$ shield contact to the panel structure provides the best connection for two reasons:

1. A low inductance connection provides the lowest impedance termination for the shield current, and 
2. The uniform shield curient entircly excludes magnetic fields from coupling the internal conductors.

Standard conduit couplings or water-pipe type fittings will provide $360^{\circ}$ electric contact to panels and the overall shields can easily be clamped to such fittings. When such fittings can not be used, short pigtails between the shield and the panels may be used. Other shield grounding methods must be avoided.

On the turntables, shielded conductors should be routed and clamped tightly to conducting structures to minimize magnetic loop areas and thereby reduce shield currents to a minimum.
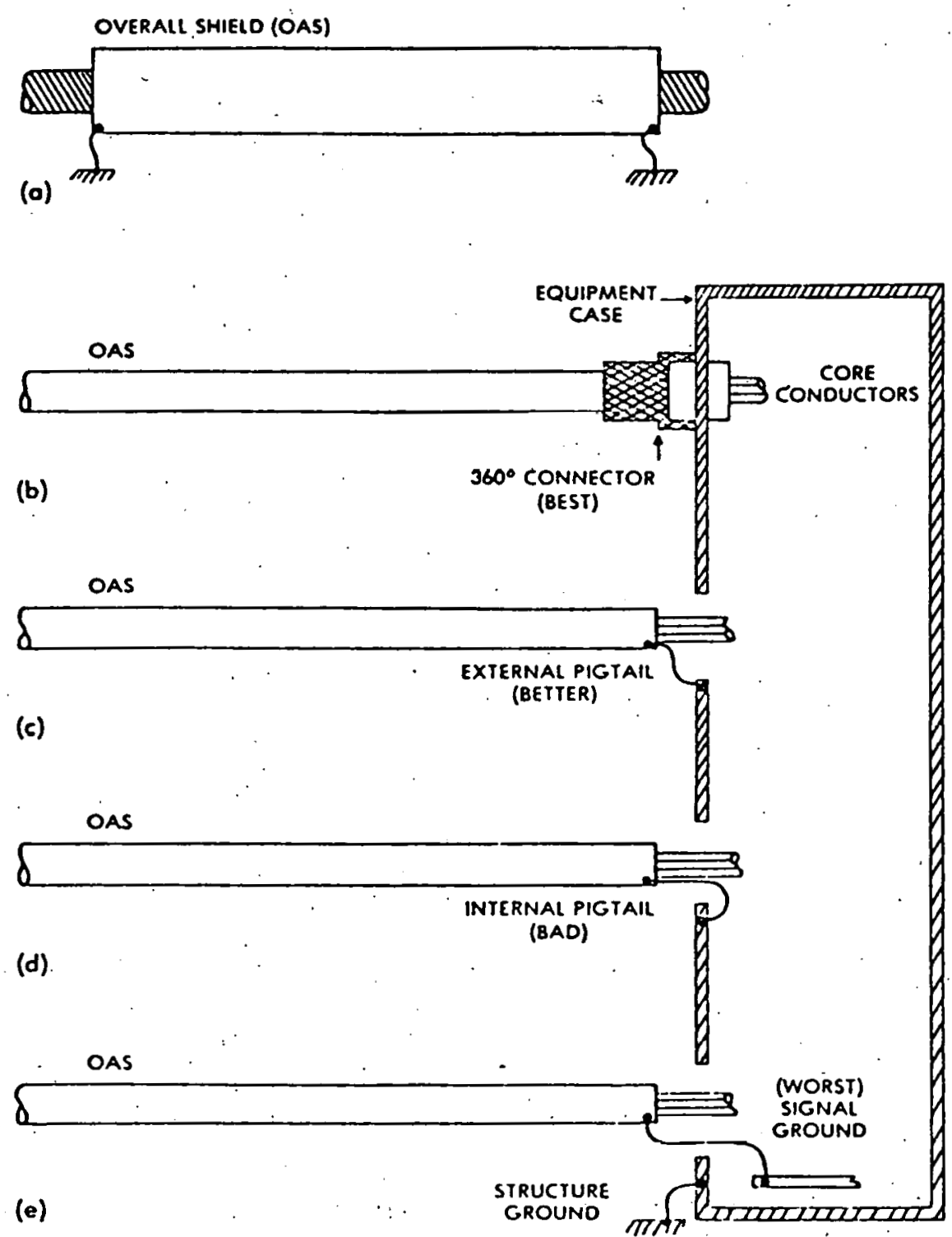

Figure 19 - Types of Grounding for Shields 


\section{References}

1. N. Cianos and E.T. Pierce, "A Ground Lightning Environment for Engineering Usage", Stanford Research Institute Technical Report 1 for McDonnell-Douglas Astronautics Co. under contract to Bell Telephone Laboratories and the U.S. Ariny Safeguard System Command, August 1972.

2. Cianos and Pierce, p. 124

3. Cianos and Pierce, p. 13

4. "World Distribution of Thunderstorm Days", World Meteorological Organization, Geneva, Switzerland, WMO/OMM No. 21. TP. 6, 1953, p. 104 .

5. Cianos and Pierce, Pp. 80-85

6. L.V. Bewley, "Travelling Waves on Transmission Systems", Second Edition, Dover Publications, Inc., New York, N.Y., PP. $127-148$.

7. Ralph E Taylor, "Radio Frequency Inductance Calculations", NASA SP-3067, pp. 222-223.

8. F.W. Grover, "Inductance Calculations", Dover Publications, Inc., New York, N.Y., p. 39. 
DISTRIBUTION :

TID-4500-R66，UC-63a (235)

Division of Distributed

Solar Technology (10)

U.S. Department of Energy 600 E Street NW

Washington, D.C. 20545

Attin: R. SanMartin

P. Maycock

A. Krántz (6)

L: Magid

A. Clorfeine

U.S. Department of Energy (6)

Albuquerque Operations Office

Albuquerque, NM 87115

Attn: D. K. Nowlin, Director Special Programs Division

SERI, Library (2)

1536 Cole Blva.. Bldg. \#4

Golden, CO 80401

SERI (2)

1536 Cole Blvd.

Golden, CO 80401

Attn: L. Mrig

H. Lauffenburger

Jet Propulsion Laboratory

4800 Oak Grove Drive

Pasadena, CA 91103

Attn: R. Forney

W. Callaghan

R. Ross

R. Ferber

P. Sutton

J. Hesse

NASA/LeRC (2)

21000 Brookpark Road

Cleveland, OH 44135

Attn: J. Deyo

A. Ratajczak

The Aerospace Corporation (2)

P. O. Box 92957

Los Angeles, CA 90009

Attn: $S$. Leonard

B. Siegel

MIT-Lincoln Lab

Box 73

Lexington, MA 02173

Attn: M. Pope

S. Sacco
MIT-Energy Lab

Cambridge, MA 02139

Attn: R. Tabors

4700 J. H. Scott

4710 G. E. Brandvold

4719 D. G. Schueler

4719 E. L. Burgess. (75)

.4720 V. L. Dugan

8266 E. A. Aas

3141 T. L. Werner. (5)

3151 W. I. Garner (3)

For: DOE/TIC (Unlimited Release) 